National Renewable

Energy Laboratory

Innovation for Our Energy Future

\title{
Effects of Intermediate Ethanol Blends on Legacy Vehicles and Small Non-Road Engines, Report 1 - Updated
}

February 2009

\author{
Prepared by \\ Keith Knoll \\ Brian West \\ Wendy Clark \\ Ronald Graves \\ John Orban \\ Steve Przesmitzki \\ Timothy Theiss
}

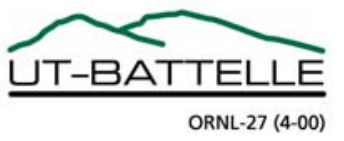




\title{
DOCUMENT AVAILABILITY
}

Reports produced after January 1, 1996, are generally available free via the U.S. Department of Energy (DOE) Information Bridge.

Web site http://www.osti.gov/bridge

Reports produced before January 1, 1996, may be purchased by members of the public from the following source.

\author{
National Technical Information Service \\ 5285 Port Royal Road \\ Springfield, VA 22161 \\ Telephone 703-605-6000 (1-800-553-6847) \\ TDD 703-487-4639 \\ Fax 703-605-6900 \\ E-mail info@ntis.gov \\ Web site http://www.ntis.gov/support/ordernowabout.htm
}

Reports are available to DOE employees, DOE contractors, Energy Technology Data Exchange (ETDE) representatives, and International Nuclear Information System (INIS) representatives from the following source.

Office of Scientific and Technical Information

P.O. Box 62

Oak Ridge, TN 37831

Telephone 865-576-8401

Fax 865-576-5728

E-mail reports@osti.gov

Web site http://www.osti.gov/contact.html

\begin{abstract}
This report was prepared as an account of work sponsored by an agency of the United States Government. Neither the United States Government nor any agency thereof, nor any of their employees, makes any warranty, express or implied, or assumes any legal liability or responsibility for the accuracy, completeness, or usefulness of any information, apparatus, product, or process disclosed, or represents that its use would not infringe privately owned rights. Reference herein to any specific commercial product, process, or service by trade name, trademark, manufacturer, or otherwise, does not necessarily constitute or imply its endorsement, recommendation, or favoring by the United States Government or any agency thereof. The views and opinions of authors expressed herein do not necessarily state or reflect those of the United States Government or any agency thereof.
\end{abstract}


NREL/TP-540-43543

ORNL/TM-2008/117

\title{
EFFECTS OF INTERMEDIATE ETHANOL BLENDS ON LEGACY VEHICLES AND SMALL NON-ROAD ENGINES, REPORT 1 - UPDATED
}

\author{
Keith Knoll, ${ }^{\dagger}$ Brian West, ${ }^{*}$ Wendy Clark, ${ }^{\dagger}$ Ronald Graves, ${ }^{*}$ John Orban, ${ }^{*}$ \\ Steve Przesmitzki, ${ }^{\dagger}$ and Timothy Theiss ${ }^{*}$
}

Date Published: February 2009

Prepared by the

National Renewable Energy Laboratory

1617 Cole Boulevard, Golden, Colorado 80401-3393

303-275-3000 • www.nrel.gov

NREL is a national laboratory of the U.S. Department of Energy

Office of Energy Efficiency and Renewable Energy

Operated by the Alliance for Sustainable Energy, LLC

Contract No. DE-AC36-08-GO28308

\footnotetext{
*Oak Ridge National Laboratory, Oak Ridge, Tennessee

†National Renewable Energy Laboratory, Golden, Colorado

*Battelle Memorial Institute, Columbus, Ohio
} 



\section{CONTENTS}

\section{Page}

LIST OF FIGURES

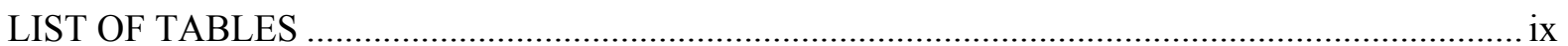

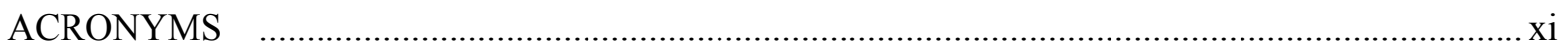

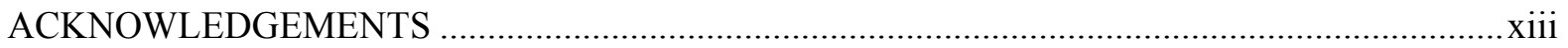

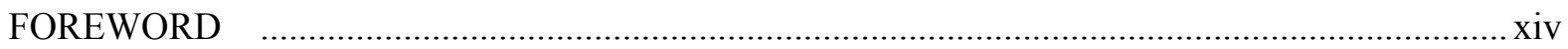

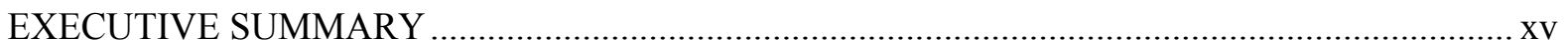

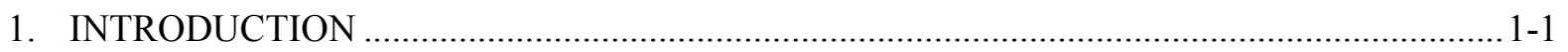

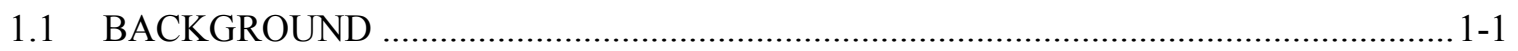

1.2 TEST PROGRAM OVERVIEW ……................................................................ 1-2

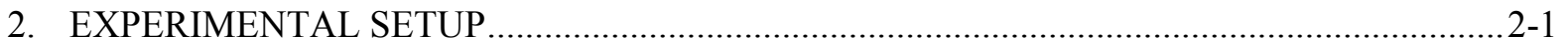

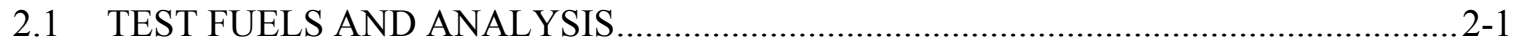

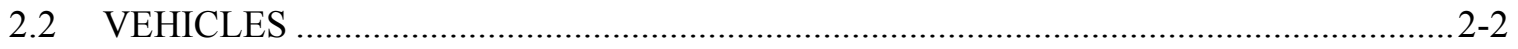

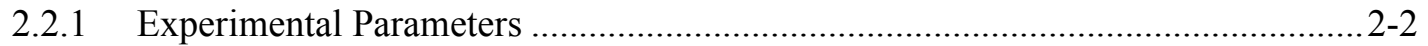

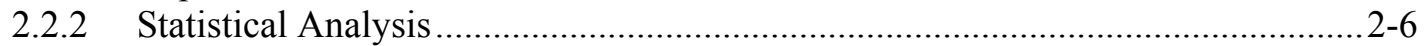

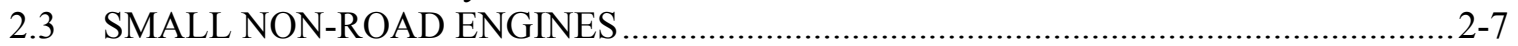

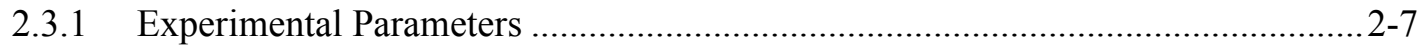

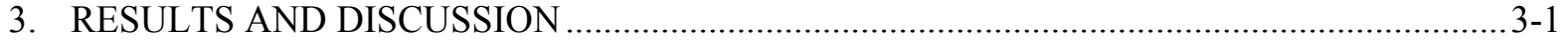

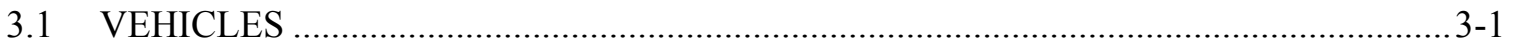

3.1.1 Emissions and Fuel Economy Summary........................................................... 3-1

3.1.2 Exhaust and Catalyst Temperature Effects Summary ........................................ 3-2

3.1.3 Unforeseen Operational Issues Summary …................................................... 3-2

3.1.4 Results and Discussion: Emissions and Fuel Economy ..................................... 3-2

3.1.5 Results and Discussion: Exhaust and Catalyst Temperature ................................ 3-6

3.1.6 Results and Discussion: Unforeseen Operational Issues...................................... 3-8

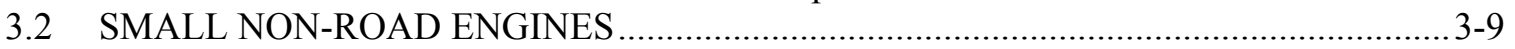

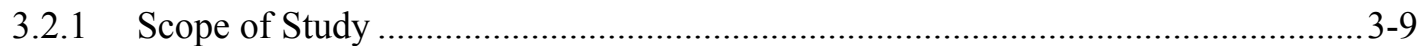

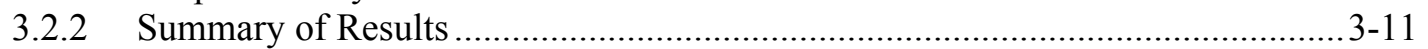

3.2.3 Results and Discussion: Engine Operation ................................................... 3-15

3.2.4 Results and Discussion: Emissions ................................................................. 3-19

3.2.5 Results and Discussion: Exhaust, Oil, and Other Temperature Data .....................3-23

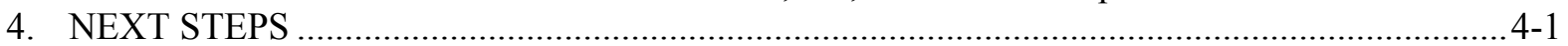

4.1 EMISSIONS AND CATALYST TEMPERATURE ..................................................... $4-1$

4.2 EMISSIONS OF VARIOUS GASOLINES AND ETHANOL BLENDS .......................... $4-1$

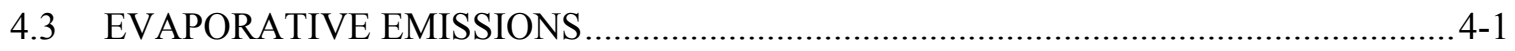

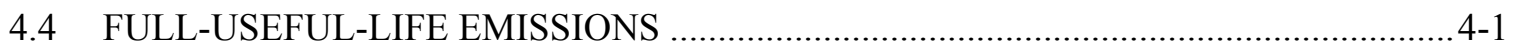

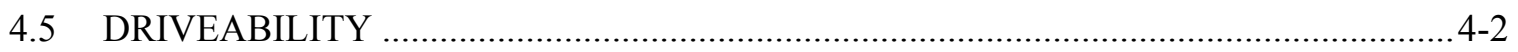

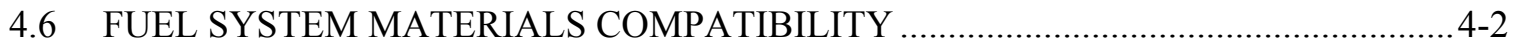

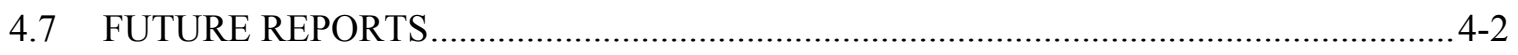

APPENDIX A VEHICIE TEST EQUIPMENT, PROCEDURES, AND RELEVANT

APPENDIX B SMALL NON-ROAD ENGINE TEST EQUIPMENT, PROCEDURES, AND RELEVANT EMISSIONS STANDARDS …....................................... B-1

APPENDIX C INDIVIDUAL VEHICLE EMISSIONS RESULTS ….......................................

APPENDIX D SMALL ENGINE FULL-USEFUL-LIFE TESTING ......................................... D-1 



\section{LIST OF FIGURES}

Figure $\quad$ Page

3.1. Average percentage change in emissions and fuel economy for all vehicles compared to E0 fuel on the LA92 cycle. .........................................................................................

3.2. Average change in ethanol and aldehyde emissions for all vehicles compared to E0

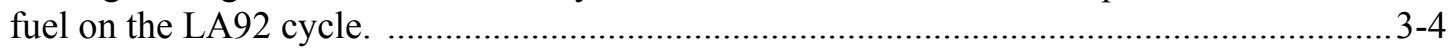

3.3. Average emissions and fuel economy for all vehicles on LA92 cycle. ............................... 3-5

3.4. Ethanol and aldehyde emissions for all vehicles on LA92 cycle. ....................................... 3-5

3.5. Change in catalyst temperature versus fuel type for wide-open throttle (WOT) open-

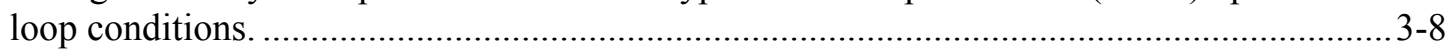

3.6. Exhaust temperature increase for all small non-road engines tested in the new and fulluseful-life (full-life) condition with ethanol blends, as compared to E0 baseline.

3.7. Average change in emissions for all small non-road engines tested in the new (top chart) and full-useful-life (full-life) (bottom chart) condition with ethanol blends, as compared to E0 baseline.

3.8. Poulan leaf blower engine speed versus time for fuels E0 through E20........................... 3-16

3.9. Aging timeline for five Weed Eater Featherlite blowers............................................... 3-18

3.10. Stihl owner's manual schematic showing location of high-speed (H), low-speed (L), and low-idle (LA) adjustment screws.

3.11. Hydrocarbon (HC) emissions for pilot study engines versus fuel ethanol content. ............3-21

3.12. Nitrogen oxide $\left(\mathrm{NO}_{\mathrm{X}}\right)$ emissions for pilot study engines versus fuel ethanol content. ........3-21

3.13. Hydrocarbon $(\mathrm{HC})+$ nitrogen oxide $\left(\mathrm{NO}_{\mathrm{X}}\right)$ emissions for pilot study engines. ................... 3-22

3.14. Carbon monoxide emissions for pilot study engines. ................................................... 3-22

3.15. Exhaust port temperature for pilot study engines at hottest condition versus ethanol blend level.

3.16. Exhaust temperature versus mode for all fuels and individual cylinders of Kohler generator.

3.17. Individual cylinder CO concentration for E0 fueling at three loads for Kohler generator.

3.18. Exhaust port temperature for Briggs and Stratton power washer engines at mode 6 condition versus ethanol blend level.

3.19. Exhaust port temperature for Class IV Stihl line trimmer engines at hottest condition (mode 1) at new and full-useful-life (full-life) condition.

A.1. Example of vehicle exhaust system instrumentation, including universal exhaust gas oxygen sensor (UEGO) and temperature and exhaust gas sample ports............................. A-3

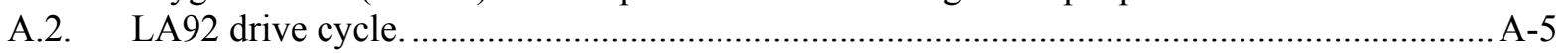

A.3. Modified Coordinating Research Council E-60 wide-open-throttle drive cycle................... A-7

A.4. Wide-open-throttle (WOT) hill climb and edge of fuel enrichment drive cycle with vehicle speed data from 2007 Buick.

C.1. Non-methane organic gas (NMOG), non-methane hydrocarbons (NMHC), carbon monoxide (CO), oxides of nitrogen $\left(\mathrm{NO}_{\mathrm{X}}\right)$, and fuel economy $(\mathrm{FE})$ for 2007 Chrysler Town and Country on LA92 cycle..

C.2. Ethanol, acetaldehyde, and formaldehyde emissions for 2007 Chrysler Town and Country on LA92 cycle.

C.3. Non-methane organic gas (NMOG), non-methane hydrocarbons (NMHC), carbon monoxide (CO), oxides of nitrogen ( $\mathrm{NO}_{\mathrm{X}}$ ), and fuel economy (FE) for 2007 Ford F150 on LA92 cycle.. 
C.4. Ethanol, acetaldehyde, and formaldehyde emissions for 2007 Ford F150 on LA92 cycle..

C.5. Non-methane organic gas (NMOG), non-methane hydrocarbons (NMHC), carbon monoxide (CO), oxides of nitrogen ( $\mathrm{NO}_{\mathrm{X}}$ ), and fuel economy (FE) for 2003 Ford F150 on LA92 cycle..

C.6. Ethanol, acetaldehyde, and formaldehyde emissions for 2003 Ford F150 on LA92 cycle.

C.7. Non-methane organic gas (NMOG), non-methane hydrocarbons (NMHC), carbon monoxide (CO), oxides of nitrogen ( $\mathrm{NO}_{\mathrm{X}}$ ), and fuel economy (FE) for 2003 Ford Taurus on LA92 cycle..

C.8. Ethanol, acetaldehyde, and formaldehyde emissions for 2003 Ford Taurus on LA92 cycle..

C.9. Non-methane organic gas (NMOG), non-methane hydrocarbons (NMHC), carbon monoxide $(\mathrm{CO})$, oxides of nitrogen $\left(\mathrm{NO}_{\mathrm{X}}\right)$, and fuel economy $(\mathrm{FE})$ for 2007 Buick Lucerne on LA92 cycle..

C.10. Ethanol, acetaldehyde, and formaldehyde emissions for 2007 Buick Lucerne on LA92 cycle..

C.11. Non-methane organic gas (NMOG), non-methane hydrocarbons (NMHC), carbon monoxide $(\mathrm{CO})$, oxides of nitrogen $\left(\mathrm{NO}_{\mathrm{X}}\right)$, and fuel economy $(\mathrm{FE})$ for 2003 Buick LeSabre on LA92 cycle..

C.12. Ethanol, acetaldehyde, and formaldehyde emissions for 2003 Buick LeSabre on LA92 cycle.

C.13. Non-methane organic gas (NMOG), non-methane hydrocarbons (NMHC), carbon monoxide $(\mathrm{CO})$, oxides of nitrogen $\left(\mathrm{NO}_{\mathrm{X}}\right)$, and fuel economy $(\mathrm{FE})$ for 2007 Chevrolet Silverado on LA92 cycle.

C.14. Ethanol, acetaldehyde, and formaldehyde emissions for 2007 Chevrolet Silverado on LA92 cycle.

C.15. Non-methane organic gas (NMOG), non-methane hydrocarbons (NMHC), carbon monoxide (CO), oxides of nitrogen ( $\mathrm{NO}_{\mathrm{X}}$ ), and fuel economy (FE) for 2007 Honda Accord on LA92 cycle..

C.16. Ethanol, acetaldehyde, and formaldehyde emissions for 2007 Honda Accord on LA92 cycle.

C.17. Non-methane organic gas (NMOG), non-methane hydrocarbons (NMHC), carbon monoxide (CO), oxides of nitrogen $\left(\mathrm{NO}_{\mathrm{X}}\right)$, and fuel economy $(\mathrm{FE})$ for 2003 Nissan Altima on LA92 cycle. Bars show average of 3 tests at $75^{\circ} \mathrm{F}$.

C.18. Ethanol, acetaldehyde, and formaldehyde emissions for 2003 Nissan Altima on LA92 cycle..

C.19. Non-methane organic gas (NMOG), non-methane hydrocarbons (NMHC), carbon monoxide $(\mathrm{CO})$, oxides of nitrogen $\left(\mathrm{NO}_{\mathrm{X}}\right)$, and fuel economy $(\mathrm{FE})$ for 2007 Toyota Camry on LA92 cycle.

C.20. Ethanol, acetaldehyde, and formaldehyde emissions for 2007 Toyota Camry on LA92 cycle..

C.21. Non-methane organic gas (NMOG), non-methane hydrocarbons (NMHC), carbon monoxide $(\mathrm{CO})$, oxides of nitrogen $\left(\mathrm{NO}_{\mathrm{X}}\right)$, and fuel economy $(\mathrm{FE})$ for 2003 Toyota Camry on LA92 cycle.

C.22. Ethanol, acetaldehyde, and formaldehyde emissions for 2003 Toyota Camry on LA92 cycle..

C.23. Non-methane organic gas (NMOG), non-methane hydrocarbons (NMHC), carbon monoxide (CO), oxides of nitrogen $\left(\mathrm{NO}_{\mathrm{X}}\right)$, and fuel economy $(\mathrm{FE})$ for 2001 Chrysler PT Cruiser on LA92 cycle. 
C.24. Ethanol, acetaldehyde, and formaldehyde emissions for 2001 Chrysler PT Cruiser on LA92 cycle..

C.25. Non-methane organic gas (NMOG), non-methane hydrocarbons (NMHC), carbon monoxide (CO), oxides of nitrogen $\left(\mathrm{NO}_{\mathrm{X}}\right)$, and fuel economy $(\mathrm{FE})$ for 1999 Ford Crown Victoria on LA92 cycle..

C.26. Ethanol, acetaldehyde, and formaldehyde emissions for 1999 Ford Crown Victoria on LA92 cycle..

C.27. Non-methane organic gas (NMOG), non-methane hydrocarbons (NMHC), carbon monoxide (CO), oxides of nitrogen ( $\mathrm{NO}_{\mathrm{X}}$ ), and fuel economy (FE) for 1999 Honda Civic on LA92 cycle.

C.28. Ethanol, acetaldehyde, and formaldehyde emissions for 1999 Honda Civic on LA92 cycle..

C.29. Non-methane organic gas (NMOG), non-methane hydrocarbons (NMHC), carbon monoxide (CO), oxides of nitrogen $\left(\mathrm{NO}_{\mathrm{X}}\right)$, and fuel economy $(\mathrm{FE})$ for 1999 Toyota Corolla on LA92 cycle.

C.30. Ethanol, acetaldehyde, and formaldehyde emissions for 1999 Toyota Corolla on LA92 cycle..

C.31. Non-methane organic gas (NMOG), non-methane hydrocarbons (NMHC), carbon monoxide (CO), oxides of nitrogen $\left(\mathrm{NO}_{\mathrm{X}}\right)$, and fuel economy $(\mathrm{FE})$ for 2004 Volkswagen Golf GTI on LA92 cycle..

C.32. Ethanol, acetaldehyde, and formaldehyde emissions for 2004 Volkswagen Golf GTI on LA92 cycle.

D.1. Hydrocarbon (HC) emissions for Class I Briggs and Stratton power washer engines on Transportation Research Center protocol at new and full-useful-life (full-life) condition.....

D.2. Nitrogen oxide $\left(\mathrm{NO}_{\mathrm{X}}\right)$ emissions for Class I Briggs and Stratton power washer engines on the Transportation Research Center protocol at new and full-useful-life (full-life) condition

D.3. Hydrocarbon $(\mathrm{HC})+$ nitrogen oxide $\left(\mathrm{NO}_{\mathrm{X}}\right)$ emissions for Class I Briggs and Stratton power washer engines on the Transportation Research Center protocol at new and fulluseful-life (full-life) condition.

D.4. Carbon monoxide emissions for Class I Briggs and Stratton power washer engines on the Transportation Research Center protocol at new and full-useful-life (full-life) condition.

D.5. Hydrocarbon (HC) emissions for Class I Briggs and Stratton power washer engines on the Briggs and Stratton Company (BASCO) protocol.

D.6. Nitrogen oxide $\left(\mathrm{NO}_{\mathrm{X}}\right)$ emissions for Class I Briggs and Stratton power washer engines on the Briggs and Stratton Company (BASCO) protocol at new and full-useful-life (full-life) condition.

D.7. Hydrocarbon $(\mathrm{HC})+$ nitrogen oxide $\left(\mathrm{NO}_{\mathrm{X}}\right)$ emissions for Class I Briggs and Stratton power washer engines on the Briggs and Stratton Company (BASCO) protocol at new and full-useful-life (full-life) condition.

D.8. Carbon monoxide emissions for Class I Briggs and Stratton power washer engines on the Briggs and Stratton Company (BASCO) protocol at new and full-useful-life (fulllife) condition.

D.9. Hydrocarbon (HC) emissions for Class I Honda generator engines at new and full-useful-life (full-life) condition.

D.10. Nitrogen oxide $\left(\mathrm{NO}_{\mathrm{x}}\right)$ emissions for Class I Honda generator engines at new and full-useful-life (full-life) condition.

D.11. Hydrocarbon $(\mathrm{HC})+$ nitrogen oxide $\left(\mathrm{NO}_{\mathrm{X}}\right)$ emissions for Class I Honda generator engines at new and full-useful-life (full-life) condition. 
D.12. Carbon monoxide emissions for Class I Honda generator engines at new and full-useful-life (full-life) condition.

D.13. Hydrocarbon (HC) emissions for Class IV Weed Eater blower engines at new and full-useful-life (full-life) condition.

D.14. Nitrogen oxide $\left(\mathrm{NO}_{\mathrm{X}}\right)$ emissions for Class IV Weed Eater blower engines at new and full-useful-life (full-life) condition.

D.15. Hydrocarbon $(\mathrm{HC})+$ nitrogen oxide $\left(\mathrm{NO}_{\mathrm{X}}\right)$ emissions for Class IV Weed Eater blower engines at new and full-useful-life (full-life) condition.

D.16. Carbon monoxide emissions for Class IV Weed Eater blower engines at new and full-useful-life (full-life) condition.

D.17. Hydrocarbon (HC) emissions for Class IV Stihl line trimmer engines at new and full-useful-life (full-life) condition.

D.18. Nitrogen oxide $\left(\mathrm{NO}_{\mathrm{X}}\right)$ emissions for Class IV Stihl line trimmer engines at new and full-useful-life (full-life) condition.

D.19. Hydrocarbon $(\mathrm{HC})+$ nitrogen oxide $\left(\mathrm{NO}_{\mathrm{X}}\right)$ emissions for Class IV Stihl line trimmer engines at new and full-useful-life (full-life)condition.

D.20. Carbon monoxide emissions for Class IV Stihl line trimmer engines at new and full-useful-life (full-life) condition.

D.21. Exhaust port temperature for Class I Briggs and Stratton power washers at mode 6 (fast idle) at new and full-useful-life (full-life) condition.

D.22. Exhaust port temperature for Class I Honda generators at mode 6 (fast idle) at new and full-useful-life (full-life) condition.

D.23. Exhaust port temperature for Class IV Weed Eater Featherlite blower engines at mode 1 (full power) at new and full-useful-life (full-life) condition.

D.24. Exhaust port temperature for Class IV Stihl line trimmers at mode 1 (full power) at new and full-useful-life (full-life) condition. 


\section{LIST OF TABLES}

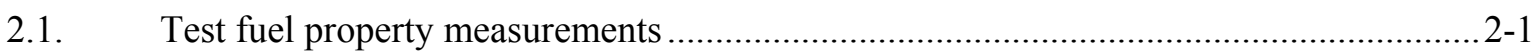

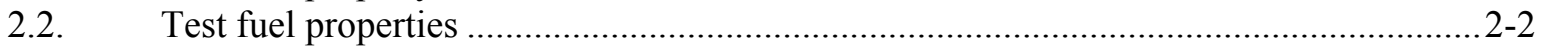

2.3. Number of registered gasoline-powered vehicles in the United States on January 1, 2007 — by model year period, manufacturer, and number of cylinders ..........2-3

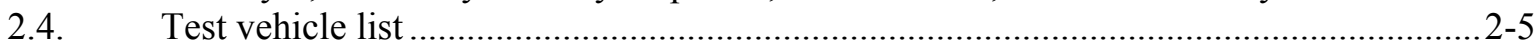

2.5. Small non-road engine classification descriptions per 40 CFR 90 ................................2-7

2.6. SNRE equipment tested in pilot and full-useful-life (full-life) studies ..........................2-9

2.7. ISO 8178 emission test cycles .................................................................................. 2-9

3.1. Estimated change (\% or $\mathrm{mg} / \mathrm{mi})$ in emissions and fuel economy relative to E0

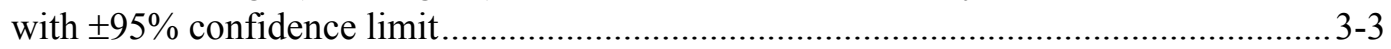

3.2. Number of vehicles with positive changes in emissions and fuel economy relative

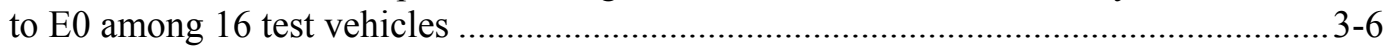

3.3. SNRE classification descriptions per 40 CFR 90 ................................................... 3-9

3.4. SNRE equipment tested in pilot and full-useful-life (full-life) studies ..........................3-10

3.5. Summary of engine operational problems at ORNL, NREL, and TRC........................ 3-14

3.6. Summary of engine, fuel, and emissions test protocols for full-useful-life (fulllife) testing Hashed areas indicate no data collected. Fuel column denotes fuel tested at that condition (E0, E10, E15, or E20)...

3.7. Baseline E0 emissions and relative change for E10, E15, and E20 for pilot study engines

3.8. Baseline Briggs and Stratton power washer engine emissions on the TRC protocol at new and full-useful-life (full-life) condition with E0 fuel, and relative change for respective ethanol blends

3.9. Briggs and Stratton power washer engine emissions on the BASCO protocol at new and full-useful-life (full-life) condition with E0 fuel, and relative change for respective ethanol blends

3.10. Baseline Honda generator engine emissions at new and full-useful-life (full-life) condition with E0 fuel, and relative change for respective ethanol blends....................3-26

3.11. Baseline Weed Eater Featherlite blower engine emissions at new and full-usefullife (full-life) condition with EO fuel, and relative change for respective ethanol blends

3.12. Baseline Stihl line trimmer engine emissions at new and full-useful-life (full-life) condition with E0 fuel, and relative change for respective ethanol blends.................... 3-28

3.13. Change in exhaust temperature with ethanol blends for hottest engine condition for six pilot study engines.

3.14. Change in exhaust temperature for engines in full-useful-life (full-life) study for hottest engine condition.

A.1. Federal certification exhaust emission standards for light-duty vehicles and light-duty trucks ....

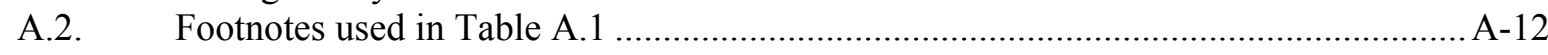

A.3. Acronyms used in Tables A.1, A.4, and A.5 ....................................................... A-13

A.4. Tier 2 and interim non-Tier 2 full-useful-life exhaust emissions standards ................ A-14

A.5. Tier 2 and interim non-Tier 2 intermediate full-useful-life (50,000 mile) exhaust

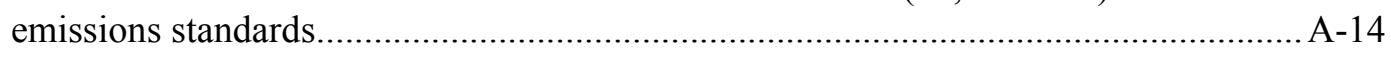

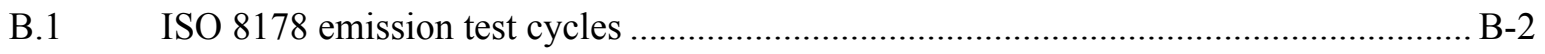


B.2. Summary of engine, fuel, and emissions test protocols for full-useful-life (fulllife) testing.

B.3. Phase 1 and Phase 2 non-handheld engine emission standards ............................... B-10

B.4. Phase 1 and Phase 2 handheld engine emission standards...................................... B-11

B.5. Full useful life periods for Phase 2 SNREs ..................................................... B-11

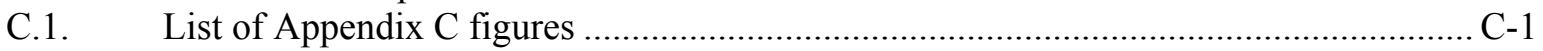

D.1. Briggs and Stratton power washer baseline E0 emissions on the TRC protocol, at new (after initial break-in) condition, and at full-useful-life

(full-life) condition

D.2. Briggs and Stratton power washer emissions on the TRC protocol in new and full-useful-life (full-life) condition with respective ethanol blends .....

D.3. Briggs and Stratton power washer emissions on the BASCO protocol, E0 and ethanol blends.....

D.4. Honda generator emissions at new and full-useful-life (full-life) condition, E0 baseline and respective ethanol blends

D.5. Weed Eater Featherlite blower emissions at new and full-useful-life (full-life) condition, E0 baseline and respective ethanol blends

D.6. Stihl line trimmer emissions, new and full-useful-life (full-life) condition, E0 baseline and respective ethanol blends 


\section{ACRONYMS}

ALDL

ANL

BASCO

CDPHE

CFR

CA LEV II

$\mathrm{CO}$

$\mathrm{COV}$

CRC

DOE

DVPE

ECU

EERE

EGO

EPA

$\mathrm{EtOH}$

FFV

FID

full life

$\mathrm{H}$

$\mathrm{HC}$

L

LA

LBT

LEV

LHV

MIL

NMHC

NMOG

$\mathrm{NO}_{\mathrm{X}}$

NREL

OBDII

OEM

ORNL

PM

RFA

RFS

RIT

RVP

SAS

SG

SNRE

SRC

THC

TLEV

TRC

UEGO
Assembly Line Diagnostic Link

Argonne National Laboratory

Briggs and Stratton Company (usually in reference to the Briggs and Stratton emissions testing protocol)

Colorado Department of Public Health and Environment

Code of Federal Regulations

California Low Emission Vehicle 2

carbon monoxide

coefficient of variation

Coordinating Research Council

U.S. Department of Energy

dry vapor pressure equivalent

Engine Control Unit

Office of Energy Efficiency and Renewable Energy (DOE)

exhaust gas oxygen

U.S. Environmental Protection Agency

ethanol

flexible-fuel vehicle

flame ionization detector (instrument for measurement of $\mathrm{HC}$ emissions)

full, useful life

high speed (mixture adjustment on Stihl line trimmer)

hydrocarbon

low speed (mixture adjustment on Stihl line trimmer)

low idle (idle speed adjustment on Stihl line trimmer)

lean best torque

low-emission vehicle

lower heating value

malfunction indicator light

non-methane hydrocarbons

non-methane organic gas

oxides of nitrogen/nitrogen oxides [nitric oxide (NO) and nitrogen dioxide $\left(\mathrm{NO}_{2}\right)$ ]

National Renewable Energy Laboratory

onboard diagnostic

original equipment manufacturer

Oak Ridge National Laboratory

particulate matter

Renewable Fuels Association (Minnesota)

renewable fuel standard

Rochester Institute of Technology

Reid vapor pressure

Statistical Analysis System (software package)

specific gravity

small, non-road engine

standard road cycle

total hydrocarbon

transitional low-emission vehicle

Transportation Research Center

universal exhaust gas oxygen (sensor) 
ULEV ultra-low-emission vehicle

USCAR United States Council for Automotive Research

WOT wide-open throttle 


\section{ACKNOWLEDGEMENTS}

This report and the work described were sponsored by the U.S. Department of Energy (DOE) Office of Energy Efficiency and Renewable Energy (EERE) Biomass Program and the EERE Vehicle Technologies Program. The authors gratefully acknowledge the support and editorial guidance of Joan Glickman and Kevin Stork at DOE. Assistance in the project management of this report from Carolyn Clark of BCS, Inc., is also greatly appreciated. This work has also benefited from substantial input and direction from numerous peers within the U.S. Council for Automotive Research, the Outdoor Power Equipment Institute, and the Environmental Protection Agency. We acknowledge and appreciate the thorough review and input from Rich Bechtold and Tom Timbario of Alliance Technical Services. Several Oak Ridge National Laboratory staff made important contributions to this work, including Shean Huff, John Thomas, Kevin Norman, Larry Moore, Ron Lentz, John Storey, Sam Lewis, and Teresa Barone. Likewise, several National Renewable Energy Laboratory staff made equally important contributions, including Colleen Alexander, Lisa Fouts, Jon Luecke, Robert McCormick, and Matt Ratcliff. Assistance with management and statistical analysis of the vehicle data by Cynthia Cooper, Bryan Fair, Tony Fristachi, and Marcie Mohnsen at Battelle is appreciated. The authors are also indebted to the staff of the Colorado State Emissions Laboratory, in particular Steve Sargent, Jim Kemper, Mike Mallory, Thad Pyzdrowski, and Mike Waida. Grateful acknowledgment is also due to Transportation Research Center, Inc. (TRC), especially Walt Dudek and Jason Holmes for their professional vehicle and small engine testing, and Steve McConnell at Argonne National Laboratory for his support of some of the vehicle testing at TRC. The authors also wish to thank the peer review panel led by Joseph Colucci for their thorough review and constructive recommendations and Brenda Smith, V. J. Ewing, Paula Pitchford, and Irene Passage for their dedication in preparation of the final manuscript.

The authors are indebted to many technical experts in industry and other government agencies. While these experts provided valuable guidance and information as noted above, this consultation does not constitute endorsement by their organizations of either the study or the results. 


\section{FOREWORD}

This report is an update of the original version, which was published in October 2008. This updated report includes results from the complete 16-vehicle fleet (the original report included only the first 13 vehicles tested) as well as corrections to minor errors identified in some of the originally reported data. Conclusions drawn from the complete dataset are nearly identical to those from the original 13-vehicle fleet but with increased statistical confidence. Significant changes to the report content are as follows:

- Summary results of vehicle emissions changes with ethanol content are updated and show improved statistical confidence.

- Tabulated vehicle emissions results (Tables 3.1 and 3.2) are updated to reflect results for the complete 16-vehicle fleet. Observed results are largely unchanged, but statistical confidence is improved.

- Charted vehicle emissions results (Figures 3.1 thru 3.4) are updated to reflect results for the complete 16-vehicle fleet. These results now include three additional older emissions classification vehicles with (generally) higher pollutant emissions.

- Charted vehicle emissions results included in Appendix $\mathrm{C}$ are updated for all vehicles; results for the three additional vehicles are added, and minor errors in the original 13-vehicle fleet are corrected. 


\section{EXECUTIVE SUMMARY}

\section{E.1 IMPACT OF INTERMEDIATE ETHANOL BLENDS ON LEGACY VEHICLES AND ENGINES}

In summer 2007, the U.S. Department of Energy (DOE) initiated a test program to evaluate the potential impacts of intermediate ethanol blends on legacy vehicles and other engines. ${ }^{*}$ The purpose of the test program is to assess the viability of using intermediate blends as a contributor to meeting national goals in the use of renewable fuels. Through a wide range of experimental activities, DOE is evaluating the effects of E15 and E20 - gasoline blended with 15\% and 20\% ethanol - on tailpipe and evaporative emissions, catalyst and engine durability, vehicle driveability, engine operability, and vehicle and engine materials.

This first report provides the results available to date from the first stages of a much larger overall test program. Results from additional projects that are currently underway or in the planning stages are not included in this first report. The purpose of this initial study was to quickly investigate the effects of adding up to $20 \%$ ethanol to gasoline on the following.

- Regulated tailpipe emissions for 16 popular late-model vehicles on a drive cycle similar to real-world driving and 28 small non-road engines (SNREs) ${ }^{\dagger}$ under certification or typical inuse procedures.

- Exhaust and catalyst temperatures of the same vehicles under more severe conditions.

- Temperature of key engine components of the same SNREs under certification or typical in-use conditions.

- Observable operational issues with either the vehicles or SNREs during the course of testing.

As discussed in the concluding section of this report, a wide range of additional studies are underway or planned to consider the effects of intermediate ethanol blends on materials, emissions, durability, and driveability of vehicles, as well as impacts on a wider range of nonautomotive engines, including marine applications, snowmobiles, and motorcycles.

Section 1 (Introduction) provides background on the test program and describes collaborations with industry and agencies to date. Section 2 (Experimental Setup) provides details concerning test fuels, vehicle and SNRE selection, and test methods used to conduct the studies presented in this report. Section 3 (Results and Discussion) summarizes the vehicle and SNRE studies and presents data from the testing completed to date. Section 4 (Next Steps) describes planned future activities. The appendixes provide test procedure details, vehicle and SNRE emissions standards, analysis details, and additional data and tables from vehicle and SNRE tests.

\section{E.2 BACKGROUND}

The Energy Independence and Security Act of 2007 calls on the nation to significantly increase its use of renewable fuels to meet its transportation energy needs. The law expands the renewable fuel standard (RFS) to require the use of 36 billion gallons of renewable fuel by 2022 . Given that ethanol is the most widely used renewable fuel in the U.S. market, ethanol will likely make up a significant portion of the 36-billion-gallon requirement.

\footnotetext{
*The test program is co-led and funded by the DOE Office of Energy Efficiency and Renewable Energy (EERE) Biomass Program and the EERE Vehicle Technologies Program with technical support from the Oak Ridge National Laboratory and the National Renewable Energy Laboratory. DOE and the laboratory team have worked closely with representatives from the U.S. Environmental Protection Agency, U.S. auto manufacturers, engine companies, and other organizations to develop and conduct a robust test program.

${ }^{\dagger}$ Ten different equipment models were tested, with multiple copies tested in some cases for a total of 28 engines.
} 
The vast majority of ethanol used in the United States is blended with gasoline to create E10 - gasoline with up to $10 \%$ ethanol. The remaining ethanol is sold in the form of E85-a gasoline blend with as much as $85 \%$ ethanol that can be used only in flexible-fuel vehicles (FFVs). Consumption of E85 is currently limited by both the size of the flex-fuel vehicle fleet and the number of E85 fueling stations.

Given projected growth in ethanol production and the new RFS, most analysts agree that the E10 market will be saturated in the next few years, possibly as soon as 2010. Although DOE remains committed to expanding the E85 infrastructure, that market represented less than $1 \%$ of the ethanol consumed in 2007 and will not be able to absorb projected volumes of ethanol in the near term. Given this reality, DOE and others have begun assessing the viability of using intermediate ethanol blends as a way to accommodate growing volumes of ethanol.

\section{E.3 DEVELOPMENT OF TEST PROGRAM}

The DOE team [DOE, the National Renewable Energy Laboratory (NREL), and the Oak Ridge National Laboratory (ORNL)] has collaborated with industry and other experts regarding the development and implementation of the test program. A number of automotive and non-road engine manufacturers provided significant input into the test protocols. This collaboration was typically coordinated through industry organizations such as the U.S. Council for Automotive Research, the Coordinating Research Council (CRC), the Outdoor Power Equipment Institute, the Alliance of Automobile Manufacturers, and the Association of International Automobile Manufacturers. Staff at the U.S. Environmental Protection Agency (EPA) provided important guidance in helping DOE design tests and select sample vehicles and small engines based on sales volumes and related test programs. In addition, statistical experts at Battelle Memorial Institute assisted in the vehicle selection process and data analysis. Argonne National Laboratory also assisted in data collection. DOE expects to continue to work closely with industry on ongoing and future tests.

Close interactions with representatives from the affected industries and EPA have been particularly helpful in refining or developing test protocols to assess the impact of intermediate ethanol blends on the equipment being tested. With respect to the specific studies presented in this report, standard test procedures were used where possible; however, in many cases, test protocols had to be modified or created where they did not yet exist.

\section{E.4 SUMMARY OF VEHICLE TESTS AND DATA}

For the studies documented in this report, vehicles were selected based on manufacturer, engine configuration and displacement, emission control system evolution, and model year. An initial group of 11 vehicles was selected primarily to span the evolution of emission control system technology and focused on two model years, 2003 and 2007. Five additional popular model vehicles were selected from a set of vehicles identified by the Coordinating Research * Council (CRC) as particularly likely to be sensitive to increased ethanol content in gasoline.* These five vehicles included three 1999 models, one 2001 model, and one 2004 model. All of the vehicles were tested on federal certification gasoline (E0), E10, E15, and E20 - that is, gasoline and three different gasoline/ethanol blends. Due to time constraints in obtaining match-blended fuels, splash blends were used in this study - that is, the E0 certification fuel was simply diluted with appropriate amounts of fuel-grade ethanol. Match-blended and splash-blended fuels have different hydrocarbon (HC) and volatility characteristics. While the different fuel characteristics

\footnotetext{
${ }^{*}$ The CRC Emissions Committee identified several vehicles suspected of not applying long-term fuel trim under high-load, open-loop conditions (http://www.crcao.com/doingbusiness/recentRFP.html, CRC Project No. E-87-1). Further details are in Sect. 2.2.1.1.
} 
were not expected to have a significant impact on the temperature measurements, the emissions results may have been influenced slightly by unintended changes in the vehicle cold start and warm up. The effect of different fuel characteristics on vehicle tailpipe emissions is currently being examined in a separate DOE-EPA jointly sponsored project.

\section{E.4.1 Fuel Economy}

- All 16 vehicles exhibited a loss in fuel economy commensurate with the energy density of the fuel. ${ }^{*}$ With E20, the average reduction in fuel economy (i.e., the reduction in miles per gallon) was $7.7 \%$ when compared to E0.

- Limited evaluations of fuel with as much as $30 \%$ ethanol were conducted, and the reduction in miles per gallon continued as a linear trend with increasing ethanol content.

\section{E.4.2 Emissions}

- Regulated tailpipe emissions remained largely unaffected by the ethanol content of the fuel.

- As ethanol content increased,

- oxides of nitrogen $\left(\mathrm{NO}_{\mathrm{X}}\right)$ and non-methane organic gases (NMOG) showed no significant change;

- non-methane hydrocarbons and carbon monoxide (CO) emissions declined on average for all ethanol blend levels tested. Neither pollutant changed appreciably from E10 to E20;

- ethanol emissions increased;

- acetaldehyde emissions increased;

- formaldehyde emissions increased slightly; and

- benzene and 1,3-butadiene were expected to decrease due to dilution, but measurements were conducted on only a subset of the vehicles and have not been thoroughly analyzed to date.

\section{E.4.3 Catalyst Temperatures}

- At closed-loop operating conditions, catalyst temperatures were cooler or unchanged with higher levels of ethanol.

- Nine of the 16 tested vehicles adjusted fueling with increased ethanol content to maintain a consistent fuel:air equivalence ratio ${ }^{\dagger}$ at wide-open throttle (WOT). ${ }^{\ddagger}$ In these cases, the catalyst temperatures at equivalent operating conditions were lower or unchanged with ethanol.

- Seven of the 16 tested vehicles ran leaner ${ }^{\S}$ (albeit still rich) with E20 fuel than with E0 fuel at WOT. For these vehicles, catalyst temperatures at WOT were between $29^{\circ} \mathrm{C}$ and $35^{\circ} \mathrm{C}$ higher with E20 relative to E0.

\footnotetext{
*This result was expected because ethanol has about $67 \%$ of the energy density of gasoline on a volumetric basis.

'Equivalence ratio is a measure of the actual fuel to air (oxidizer) compared to stoichiometric conditions. "Stoichiometric" is the condition in which $100 \%$ of both fuel and air are consumed in the combustion reaction, resulting in no excess oxygen or unburned fuel.

${ }^{\ddagger}$ Wide-open throttle (WOT) is the full power condition for spark-ignition engines and is often an open-loop condition.

\&"Lean" refers to a condition in which $100 \%$ of the fuel is consumed, but excess oxygen remains after the reaction. "Rich" refers to a condition in which $100 \%$ of the air is consumed, but excess unburned fuel remains after combustion.
} 


\section{E.4.4 Operability}

Although formal driveability testing was not conducted during the testing reported here, no operability or driveability issues were identified when any of the ethanol blends were used during the limited time of the project. Each vehicle accumulated at least 100 miles on each ethanol blend, and at least 200 miles on gasoline (E0 fuel). Mileage accumulations for the vehicles ranged from 500-1,200 miles due to additional tests on some of the vehicles. The following observations were noted during the limited test period.

- None of the vehicles displayed a malfunction indicator light (MIL) as a result of the ethanol content of the fuel.

- No fuel filter plugging symptoms were observed.

- No cold start problems were observed in $75^{\circ} \mathrm{F}$ and $50^{\circ} \mathrm{F}$ laboratory conditions.

- No fuel leaks or conspicuous degradation of the fuel systems were observed.

\section{E.5 SUMMARY OF SMALL NON-ROAD ENGINE TESTS AND DATA}

Millions of SNREs are sold each year, including leaf blowers and line trimmers, lawn mowers, generator sets, and small tractors (all under $25 \mathrm{hp}$ ). EPA certifies on the order of 900 engine emission "families" for SNREs each year. Unlike the engines in modern light-duty vehicles, SNREs are typically open-loop engines - that is, these engines do not have exhaust oxygen sensing capabilities and therefore cannot compensate for ethanol content in the fuel. These open-loop engines are commonly air-cooled, and they customarily operate fuel-rich to achieve cooler combustion temperatures for longevity purposes. With a fixed fueling calibration, as ethanol content in the fuel increases, combustion becomes leaner, leading to higher combustion temperatures and higher component temperatures, as well as changes in emissions and sometimes idle speed.

Initial tests conducted by ORNL and NREL focused on identifying emissions or operational issues and measurement of several key engine temperatures with federal certification gasoline (E0) and three splash-blended fuels (E10, E15, and E20). One copy of each engine was tested on all four fuels in this pilot study.

In addition to the ORNL and NREL tests, DOE funded the Transportation Research Center (TRC) through an ORNL subcontract to test four copies of several small engines to full useful life (full life). All of these engines were tested on E0 and then aged on a dedicated fuel-E0, E10, E15, or E20. The tests performed at TRC measured emissions and temperatures at various stages of the engines' lives - when new, at half life, and at full life. The primary focus of these tests was to assess any operational problems during aging to full life and to evaluate how engine operation and emissions change over time with exposure to various levels of ethanol.

Similar to the vehicle tests, splash-blended fuels were used in this study instead of matchblended fuels - that is, the E0 fuel was simply diluted with appropriate amounts of ethanol. Similar to the vehicle results, the different fuel characteristics of match-blended and splashblended fuels were not expected to have a significant impact on temperature. In addition, the emission results for the SNRE testing are not expected to vary significantly between splashblended and match-blended fuels because a cold start and warm up were not included in the testing. 


\section{E.5.1 Emissions}

Results from the tests of 28 SNREs generally indicated that, as ethanol content increased to as much as $20 \%$, open-loop engines operated leaner with increasing ethanol. Effects of this enleanment ${ }^{*}$ on emissions included the following.

- $\mathrm{NO}_{\mathrm{X}}$ emissions increased.

- $\mathrm{HC}$ emissions generally decreased.

- Regulated emissions - combined $\mathrm{HC}+\mathrm{NO}_{\mathrm{X}}$ - decreased in most cases.

- $\mathrm{CO}$ emissions decreased.

\section{E.5.2 Performance and Operability}

The following observations were noted during testing of the small, open-loop engines.

- With greater ethanol content, temperatures of the exhaust components, cylinder head, and cylinders generally increased. The largest increases were in exhaust temperature, rising $10^{\circ} \mathrm{C}$ to $50^{\circ} \mathrm{C}$ from $\mathrm{E} 0$ to $\mathrm{E} 15$ and $20^{\circ} \mathrm{C}$ to $70^{\circ} \mathrm{C}$ from $\mathrm{E} 0$ to E20. For the six engines in the pilot study in which temperatures were measured on all four fuels for each engine, temperature increases from E10 to E15 ranged between $5^{\circ} \mathrm{C}$ and $10^{\circ} \mathrm{C}$.

- With greater ethanol content, three handheld trimmers demonstrated higher idle speed and experienced unintentional clutch engagement. The increased speed was again caused by the fuel:air mixture enleanment, which can be adjusted and mitigated in some engines.

- Residential and Commercial Class I and Class IV engines were aged to full life. The residential Class I as well as the commercial engines exhibited no sensitivity to ethanol from a durability perspective. The effect of ethanol on durability of the residential Class IV engines was not clear, given that a number of these engines failed during full-life aging regardless of fuel type. The failure of these engines may have been related to the engine mounting method.

- Although not specifically characterized, no obvious materials compatibility issues were noted during the limited duration of this program.

- In the case of the 2-cylinder engine tested, temperatures and emissions varied from cylinder to cylinder due to differences in the air-fuel distribution between cylinders. Given this observation, multicylinder open-loop engines may prove to be more sensitive to ethanol blends.

\footnotetext{
${ }^{*}$ Enleanment means moving toward a leaner fuel:air equivalence ratio. In this case, from a rich condition to a leaner (albeit still rich) fuel:air equivalence ratio.
} 



\section{INTRODUCTION}

\subsection{BACKGROUND}

The Energy Independence and Security Act of 2007 calls on the nation to significantly increase its use of renewable fuels to meet its transportation energy needs. The law establishes a new renewable fuel standard (RFS) that requires the nation to use 36 billion gallons of renewable fuel in its vehicles by 2022. Given that ethanol is the most widely used renewable fuel in the United States* and production is expected to grow steadily over the next several years, ethanol—both from $\operatorname{corn}^{\dagger}$ and from cellulosic feedstocks - will likely make up a significant portion of the new renewable fuel requirements. The vast majority of ethanol used in the United States is blended with gasoline to create E10 - that is, gasoline with up to $10 \%$ ethanol. The remaining ethanol is sold in the form of E85-a gasoline blend with as much as $85 \%$ ethanol that can be used only in flexible-fuel vehicles (FFVs). Consumption of E85 is currently limited by both the size of the flex-fuel vehicle fleet and the number of E85 fueling stations. ${ }^{\ddagger}$ While U.S. automakers have committed to significantly ramping up production of FFVs, only about $7 \%$ of the existing U.S. fleet is replaced each year. That means a significant number of the non-FFVs in use today will remain in the vehicle stock for many years to come.

In light of projected growth in ethanol production, as well as the new RFS, most analysts agree that the E10 market will be saturated in the next few years, possibly as soon as $2010 .^{\S}$ Although the U.S. Department of Energy (DOE) remains committed to expanding E85 infrastructure, that market will not be able to absorb projected volumes of ethanol in the near term. Given this reality, DOE and others have begun assessing the viability of using intermediate ethanol blends as one way to potentially accommodate growing volumes of ethanol.

In summer 2007, DOE initiated a test program to assess the potential impacts of intermediate ethanol blends on typical vehicles (non-FFVs) as well as on other engines that rely on gasoline. The latter include small non-road engines (SNREs) such as those used in lawn and garden equipment and engines for marine applications, motorcycles, and snowmobiles.

The DOE program has been co-led and funded by the DOE Office of Energy Efficiency and Renewable Energy (EERE) Biomass Program and the EERE Vehicle Technologies Program with technical support from the Oak Ridge National Laboratory (ORNL) and the National Renewable Energy Laboratory (NREL). Before designing the test program, DOE tasked ORNL to conduct a literature search on the subject, which indicated that insufficient data exists to predict the impacts of these fuels on U.S. vehicles and engines.**

DOE's test program focuses specifically on the effects of E15 and E20 - gasoline blended with $15 \%$ and $20 \%$ ethanol - but considers both E0 (gasoline) and E10 as baseline fuels. Through a wide range of experimental activities, DOE is evaluating the effects of these intermediate ethanol blends on a variety of potentially affected equipment. Some of these activities are being co-funded and managed by other entities, including the Coordinating Research Council (CRC) and the U.S. Environmental Protection Agency (EPA).

\footnotetext{
*In 2007, the United States produced more than 6.5 billion gallons of ethanol and imported another 450 million gallons.

${ }^{\dagger}$ The law puts a 15-billion-gallon limit on credits available for the amount of corn ethanol that can contribute to the renewable fuel standard.

${ }^{*}$ Less than $1 \%$ of the ethanol used in the United States today is sold in the form of E85. Approximately 7 million flexfuel vehicles, or about $3 \%$ of the U.S. fleet, are in use today with less than $1 \%$ of U.S. fueling stations providing E85.

${ }^{\S}$ At this time, less than $50 \%$ of gasoline is blended with $10 \%$ ethanol due to blending infrastructure limitations, some state specifications, and other factors. If these limits are removed, the E10 market could be saturated once ethanol levels reach about 14 billion gallons.

${ }^{* *}$ R. Bechtold, J. F. Thomas, S. P. Huff, J. P. Szybist, T. J. Theiss, B. H. West, M. Goodman, T. A. Timbario, "Technical Issues Associated with the Use of Intermediate Ethanol Blends (>E10) in the U.S. Legacy Fleet," ORNL/ TM-2007/37, August 2007.
} 
For example, DOE is evaluating the impact of intermediate ethanol blends on tailpipe emissions over the full useful life of a wide range of high-sales-volume vehicles. DOE is also funding studies that evaluate the effects of intermediate blends on driveability as well as materials used in vehicles and infrastructure components. Current and additional projects are continually being evaluated and modified as appropriate or as needed based on funding availability. Additional details are contained in Section 4 of this report.

This first report provides results from the first stages of a much larger overall test program.

Results from additional projects that are currently underway or in the planning stages are not included in this first report. The purpose of this initial study was to quickly investigate the effects of adding up to $20 \%$ ethanol to gasoline on the following.

- Regulated tailpipe emissions for 16 popular late model vehicles on a drive cycle similar to real-world driving and 28 SNREs under certification or typical in-use conditions.

- Exhaust and catalyst temperatures of the same vehicles under more severe conditions.

- Temperature of key engine components of the same SNREs under certification or typical in-use conditions.

- Observable operational issues with either the vehicles or SNREs during the course of testing. (Studies focused on operational issues, including safety aspects of personal and recreational engines, are viewed as important but are beyond the scope of this first report.)

\subsection{TEST PROGRAM OVERVIEW}

The DOE team (DOE, NREL, and ORNL) collaborated with industry and other experts regarding the development and implementation of the test program. A number of automotive and non-road engine manufacturers provided significant input to the test protocols. This collaboration was typically coordinated through industry organizations such as the U.S. Council for Automotive Research, the CRC, the Outdoor Power Equipment Institute, the Alliance of Automobile Manufacturers, the Association of International Automobile Manufacturers, and the National Marine Manufacturers Association. Staff at EPA provided important guidance for test design and sample vehicle and small engine selection based on sales volumes and related test programs. In addition, statistical experts at Battelle Memorial Institute assisted in the vehicle selection process and data analysis. Argonne National Laboratory (ANL) also assisted in data collection. DOE expects to continue to work closely with industry, EPA, and others on ongoing and future tests.

Close interactions with representatives from the affected industries as well as EPA have been particularly helpful in refining or developing test protocols to assess the impact of intermediate ethanol blends on the equipment being tested. With respect to the specific studies presented in this report, standard test procedures were used where possible; however, in many cases, test protocols had to be modified or created where they did not yet exist.

In the interest of gathering data as quickly, accurately, and efficiently as possible, DOE is working with industry and EPA to leverage parallel and related studies where possible. In some cases, DOE is funding studies jointly with industry; however, in all instances, independent laboratories conduct the tests and provide raw data. These efforts include, but are not limited to, the following.

- DOE is providing technical input, reviewing data, and monitoring the progress of intermediate blends testing underway at other organizations [e.g., Rochester Institute of Technology (RIT), State of Minnesota, Renewable Fuels Association (RFA)]. The Minnesota/RFA E20 studies include a project to assess the materials compatibility of E20 on typical fuel system materials. In the case of RIT, test protocols have been harmonized to potentially allow a combined analysis of this dataset with DOE's dataset once testing is completed.

\footnotetext{
${ }^{*}$ Ten different equipment models were tested, with multiple copies tested in some cases for a total of 28 engines.
} 
- Four of the vehicle test projects are being conducted in partnership with CRC, a research organization established and funded by the automotive and petroleum industry. These studies are jointly funded by DOE and CRC.

This report provides results available to date from the first stages of the overall test program. Emissions and temperature data, as well as operational observations, from testing 16 vehicles and 28 SNREs are summarized.

Section 2 (Experimental Setup) provides detailed information concerning the protocols and procedures used to conduct the studies presented in this report. Section 3 (Results and Discussion) summarizes the vehicle and SNRE studies and presents data from testing completed to date. Section 4 (Next Steps) describes planned future work. The appendixes provide test procedure details, vehicle and SNRE emissions standards, analysis details, and additional data and tables from vehicle and SNRE tests. 


\section{EXPERIMENTAL SETUP}

The DOE team used existing test protocols where available and developed test plans where needed to evaluate E0, E10, E15, and E20 on vehicles and SNREs. In some cases, the DOE team adjusted test procedures based on the manufacturer's input. The specific procedures for all tests are outlined in this section.

\section{$2.1 \quad$ TEST FUELS AND ANALYSIS}

Four fuels of varying ethanol blend level were included in this program to determine each vehicle's or small engine's response to intermediate ethanol blend concentrations. Ethanol blend concentration levels were specified on a volume-percent basis and included $0 \%, 10 \%, 15 \%$, and 20\% (E0, E10, E15, and E20). E0 and E10 were both included as they represent legal fuels for sale in the United States.

All fuels were splash blends of E0 (certification gasoline, i.e., Indolene) with fuel-grade ethanol (per ASTM D4806) supplied by Gage Products Company. Splash blends were used for expediency in this pilot study due to the long iterative development process required to obtain match-blended fuels. The main differences in fuel chemistry between splash-blended and match-blended fuels are expected to be vapor pressure and hydrocarbon profile, neither of which is expected to have a significant effect on the major findings of this study. This assertion will be validated by other activities within the DOE test program, which will use match-blended fuels.

Fuels were analyzed by the Fuel Analysis Laboratory at Southwest Research Institute. Table 2.1 summarizes the analyses performed and methods used.

A summary of selected fuel properties for fuel samples taken from each of the test laboratories is included in Table 2.2. Fuels labeled as ANL and ORNL were used for ANL-specific and ORNLspecific vehicle testing at the Transportation Research Center (TRC). ORNL fuels were also supplied directly to the ORNL laboratory for in-house vehicle and small engine testing. NREL fuels were used for all vehicle tests at the Colorado Department of Public Health and Environment (CDPHE) test site.

Table 2.1. Test fuel property measurements

\begin{tabular}{|l|c|l|}
\hline \multicolumn{1}{|c|}{ Property } & $\begin{array}{c}\text { ASTM } \\
\text { specification }\end{array}$ & \multicolumn{1}{c|}{ Description } \\
\hline $\begin{array}{c}\text { Volume percent } \\
\text { ethanol and oxygen } \\
\text { weight fraction }\end{array}$ & D5599 & $\begin{array}{l}\text { Standard test method for determination of oxygenates in } \\
\text { gasoline by gas chromatography and oxygen selective } \\
\text { flame ionization detection }\end{array}$ \\
\hline Dry vapor pressure & D5191 & $\begin{array}{l}\text { Standard test method for vapor pressure of petroleum } \\
\text { products (mini method) }\end{array}$ \\
\hline Lower heating value & D240 & $\begin{array}{l}\text { Standard test method for heat of combustion of liquid } \\
\text { hydrocarbon fuels by bomb calorimeter }\end{array}$ \\
\hline Specific gravity & D4052 & $\begin{array}{l}\text { Standard test method for density and relative density of } \\
\text { liquids by digital density meter }\end{array}$ \\
\hline $\begin{array}{c}\text { Carbon/hydrogen } \\
\text { weight fraction }\end{array}$ & D5291 & $\begin{array}{l}\text { Standard test method for instrumental determination of } \\
\text { carbon, hydrogen, and nitrogen in petroleum products and } \\
\text { lubricants }\end{array}$ \\
\hline
\end{tabular}


Table 2.2. Test fuel properties

\begin{tabular}{|c|c|c|c|c|c|c|c|c|}
\hline $\begin{array}{c}\text { Test } \\
\text { laboratory }\end{array}$ & Fuel & $\begin{array}{c}\text { EtOH } \\
\text { (vol \%) }\end{array}$ & $\begin{array}{c}\text { DVPE } \\
\text { (psi) }\end{array}$ & $\begin{array}{c}\text { LHV } \\
\text { (Btu/lbm) }\end{array}$ & SG & $\begin{array}{c}\text { C } \\
\text { (wt frac) }\end{array}$ & $\begin{array}{c}\text { H } \\
\text { (wt frac) }\end{array}$ & $\begin{array}{c}\text { O } \\
\text { (wt frac) }\end{array}$ \\
\hline \multirow{4}{*}{ NREL } & E0 & 0.0 & 8.96 & 18,533 & 0.746 & 0.8615 & 0.1305 & 0.0000 \\
\cline { 2 - 9 } & E10 & 9.9 & 9.81 & 17,873 & 0.750 & 0.8184 & 0.1237 & 0.0365 \\
\cline { 2 - 9 } & E15 & 13.9 & 9.63 & 17,471 & 0.752 & 0.8072 & 0.1268 & 0.0511 \\
\cline { 2 - 9 } & E20 & 18.6 & 9.65 & 17,091 & 0.754 & 0.7877 & 0.1292 & 0.0679 \\
\hline \multirow{4}{*}{ ORNL } & E0 & 0.0 & 8.40 & 18,534 & 0.746 & 0.8683 & 0.1297 & 0.0000 \\
\cline { 2 - 9 } & E10 & 9.1 & 9.48 & 17,844 & 0.750 & 0.8256 & 0.1262 & 0.0336 \\
\cline { 2 - 9 } & E15 & 14.4 & 9.33 & 17,485 & 0.752 & 0.8016 & 0.1252 & 0.0527 \\
\cline { 2 - 9 } & E20 & 19.8 & 9.23 & 17,043 & 0.755 & 0.7966 & 0.1284 & 0.0723 \\
\hline \multirow{4}{*}{ ANL } & E0 & 0.0 & 8.49 & 18,542 & 0.746 & 0.8683 & 0.1285 & 0.0000 \\
\cline { 2 - 9 } & E10 & 9.9 & 9.34 & 17,793 & 0.751 & 0.8229 & 0.1285 & 0.0362 \\
\cline { 2 - 9 } & E15 & 14.3 & 9.39 & 17,412 & 0.752 & 0.8058 & 0.1341 & 0.0524 \\
\cline { 2 - 9 } & E20 & 19.6 & 9.15 & 17,044 & 0.755 & 0.7897 & 0.1271 & 0.0717 \\
\hline
\end{tabular}

Abbreviations: $\mathrm{EtOH}=$ ethanol; DVPE = dry vapor pressure equivalent; $\mathrm{LHV}=$ lower heating value; $\mathrm{SG}=$ specific gravity; $\mathrm{C}=$ carbon; $\mathrm{H}=$ hydrogen; $\mathrm{O}=$ oxygen.

\subsection{VEHICLES}

\subsubsection{Experimental Parameters}

The main factors in the experimental setup for this study were

- fuel type,

- vehicle type, and

- test cycle.

Vehicles were selected based on manufacturer and engine configuration (cylinders and displacement, etc). Fuels were chosen to include both currently legal and potential intermediate ethanol blends. Each vehicle was tested using four fuels of varying ethanol blend level. Emissions were determined using the LA92 drive cycle, also known as the unified cycle." The LA92 was chosen for all emissions testing based on consultation with EPA and the fact that it is being used in the EPAct program. This cycle is considered representative of real-world emission changes as it more accurately represents typical acceleration rates and speeds of actual drivers on the road than does the Federal Test Procedure (used for emissions certification testing). Details on test and measurement hardware and test procedures are provided in Appendix A, as well as emissions standards relevant to the vehicles tested.

\subsubsection{Vehicle selection}

A database of registered vehicles was purchased from R. L. Polk \& Co. to characterize the population of light-duty vehicles in the U.S. fleet during 2007. Table 2.3 shows the number of

*http://www.arb.ca.gov/msei/onroad/briefs/Publication3.pdf 
Table 2.3. Number of registered gasoline-powered vehicles ${ }^{a}$ in the United States on January 1, 2007-by model year period, manufacturer, and number of cylinders (vehicle numbers are in thousands)

\begin{tabular}{|c|c|c|c|c|c|c|}
\hline \multirow{2}{*}{$\begin{array}{l}\text { Model year } \\
\text { period }\end{array}$} & \multirow{2}{*}{ Manufacturer } & \multicolumn{4}{|c|}{ Number of cylinders } & \multirow{2}{*}{ Total } \\
\hline & & 4 & 6 & 8 & Other & \\
\hline $\begin{array}{l}\text { Pre-1996 } \\
\text { (Tier } 0 \text { and } \\
\text { older) }\end{array}$ & All & 25,948 & 34,597 & 16,512 & 1,573 & 78,630 \\
\hline \multirow{9}{*}{$\begin{array}{l}\text { 1996-1999 } \\
\text { (Tier 1) }\end{array}$} & Chrysler & 1,338 & 3,943 & 1,584 & 45 & 6,910 \\
\hline & Ford & 1,894 & 5,100 & 4,021 & 100 & 11,116 \\
\hline & GM & 3,421 & 7,090 & 3,851 & 44 & 14,406 \\
\hline & Honda & 2,581 & 540 & - & 35 & 3,157 \\
\hline & Nissan & 1,146 & 914 & 28 & 0 & 2,088 \\
\hline & Toyota & 2,492 & 1,438 & 130 & 1 & 4,061 \\
\hline & Volkswagen & 542 & 188 & 6 & 0 & 737 \\
\hline & Other & 2,228 & 1,206 & 294 & 278 & 4,006 \\
\hline & Subtotal & 15,642 & 20,420 & 9,915 & 504 & 46,481 \\
\hline \multirow{9}{*}{$\begin{array}{l}\text { 2000-2004 } \\
\text { (Tier } 2 \\
\text { Transitional) }\end{array}$} & Chrysler & 1,788 & 4,191 & 2,445 & 25 & 8,449 \\
\hline & Ford & 1,586 & 5,603 & 5,300 & 256 & 12,744 \\
\hline & GM & 3,474 & 9,894 & 5,996 & 88 & 19,452 \\
\hline & Honda & 3,671 & 2,154 & - & 0 & 5,825 \\
\hline & Nissan & 1,293 & 2,045 & 163 & 0 & 3,501 \\
\hline & Toyota & 3,778 & 3,174 & 1,001 & - & 7,953 \\
\hline & Volkswagen & 1,309 & 474 & 55 & 0 & 1,838 \\
\hline & Other & 4,466 & 4,139 & 784 & 447 & 9,836 \\
\hline & Subtotal & 21,366 & 31,673 & 15,743 & 816 & 69,598 \\
\hline \multirow{9}{*}{$\begin{array}{c}\text { 2005-2007 } \\
\text { (Tier 2) }\end{array}$} & Chrysler & 767 & 2,528 & 1,071 & 8 & 4,373 \\
\hline & Ford & 715 & 2,095 & 1,934 & 43 & 4,786 \\
\hline & GM & 1,652 & 3,589 & 2,265 & 273 & 7,779 \\
\hline & Honda & 1,752 & 1,273 & - & - & 3,025 \\
\hline & Nissan & 872 & 1,088 & 238 & - & 2,199 \\
\hline & Toyota & 2,457 & 1,935 & 499 & - & 4,892 \\
\hline & Volkswagen & 288 & 91 & 41 & 181 & 601 \\
\hline & Other & 1,956 & 2,000 & 425 & 278 & 4,659 \\
\hline & Subtotal & 10,458 & 14,599 & 6,474 & 782 & 32,313 \\
\hline & Grand total & 73,414 & 101,289 & 48,645 & 3,675 & 227,022 \\
\hline
\end{tabular}

${ }^{a}$ Does not include flexible-fuel vehicles.

gasoline-powered (non-FFV) registered vehicles by model year period, manufacturer, fuel type, and number of cylinders. The total population includes all vehicle manufacturers; however, subtotals are presented only for the top seven vehicle manufacturers. The Polk database also provided details such as vehicle make and model, engine displacement, fuel type, and transmission type.

Model year periods were generally defined to correspond to different regulatory periods. For the purposes of this study, vehicles were categorized by model year into four basic emission level groups, as follows.

- $\quad$ Tier 0, Pre-1996: Tier 0 gaseous emissions standards were in force from 1981 through 1993 (although not denoted Tier 0 until 1987). These standards were phased out from 1994 through 1996. 
- $\quad$ Tier 1, 1996 through 1999: Tier 1 emissions standards were phased in from 1994 through 1996 with full compliance required in 1996.

- Tier 2 Transitional, 2000 through 2004: The National Low Emission Vehicle program began transition to Tier 2 emissions levels from 2000 through 2004.

- Tier 2, 2004 through 2007: Tier 2 emissions standards were phased in for light-duty passenger car vehicles beginning in 2004, with full compliance required in 2007.

Vehicles were selected to meet several analysis objectives. Of the initial 11 vehicles, three pairs were selected to represent a range of engine sizes and manufacturers, with each pair consisting of a 2003 and a 2007 vehicle from the same manufacturer and similar engine configuration. The vehicle pairs were chosen to evaluate the effect of ethanol during the progression in emissions control technology from transitional Tier 2 to full Tier 2 compliance.

- 2003 and 2007 Toyota Camry 2.4L I4

- 2003 and 2007 GM LeSabre/Lucerne 3.8L V6

- 2003 and 2007 Ford F150 5.4L V8

Five additional vehicles were selected based on sales volume data; however, some consideration was also given to vehicles that complemented those selected for EPA's EPAct (Energy Policy Act) study, which involved a similar test protocol.

- 2003 Ford Taurus 3.0L V6

- 2003 Nissan Altima 3.5L V6

- 2007 Honda Accord 2.4L I4

- $\quad 2007$ Chrysler Town \& Country 3.3L V6

- 2007 GM Silverado 4.8L V8

Following this initial selection of 11 vehicles (Phase A), a second set of vehicles was selected (Phase B). These vehicles were selected using information from auto manufacturers concerning specific models that were most likely to be sensitive to increased ethanol content in gasoline, ${ }^{*}$ while also considering sales volumes.

- 1999 Honda Civic

- 2004 VW Golf GTI

- 1999 Ford Crown Victoria

- 1999 Toyota Corolla

- 2001 Chrysler PT Cruiser

A summary of all vehicles selected for testing is included in Table 2.4. This table contains information about each vehicle, including odometer reading, engine family, and applicable emissions standard.

Results presented in this report are based on results for the 11 vehicles selected in Phase A as well as all five of the Phase B vehicles. Although these 16 vehicles were not selected "at random," with the exception of the three 1999 model year vehicles they are generally representative of the population of late model gasoline-powered vehicles (model year 2000 to 2007) that were on the road in early 2007. In particular, the number of vehicles tested was nearly proportional to the population counts for each manufacturer, engine size category (number of cylinders), and emissions standard period (Transitional Tier 2: 2000 through 2004 or Tier 2: 2005 through 2007).

\footnotetext{
${ }^{*}$ The CRC Emissions Committee identified several vehicles suspected of not applying long-term fuel trim under high-load, open-loop conditions (http://www.crcao.com/doingbusiness/recentRFP.html, CRC Project No. E-87-1).
} 
Table 2.4. Test vehicle list

\begin{tabular}{|c|c|c|c|c|c|c|c|c|}
\hline $\begin{array}{c}\text { OEM } \\
\text { (make) }\end{array}$ & Model & Year & Engine & $\begin{array}{c}\text { Initial } \\
\text { odometer } \\
\text { reading } \\
\text { (miles) }\end{array}$ & $\begin{array}{l}\text { EPA engine } \\
\text { family }\end{array}$ & $\begin{array}{l}\text { Emission } \\
\text { standard }\end{array}$ & Test site & Phase \\
\hline Chrysler & Town \& Country & 2007 & $3.3 \mathrm{~L} \mathrm{~V} 6$ & 35,000 & 7CRXT03.8NEO & Tier 2, Bin 5 & NREL/CDPHE & A \\
\hline Ford & F150 & 2007 & $5.4 \mathrm{~L} \mathrm{V8}$ & 28,600 & 7FMXT05.44H7 & Tier 2, Bin 8 & TRC & A \\
\hline Ford & $\mathrm{F} 150$ & 2003 & $5.4 \mathrm{~L} \mathrm{V8}$ & 57,000 & 3MFXT05.4PFB & Tier 1 LEV & TRC & A \\
\hline Ford & Taurus & 2003 & $3.0 \mathrm{~L} \mathrm{V6}$ & 89,600 & 3FMXV03.0VF3 & Tier 2 , Bin 8 & TRC & $\mathrm{A}$ \\
\hline GM (Buick) & Lucerne & 2007 & $3.8 \mathrm{~L} \mathrm{V6}$ & 10,000 & 7GMXV03.9146 & $\begin{array}{l}\text { Tier 2, Bin } 5 \\
\text { (CA LEV II) }\end{array}$ & $\begin{array}{l}\text { NREL/CDPHE } \\
\text { and ORNL }\end{array}$ & A \\
\hline GM (Buick) & LeSabre & 2003 & $3.8 \mathrm{~L} \mathrm{V6}$ & 78,000 & 3GMXV03.8044 & Tier 2 , Bin 8 & NREL/CDPHE & $\mathrm{A}$ \\
\hline GM & Silverado & 2007 & $4.8 \mathrm{~L} \mathrm{V8}$ & 12,800 & 7GMXT05.3379 & Tier 2, Bin 8 & TRC & $\mathrm{A}$ \\
\hline Honda & Accord & 2007 & $2.4 \mathrm{~L} \mathrm{I} 4$ & 11,400 & 7HNXV02.4KKC & $\begin{array}{l}\text { Tier 2, Bin } 5 \\
\text { (CA LEV II) }\end{array}$ & TRC & A \\
\hline Nissan & Altima & 2003 & 3.5 L V6 & 53,300 & 3NSXV03.5C7A & LEV & TRC & $\mathrm{A}$ \\
\hline Toyota & Camry & 2007 & $2.4 \mathrm{~L} \mathrm{I} 4$ & 26,440 & 7TYXV02.4BEB & Tier 2, Bin 5 & $\begin{array}{l}\text { ORNL and } \\
\text { NREL/CDPHE }\end{array}$ & A \\
\hline Toyota & Camry & 2003 & $2.4 \mathrm{~L} \mathrm{I} 4$ & 72,800 & 3TYXV02.4HHA & ULEV & ORNL & A \\
\hline Chrysler & PT Cruiser & 2001 & $2.4 \mathrm{~L} \mathrm{I} 4$ & 93,400 & 1CRXV02.4VD0 & NLEV & NREL/CDPHE & $\mathrm{B}$ \\
\hline Ford & Crown Victoria & 1999 & $4.6 \mathrm{~L} \mathrm{V8}$ & 50,900 & XFMXV04.6VBE & ULEV & NREL/CDPHE & $\mathrm{B}$ \\
\hline Honda & Civic & 1999 & $1.6 \mathrm{~L} \mathrm{I} 4$ & 79,680 & XHNXV01.6TA3 & Tier 1 & ORNL & $\mathrm{B}$ \\
\hline Toyota & Corolla & 1999 & $1.8 \mathrm{~L} \mathrm{I} 4$ & 96,400 & XTYXV01.8XBA & Tier 1 & NREL/CDPHE & $\mathrm{B}$ \\
\hline VW & Golf GTI & 2004 & 1.8 L I4 Turbo & 32,900 & 4ADXV01.8356 & Tier 2 , Bin 8 & ORNL & $\mathrm{B}$ \\
\hline
\end{tabular}

${ }^{a}$ Round-robin vehicle tested at two sites; abbreviations: LEV = low-emissions vehicle, NLEV = National Low Emission Vehicle Program vehicle, ULEV $=$ ultra-lowemissions vehicle. 


\subsubsection{Test sites}

Vehicle testing was conducted simultaneously at three separate emissions laboratories to expedite the program.

- ORNL, Knoxville, Tennessee

- TRC, East Liberty, Ohio

- CDPHE emissions test laboratory, Aurora, Colorado

\subsubsection{Test condition temperature}

Nominal testing temperature for all reported data was $75^{\circ} \mathrm{F}$ per Code of Federal Regulations (CFR) requirements. Testing over a wider temperature range will be necessary to fully evaluate the vehicle emissions impacts of intermediate ethanol blends; however, such testing was beyond the scope of this pilot program.

\subsubsection{Statistical Analysis}

For this first report, statistical analysis was conducted to address two main objectives.

1. Determine whether the relative change in emissions when using ethanol in the fuel (E10, E15, or E20) versus E0, averaged across all vehicles, is different from zero.

2. Determine whether the percentage of vehicles that experience an increase in emissions when using ethanol fuel versus E0 is different from $50 \%$.

This approach involved calculating the change in average measured emissions and fuel economy (based on triplicate emissions tests) between the fuels containing ethanol (E10, E15, and E20) and E0. The relative change for each vehicle was obtained by dividing by the average emissions with E0. The null hypothesis assumed for all data was that there is no correlation between the ethanol content of the fuel and emissions or fuel economy results. Thus, the average change in emissions among all vehicles should be zero, and the percentage of vehicles with positive changes in emissions should be $50 \%$.

To address the first objective, a standard t-test was performed to test the hypothesis that the average change is zero. For this analysis, the 16 tested vehicles were treated as a random sample from the population of late model vehicles (model year 2000 to 2007) in the United States in early 2007. Although the vehicles were not selected at random, they are generally representative of the target population, as discussed above. The use of a t-test is equivalent to calculating $95 \%$ confidence limits on the average change in emissions. For example, if the t-test determines that the estimated average change in emissions is statistically significant (i.e., different from zero) at the 5\% significance level, then the $95 \%$ confidence bounds on the estimated average would not include the value zero. That is, the magnitude of the confidence limit is smaller than the magnitude of the estimated average change.

The second objective was addressed using the "sign" test to determine whether the frequency of positive or negative changes (among the 16 vehicles) was significantly different from $50 \%$. According to this procedure, if 13 or more of the changes in emissions among the 16 vehicles have the same sign (positive or negative), the finding is statistically significant at the $5 \%$ level. Significance levels were determined using the binomial probability distribution function. Generally, the sign test and the t-test produce similar results.

This analysis was performed using the various procedures in the Statistical Analysis System (SAS) software package. 


\subsection{SMALL NON-ROAD ENGINES}

\subsubsection{Experimental Parameters}

SNREs were examined in two distinct studies: a 6-engine pilot study and a 22-engine full-usefullife (full-life) study. The main factors in the experimental setup for the two studies were

- fuel type,

- engine type,

- emissions test cycles, and

- $\quad$ aging test cycles.

\subsubsection{Engine selection}

SNREs under $25 \mathrm{hp}$ are categorized by EPA according to engine displacement and application. A summary of engine classifications is shown in Table 2.5. The highlighted sections of this table represent the classifications that have been tested under the first phase of this test program.

Table 2.5. Small non-road engine classification descriptions per 40 CFR 90 ${ }^{a}$

\begin{tabular}{|c|c|c|c|c|c|c|}
\hline \multirow[b]{2}{*}{ Class } & \multirow[b]{2}{*}{ Type } & \multirow{2}{*}{$\begin{array}{c}\text { Typical } \\
\text { application }\end{array}$} & \multirow{2}{*}{$\begin{array}{l}\text { Displacement } \\
\text { (cc) }\end{array}$} & \multicolumn{2}{|c|}{ Full, useful life (hr) } & \multirow{2}{*}{$\begin{array}{l}\text { ISO } 8178 \\
\text { emissions } \\
\text { test cycle }^{b}\end{array}$} \\
\hline & & & & $\begin{array}{c}\begin{array}{c}\text { Residential } \\
\text { (moderate use) }\end{array} \\
\end{array}$ & $\begin{array}{c}\text { Commercial } \\
\text { (extended use) }\end{array}$ & \\
\hline I-A & \multirow{3}{*}{ Non-handheld } & \multirow{3}{*}{$\begin{array}{l}\text { Lawnmower } \\
\text { small generator } \\
\text { set }\end{array}$} & $<66$ & 50 & 300 & \multirow{3}{*}{$\mathrm{G} 1$ or $\mathrm{G} 2$} \\
\hline I-B & & & $66 \leq \operatorname{disp}<100$ & 125 & 500 & \\
\hline I & & & $100 \leq \operatorname{disp}<225$ & 125 & 500 & \\
\hline II & Non-handheld & $\begin{array}{l}\text { Larger equip. } \\
\text { small tractor }\end{array}$ & $\geq 225$ & 250 & 1,000 & $\mathrm{G} 1$ or $\mathrm{G} 2$ \\
\hline III & \multirow{3}{*}{ Handheld } & \multirow{3}{*}{$\begin{array}{l}\text { Line-trimmer } \\
\text { blower chainsaw }\end{array}$} & $<20$ & \multirow{3}{*}{50} & \multirow{3}{*}{300} & \multirow{3}{*}{ G3 } \\
\hline IV & & & $20 \leq \operatorname{disp}<50$ & & & \\
\hline $\mathrm{V}$ & & & $\geq 50$ & & & \\
\hline
\end{tabular}

${ }^{a}$ Highlighted sections indicate the classifications that have been tested under the first phase of this test program. ${ }^{b}$ Cycles are described in greater detail in Table 2.7 .

EPA staff were consulted on engine selection and equipment to ensure that engines selected reflected those commonly found in popular, high-sales-volume equipment.

The laboratories conducting the pilot studies were not equipped with small engine dynamometers, so engines that could readily be operated using the installed machine in lieu of a dynamometer were preferentially considered for both studies. Aging engines using the installed machine in the full-life study allowed aging of all engines in parallel with a realistic, in-use load.

The pilot study focused on these engine classes/classifications, as detailed in Table 2.6.

- Class I and II engines-generator sets

- 1 commercial Class I (500-hr life)

- 1 field-aged Class I (no full-life hour requirement in 1999)

- 1 residential Class II (250-hr life)

- 1 commercial Class II (1,000-hr life)

- Class IV engines

- 1 residential blower (50-hr life)

- 1 commercial line trimmer (300-hr life) 
The subcontracted full-life study focused on these four engine classes, as highlighted in Table 2.6.

- Power washer-1 residential Class I (125-hr-life power washer)

- Generator set -1 commercial Class I (500-hr-life generator)

- Leaf blower-1 residential Class IV (50-hr-life leaf blower)

- Line trimmer-1 commercial Class IV (300-hr-life line trimmer)

The engines selected allowed for full-life testing to be conducted on the equipment rather than on the dynamometer, allowing all four engines of a type to be aged in parallel on their respective fuels without tying up dynamometer stands.

\subsubsection{Emission test cycles}

SNREs are categorized by EPA according to engine displacement and application, which determine the required emissions test cycle, as noted in Table 2.5. A summary of emission test cycle requirements and weighting factors for computing composite emissions is shown in Table 2.7 and described below.

During G1 and G2 emission tests, the engine is operated in the following manner.

- Mode Point 1 (Title 40 CFR 90 A-Cycle): Engine operated at intermediate (G1) or rated (G2) speed at wide-open throttle (WOT).

- Mode Points 2-5 (Title 40 CFR 90 A-Cycle): The governor in its production configuration will control engine speed at the specified load points.

- Mode Point 6 (Title 40 CFR 90 A-Cycle): If the engine does not have a user-selectable governor, it will be allowed to operate at high idle speed determined by the installed governor. Otherwise, the engine will be operated at user-selectable low idle speed.

During G3 emissions tests, the engine is operated in the following manner.

- Mode Point 1 (Title 40 CFR 90 C-Cycle): Engine operated at rated speed at WOT.

- Mode Point 6 (Title 40 CFR 90 C-Cycle): If the engine does not have a user-selectable governor, it will be allowed to operate at high idle speed determined by the installed governor. Otherwise, the engine will be operated at user-selectable low idle speed.

These testing procedures were largely followed in both the pilot and full-life studies; however, any deviations are noted in the Test Procedures section of Appendix B. Appendix B also contains tables showing the Phase 1 and Phase 2 emissions standards applicable to SNREs. 
Table 2.6. SNRE equipment tested in pilot and full-useful-life (full-life) studies

\begin{tabular}{|c|c|c|c|c|c|c|c|}
\hline $\begin{array}{l}\text { Equipment tested } \\
\text { (EPA family } \\
\text { number) }\end{array}$ & $\begin{array}{c}\text { Class } \\
\text { (residential/ } \\
\text { commercial) }\end{array}$ & $\begin{array}{l}\text { Engine } \\
\text { size } \\
\text { (cc) }\end{array}$ & $\begin{array}{l}\text { Full life } \\
\text { (hr) }\end{array}$ & $\begin{array}{l}\text { Included } \\
\text { full-life } \\
\text { testing }\end{array}$ & $\begin{array}{c}\text { Testing } \\
\text { laboratory }\end{array}$ & New/full life & $\begin{array}{l}\text { Number of } \\
\text { engines }^{a}\end{array}$ \\
\hline \multicolumn{8}{|c|}{ Pilot study } \\
\hline $\begin{array}{l}\text { Honda generator } \\
\text { 2HNXS.1961AK }\end{array}$ & I-Commercial & 196 & 500 & No & ORNL & New & 1 \\
\hline $\begin{array}{l}\text { Honda generator }^{b} \\
\text { (used) } \\
\text { XHNXS.1631AA }\end{array}$ & $\mathrm{I}-\mathrm{N} / \mathrm{A}$ & 163 & NA & Yes $^{b}$ & ORNL & Full life & 1 \\
\hline $\begin{array}{l}\text { Briggs and Stratton } \\
\text { generator } \\
\text { 7BSXS.2492HC }\end{array}$ & II-Residential & 249 & 250 & No & ORNL & New & 1 \\
\hline $\begin{array}{l}\text { Kohler generator } \\
\text { 6KHXS.7252GC }\end{array}$ & II-Commercial & $\begin{array}{l}725 \\
(2-\text { cyl })\end{array}$ & 1,000 & No & ORNL & New & 1 \\
\hline $\begin{array}{l}\text { Poulan leaf blower } \\
\text { 7PWES.0254BM }\end{array}$ & IV_-Residential & 25 & 50 & Yes & NREL & New & 1 \\
\hline $\begin{array}{r}\text { Stihl line trimmer } \\
\text { 6A8XS.0284RA }\end{array}$ & IV_Commercial & 28.4 & 300 & No & NREL & New & 1 \\
\hline \multicolumn{8}{|c|}{ Full-life study } \\
\hline $\begin{array}{l}\text { Briggs \& Stratton } \\
\text { power washer } \\
\text { 6BSXS.1581VG }\end{array}$ & I-Residential & 158 & 125 & Yes & $\mathrm{TRC}$ & Both & 6 \\
\hline $\begin{array}{l}\text { Honda generator } \\
\text { 6HNXS.196A5A }\end{array}$ & I-Commercial & 196 & 500 & Yes & TRC & Both & 4 \\
\hline $\begin{array}{l}\text { Weed Eater blower } \\
\text { 7PWES.0254BA }\end{array}$ & IV_-Residential & 23 & 50 & Yes & $\mathrm{TRC}$ & Both & 8 \\
\hline $\begin{array}{l}\text { Stihl line trimmer } \\
\text { 6A8XS.0314RC }\end{array}$ & IV_Commercial & 31.4 & 300 & Yes & TRC & Both & 4 \\
\hline
\end{tabular}

${ }^{a}$ Where number of engines is greater than four, more than four engines were baselined before commencement of aging four engines.

${ }^{b}$ The used Honda engine at ORNL was field-aged (considered full life given its age) and tested on only E0, E10, and E20.

Table 2.7. ISO 8178 emission test cycles

\begin{tabular}{|l|c|c|c|c|c|c|c|c|c|c|c|}
\hline \multirow{2}{*}{ Test cycle } & \multicolumn{10}{|c|}{ Mode weighting factors from ISO 8178 test cycle } \\
\cline { 2 - 13 } & $\mathbf{1}$ & $\mathbf{2}$ & $\mathbf{3}$ & $\mathbf{4}$ & $\mathbf{5}$ & $\mathbf{1}$ & $\mathbf{2}$ & $\mathbf{3}$ & $\mathbf{4}$ & $\mathbf{5}$ & $\mathbf{6}$ \\
\hline \hline Torque, \% & 100 & 75 & 50 & 25 & 10 & 100 & 75 & 50 & 25 & 10 & 0 \\
\hline & \multicolumn{9}{|c|}{ Rated speed } & \multicolumn{7}{|c|}{ Intermediate speed } & $\begin{array}{c}\text { Low } \\
\text { idle }\end{array}$ \\
\hline G1 & - & - & - & - & - & 0.90 & 0.20 & 0.29 & 0.30 & 0.07 & 0.05 \\
\hline G2 & 0.09 & 0.20 & 0.29 & 0.30 & 0.07 & - & - & - & - & - & 0.05 \\
\hline G3 & 0.85 & - & - & - & - & - & - & - & - & - & 0.15 \\
\hline
\end{tabular}




\subsubsection{Test sites}

SNRE testing was conducted at the following laboratories.

- Pilot study

- ORNL_Fuels, Engines, and Emissions Research Center, Knoxville, Tennessee

- NREL-ReFUEL Laboratory, Golden, Colorado*

- Full-life study

- TRC, East Liberty, Ohio

\subsubsection{Test condition temperature}

Nominal temperature for emissions testing at all labs was $75^{\circ} \mathrm{F}$. Aging was conducted outside at a range of ambient temperatures.

\footnotetext{
*The ReFUEL Laboratory is at 1,700 m (5,700 ft) elevation.
} 


\section{RESULTS AND DISCUSSION}

\subsection{VEHICLES}

The goals of this study were to assess the effects of using intermediate ethanol blends up to E20 on the following:

- emissions and fuel economy,

- exhaust and catalyst temperature, and

- informal observations of operation and driveability.

Sixteen in-use, properly functioning light-duty passenger vehicles were included in this study. The objective was to determine the extent to which ethanol in the fuel has an immediate effect on regulated emissions, selected aldehyde emissions, and fuel economy for the "average" light-duty vehicle.

A summary of findings is provided below, with additional details in the remainder of this section.

\subsubsection{Emissions and Fuel Economy Summary}

Test results were statistically analyzed to determine whether sufficient evidence existed in the data to conclude that ethanol concentrations up to $20 \%$ in the fuel changed emissions or fuel economy, either when averaged across all vehicles or for a majority of vehicles. Results are presented in terms of statistical significance based on a Student's t-test as described in Sect. 2. "Statistically significant" results are those that can be stated with a 95\% confidence level or better. "Marginally significant" results correspond to a $90 \%$ or higher confidence level.

The following regulated tailpipe emissions showed no discernable trend with increasing ethanol content.

- Oxides of nitrogen $\left(\mathrm{NO}_{\mathrm{X}}\right)$ and non-methane organic gases (NMOG) showed no statistically significant trend with fuel type.

The following trends from E0 to E20 were found to be statistically significant.

- Carbon monoxide emissions declined with E20 (12\% on average) when compared to E0. This result was statistically significant, and similar reductions were found with E10 and E15 (15\% on average for each).

- Non-methane hydrocarbons (NMHC) decreased with E20 (15\% on average) when compared to E0. This result was statistically significant, and similar reductions were found with E10 and E15 ( $12 \%$ and $11 \%$ on average, respectively).

- Fuel economy decreased (7.7\% on average), consistent with the energy density reduction associated with ethanol blending (in limited tests, this trend was observed to continue to E30).

- Ethanol emissions increased with E20 from zero by an average $8.2 \mathrm{mg} / \mathrm{mi}$. Increases for E10 and E15 were $5.6 \mathrm{mg} / \mathrm{mi}$ and $6.8 \mathrm{mg} / \mathrm{mi}$, respectively.

- Acetaldehyde emissions increased with E20 by an average of $0.81 \mathrm{mg} / \mathrm{mi}$ from an average of $0.35 \mathrm{mg} / \mathrm{mi}$ for E0. Increases for E10 and E15 were $0.38 \mathrm{mg} / \mathrm{mi}$ and $0.70 \mathrm{mg} / \mathrm{mi}$, respectively.

- Formaldehyde emissions increased with E20 by an average of $0.11 \mathrm{mg} / \mathrm{mi}$ from an average of $0.71 \mathrm{mg} / \mathrm{mi}$ for E0. Increases for E10 and E15 were $0.11 \mathrm{mg} / \mathrm{mi}$ and $0.14 \mathrm{mg} / \mathrm{mi}$, respectively. 


\subsubsection{Exhaust and Catalyst Temperature Effects Summary}

The following observations were made based on measurements of exhaust fuel:air ratio and temperatures of the exhaust system and catalyst with E0 and E20.

- Seven vehicles ran leaner with E20 than with E0 fuel, but still rich, at wide open throttle. The change in fuel:air equivalence ratio roughly corresponded to the oxygen content of the fuel. A hypothesis about differences in engine control system approach to explain this leaner operation is presented in Sect. 3.1.5.1.

- For vehicles that ran leaner on E20, peak catalyst temperatures were found to increase by $29^{\circ}$ to $35^{\circ} \mathrm{C}$ during WOT accelerations when compared to operation on E0.

- For vehicles that did not run leaner on E20, peak catalyst temperatures were slightly cooler on average but largely unchanged during WOT accelerations when compared to operation on E0.

- During closed-loop (stoichiometric) operation, exhaust and catalyst temperatures were slightly cooler on average but largely unchanged with increased ethanol content on all vehicles tested.

\subsubsection{Unforeseen Operational Issues Summary}

- No driveability or operability issues were observed for the 16 vehicles tested in this pilot study.

- Although malfunction indicator lights (MILs) did illuminate on two of the vehicles, in no cases did MILs appear to illuminate as a result of the ethanol content of the fuel.

\subsubsection{Results and Discussion: Emissions and Fuel Economy}

This section presents a summary and statistical analysis of the emissions and fuel economy data obtained from the 16 vehicles tested. Results presented address two statistical analysis objectives.

1. Determine whether the relative change in emissions when using ethanol in the fuel (E10, E15, or E20) versus E0, averaged across all vehicles, is different from zero.

2. Determine whether the percentage of vehicles that experience an increase in emissions when using ethanol fuel versus E0 is different from $50 \%$.

For this analysis, the vehicles were treated as being selected at random from the population of late model vehicles (model years 2000 to 2007) that were on the road in early 2007. Although the tested vehicles were not selected at random, they are representative of this population in that the numbers of tested vehicles are nearly proportional to the population counts for each manufacturer, engine size category (number of cylinders), and emissions standard period (Transitional Tier 2: 2000 through 2004 or Tier 2: 2005 through 2007).

Table 3.1 shows the average changes in regulated emissions, fuel economy, and selected aldehyde emissions with E10, E15, and E20, relative to E0. Results are presented for fuel economy as well as the regulated emissions [non-methane organic gas (NMOG), $\mathrm{CO}, \mathrm{NO}_{\mathrm{X}}$, and formaldehyde] and NMHC, ethanol, and acetaldehyde, which constitute the majority of NMOG emissions. The average relative changes were obtained by determining the relative change (from E0 to E20, for example) in average emissions measurements for each vehicle, then calculating the average and confidence limits using the data from all 16 test vehicles. Changes in ethanol, acetaldehyde, and formaldehyde emissions are presented in milligrams per mile, while other emissions changes are presented as percent change relative to E0. Results are shown graphically in Figs. 3.1 through 3.4. Bars in Figs. 3.1 and 3.2 show the average change in emissions with ethanol content considering all vehicles in aggregate, while the individual data points show the change for individual vehicles, illustrating the

\footnotetext{
${ }^{*}$ The detailed results on operational issues at the end of this section provides specific information on when malfunction indicator lights were observed and the presumed causes for the MIL illuminations.
} 
variability in emissions and fuel economy among the vehicles tested. Figure 3.3 shows the actual aggregate emissions in $\mathrm{g} / \mathrm{mi}$ and fuel economy in mpg, and Fig. 3.4 shows the ethanol, acetaldehyde, and formaldehyde emissions in $\mathrm{mg} / \mathrm{mi}$. Again, the bars show the average across all vehicles and each individual point represents a single vehicle average. Results for each individual vehicle plotted separately are provided in Appendix C.

Table 3.1. Estimated change ( $\%$ or $\mathrm{mg} / \mathrm{mi}$ ) in emissions and fuel economy relative to $\mathrm{EO}$ with $\pm 95 \%$ confidence limit

\begin{tabular}{|c|c|c|c|}
\hline $\begin{array}{c}\text { Emission } \\
\text { (unit of change) }\end{array}$ & E10 & E15 & E20 \\
\hline NMOG (\%) & $-2.32 \pm 8.96$ & $1.35 \pm 12.07$ & $-0.12 \pm 11.58$ \\
\hline NMHC (\%) & $-12.04 \pm 7.63^{a}$ & $-11.49 \pm 9.62^{a}$ & $-15.13 \pm 9.04^{a}$ \\
\hline $\mathrm{CO}(\%)$ & $-14.98 \pm 8.31^{\mathrm{a}}$ & $-15.11 \pm 10.38^{a}$ & $-12.31 \pm 11.96^{\mathrm{a}}$ \\
\hline $\mathrm{NO}_{\mathrm{X}}(\%)$ & $-5.48 \pm 16.85$ & $-0.61 \pm 18.38$ & $12.23 \pm 16.69$ \\
\hline Fuel economy (\%) & $-3.68 \pm 0.44^{a}$ & $-5.34 \pm 0.53^{a}$ & $-7.71 \pm 0.88^{a}$ \\
\hline Ethanol (mg/mi) & $5.55 \pm 0.23^{\mathrm{a}}$ & $6.85 \pm 0.16^{\mathrm{a}}$ & $8.21 \pm 0.23^{\mathrm{a}}$ \\
\hline Acetaldehyde (mg/mi) & $0.38 \pm 0.20^{\mathrm{a}}$ & $0.70 \pm 0.44^{\mathrm{a}}$ & $0.81 \pm 0.45^{\mathrm{a}}$ \\
\hline Formaldehyde (mg/mi) & $0.11 \pm 0.08^{\mathrm{a}}$ & $0.14 \pm 0.13^{\mathrm{a}}$ & $0.11 \pm 0.10^{\mathrm{a}}$ \\
\hline
\end{tabular}

${ }^{a}$ Statistically significant at the $95 \%$ confidence level (shaded).

The 95\% confidence limits shown in Table 3.1 characterize the statistical uncertainty in the average changes. If the magnitude of the confidence limit is greater than the absolute value of the relative or absolute change, there is no statistical evidence (at the $95 \%$ confidence level) that the percent change is different from zero. All estimated changes for NMHC, CO, fuel economy, ethanol, acetaldehyde, and formaldehyde were significantly different from zero at the $95 \%$ confidence level.

Changes in fuel economy were consistent based on fuel type and the change in energy density of the ethanol blends - approximately a 3.5\% decrease in energy for every $10 \%$ of ethanol in the fuel. There is no statistical evidence that $\mathrm{NMOG}$ or $\mathrm{NO}_{\mathrm{X}}$ emissions were affected by ethanol content.

An alternative method of calculating the change in emissions from E0 to E20 based on a regression of emissions versus the ethanol content of the fuel produced very similar results. Changes in fuel economy and emissions of NMHC, CO, ethanol, and acetaldehyde from E0 to E20 were found to be statistically significant at the $95 \%$ confidence level.

Table 3.2 presents results of an alternative approach to establishing statistical significance of the changes in emissions. Each column shows the number of cases (out of 16 vehicles) for which the change in average emissions (from E0 to the indicated fuel) was positive. If the number of positive changes is greater than 13 or less than 3 , we can conclude at the $95 \%$ confidence level that the population percentage is different from $50 \%$-indicating there is either a positive or negative effect of ethanol. The results for fuel economy, ethanol, and acetaldehyde are consistent with the average changes observed in Table 3.1. That is, almost all vehicles realized a decrease in fuel economy and increases in ethanol and acetaldehyde emissions. Although the percentages of increases in NMHC and $\mathrm{CO}$ were consistently less than $50 \%$, suggesting a reduction in emissions, the statistical evidence based on this methodology is not conclusive. 


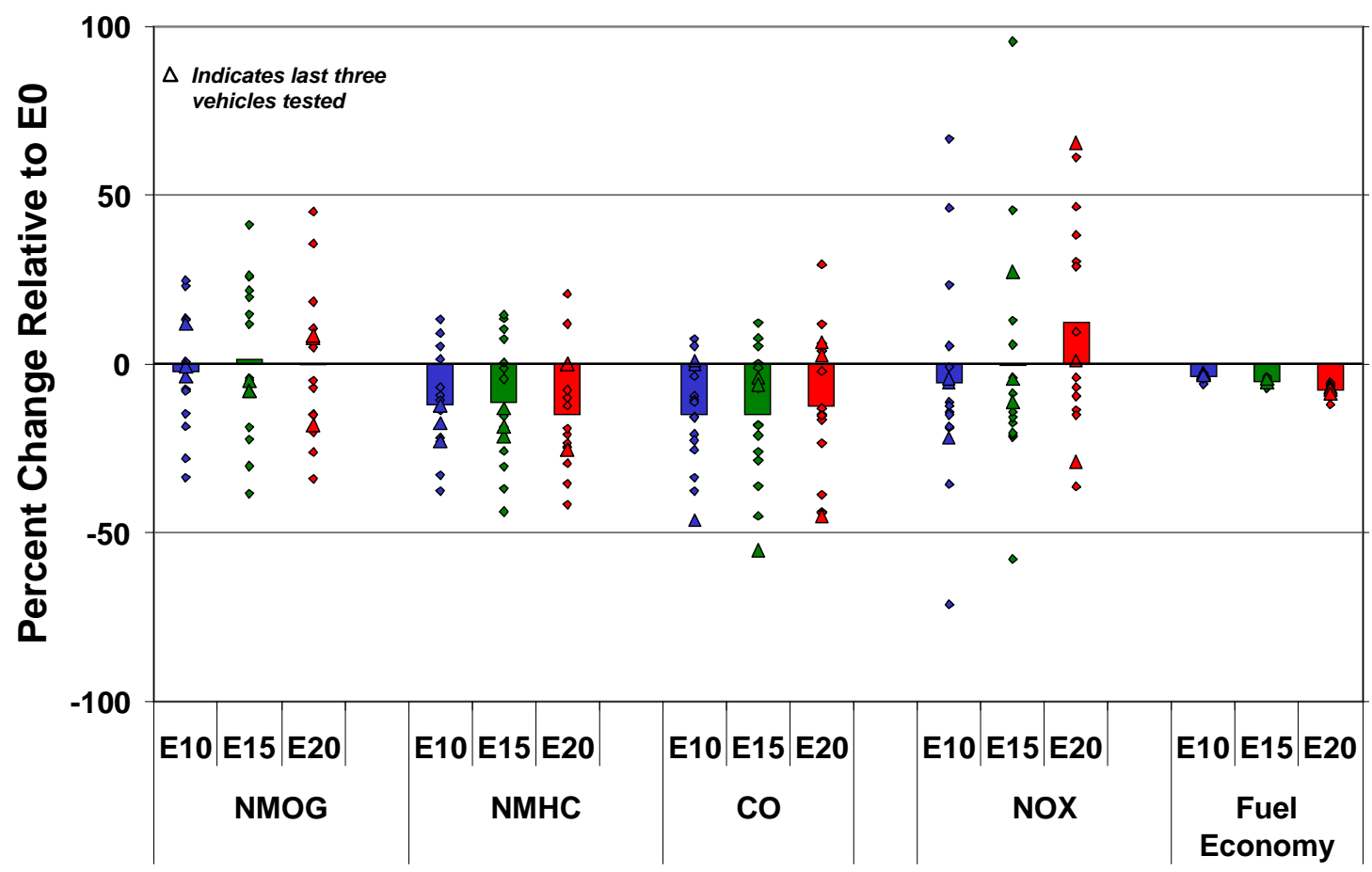

Fig. 3.1. Average percentage change in emissions and fuel economy for all vehicles compared to E0 fuel on the LA92 cycle. Bars show average for all vehicles, while discrete data points show the change for each vehicle tested.

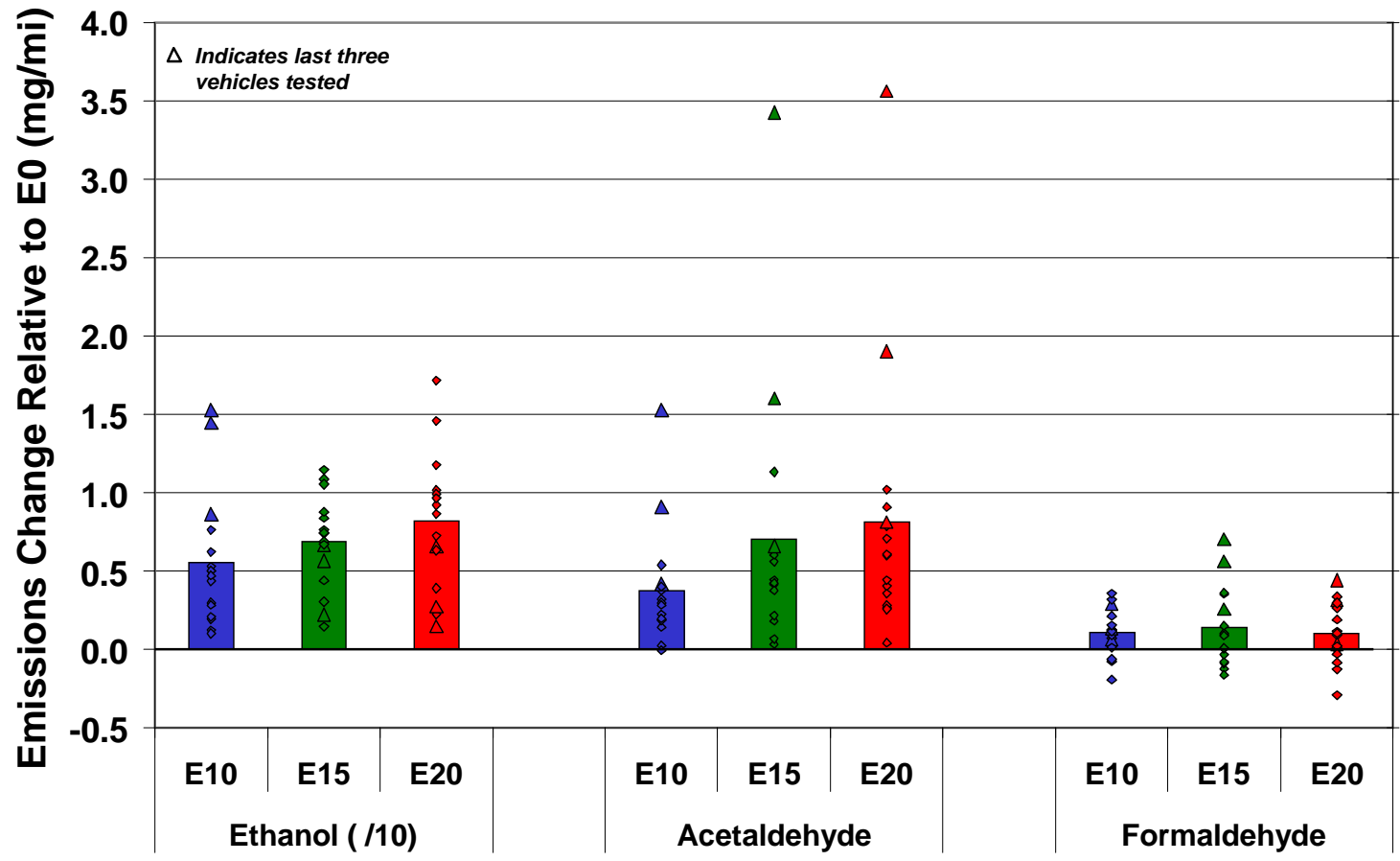

Fig. 3.2. Average change in ethanol and aldehyde emissions for all vehicles compared to E0 fuel on the LA92 cycle. Bars show average for all vehicles, while discrete data points show the change for each vehicle tested. 


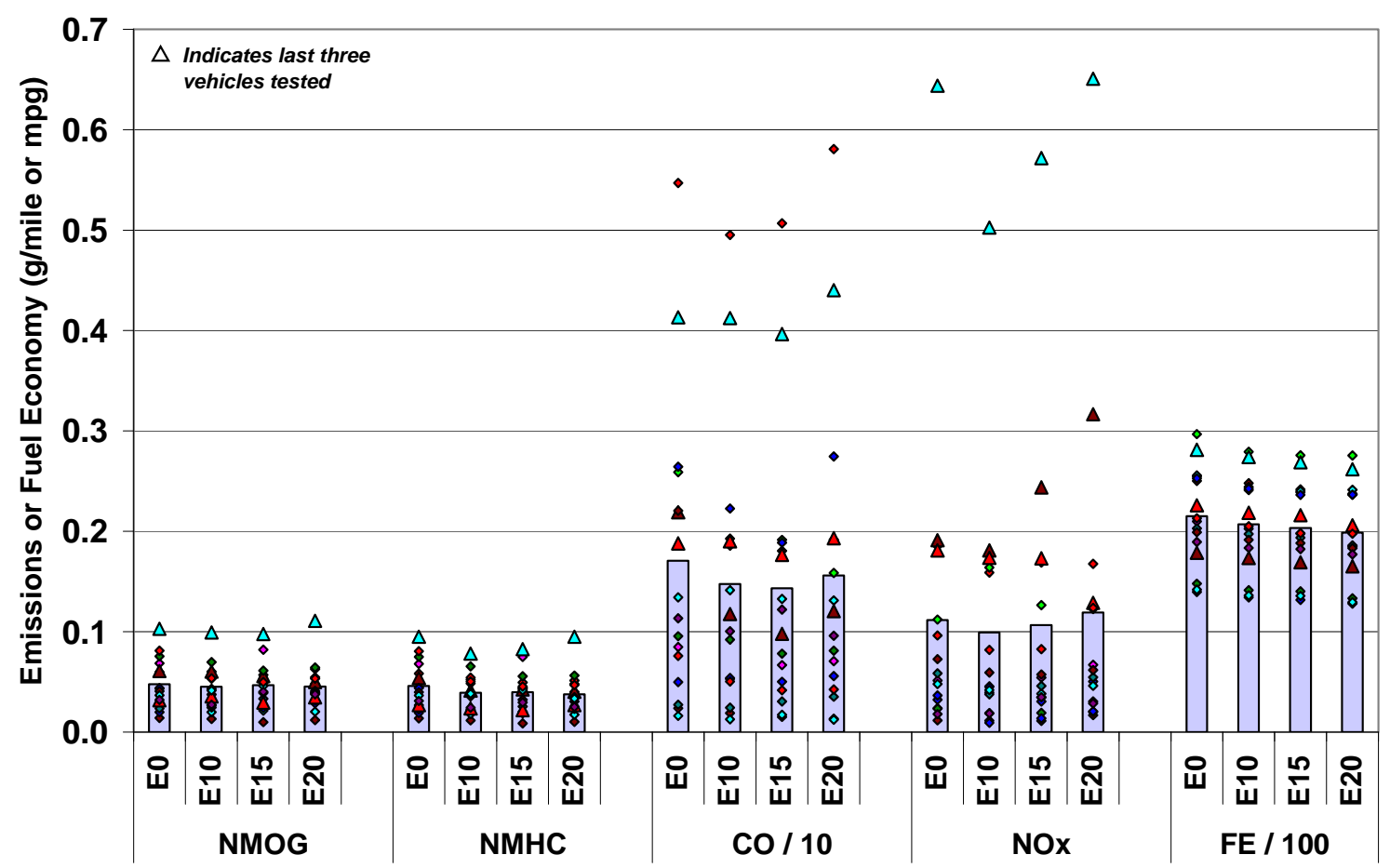

Fig. 3.3. Average emissions and fuel economy for all vehicles on LA92 cycle. Bars show average for all vehicles, while discrete data points show each individual vehicle average.

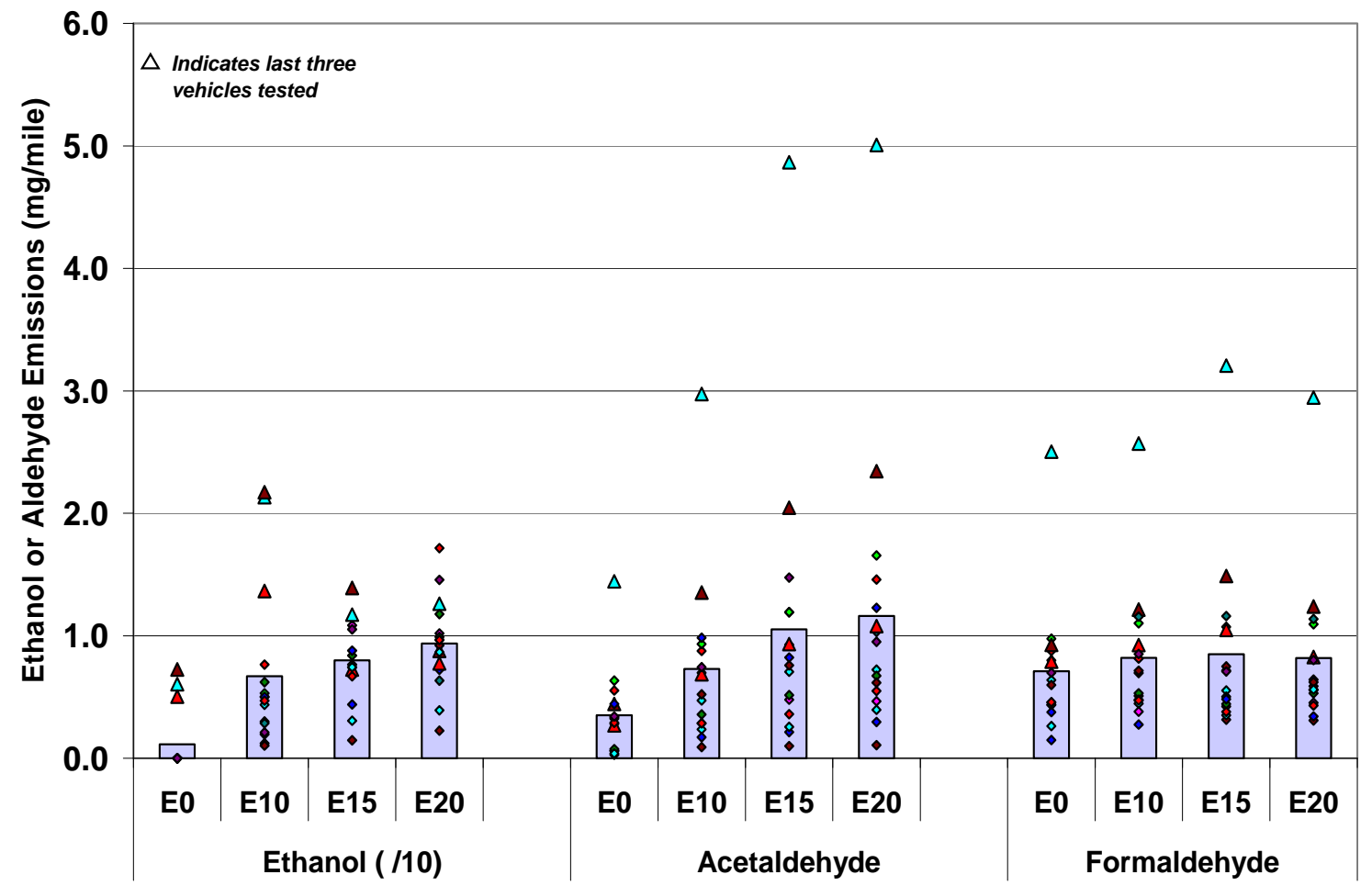

Fig. 3.4. Ethanol and aldehyde emissions for all vehicles on LA92 cycle. Bars show average for all vehicles, while discrete data points show each individual vehicle average. 
Table 3.2. Number of vehicles with positive changes in emissions and fuel economy relative to E0 among 16 test vehicles

\begin{tabular}{lccc}
\hline \multicolumn{1}{r}{ Emission } & E10 & E15 & E20 \\
\hline NMOG & 5 & 7 & 8 \\
NMHC & $4^{\mathrm{b}}$ & 5 & $4^{\mathrm{b}}$ \\
$\mathrm{CO}$ & $3^{\mathrm{a}}$ & $4^{\mathrm{b}}$ & 6 \\
$\mathrm{NO}_{\mathrm{x}}$ & $4^{\mathrm{b}}$ & 5 & 9 \\
Fuel economy & $0^{\mathrm{a}}$ & $0^{\mathrm{a}}$ & $0^{\mathrm{a}}$ \\
Ethanol & $16^{\mathrm{a}}$ & $16^{\mathrm{a}}$ & $16^{\mathrm{a}}$ \\
Acetaldehyde & $15^{\mathrm{a}}$ & $16^{\mathrm{a}}$ & $16^{\mathrm{a}}$ \\
Formaldehyde & $13^{\mathrm{a}}$ & 11 & 11 \\
\hline
\end{tabular}

${ }^{a}$ Estimated percent of positive changes (out of 16 vehicles) is significantly different from $50 \%$ at the $95 \%$ confidence level (shaded).

${ }^{\mathrm{b}}$ Estimated percent of positive changes (out of 16 vehicles) is significantly different from $50 \%$ at the $90 \%$ confidence level.

\subsubsection{Results and Discussion: Exhaust and Catalyst Temperature}

\subsubsection{Long-term fuel trim correction strategies}

Per EPA guidelines, each engine manufacturer may use up to $6 \%$ enrichment (extra fuel) beyond LBT (lean best torque) if necessary to protect engine or emissions control hardware from overheating. Such enrichment is typically necessary at high engine load and/or high engine speeds.

The exhaust gas oxygen (EGO) sensor used on most modern vehicles (post-1970s) is a switching type oxygen sensor. This type of sensor can determine whether the engine is running rich or lean but provides no indication of how rich or how lean. Consequently, this sensor is only able to actively adjust for differences in the fuel:air equivalence ratio from the calibrated value during closed-loop stoichiometric operation. It is typical for such fuel correction values to be stored in the Engine Control Unit (ECU). Thereafter, the previously stored corrections can be applied whenever the engine operates in a similar operating condition. Such stored values used for fuel correction are typically referred to as long-term fuel trim.

During certain operating conditions, such as WOT, the engine control system switches from closed-loop stoichiometric operation to a fuel enrichment mode to protect both engine and exhaust emission control components. This enrichment mode is typically open-loop, using a fuel enrichment strategy programmed into the ECU.

During the course of testing, 7 of the 16 vehicles tested were observed to run significantly leaner at WOT as ethanol content in the fuel increased. Furthermore, it was observed that this increase in fuel:air equivalence ratio corresponded roughly, on a percent basis, with the increased oxygen content of the fuel. For the balance of vehicles tested ( 9 of 16), the fuel:air equivalence ratio at WOT remained nearly constant as ethanol content in the fuel was increased. The hypothesis is that vehicles exhibiting nearly constant fuel:air equivalence ratio during WOT used long-term fuel trim values acquired during closed-loop operation - including those due to the oxygen content of the fuel-and applied this information to open-loop conditions. It is believed that long-term fuel trim correction was not being applied during WOT experiments in the remaining seven vehicles, which ran leaner at WOT. When long-term fuel trim is not applied to open-loop operation, leaner operation, though still rich, is likely when using ethanol blends of up to E20 compared to E0 fuel during open-loop operation. Although application of long-term fuel trim to open-loop operation was generally more prevalent for the later model vehicles, two of the 2007 model-year vehicles tested in this program did not appear to apply long-term fuel trim to open-loop operation. 
It is unclear whether vehicles that did not apply long-term fuel trim during WOT operation did so by design or whether inadequate time or operating range was allowed for complete adaptation. In follow-on experiments with two of the vehicles found to run leaner with increased ethanol content, WOT tests with E20 were repeated after six consecutive standard road cycles (SRCs) operated on E20. The SRC is a dynamometer driving schedule developed by EPA for vehicle aging and covers a broad portion of the engine operating map. After multiple SRCs, the WOT fueling strategy for these two vehicles remained unchanged.

\subsubsection{Temperatures at wide-open throttle}

Vehicles that ran leaner during WOT than the E0 baseline experienced higher catalyst temperatures as ethanol content increased. The long-term effect of this catalyst temperature increase on catalyst durability is not known at the current time and requires further work.

Figure 3.5 shows the average difference in peak catalyst temperature and the range of this difference for the 16 vehicles tested. The right-most series of bars (red) in this figure represents the temperature increase for the seven vehicles that ran leaner with increased ethanol content during WOT accelerations. This data showed an average increase of between $29^{\circ} \mathrm{C}$ and $35^{\circ} \mathrm{C}$ from E0 to E20 and an average increase of about $20^{\circ} \mathrm{C}$ from E10 to E20.

The blue series of bars in Fig. 3.5 shows data for the nine vehicles that appeared to apply longterm fuel trim at WOT. For these vehicles, the average peak catalyst temperature difference was essentially unchanged (less than $5^{\circ} \mathrm{C}$ on average) for E20 compared to E0. The range of temperature changes measured for all fuels was between $-14^{\circ} \mathrm{C}$ and $14^{\circ} \mathrm{C}$.

\subsubsection{Temperature effects in closed-loop at high engine load}

For closed-loop, stoichiometric operation at high engine load, no increase in catalyst temperature was observed with increasing ethanol content. This testing was conducted under the same operating conditions as the hill climb WOT protocol but at a point just before fuel enrichment engaged. Appendix A contains details of the test procedure used for this series of tests.

\subsubsection{Altitude effects}

Two of the test sites (TRC and ORNL) are located at approximately 1,000 feet above sea level and one lab (CDPHE) is sited at an altitude of roughly 5,400 feet. While testing at altitude is considered valid for comparing relative fuel effects on catalyst temperature, comparing the WOT conditions between test sites at different altitudes is not considered valid. WOT conditions at higher altitude will result in reduced mass-air flow due to lower air density. Comparing part throttle results from the different test sites is considered valid, since throttling of the intake air should have mitigated any significant air density differences. 


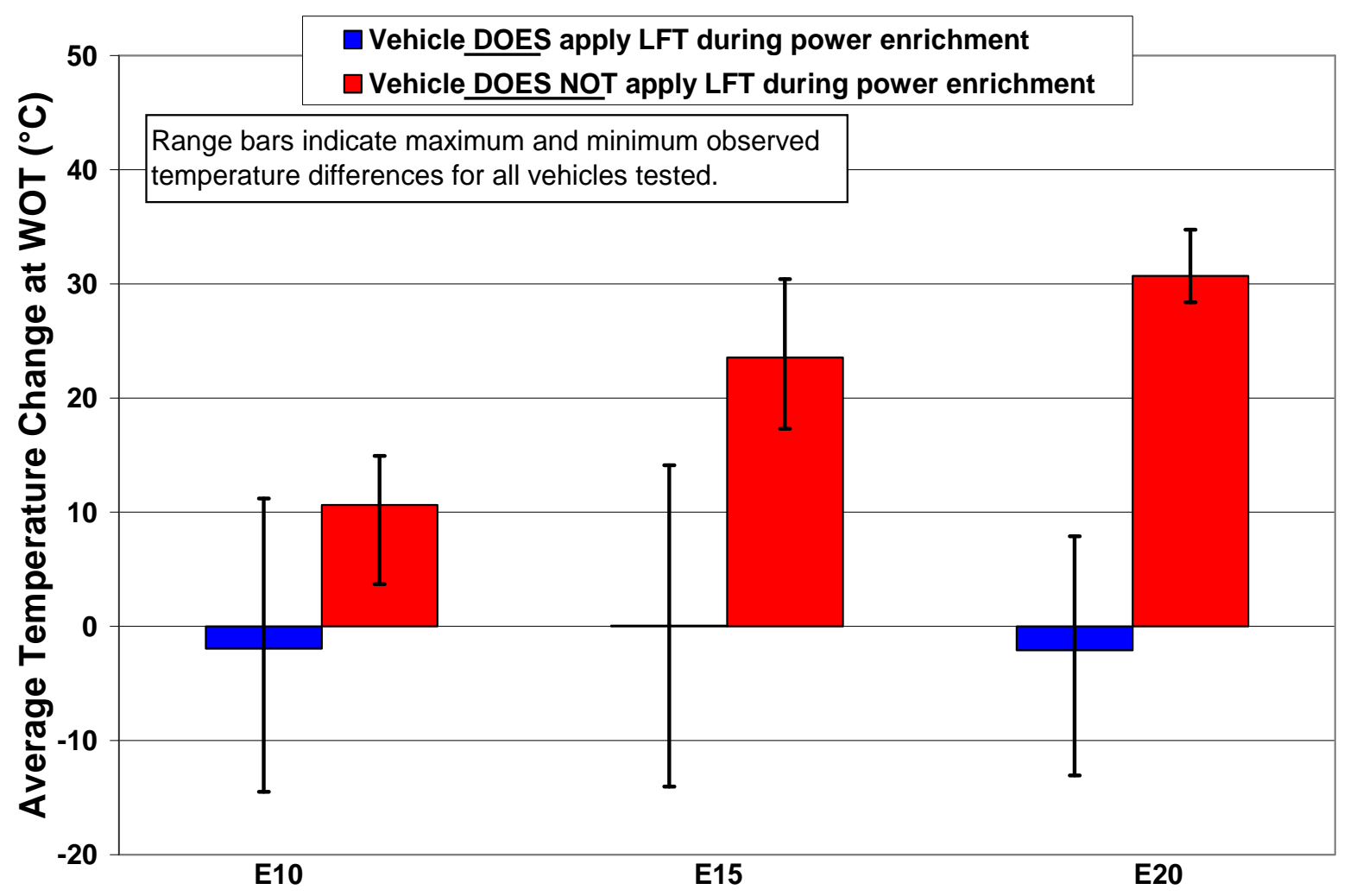

Fig. 3.5. Change in catalyst temperature versus fuel type for wide-open throttle (WOT) open-loop conditions.

\subsubsection{Results and Discussion: Unforeseen Operational Issues}

While driveability was not a focus of this study, no driveability issues associated with ethanol fueling were noted for the duration of testing by either the engineers or emissions test drivers. It should be noted, however, that the drivers and engineers were not trained specifically to recognize driveability problems. Furthermore, environmental conditions for this test program were limited to only $50^{\circ}$ and $75^{\circ} \mathrm{F}$. Other activities within the DOE test program, summarized in Sect. 1, will evaluate ethanol-related driveability issues over a broader range of conditions and with a wider range of vehicles.

While no ethanol fuel-related MILs were observed, a few MIL codes illuminated for other apparent reasons. The 2003 Ford Taurus at TRC illuminated its MIL (code P0191, fuel rail pressure circuit) during its first fuel change. This MIL occurred while draining the fuel tank through the fuel rail using the in-tank fuel pump. This MIL was believed to be related to the low fuel pressure experienced during the fuel drain with the ignition key on. The code was reset and did not recur throughout the testing program.

Another MIL, related to the catalyst system monitor but not exclusive to ethanol fuel, occurred on the 2003 Toyota Camry at ORNL (code P0420). Throughout the course of testing this vehicle, some 40 individual tests were run (triplicate LA92 on each fuel, WOT tests on each fuel, and four preparatory cycles during each fuel switch). The P0420 code was found to be in a pending mode frequently and normally reset on its own. The MIL illuminated four times, including testing on E0, and was reset each time. The P0420 code would generally set during the fuel change procedures or WOT testing. Emissions tests indicated the vehicle was not a gross emitter. After discussions with several peers, it was decided to keep the vehicle in the program. 


\subsection{SMALL NON-ROAD ENGINES}

SNREs under $25 \mathrm{hp}$ are categorized by EPA according to engine displacement and application, which determine the required emissions test cycle. A summary of engine classifications is shown in Table 3.3. DOE's small engine testing to date has focused on engine types that fall within the highlighted sections of Table 3.3.

Table 3.3. SNRE classification descriptions per 40 CFR $90^{a}$

\begin{tabular}{|c|c|c|c|c|c|c|}
\hline \multirow[b]{2}{*}{ Class } & \multirow[b]{2}{*}{ Type } & \multirow{2}{*}{$\begin{array}{c}\text { Typical } \\
\text { application }\end{array}$} & \multirow{2}{*}{$\begin{array}{l}\text { Displacement } \\
\text { (cc) }\end{array}$} & \multicolumn{2}{|c|}{ Full, useful life (hr) } & \multirow{2}{*}{$\begin{array}{l}\text { ISO } 8178 \\
\text { emissions } \\
\text { test cycle }^{b}\end{array}$} \\
\hline & & & & $\begin{array}{c}\text { Residential } \\
\text { (moderate use) }\end{array}$ & $\begin{array}{c}\text { Commercial } \\
\text { (extended use) }\end{array}$ & \\
\hline I-A & \multirow{3}{*}{ Non-handheld } & \multirow{3}{*}{$\begin{array}{l}\text { Lawn mower } \\
\text { small gen. } \\
\text { set }\end{array}$} & $<66$ & 50 & 300 & \multirow[t]{3}{*}{$\mathrm{G} 1$ or $\mathrm{G} 2$} \\
\hline I-B & & & $66 \leq$ disp. $<100$ & 125 & 500 & \\
\hline $\mathrm{I}$ & & & $100 \leq$ disp. $<225$ & 125 & 500 & \\
\hline II & Non-handheld & $\begin{array}{l}\text { Larger equip. } \\
\text { small tractor }\end{array}$ & $\geq 225$ & 250 & 1,000 & G1 or G2 \\
\hline III & \multirow{3}{*}{ Handheld } & \multirow{3}{*}{$\begin{array}{l}\text { Line-trimmer } \\
\text { blower } \\
\text { chainsaw }\end{array}$} & $<20$ & \multirow{3}{*}{50} & \multirow{3}{*}{300} & \multirow{3}{*}{ G3 } \\
\hline IV & & & $20 \leq$ disp. $<50$ & & & \\
\hline $\mathrm{V}$ & & & $\geq 50$ & & & \\
\hline
\end{tabular}

${ }^{a}$ Highlighted sections indicate the classifications that have been tested under the first phase of this test program.

${ }^{b}$ ISO 8178 test cycles are defined in Sect. 2.

Given that there may be more than 900 individual emissions-certified SNRE families sold for any given model year, DOE's test program could focus only on a small subset of these engine families. DOE consulted with EPA on engine selection to ensure that the engines being tested reflected those commonly found in popular, high-sales-volume equipment.

Small engines such as those in lawn mowers and lawn tractors, generators, line trimmers, chainsaws, and other similar equipment are open-loop engines, in that exhaust-sensing feedback is not used to control the fueling rate. Open-loop engines are commonly air-cooled and customarily operate in the fuel-rich regime to achieve cooler combustion temperatures. With a fixed fueling calibration, as ethanol content is increased, the relative combustion stoichiometry changes to a leaner (or less rich) equivalence ratio, leading to a higher combustion temperature and hence higher component temperatures. Similarly, emissions of $\mathrm{HC}, \mathrm{NO}_{\mathrm{X}}$, and $\mathrm{CO}$ are also related to the combustion stoichiometry, so these emissions can also be expected to change. Leaner mixtures can also increase idle speed on some engines, creating unexpected engagement of centrifugal clutches on equipment such as chainsaws or line trimmers. Finally, various fuel-wetted materials in some small engines may not be compatible with all ethanol blends.

\subsubsection{Scope of Study}

In late summer 2007, ORNL and NREL acquired six SNREs for preliminary examination (pilot study) while a subcontract for a larger full-life study was initiated at TRC, a commercial testing laboratory in East Liberty, Ohio. Table 3.4 shows the specific engines tested at the three sites.

Tests at ORNL and NREL focused on identifying immediate emissions or operational issues with federal certification gasoline (E0) and three splash-blended fuels (E10, E15, and E20) and measurements of several key engine temperatures. One copy of each engine was tested on all four fuels at ORNL and NREL (with one exception, the field-aged Honda generator was not tested on E15).

The TRC program tested four copies of each engine to full life. All engines were tested on E0 and then each engine was tested exclusively on E0, E10, E15, or E20. While TRC also measured 
temperatures, its main focus was to assess any operational problems during full-life aging and to evaluate how engine operation and emissions change over time with exposure to various levels of ethanol. Table 3.4 provides additional details on these tests.

The tests performed at TRC measured emissions and temperature at various stages of the engines' lives - when new, at half life, and at full life. In this set of tests, four engine models were selected:

- Briggs and Stratton residential Class I (power washer),

- Honda commercial-Class I (generator),

- Weed Eater residential Class IV (leaf blower), and

- Stihl commercial Class IV (line trimmer).

Table 3.4. SNRE equipment tested in pilot and full-useful-life (full-life) studies

\begin{tabular}{|c|c|c|c|c|c|c|c|}
\hline $\begin{array}{l}\text { Equipment tested } \\
\text { (EPA family } \\
\text { number) }\end{array}$ & $\begin{array}{c}\text { Class residential/ } \\
\text { commercial }\end{array}$ & \begin{tabular}{|} 
Engine \\
size \\
(cc)
\end{tabular} & $\begin{array}{l}\text { Full life } \\
\text { (hr) }\end{array}$ & $\begin{array}{c}\text { Engines } \\
\text { aged to full } \\
\text { life? }\end{array}$ & $\begin{array}{c}\text { Testing } \\
\text { laboratory }\end{array}$ & $\begin{array}{l}\text { Engine } \\
\text { condition for } \\
\text { emissions } \\
\text { testing }\end{array}$ & $\begin{array}{c}\text { Number } \\
\text { of } \\
\text { engines }^{a}\end{array}$ \\
\hline \multicolumn{8}{|c|}{ Pilot study } \\
\hline $\begin{array}{l}\text { Honda generator } \\
\text { 2HNXS.1961AK }\end{array}$ & I-Commercial & 196 & 500 & No & ORNL & New & 1 \\
\hline $\begin{array}{l}\text { Honda generator }^{\mathrm{b}} \\
\text { (used) } \\
\text { XHNXS.1631AA }\end{array}$ & $\mathrm{I}-\mathrm{N} / \mathrm{A}$ & 163 & NA & $\mathrm{No}^{b}$ & ORNL & Full life & 1 \\
\hline $\begin{array}{l}\text { Briggs and Stratton } \\
\text { generator } \\
\text { 7BSXS.2492HC } \\
\end{array}$ & II-Residential & 249 & 250 & No & ORNL & New & 1 \\
\hline \begin{tabular}{|l|} 
Kohler generator \\
6KHXS.7252GC
\end{tabular} & II-Commercial & \begin{tabular}{|l}
725 \\
$(2-c y l)$
\end{tabular} & 1,000 & No & ORNL & New & 1 \\
\hline \begin{tabular}{|c|} 
Poulan leaf blower \\
7PWES.0254BM \\
\end{tabular} & IV_-Residential & 25 & 50 & Yes & NREL & New & 1 \\
\hline $\begin{array}{r}\text { Stihl line trimmer } \\
\text { 6A8XS.0284RA }\end{array}$ & IV_Commercial & 28.4 & 300 & No & NREL & New & 1 \\
\hline \multicolumn{8}{|c|}{ Full-life study } \\
\hline $\begin{array}{l}\text { Briggs \& Stratton } \\
\text { power washer } \\
\text { 6BSXS.1581VG }\end{array}$ & I-Residential & 158 & 125 & Yes & TRC & $\begin{array}{l}\text { New } \\
\text { Half life } \\
\text { Full life }\end{array}$ & 6 \\
\hline $\begin{array}{l}\text { Honda generator } \\
\text { 6HNXS.196A5A }\end{array}$ & $\mathrm{I}-$ Commercial & 196 & 500 & Yes & TRC & $\begin{array}{l}\text { New } \\
\text { Half life } \\
\text { Full life } \\
\end{array}$ & 4 \\
\hline $\begin{array}{l}\text { Weed Eater blower } \\
\text { 7PWES.0254BA }\end{array}$ & IV_-Residential & 23 & 50 & Yes & $\mathrm{TRC}$ & $\begin{array}{l}\text { New } \\
\text { Half life } \\
\text { Full life }\end{array}$ & 8 \\
\hline $\begin{array}{l}\text { Stihl line trimmer } \\
\text { 6A8XS.0314RC }\end{array}$ & IV-Commercial & 31.4 & 300 & Yes & TRC & $\begin{array}{l}\text { New } \\
\text { Half life } \\
\text { Full life } \\
\end{array}$ & 4 \\
\hline
\end{tabular}

${ }^{a}$ Where the number of engines is greater than four, more than four engines were baselined before commencement of aging four engines.

${ }^{b}$ The used Honda engine at ORNL was field-aged (considered full life given its age) and tested on only E0, E10, and E20. The engine was not aged in this test program. 
TRC initially tested six power washers and eight leaf blowers on E0. For each residential engine model type, four engines were selected and randomly assigned to one of the fuel types (E0, E10, E15, or E20) for testing. Once an engine was introduced to its specific ethanol blend, it was not exposed to E0 again until the full-life emissions tests.

The purpose of "down-selecting" engines from a larger group was to help ensure that the engines tested were fairly consistent with each other to elucidate fuel effects that might otherwise be obscured by engine-to-engine scatter. As discussed below and illustrated by the data, the engine tests confirmed that emissions and temperature can vary considerably from engine-to-engine, even among engines with the same model number, and even on E0. This engine-to-engine scatter appeared particularly pronounced with the residential-grade engines. Only four of each of the commercial engines was tested initially on E0, and engine-to-engine scatter was deemed not as problematic.

The testing protocols used at ORNL, NREL, and TRC are described in full in Appendix B. When feasible, emissions test methods were consistent with EPA guidelines, although in several cases reasonable surrogates were used. Class I and II engines were emissions-tested on the 6-mode cycle, and Class IV engines were tested on the 2-mode cycle. Engines were aged using their respective emissions testing protocol in most cases. The Class I power washer engines were emissions-tested on two different 6-mode cycles, but aged using a 2-mode cycle similar to their use in the field.

\subsubsection{Summary of Results}

Open-loop engines tested in this study exhibited the following trends in emissions and temperatures with varying levels of ethanol.

- As ethanol levels increased, leaner engine operation was observed in all of the tested engines, as indicated by decreased $\mathrm{CO}$ emissions.

- Temperatures of both the exhaust and engine components increased as ethanol levels increased.

- HC emissions generally decreased with increasing ethanol, although increases in HC emissions occurred in some engines.

- $\mathrm{NO}_{\mathrm{X}}$ emissions increased with higher levels of ethanol in all engines; however, combined $\mathrm{NO}_{\mathrm{X}}+$ $\mathrm{HC}$ emissions (which are regulated as such) were tempered by decreasing $\mathrm{HC}$ emissions in most cases. Net changes of $\mathrm{HC}+\mathrm{NO}_{\mathrm{X}}$ with increasing ethanol ranged from $-36 \%$ to $+41 \%$ and were engine-specific.

- CO emissions decreased with higher levels of ethanol.

- In the case of the 2-cylinder engine tested, temperatures and emissions varied from cylinder to cylinder due to differences in the fuel:air distribution between cylinders. Given this observation, multicylinder open-loop engines may prove to be more sensitive to ethanol blends than singlecylinder engines.

- With greater ethanol content, three handheld trimmers demonstrated higher idle speed and experienced unintentional clutch engagement. The increased speed was again caused by the fuel:air mixture enleanment, ${ }^{\dagger}$ which can be adjusted and mitigated in some engines.

- Residential and Commercial Class I and Class IV engines were aged to full life. The residential Class I as well as the commercial engines exhibited no sensitivity to ethanol from a durability perspective in the short duration of this project. The effect of ethanol on the durability of the residential Class IV engines was not clear given that a number of these engines failed during fulllife aging regardless of fuel type. Failure of these engines may have been related to the engine mounting method.

\footnotetext{
*D'Alleva and Lovell, SAE 360106.

†Enleanment means moving toward a leaner fuel:air equivalence ratio-in this case, from a rich condition to a leaner (albeit still rich) fuelair equivalence ratio.
} 
- No materials compatibility issues were observed in the short duration of this project, but they were not specifically characterized as part of this study.

Figure 3.6 shows the average exhaust temperature rise due to ethanol addition for all engines tested both when new (e.g., after initial break-in) as well as at full life. Data points indicate the range of changes observed at the hottest condition for individual engines. While the aged engines also show higher operating temperature with ethanol addition, the increases are not as high as in the new engines. Note that not all engines were tested in both the new and full-life conditions, and the trendlines shown are for a regression through the simple numerical average of the available data. The trends noted are the same when data are parsed out and considered separately by engine class.

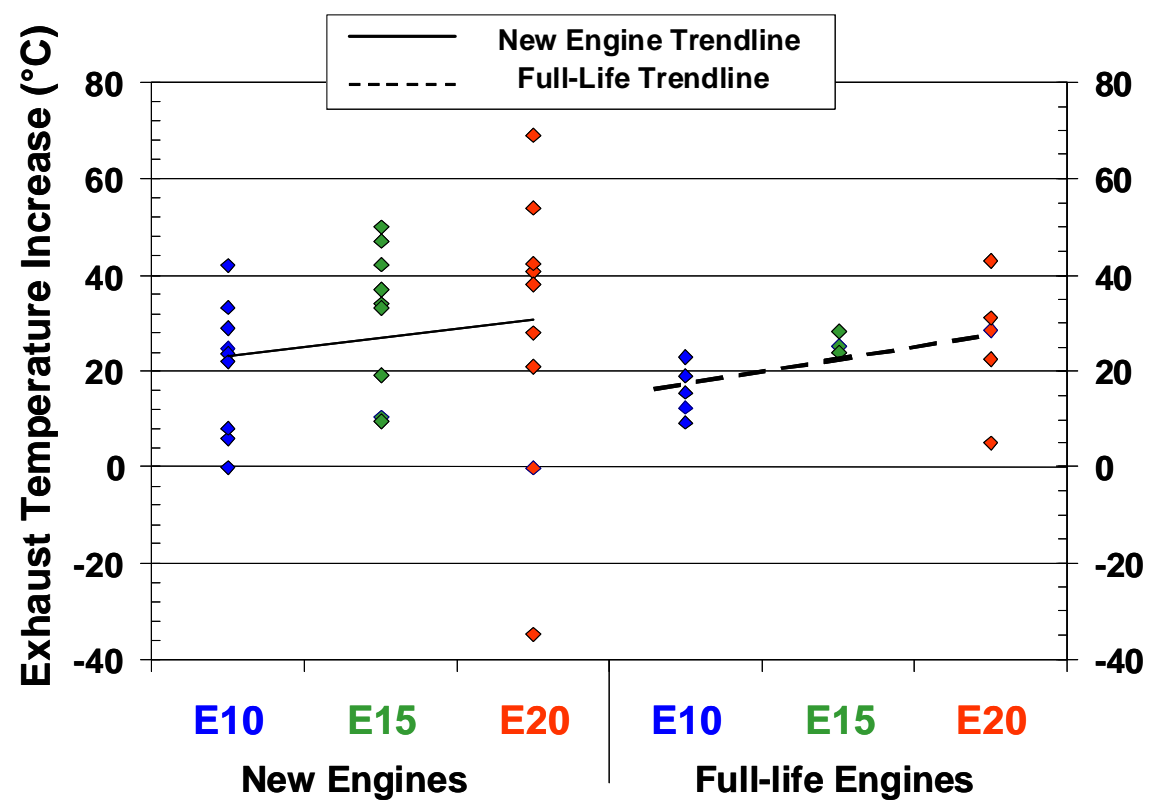

Fig. 3.6. Exhaust temperature increase for all small non-road engines tested in the new and full-useful-life (full-life) condition with ethanol blends, as compared to E0 baseline. Highest temperature operation points for each engine are plotted. Trendlines show regression through numerical average of all engines. Negative E20 data point for new engines is due to Honda generator running erratically on E20 in idle mode.

Figure 3.7 illustrates the average change in emissions with ethanol addition for all engines tested both when new and at full life. Data points represent the change observed in each individual engine. $\mathrm{HC}$ emissions tend to decrease with increasing ethanol content, although $\mathrm{HC}$ emissions actually increased in some of the engines in which erratic operation was noted, skewing the trendline for the new engines. The Honda generator at TRC ran erratically at light loads in the new condition, generating unusually high $\mathrm{HC}$ emissions (the highest single E20 point in the top chart in Fig. 3.7). If that point is omitted, the general trend shows a decrease in $\mathrm{HC}$ with increasing ethanol. For the fulllife data, one of the Briggs and Stratton power washer engines had unusually high $\mathrm{HC}$ emissions with E10. If this point is omitted, the full-life $\mathrm{HC}$ emissions show a very slight decrease with increasing ethanol. HC emissions here are as indicated by the flame ionization detector (FID), and do not include any correction for oxygenated compounds in the exhaust such as ethanol or aldehydes. CO emissions decreased and $\mathrm{NO}_{\mathrm{X}}$ emissions increased with increasing ethanol content for all engines tested in the new condition. The general trends for the full-life data are the same as noted for the engines in the new condition, with the exception that $\mathrm{NO}_{\mathrm{X}}$ decreased for one engine type with E20 fuel. Not all engines were tested in both the new and full-life conditions, and the trendlines shown are for a 
regression through the simple numerical average of the available data. These same data were also parsed by engine class, and the trends noted were largely the same.

More detailed results and discussion follow, and additional figures and tables for the individual engines are provided in Appendix D.
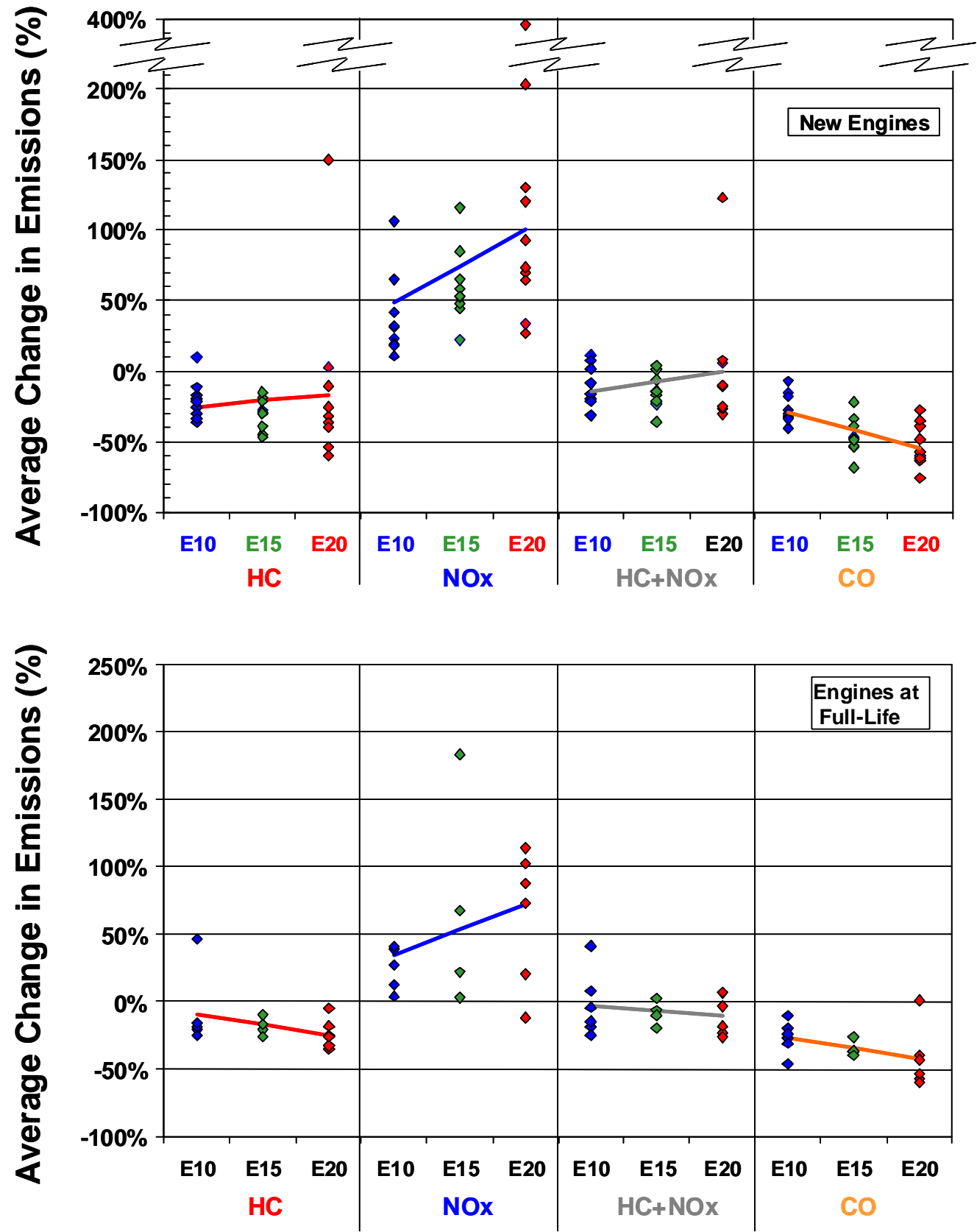

Fig. 3.7. Average change in emissions for all small non-road engines tested in the new (top chart) and full-useful-life (full-life) (bottom chart) condition with ethanol blends, as compared to E0 baseline. Data points are the numerical average of multiple composite test results for each fuel compared to the E0 baseline for the same engine at the same age condition. Trendlines show linear regression through numerical average of all data shown for each emissions constituent. Trendlines for $\mathrm{HC}$ emissions are heavily influenced by two outlier points (see report text for more detail). 
Table 3.5. Summary of engine operational problems at ORNL, NREL, and TRC

\begin{tabular}{|c|c|c|c|c|}
\hline $\begin{array}{l}\text { Equipment tested } \\
\text { (EPA family number } \\
\text { Model Year) }\end{array}$ & $\begin{array}{r}\text { Operatio } \\
\text { w }\end{array}$ & $\begin{array}{l}\text { ues noted- } \\
\text { uel(s) }\end{array}$ & $\begin{array}{l}\text { Test } \\
\text { site }\end{array}$ & Nature of noted operational issue \\
\hline \multicolumn{5}{|c|}{ Pilot study (ORNL and NREL) } \\
\hline $\begin{array}{l}\text { Honda generator } \\
\text { 2HNXS.1961AK } \\
2002\end{array}$ & No & NA & ORNL & NA \\
\hline $\begin{array}{l}\text { Honda generator (used) } \\
\text { XHNXS.1631AA } \\
1999\end{array}$ & No & NA & ORNL & NA \\
\hline $\begin{array}{l}\text { Briggs and Stratton } \\
\text { generator } \\
\text { 7BSXS.2492HC } \\
\text { 2007 }\end{array}$ & Yes & E20 & ORNL & $\begin{array}{l}\text { Engine stalled twice on E20 fuel. Cause } \\
\text { unknown }\end{array}$ \\
\hline $\begin{array}{l}\text { Kohler generator } \\
\text { 6KHXS.7252GC } \\
2006 \\
\end{array}$ & No & NA & ORNL & NA \\
\hline $\begin{array}{l}\text { Poulan leaf blower } \\
\text { 7PWES.0254BM } \\
\text { 2007 }\end{array}$ & Yes & $\begin{array}{l}\text { E15 } \\
\text { E20 }\end{array}$ & NREL & $\begin{array}{l}\text { Erratic operation on E15 and E20, near full- } \\
\text { useful-life (full-life) hours }\end{array}$ \\
\hline $\begin{array}{l}\text { Stihl line trimmer } \\
\text { 6A8XS.0284RA } \\
\text { 2006 }\end{array}$ & Yes & $\begin{array}{l}\text { E15 } \\
\text { E20 }\end{array}$ & NREL & $\begin{array}{l}\text { High idle with E15 and E20 caused clutch } \\
\text { engagement at idle }\end{array}$ \\
\hline \multicolumn{5}{|c|}{ Full-life study (TRC) } \\
\hline $\begin{array}{l}\text { Briggs \& Stratton } \\
\text { power washer } \\
\text { 6BSXS.1581VG } \\
\text { 2006 }\end{array}$ & Yes & E10 (PW5) & $\mathrm{TRC}$ & $\begin{array}{l}\text { PW5 was baselined on E0 on both TRC and } \\
\text { BASCO }^{b} \text { protocols, then failed during E10 } \\
\text { BASCO testing }\end{array}$ \\
\hline $\begin{array}{l}\text { Honda generator } \\
\text { 6HNXS.196A5A } \\
\text { 2006 }\end{array}$ & Yes & E20 (G4) & $\mathrm{TRC}$ & $\begin{array}{l}\text { Initial E20 test had high HC emissions due to } \\
\text { erratic operation at light loads (unstable } \\
\text { governor). Problem did not recur at half life or } \\
\text { full life }\end{array}$ \\
\hline $\begin{array}{l}\text { Weed Eater blower } \\
\text { 7PWES.0254BA } \\
\text { 2007 }\end{array}$ & Yes & $\begin{array}{l}\text { E0 (B2) } \\
\text { E15 (B7) } \\
\text { E15 (B3) } \\
\text { E20 (B8) } \\
\text { E20 (B4) }\end{array}$ & $\mathrm{TRC}$ & $\begin{array}{l}\text { E0 engine(B2) failed at } 41: 30 \\
\text { E15 engine (B7) failed at } 25 \mathrm{hr} \\
\text { 2nd E15 engine (B3) failed at } 21: 47 \\
\text { E20 engine (B8) would not idle, replaced by B6 } \\
\text { B4 would not make full power on E20 }\end{array}$ \\
\hline $\begin{array}{l}\text { Stihl line trimmer } \\
\text { 6A8XS.0314RC } \\
\text { 2006 }\end{array}$ & Yes & $\begin{array}{l}\text { E15 (T3) } \\
\text { E20 (T4) }\end{array}$ & TRC & $\begin{array}{l}\text { High idle speed with E15 and E20 caused } \\
\text { clutch engagement at idle. Correctable via } \\
\text { carburetor adjustment }\end{array}$ \\
\hline
\end{tabular}

${ }^{a}$ Field-aged Honda generator considered full-life engine.

${ }^{b}$ BASCO refers to Briggs and Stratton Company (BASCO) emissions testing protocol. See Appendix B.

ORNL $=$ Oak Ridge National Laboratory, NREL $=$ National Renewable Energy Laboratory, TRC $=$ Transportation Research Center 


\subsubsection{Results and Discussion: Engine Operation}

One objective of the SNRE studies was to assess engine operation with the various ethanol blends through operator observations during emissions testing or aging. A few engine operation problems were noted during the program and will be discussed here. Table 3.5 highlights which engines experienced operational problems. A brief discussion for each engine for which an occurrence is noted is provided below.

Briggs and Stratton 3500W generator (pilot study). The Briggs and Stratton generator ran normally on E0 but began losing power on E20 at full load. The off-board fuel tanks used for gravimetric fuel consumption measurement were set to the same elevation as the factory tank in this testing because the engine uses a gravity-feed carburetor. When the engine began to stall on E20, the operators elevated the tank several inches and found the engine would run normally. Emissions tests on E20 were completed with the tank in the elevated position. After emissions testing, the tank was returned to its normal level to see whether the problem would recur, but the engine appeared to run normally. Tests with E15, E10, and an E0 repeat were without incident; however, when fueling with E20 a second time, the engine stopped abruptly. The engine was restarted and ran normally for the duration of the E20 test.

The operational problem observed on E20 could not be replicated enough times to definitively determine a cause. However, two working hypotheses have been developed. Some elastomers and plastics are known to swell with ethanol exposure, and the carburetor on this engine uses a plastic float and an elastomeric seat for the needle in the carburetor bowl. The seat is only $5 \mathrm{~mm}$ across with a $1.5-\mathrm{mm}$ hole. All of the fuel must flow through this $1.5-\mathrm{mm}$-diameter hole in the seat. The first hypothesis involves the potential swelling of the elastomeric seat. If the seat were to swell with ethanol exposure, it is conceivable that a restricted fuel flow condition might be reached that would limit engine power. The second hypothesis involves the carburetor float. The float that presses the metal needle into the seat when the bowl is full is constructed of a hard, white plastic material. If this component were to swell or distort, it could conceivably alter the carburetor function. Numerous carburetor seats and several carburetor bowls for this engine were acquired for ethanol-blend compatibility tests. No results from these experiments are available at this time. Again, no definitive cause has been determined for this engine's apparent problem with E20.

Poulan leaf blower (pilot study). The Poulan leaf blower was tested to full life at the NREL ReFUEL site in Golden, Colorado. Emissions tests on E0 through E20 were conducted in the first $12 \mathrm{hr}$ of engine operation; then, the engine was aged $8 \mathrm{hr}$ on each fuel. ${ }^{*}$ Operators noted that the engine began to run poorly during the aging with E15 at about $34 \mathrm{hr}$. The engine ran very poorly during the final E20 phase. Normal operation could not be restored on E0. Figure 3.8 shows mode 1 engine speed for the duration of the Poulan testing. Rated speed for this engine is 8,000 RPM, although it is not surprising that slightly lower speeds would be realized at the higher altitude. Degraded performance with E15 at around 30-35 hr is apparent in the figure, continuing with E20 fuel. Operators noted that idle speed was fairly consistent after the first $12 \mathrm{hr}$, but speed stability (in revolutions per minute) began to degrade at about $30 \mathrm{hr}$ while operating on E15 fuel. At around $45 \mathrm{hr}$, engine operation was noted to be very poor and erratic. Problems with data collection precluded any data beyond $47 \mathrm{hr}$; however, the operators continued to run the engine and noted that at $52 \mathrm{hr}$ the engine could not be restarted. It is important to note that this engine has a $50 \mathrm{hr}$ life, and only one engine was tested to full life in the pilot study. Given that only one engine was tested, it is not clear whether the fuels affected the life of this engine.

The engine was emissions-tested on E0, E10, E15, and E20 during first $12 \mathrm{hr}$ of life then aged $8 \mathrm{hr}$ on each fuel. Note the decrease in mode 1 engine speed during durability testing with E15 and E20 fuel.

\footnotetext{
*Plans were to conduct emissions tests after each 8-hour aging interval; however, the emissions measurement system used was no longer available at that juncture in the program.
} 


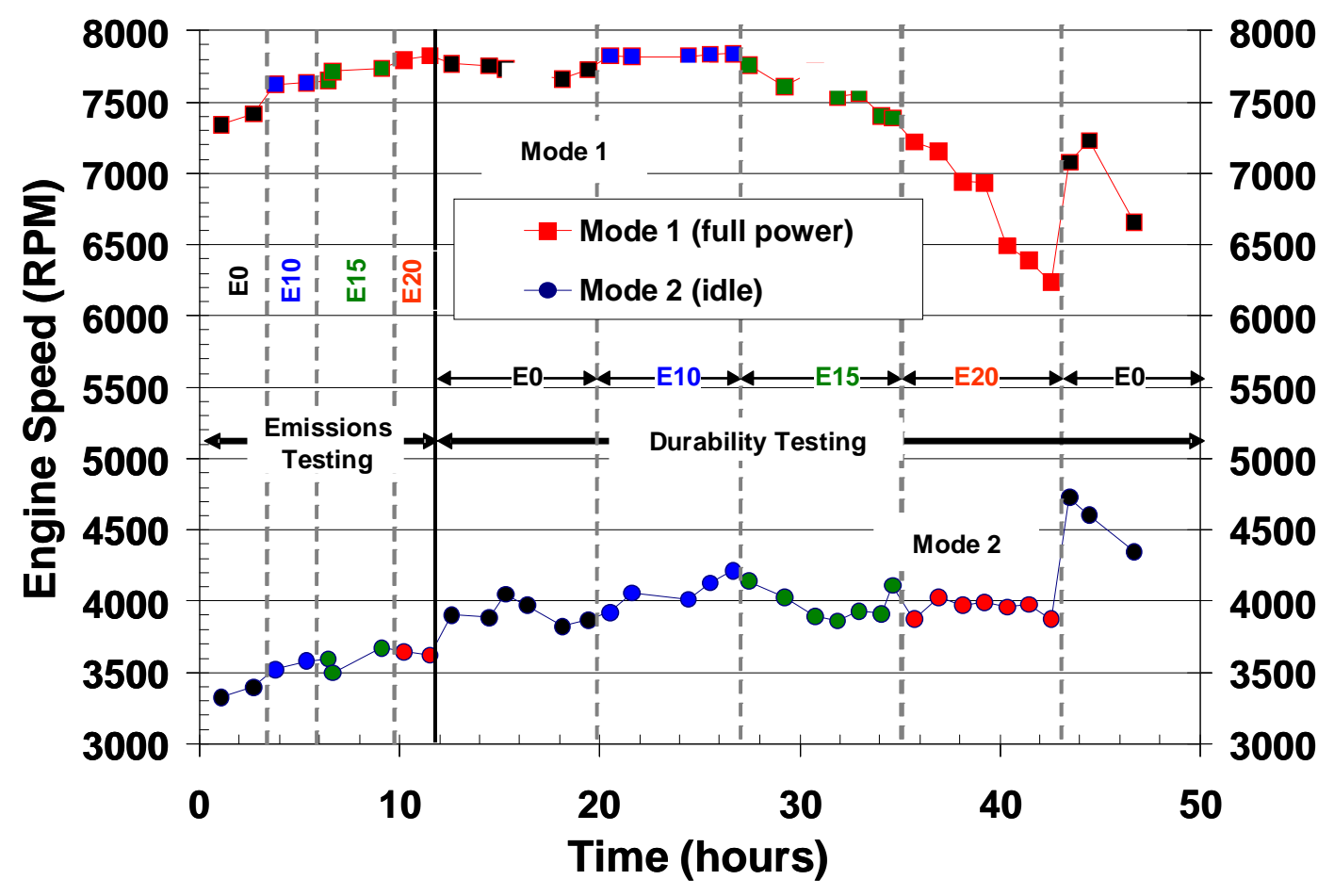

Fig. 3.8. Poulan leaf blower engine speed versus time for fuels E0 through E20.

Stihl FS 90 line trimmer (pilot study). The commercial Stihl line trimmer tested at NREL ran poorly on E20, and high idle speed on E15 and E20 led to clutch engagement at idle. In this pilot study, no attempts were made to adjust carburetors; rather, engines were tested in their as-received condition. It is important to note also that the measured mode 1 engine speed for the Stihl tests was on the order of 10,000 RPM, not the rated power condition of 8,000 RPM.

Briggs and Stratton power washer (full-life study). Six residential Briggs and Stratton power washer engines were tested at TRC. Each engine was baselined on E0 using the TRC protocol (see footnote $\mathrm{b}$ in Table 3.6); then, four of the engines (PW1-PW4) were selected for the aging program. All four units ran similarly for the full $125 \mathrm{hr}$ of operation, with each engine run exclusively on one of the test fuels (E0, E10, E15, or E20), as illustrated in Table 3.6. Emissions tests on the respective dedicated fuels were conducted in the new condition, at half life, and at full life. Operators noted that the engines were "missing" at the lighter loads on the TRC protocol on all fuels.

Because the BASCO protocol ${ }^{*}$ was not run until full-life testing was complete, another power washer (PW5) was to be tested on all fuels using the BASCO protocol. PW5 was tested successfully with E0 fuel but began to run erratically and produce excessive $\mathrm{HC}$ emissions during the E10 BASCO tests at about $15 \mathrm{hr}$ of total engine operation. Reasons for the engine problem are unknown.

Honda EB3000c generator (full-life study). Four commercial Honda generators were tested at TRC. For the one engine tested on E20, operators noted that the engine was "bouncing off the governor" at light loads when testing began, indicating unstable governed speed operation. However, after 250 and then $500 \mathrm{hr}$ of aging on E20, the engine ran normally at all loads.

Weed Eater leaf blower (full-life study). A number of operational issues were observed on these inexpensive, residential Class IV leaf blowers, regardless of fuel type. Eight residential Class IV Weed Eater Featherlite Blowers were baseline tested on E0 after an initial 2-hr break-in. Four similar blowers were selected for the aging program and dedicated to one of the four fuels, in numerical order, with B2 dedicated to E0 and B5, B7, and B8 dedicated to E10, E15, and E20, respectively.

\footnotetext{
*BASCO protocol refers to the Briggs and Stratton Company emissions testing protocol.
} 
Table 3.6. Summary of engine, fuel, and emissions test protocols for full-useful-life (full-life) testing Hashed areas indicate no data collected. Fuel column denotes fuel tested at that condition

(E0, E10, E15, or E20)

\begin{tabular}{|c|c|c|c|c|c|c|}
\hline \multirow{2}{*}{\multicolumn{2}{|c|}{$\begin{array}{c}\text { Engine/equipment } \\
\text { (emissions test protocol) }\end{array}$}} & \multicolumn{2}{|c|}{$\mathrm{New}^{a}$} & \multirow{3}{*}{$\begin{array}{c}\text { Half life } \\
\text { E0 }\end{array}$} & \multicolumn{2}{|c|}{ Full life } \\
\hline & & \multirow{2}{*}{$\frac{\text { E0 }^{b} \text { baseline }}{\mathrm{E} 0}$} & \multirow{2}{*}{$\begin{array}{c}\text { Fuel } \\
\text { E0 }\end{array}$} & & \multirow{2}{*}{$\begin{array}{c}\text { Fuel } \\
\text { E0 }\end{array}$} & \multirow{2}{*}{$\begin{array}{c}\text { Baseline } \\
\text { E0 }\end{array}$} \\
\hline \multirow{6}{*}{$\begin{array}{l}\text { Briggs and Stratton } \\
\text { power washer } \\
\text { (6-mode dyno test, } \\
\text { TRC Protocol) })^{c}\end{array}$} & PW1 & & & & & \\
\hline & $\begin{array}{l}\text { PW2 } \\
\end{array}$ & E0 & E10 & E10 & E10 & E0 \\
\hline & PW3 & E0 & E15 & E15 & E15 & E0 \\
\hline & PW4 & E0 & E20 & E20 & E20 & E0 \\
\hline & PW5 & E0 & & & & \\
\hline & PW6 & E0 & & & & \\
\hline \multirow{6}{*}{$\begin{array}{l}\text { Briggs and Stratton } \\
\text { power washer } \\
\text { (6-mode dyno test, } \\
\text { BASCO Protocol) }\end{array}$} & PW1 & & & & E0 & E0 \\
\hline & PW2 & & & & E10 & E0 \\
\hline & PW3 & & & & E15 & E0 \\
\hline & PW4 & & & & E20 & E0 \\
\hline & PW5 & E0 & & & & \\
\hline & PW6 & & & & & \\
\hline \multirow{4}{*}{$\begin{array}{l}\text { Honda generator } \\
\text { (6-mode test, } \\
\text { generator as engine } \\
\text { brake) }\end{array}$} & G1 & E0 & E0 & E0 & E0 & E0 \\
\hline & G2 & E0 & E10 & E10 & E10 & E0 \\
\hline & G3 & E0 & E15 & E15 & E15 & E0 \\
\hline & G4 & E0 & E20 & E20 & E20 & E0 \\
\hline \multirow{8}{*}{$\begin{array}{l}\text { Weed Eater blower } \\
\text { ( } 2 \text {-mode test, } \\
\text { blower wheel as } \\
\text { engine brake) }\end{array}$} & $\bar{B} 2^{e, f}$ & E0 & E0 & E0 & & \\
\hline & $\mathrm{B}^{e}$ & E0 & E10 & E10 & E10 & E0 \\
\hline & $\mathrm{B} 7^{f, g}$ & E0 & E15 & & & \\
\hline & $\mathrm{B}^{g, h}$ & E0 & E15 & & & \\
\hline & $\mathrm{B} 8^{e, i}$ & E0 & $\mathrm{E}^{2}{ }^{i}$ & & & \\
\hline & $\mathrm{B} 6^{k}$ & E0 & E20 & E20 & E20 & E0 \\
\hline & B1 & E0 & & & & \\
\hline & B4 & E0 & & & & \\
\hline \multirow{4}{*}{$\begin{array}{l}\text { Stihl line trimmer } \\
\text { (2-mode dyno test) }\end{array}$} & T1 & E0 & E0 & E0 & E0 & E0 \\
\hline & $\mathrm{T} 2$ & E0 & E10 & E10 & E10 & E0 \\
\hline & T3 & E0 & E15 & E15 & E15 & E0 \\
\hline & $\mathrm{T} 4$ & E0 & E20 & E20 & E20 & E0 \\
\hline
\end{tabular}

${ }^{a}$ New refers to engines following 2-hr initial break-in.

${ }^{b} \mathrm{E} 0$ is federal certification gasoline.

${ }^{c}$ TRC protocol allowed engine to run on governor in mode 1 , similar to power washer operation in spray mode.

${ }^{d}$ BASCO protocol involved override of governor for wide-open throttle operation in mode 1. Because BASCO protocol not initially run on PW1-PW4 in new condition, PW5 tested on BASCO protocol for new engine comparison. PW5 failed during E10 testing on BASCO protocol.

${ }^{e}$ Engine initially selected for aging program (B2-E0, B5-E10, B7-E15, B8-E20).

${ }^{f}$ B2 failed before full life $(50 \mathrm{hr})$.

${ }^{g}$ Failed before half life.

${ }^{h} \mathrm{~B} 3$ replaced B7 as E15 engine after B7 failure.

${ }^{i}$ No E20 emissions data obtained from B8 (would not idle).

${ }^{k} \mathrm{~B} 6$ replaced B8 as E20 engine when B8 would not idle on E20. 
Figure 3.9 shows the aging timeline for six of the engines. Immediately upon testing, B8 would not idle with E20 fuel. To gauge whether this occurrence might be a chronic problem for this engine type, a brief operational test was conducted on the remaining four blowers (B1, B3, B4, and B6) to observe whether the units would operate properly on E20. Results of this experiment showed that all four engines were able to idle with E20, although one of these blowers (B4) would not run continuously at WOT. Baseline testing with E0 showed that B4 was the leanest of the group with E0 fuel (as indicated by lowest CO emissions), suggesting that the additional enleanment from E20 put it outside of the stable combustion limits. After this brief operational test, B8 was replaced by B6 as the new E20 blower.

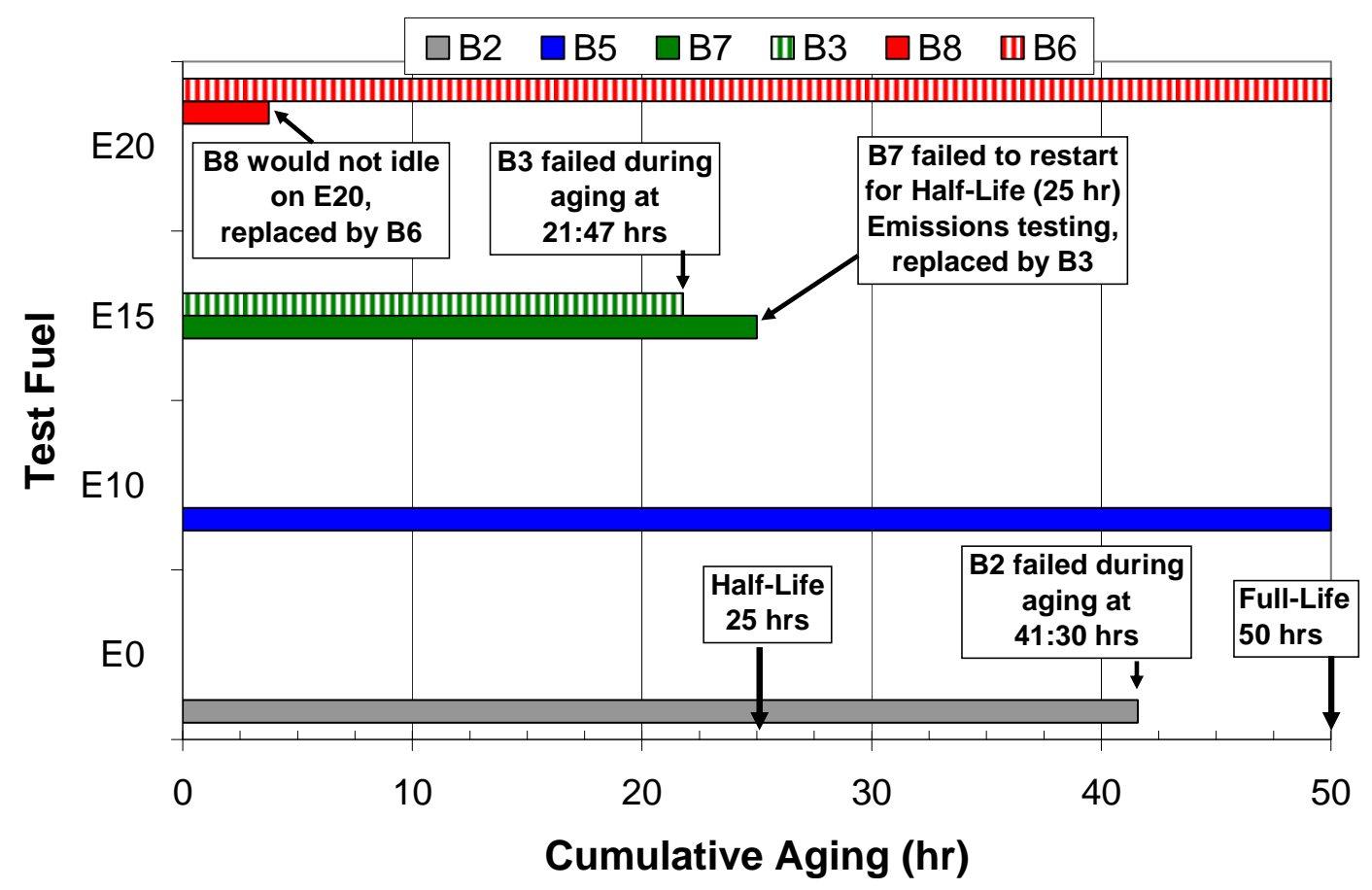

Fig. 3.9. Aging timeline for five Weed Eater Featherlite blowers.

Additional operational problems occurred with the blowers and are summarized in Fig. 3.9 and Table 3.5. B7 would not start for its half-life emissions test ( $25 \mathrm{hr}$ ). In an attempt to acquire half-life and full-life emissions data for an engine on E15, B3 was selected to replace B7 as the E15-specific engine (despite having spent a few minutes running on E20). However, B3 failed before reaching half life. B2, running exclusively on E0, stopped working at 41:30 hr. Only two of the five engines subjected to the aging program survived to full-life for a 50-hr emissions test-B5 (run on E10) and B6 (run on E20). After the completion of the program, an industry peer suggested that the blower mounting system may have contributed to premature failure of some of these engines. The way in which the pneumatic throttle actuator was mounted may have compromised the carburetor mounting. If the carburetor mount was compromised, the resulting air-leak could potentially lead to enleanment and engine failure. Inspections of the engines by the manufacturer were planned but not completed when this report was prepared.

Stihl line trimmer (full-life study). The commercial Class IV Stihl line trimmers are equipped with three carburetor adjustment screws - one for low-speed mixture, one for high-speed mixture, and one for low-idle speed. The as-received condition was "rich-rich" for the two carburetor mixture adjustment screws (see Fig. 3.10, $\mathrm{H}$ and $\mathrm{L}$ at full counterclockwise setting). Instructions to TRC were to leave the carburetor screw settings in the as-received condition unless an operational problem was noted. Engineers at Stihl were also consulted and they agreed that this setting was a reasonable way to proceed with the program. At $225 \mathrm{hr}$, the idle speed of the E15 and E20 engines had crept up to the 
point of clutch engagement. The technicians adjusted the low-idle adjustment (LA) screw and were able to bring idle speed back down to 3,000 RPM and eliminate trimmer head spinning during mode 2 (idle) operation. At the end of the aging program, clutch engagement speed was measured on all four

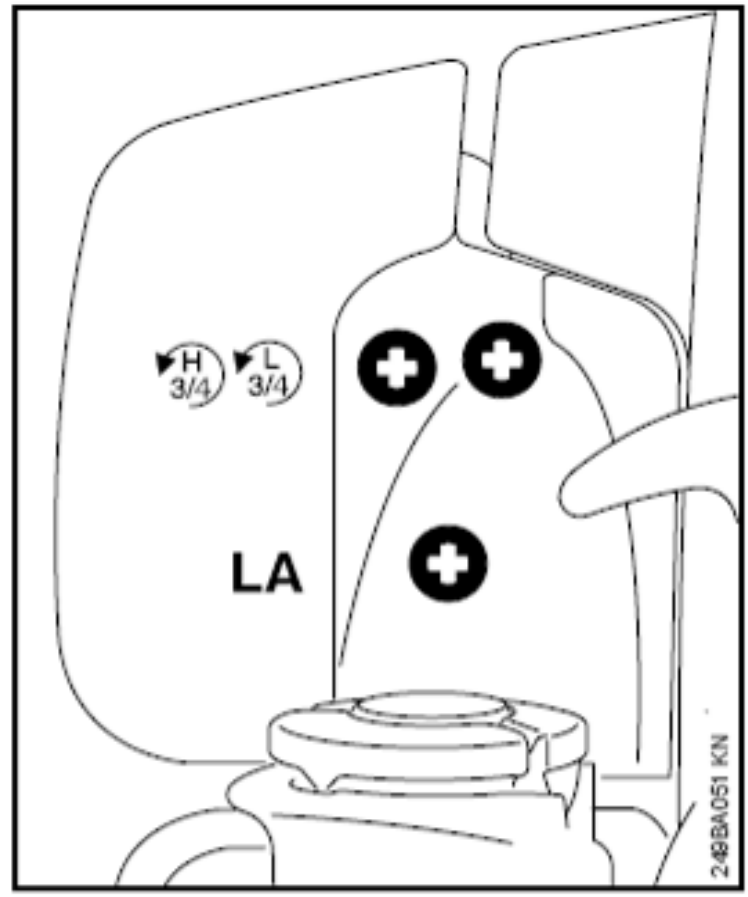

Fig. 3.10. Stihl owner's manual schematic showing location of high-speed (H), low-speed (L), and low-idle (LA) adjustment screws. (Used with permission.)

trimmers and found to range from 3,300 to 3,600 RPM. With E0 fuel in all trimmers, the range of achievable idle speeds was measured to determine the range of authority of the LA screw. With the low-speed (L) adjustment screw in the rich (full counterclockwise) position, the LA screw could vary idle from below 2,000 RPM to over 4,500 RPM. Setting the L screw to the lean or clockwise position, the LA screw could vary idle from around 2,700 RPM to more than 6,000 RPM. The owner's manual contains detailed instructions on adjusting this engine's carburetor.

\subsubsection{Results and Discussion: Emissions}

As discussed in detail in Sect. 2, five new engines in the pilot study were tested on all four fuels (E0, E10, E15, and E20), and the field-aged Honda generator was tested on all but E15. All of the engines at TRC were tested on $\mathrm{E} 0$; then one of each engine type was dedicated to a specific ethanol blend (i.e., E0, E10, E15, or E20) for full-life aging.

\subsubsection{ORNL and NREL pilot study: emissions results}

Baseline E0 emissions for each engine and the relative changes in emissions for each of the ethanol blends are summarized in Table 3.7.

- In general, $\mathrm{HC}$ emissions decreased with increasing ethanol, while $\mathrm{NO}_{\mathrm{X}}$ increased.

- Changes in $\mathrm{HC}+\mathrm{NO}_{\mathrm{X}}$ ranged from a $36 \%$ decrease for the Stihl engine with E15 when compared to $\mathrm{E} 0$ to an $8 \%$ increase for the Kohler engine with E20 when compared to E0. 
- For the Class I and II four-stroke engines, the large increases in $\mathrm{NO}_{\mathrm{X}}$ were largely tempered by similar decreases in $\mathrm{HCs}$, such that $\mathrm{HCs}+\mathrm{NO}_{\mathrm{X}}$ decreased for three of the engines, while increasing with increasing ethanol for the Kohler engine.

Table 3.7. Baseline E0 emissions and relative change for E10, E15, and E20 for pilot study engines

\begin{tabular}{|c|c|c|c|c|c|}
\hline \multirow{2}{*}{$\begin{array}{l}\text { Engine } \\
\text { type }\end{array}$} & \multirow{2}{*}{ Engine/equipment } & \multirow{2}{*}{$\begin{array}{l}\text { E0 baseline } \\
\text { (g/kWh) }\end{array}$} & \multicolumn{3}{|c|}{ Percent change in HC from E0 to: } \\
\hline & & & E10 & E15 & E20 \\
\hline \multirow{2}{*}{$\begin{array}{l}\text { Class I, } \\
\text { 4-stroke }\end{array}$} & Honda EB3000c generator & 6.1 & -36.3 & -45.0 & -53.9 \\
\hline & Honda EM2500 generator ${ }^{a}$ & 13.2 & -15.5 & & -26.1 \\
\hline \multirow{2}{*}{$\begin{array}{l}\text { Class II, } \\
\text { 4-stroke }\end{array}$} & Briggs and Stratton generator & 7.5 & -25.7 & -29.9 & -39.8 \\
\hline & Kohler generator & 4.0 & -30.5 & -47.0 & -60.0 \\
\hline \multirow{2}{*}{ Class IV } & Stihl line trimmer (4-mix $®)$ & 38.5 & -33.8 & -39.5 & -10.6 \\
\hline & Poulan blower (2-stroke) & 38.3 & -21.9 & -15.1 & -25.6 \\
\hline \multicolumn{2}{|c|}{ Numerical average (new engines) } & 18.9 & -29.6 & -35.3 & -38.0 \\
\hline \multirow{2}{*}{$\begin{array}{l}\text { Engine } \\
\text { type }\end{array}$} & \multirow{2}{*}{ Engine/equipment } & \multirow{2}{*}{$\begin{array}{l}\text { E0 baseline } \\
\text { (g/kWh) }\end{array}$} & \multicolumn{3}{|c|}{ Percent change in $\mathrm{NO}_{\mathrm{X}}$ from $\mathrm{EO}$ to: } \\
\hline & & & E10 & E15 & E20 \\
\hline \multirow{2}{*}{$\begin{array}{l}\text { Class I, } \\
\text { 4-stroke }\end{array}$} & Honda EB3000c generator & 3.6 & 18.2 & 58.7 & 64.5 \\
\hline & Honda EM2500 generator $^{a}$ & 3.3 & 41.1 & & 87.8 \\
\hline \multirow{2}{*}{$\begin{array}{l}\text { Class II, } \\
\text { 4-stroke }\end{array}$} & Briggs and Stratton generator & 1.5 & 31.2 & 64.9 & 130.5 \\
\hline & Kohler generator & 4.1 & 32.2 & 52.8 & 73.6 \\
\hline \multirow{2}{*}{ Class IV } & Stihl line trimmer (4-mix $\left.{ }^{\circledR}\right)$ & 1.06 & 65.1 & 85.0 & 26.7 \\
\hline & Poulan blower (2-stroke) & 0.15 & 106.7 & 53.3 & 120.0 \\
\hline \multicolumn{2}{|c|}{ Numerical average (new engines) } & 2.08 & 50.6 & 63.0 & 83.1 \\
\hline \multirow{2}{*}{$\begin{array}{l}\text { Engine } \\
\text { type }\end{array}$} & \multirow{2}{*}{ Engine/equipment } & \multirow{2}{*}{$\begin{array}{l}\text { E0 baseline } \\
\text { (g/kWh) }\end{array}$} & \multicolumn{3}{|c|}{ Percent change in $\mathrm{HC}+\mathrm{NO}_{\mathrm{X}}$ from $\mathrm{EO}$ to } \\
\hline & & & E10 & E15 & E20 \\
\hline \multirow{2}{*}{$\begin{array}{l}\text { Class I, } \\
\text { 4-stroke }\end{array}$} & Honda EB3000c generator & 9.7 & -16.0 & -6.2 & -9.7 \\
\hline & Honda EM2500 generator $^{a}$ & 16.5 & -4.1 & & -3.3 \\
\hline \multirow{2}{*}{$\begin{array}{l}\text { Class II, } \\
\text { 4-stroke }\end{array}$} & Briggs and Stratton generator & 9.0 & -16.1 & -13.9 & -11.0 \\
\hline & Kohler generator & 8.1 & 1.4 & 3.9 & 8.0 \\
\hline \multirow{2}{*}{ Class IV } & Stihl line trimmer $\left(4-\operatorname{mix}{ }^{\circledR}\right)$ & 39.6 & -31.1 & -36.2 & -9.7 \\
\hline & Poulan blower (2-stroke) & 38.5 & -21.4 & -14.9 & -25.0 \\
\hline \multicolumn{2}{|c|}{ Numerical average (new engines) } & 21.0 & -16.6 & -13.5 & -9.5 \\
\hline \multirow{2}{*}{$\begin{array}{l}\text { Engine } \\
\text { type }\end{array}$} & \multirow{2}{*}{ Engine/equipment } & \multirow{2}{*}{$\begin{array}{l}\text { E0 baseline } \\
\text { (g/kWh) }\end{array}$} & \multicolumn{3}{|c|}{ Percent change in CO from E0 to: } \\
\hline & & & E10 & E15 & E20 \\
\hline Class I, & Honda EB3000c generator & 339 & -30.7 & -47.7 & -56.9 \\
\hline 4-stroke & Honda EM2500 generator $^{a}$ & 454 & -24.0 & & -43.0 \\
\hline Class II, & Briggs and Stratton generator & 510 & -18.3 & -22.4 & -34.8 \\
\hline 4-stroke & Kohler generator & 301 & -33.1 & -53.7 & -63.6 \\
\hline Cloce JV & Stihl line trimmer $\left(4-\operatorname{mix}{ }^{\circledR}\right)$ & 630 & -40.5 & -53.5 & -27.8 \\
\hline Class iv & Poulan blower (2-stroke) & 270 & -34.1 & -48.9 & -61.9 \\
\hline Nun & herical average (new engines) & 410 & -31.3 & -45.2 & -49.0 \\
\hline
\end{tabular}

${ }^{a}$ Field-aged Honda considered full-useful life. Not included in numerical averages.

- Given that the $\mathrm{HCs}+\mathrm{NO}_{\mathrm{X}}$ is dominated by the $\mathrm{HC}$ emissions for the Class IV handheld engines, $\mathrm{HCs}+\mathrm{NO}_{\mathrm{X}}$ decreased for all ethanol blends.

- CO emissions decreased consistently for all engines with increasing ethanol. 
These emissions trends are graphically represented in Figs. 3.11-3.14. The trendlines in Figs. 3.11-3.14 represent average data for the new engines, but do not include the field-aged Honda data because it was used when testing began and was not tested with E15. As discussed in Sect. 2, the brake-specific emissions for the Stihl line trimmer and Poulan blower were estimated from raw exhaust concentration measurements and engineering assumptions about exhaust flow rates. Mass emissions rates were measured for the generator tests. The electrical load on the generators was measured, and a constant generator efficiency of $90 \%$ was assumed for calculating the emissions on an engine brake-specific basis. HC emissions are as indicated by the FID, and they do not include any correction for oxygenated compounds in the exhaust such as ethanol or aldehydes.

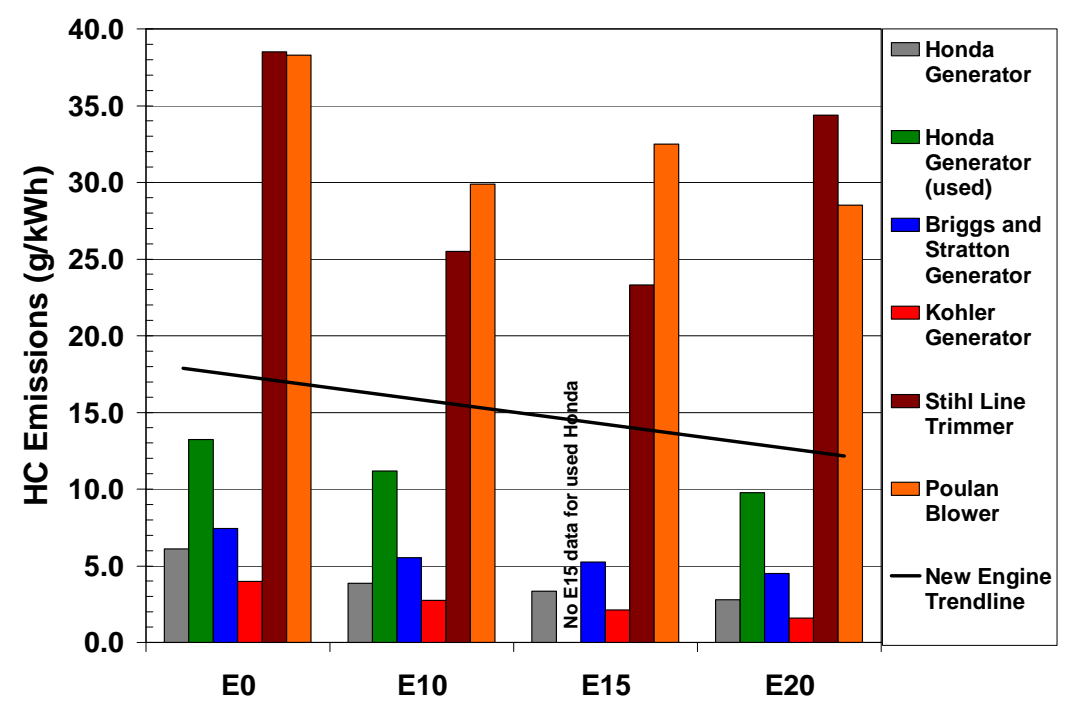

Fig. 3.11. Hydrocarbon (HC) emissions for pilot study engines versus fuel ethanol content. With the exception of the Stihl line trimmer, which ran poorly with E20, HC emissions decrease with increasing ethanol. Trendline for average of all five new engines.

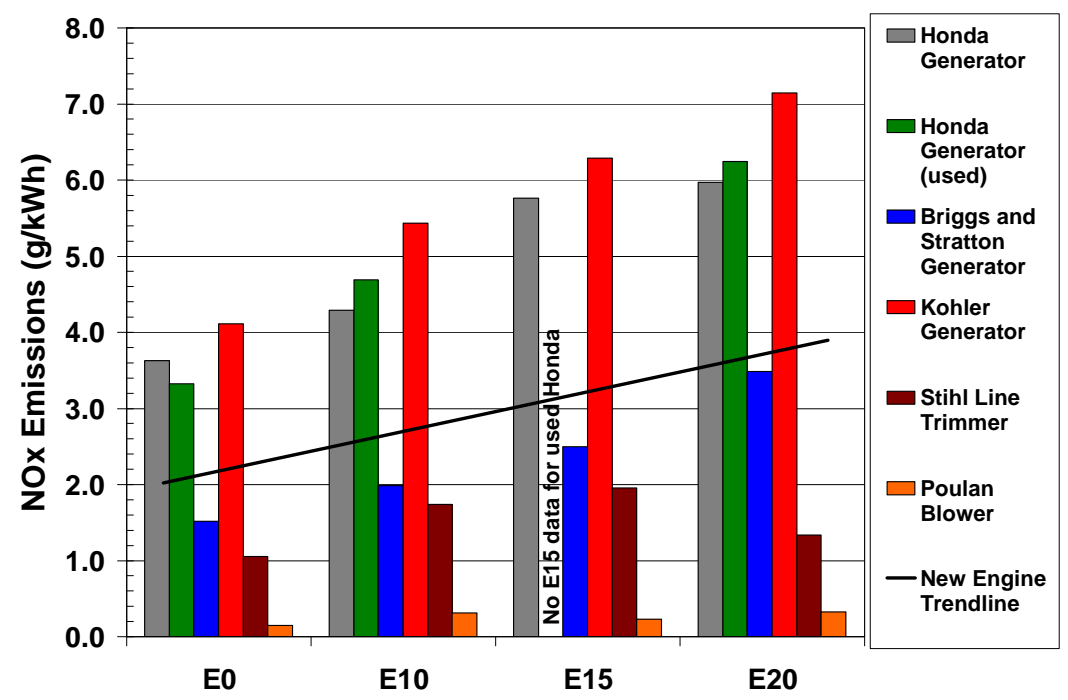

Fig. 3.12. Nitrogen oxide $\left(\mathrm{NO}_{\mathrm{x}}\right)$ emissions for pilot study engines versus fuel ethanol content. $\mathrm{NO}_{\mathrm{X}}$ increases with increasing ethanol. Poor operation of the Stihl line trimmer with $\mathrm{E} 20$ caused reduced $\mathrm{NO}_{\mathrm{X}}$ with that fuel. The Poulan blower is equipped with a three-way catalyst that oxidizes hydrocarbons and $\mathrm{CO}$ while also reducing $\mathrm{NO}_{\mathrm{X}}$ emissions. Trendline for average of all five new engines. 


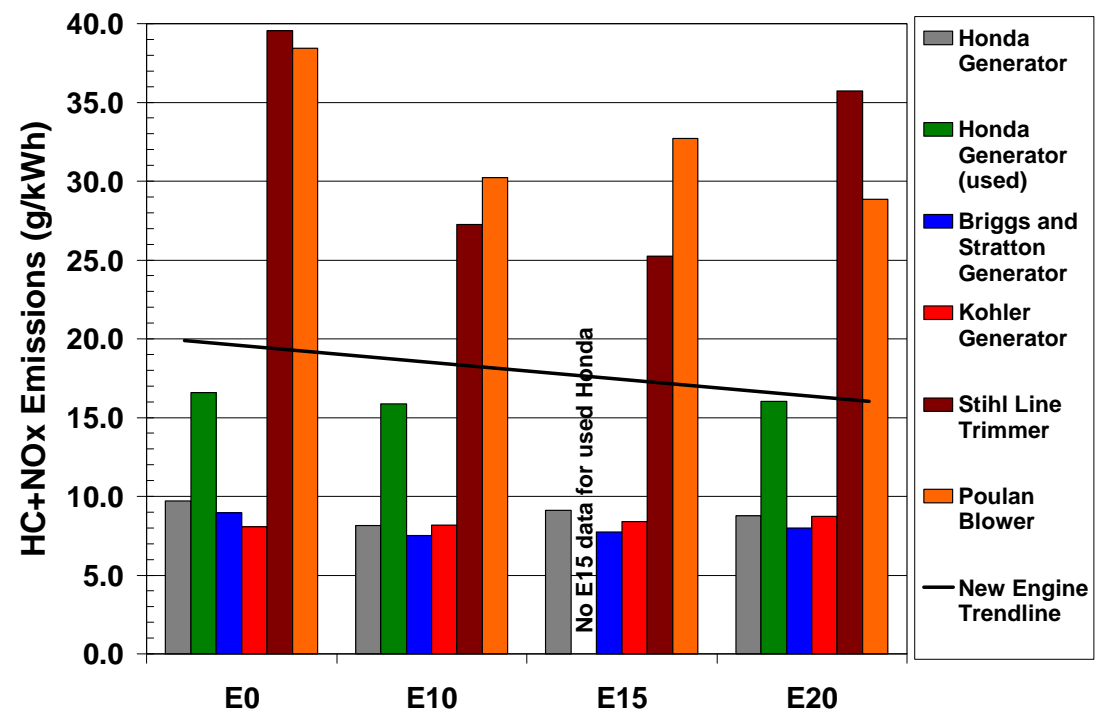

Fig. 3.13. Hydrocarbon $(\mathrm{HC})$ + nitrogen oxide $\left(\mathrm{NO}_{\mathrm{x}}\right)$ emissions for pilot study engines. Decreasing $\mathrm{NO}_{\mathrm{X}}$ and increasing $\mathrm{HC}$ temper any drastic changes in $\mathrm{HC}+\mathrm{NO}_{\mathrm{x}}$. Trendline for average of all five new engines shows overall decrease with increasing ethanol.

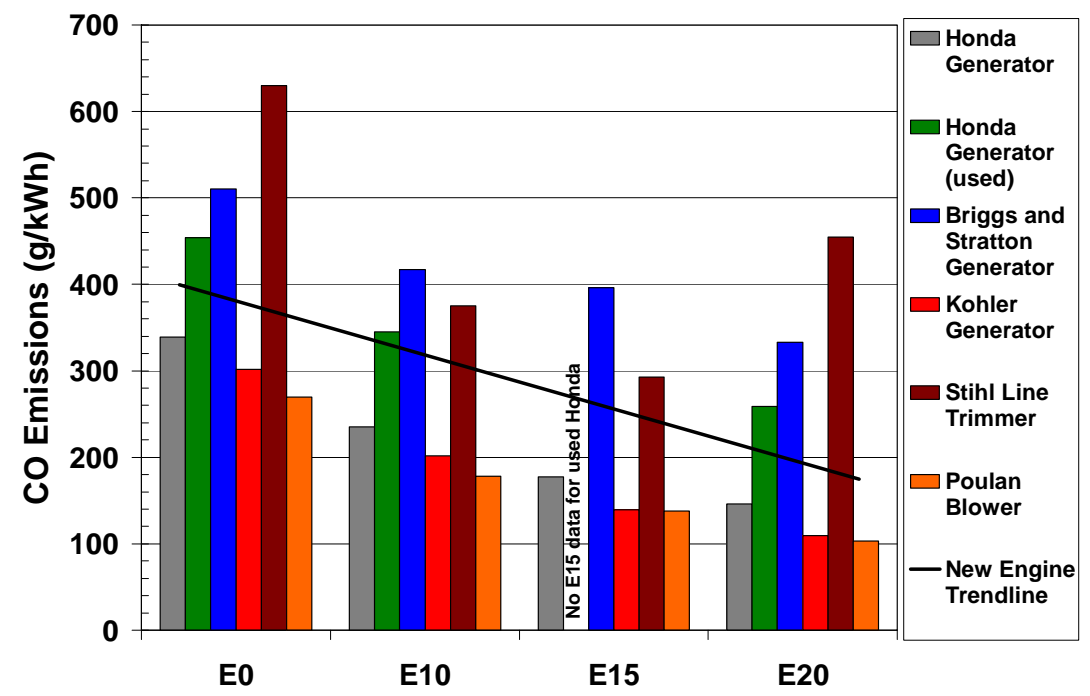

Fig. 3.14. Carbon monoxide emissions for pilot study engines. With the exception of the Stihl line trimmer, which ran poorly on E20, CO emissions decrease with increasing ethanol. Trendline for average of all five new engines. 


\subsubsection{Full-life study emissions results}

Twenty-two engines were baseline tested on E0 at TRC, and 17 of these engines were run to their rated full-life period or to failure. Table 3.6 indicates which engines were tested on which fuels. Results for all E0 baseline tests at the new and full-life condition are presented in Table 3.8 through Table 3.12, with the relative change to the E0 baseline for each engine/ethanol blend combination. Table 3.8 and Table 3.9 show the Briggs and Stratton power washer engine results. Table 3.8 has results for the TRC protocol tests, and Table 3.9 presents results for the BASCO protocol. These two test protocols are discussed in detail in the experimental setup section. Similar information for the Honda generators, the Weed Eater blowers, and the Stihl line trimmers are provided in Table 3.10, Table 3.11, and Table 3.12, respectively.

In general, results in the full-life study were similar to those in the pilot study.

- $\mathrm{HC}$ and $\mathrm{CO}$ emissions tended to decrease with increasing ethanol content, while $\mathrm{NO}_{\mathrm{X}}$ tended to increase. These trends were observed both at new and full-life conditions.

- Engine-to-engine differences on E0 fuel were fairly large for the residential engines - in some cases as large as the changes due to introduction of the ethanol blends.

- Changes from the new condition to the full-life condition on the E0 fuel showed a general increase in $\mathrm{HC}$ and $\mathrm{CO}$, and no dramatic change in $\mathrm{NO}_{\mathrm{X}}$.

Appendix D contains figures for each engine type in the full-life study, showing $\mathrm{HC}, \mathrm{NO}_{\mathrm{X}}, \mathrm{HC}+$ $\mathrm{NO}_{\mathrm{X}}$, and $\mathrm{CO}$ emissions for each engine on E0 fuel at the new and full-life conditions and results from each engine running its dedicated ethanol blend. In addition, these results are tabulated with average, maximum, minimum, and coefficient of variation (COV) for each series of tests. For all engines, $\mathrm{HC}$ emissions are as indicated by the FID, and do not include any correction for oxygenated compounds in the exhaust such as ethanol or aldehydes.

\subsubsection{Results and Discussion: Exhaust, Oil, and Other Temperature Data}

\subsubsection{ORNL and NREL pilot study: temperature results}

Exhaust temperature, oil temperature (where applicable), and several surface temperatures were measured. The largest temperature change noted in any of the engines was in the exhaust. Table 3.13 shows the baseline E0 temperature for each engine in the pilot study and the change in temperature for each of the fuels tested (E10, E15, and E20). The hottest engine condition is reported here, which for all but the Kohler engine was observed in the mode 1 condition. The hottest exhaust temperature measured on the Kohler V-twin engine was at the fast idle or standby condition.

As the table indicates, temperature increases between E0 and E20 ranged from $31^{\circ}$ to $69^{\circ} \mathrm{C}$, but only between $8^{\circ}$ and $20^{\circ} \mathrm{C}$ from E10 to E15. Also, the exhaust temperature for the Briggs and Stratton engine actually decreased from E10 to E15.

Figure 3.15 shows the actual temperature measurements for the same data as well as a trendline based on the average temperature increases for the five new engines for all ethanol levels.

Kohler V-twin engine. The temperature results on the Kohler V-twin engine show some interesting differences from the single-cylinder-engine generators. While the hottest temperature in the single-cylinder engines was in mode 1 or at the peak power condition, the highest exhaust temperature measured on the Kohler engine was for the cylinder 1 exhaust manifold at mode 6 , the no-load (fast idle, or standby) condition. Similarly, the highest temperature rise due to ethanol enleanment was for this same cylinder and engine load. 
Table 3.8. Baseline Briggs and Stratton power washer engine emissions on the TRC protocol at new and full-useful-life (full-life) condition with $\mathrm{EO}$ fuel, and relative change for respective ethanol blends

("Ethanol blend" refers to E10, E15, or E20, as noted.)

\begin{tabular}{|c|c|c|c|c|}
\hline \multirow[b]{2}{*}{ Engine/equipment } & \multicolumn{2}{|c|}{ New } & \multicolumn{2}{|c|}{ Full life } \\
\hline & $\begin{array}{c}\text { New E0 } \\
\text { (g/kW-hr) }\end{array}$ & $\begin{array}{l}\text { Change from } \\
\text { E0 to ethanol } \\
\text { blend }\end{array}$ & $\begin{array}{c}\text { Full-life E0 } \\
\text { (g/kW-hr) }\end{array}$ & $\begin{array}{l}\text { Change from } \\
\text { E0 to ethanol } \\
\text { blend }\end{array}$ \\
\hline \multicolumn{5}{|c|}{ HC emissions-TRC protocol } \\
\hline Briggs PW1 (E0 engine) & 11.7 & & 11.1 & \\
\hline Briggs PW2 (E10 engine) & 12.6 & $10 \%$ & 18.2 & $-21 \%$ \\
\hline Briggs PW3 (E15 engine) & 16.6 & $-28 \%$ & 41.4 & $-21 \%$ \\
\hline Briggs PW4 (E20 engine) & 16.5 & $3 \%$ & 32.8 & $-25 \%$ \\
\hline Briggs PW5 (alternate) & 10.7 & & & \\
\hline Briggs PW6 (alternate) & 20.8 & & & \\
\hline Numerical average & 14.8 & & 25.9 & \\
\hline \multicolumn{5}{|c|}{$\mathrm{NO}_{\mathrm{X}}$ emissions-TRC protocol } \\
\hline Briggs PW1 (E0 engine) & 2.1 & & 3.7 & \\
\hline Briggs PW2 (E10 engine) & 2.0 & $23 \%$ & 1.9 & $4 \%$ \\
\hline Briggs PW3 (E15 engine) & 1.6 & $22 \%$ & 1.6 & $3 \%$ \\
\hline Briggs PW4 (E20 engine) & 1.4 & $33 \%$ & 1.6 & $21 \%$ \\
\hline Briggs PW5 (alternate) & 3.1 & & & \\
\hline Briggs PW6 (alternate) & 2.6 & & & \\
\hline Numerical average & 2.1 & & 2.2 & \\
\hline \multicolumn{5}{|c|}{$\mathrm{HC}+\mathrm{NO}_{\mathrm{X}}$ emissions-TRC protocol } \\
\hline Briggs PW1 (E0 engine) & 13.2 & & 14.8 & \\
\hline Briggs PW2 (E10 engine) & 14.6 & $12 \%$ & 20.1 & $-19 \%$ \\
\hline Briggs PW3 (E15 engine) & 18.1 & $-24 \%$ & 43.1 & $-20 \%$ \\
\hline Briggs PW4 (E20 engine) & 17.9 & $5 \%$ & 34.4 & $-23 \%$ \\
\hline Briggs PW5 (alternate) & 13.8 & & & \\
\hline Briggs PW6 (alternate) & 23.4 & & & \\
\hline Numerical average & 16.8 & & 28.1 & \\
\hline \multicolumn{5}{|c|}{ CO emissions-TRC protocol } \\
\hline Briggs PW1 (E0 engine) & 312 & & 164 & \\
\hline Briggs PW2 (E10 engine) & 330 & $-15 \%$ & 450 & $-27 \%$ \\
\hline Briggs PW3 (E15 engine) & 347 & $-46 \%$ & 724 & $-37 \%$ \\
\hline Briggs PW4 (E20 engine) & 402 & $-60 \%$ & 472 & $-57 \%$ \\
\hline Briggs PW5 (alternate) & 227 & & & \\
\hline Briggs PW6 (alternate) & 215 & & 20 & \\
\hline Numerical average & 306 & & 453 & \\
\hline
\end{tabular}


Table 3.9. Briggs and Stratton power washer engine emissions on the BASCO protocol at new and full-useful-life (full-life) condition with E0 fuel, and relative change for respective ethanol blends

("Ethanol blend" refers to E10, E15, or E20, as noted.)

\begin{tabular}{|c|c|c|c|c|}
\hline \multirow[b]{2}{*}{ Engine/equipment } & \multicolumn{2}{|c|}{ New } & \multicolumn{2}{|c|}{ Full life } \\
\hline & $\begin{array}{c}\text { New E0 } \\
\text { (g/kw-hr) }\end{array}$ & $\begin{array}{l}\text { Change from } \\
\text { E0 to ethanol } \\
\text { blend }\end{array}$ & $\begin{array}{c}\text { Full-life E0 } \\
\text { (g/kw-hr) }\end{array}$ & $\begin{array}{l}\text { Change from } \\
\text { E0 to ethanol } \\
\text { blend }\end{array}$ \\
\hline \multicolumn{5}{|c|}{ HC emissions-BASCO protocol } \\
\hline Briggs PW1 (E0 engine) & & & 16.1 & \\
\hline Briggs PW2 (E10 engine) & & & 11.5 & $47 \%$ \\
\hline Briggs PW3 (E15 engine) & & & 18.6 & $-9 \%$ \\
\hline Briggs PW4 (E20 engine) & & & 16.2 & $-4 \%$ \\
\hline Briggs PW5 (alternate) & 11.9 & & & \\
\hline \multicolumn{5}{|l|}{ Briggs PW6 (alternate) } \\
\hline Numerical average & 11.9 & & 15.6 & \\
\hline \multicolumn{5}{|c|}{$\mathrm{NO}_{\mathrm{X}}$ emissions-BASCO protocol } \\
\hline Briggs PW1 (E0 engine) & & & 5.3 & \\
\hline Briggs PW2 (E10 engine) & & & 2.2 & $13 \%$ \\
\hline Briggs PW3 (E15 engine) & & & 2.1 & $22 \%$ \\
\hline Briggs PW4 (E20 engine) & & & 2.7 & $73 \%$ \\
\hline Briggs PW5 (alternate) & 4.5 & & & \\
\hline \multicolumn{5}{|l|}{ Briggs PW6 (alternate) } \\
\hline Numerical average & 4.5 & & 3.1 & \\
\hline \multicolumn{5}{|c|}{$\mathrm{HC}+\mathrm{NO}_{\mathrm{x}}$ emissions-BASCO protocol } \\
\hline Briggs PW1 (E0 engine) & & & 21.3 & \\
\hline Briggs PW2 (E10 engine) & & & 13.7 & $41 \%$ \\
\hline Briggs PW3 (E15 engine) & & & 20.8 & $-6 \%$ \\
\hline Briggs PW4 (E20 engine) & & & 18.9 & $7 \%$ \\
\hline Briggs PW5 (alternate) & 16.4 & & & \\
\hline \multicolumn{5}{|l|}{ Briggs PW6 (alternate) } \\
\hline Numerical average & 16.4 & & 18.7 & \\
\hline \multicolumn{5}{|c|}{ CO emissions-BASCO protocol } \\
\hline Briggs PW1 (E0 engine) & & & 227 & \\
\hline Briggs PW2 (E10 engine) & & & 429 & $-10 \%$ \\
\hline Briggs PW3 (E15 engine) & & & 396 & $-27 \%$ \\
\hline Briggs PW4 (E20 engine) & & & 332 & $-53 \%$ \\
\hline Briggs PW5 (alternate) & 241 & & & \\
\hline \multicolumn{5}{|l|}{ Briggs PW6 (alternate) } \\
\hline Numerical average & 241 & & 346 & \\
\hline
\end{tabular}


Table 3.10. Baseline Honda generator engine emissions at new and full-useful-life (full-life) condition with E0 fuel, and relative change for respective ethanol blends

("Ethanol blend" refers to E10, E15, or E20, as noted.)

\begin{tabular}{|c|c|c|c|c|}
\hline \multirow[b]{2}{*}{ Engine/equipment } & \multicolumn{2}{|c|}{ New } & \multicolumn{2}{|c|}{ Full life } \\
\hline & $\begin{array}{c}\text { New E0 } \\
\text { (g/kW-hr) }\end{array}$ & $\begin{array}{l}\text { Change from } \\
\text { E0 to ethanol } \\
\text { blend }\end{array}$ & $\begin{array}{c}\text { Full-life E0 } \\
\text { (g/kW-hr) }\end{array}$ & $\begin{array}{l}\text { Change from } \\
\text { E0 to ethanol } \\
\text { blend }\end{array}$ \\
\hline \multicolumn{5}{|c|}{ HC emissions } \\
\hline Honda G1 (E0 engine) & 5.2 & & 6.5 & \\
\hline Honda G2 (E10 engine) & 5.1 & $-17 \%$ & 5.3 & $-16 \%$ \\
\hline Honda G3 (E15 engine) & 6.2 & $-30 \%$ & 8.8 & $-26 \%$ \\
\hline Honda G4 (E20 engine) ${ }^{a}$ & 5.5 & $150 \%$ & 9.3 & $-35 \%$ \\
\hline Numerical average & 5.5 & & 7.5 & \\
\hline \multicolumn{5}{|c|}{$\mathrm{NO}_{\mathrm{X}}$ emissions } \\
\hline Honda G1 (E0 engine) & 3.7 & & 3.7 & \\
\hline Honda G2 (E10 engine) & 3.6 & $42 \%$ & 4.0 & $40 \%$ \\
\hline Honda G3 (E15 engine) & 4.4 & $44 \%$ & 3.8 & $68 \%$ \\
\hline Honda G4 (E20 engine) & 5.0 & $93 \%$ & 4.2 & $102 \%$ \\
\hline Numerical average & 4.2 & & 3.9 & \\
\hline \multicolumn{5}{|c|}{$\mathrm{HC}+\mathrm{NO}_{\mathrm{X}}$ emissions } \\
\hline Honda G1 (E0 engine) & 9.0 & & 10.2 & \\
\hline Honda G2 (E10 engine) & 8.8 & $7 \%$ & 9.2 & $8 \%$ \\
\hline Honda G3 (E15 engine) & 10.6 & $1 \%$ & 12.6 & $2 \%$ \\
\hline${\text { Honda G4 (E20 engine) }{ }^{a}}$ & 10.5 & $123 \%$ & 13.5 & $7 \%$ \\
\hline Numerical average & 9.7 & & 11.4 & \\
\hline \multicolumn{5}{|c|}{ CO emissions } \\
\hline Honda G1 (E0 engine) & 329 & & 374 & \\
\hline Honda G2 (E10 engine) & 306 & $-28 \%$ & 320 & $-31 \%$ \\
\hline Honda G3 (E15 engine) & 310 & $-34 \%$ & 359 & $-37 \%$ \\
\hline Honda G4 (E20 engine) & 270 & $-39 \%$ & 335 & $-60 \%$ \\
\hline Numerical average & 304 & & 347 & \\
\hline
\end{tabular}

${ }^{a}$ Unusually high HC emissions with E20 due to unstable speed governor operation at light loads. 
Table 3.11. Baseline Weed Eater Featherlite blower engine emissions at new and full-useful-life (full-life) condition with EO fuel, and relative change for respective ethanol blends

("Ethanol blend" refers to E10, E15, or E20, as noted.)

\begin{tabular}{|c|c|c|c|c|}
\hline \multirow[b]{2}{*}{ Engine/equipment } & \multicolumn{2}{|c|}{ New } & \multicolumn{2}{|c|}{ Full life } \\
\hline & $\begin{array}{c}\text { New E0 } \\
\text { (g/kW-hr) }\end{array}$ & $\begin{array}{l}\text { Change from } \\
\text { E0 to ethanol } \\
\text { blend }\end{array}$ & $\begin{array}{c}\text { Full-life E0 } \\
\text { (g/kW-hr) }\end{array}$ & $\begin{array}{l}\text { Change from } \\
\text { E0 to ethanol } \\
\text { blend }\end{array}$ \\
\hline \multicolumn{5}{|c|}{ HC emissions } \\
\hline Weed Eater B1 (alternate) & 28.4 & & & \\
\hline Weed Eater B2 (E0 engine) & 47.6 & & & \\
\hline Weed Eater B3 (E15 engine) $^{a}$ & 42.4 & $-22 \%$ & & \\
\hline Weed Eater B4 (alternate) & 36.5 & & & \\
\hline Weed Eater B5 (E10 engine) & 57.8 & $-20 \%$ & 48.1 & $-25 \%$ \\
\hline${ }_{\text {Weed Eater B6 (E20 engine) }}{ }^{b}$ & 49.8 & $-32 \%$ & 43.3 & $-18 \%$ \\
\hline Weed Eater B7 (E15 engine) & 38.4 & $-19 \%$ & & \\
\hline Weed Eater B8 (E20 engine) & 46.6 & & & \\
\hline Numerical average & 43.4 & & 45.7 & \\
\hline \multicolumn{5}{|c|}{$\mathrm{NO}_{\mathrm{X}}$ Emissions } \\
\hline Weed Eater B1 (alternate) & 0.9 & & & \\
\hline Weed Eater B2 (E0 engine) & 0.3 & & & \\
\hline${\text { Weed Eater B3 (E15 engine) }{ }^{a}}$ & 0.2 & $48 \%$ & & \\
\hline Weed Eater B4 (alternate) & 1.3 & & & \\
\hline Weed Eater B5 (E10 engine) & 0.2 & $19 \%$ & 0.3 & $27 \%$ \\
\hline Weed Eater B6 (E20 engine) ${ }^{b}$ & 0.3 & $203 \%$ & 1.1 & $-12 \%$ \\
\hline Weed Eater B7 (E15 engine) & 0.2 & $399 \%$ & & \\
\hline Weed Eater B8 (E20 engine) & 0.3 & & & \\
\hline Numerical average & 0.5 & & 0.7 & \\
\hline \multicolumn{5}{|c|}{$\mathrm{HC}+\mathrm{NO}_{\mathrm{X}}$ Emissions } \\
\hline Weed Eater B1 (alternate) & 29.3 & & & \\
\hline Weed Eater B2 (E0 engine) & 47.9 & & & \\
\hline 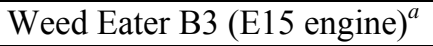 & 42.6 & $-21 \%$ & & \\
\hline Weed Eater B4 (alternate) & 37.8 & & & \\
\hline Weed Eater B5 (E10 engine) & 58.0 & $-19 \%$ & 48.4 & $-25 \%$ \\
\hline Weed Eater B6 (E20 engine) $)^{b}$ & 50.0 & $-31 \%$ & 44.4 & $-18 \%$ \\
\hline Weed Eater B7 (E15 engine) & 38.6 & $-17 \%$ & & \\
\hline Weed Eater B8 (E20 engine) & 46.8 & & & \\
\hline Numerical average & 43.9 & & 46.4 & \\
\hline \multicolumn{5}{|c|}{ CO Emissions } \\
\hline Weed Eater B1 (alternate) & 43 & & & \\
\hline Weed Eater B2 (E0 engine) & 366 & & & \\
\hline 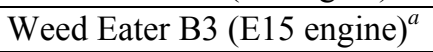 & 355 & $-42 \%$ & & \\
\hline Weed Eater B4 (alternate) & 19 & & & \\
\hline Weed Eater B5 (E10 engine) & 448 & $-32 \%$ & 314 & $-46 \%$ \\
\hline Weed Eater B6 (E20 engine) $)^{b}$ & 353 & $-76 \%$ & 83 & $1 \%$ \\
\hline Weed Eater B7 (E15 engine) & 239 & $-95 \%$ & & \\
\hline Weed Eater B8 (E20 engine) & 369 & & & \\
\hline Numerical average & 274 & & 199 & \\
\hline
\end{tabular}

${ }^{a} \mathrm{~B} 3$ was replacement $\mathrm{E} 15$ engine after failure of $\mathrm{B} 7$.

${ }^{b} \mathrm{~B} 6$ was replacement E20 engine when B8 would not idle on E20. 
Table 3.12. Baseline Stihl line trimmer engine emissions at new and full-useful-life (full-life) condition with EO fuel, and relative change for respective ethanol blends

("Ethanol blend" refers to E10, E15, or E20, as noted.)

\begin{tabular}{|c|c|c|c|c|}
\hline \multirow[b]{2}{*}{ Engine/equipment } & \multicolumn{2}{|c|}{ New } & \multicolumn{2}{|c|}{ Full life } \\
\hline & $\begin{array}{c}\text { New E0 } \\
\text { (g/kW-hr) }\end{array}$ & $\begin{array}{l}\text { Change from } \\
\text { E0 to ethanol } \\
\text { blend }\end{array}$ & $\begin{array}{c}\text { Full-life E0 } \\
\text { (g/kW-hr) }\end{array}$ & $\begin{array}{c}\text { Change from } \\
\text { E0 to ethanol } \\
\text { blend }\end{array}$ \\
\hline \multicolumn{5}{|c|}{ HC emissions } \\
\hline Stihl T1 (E0 engine) & 33.6 & & 76.4 & \\
\hline Stihl T2 (E10 engine) & 29.9 & $-11 \%$ & 65.6 & $-19 \%$ \\
\hline Stihl T3 (E15 engine) & 28.5 & $-29 \%$ & 71.3 & $-17 \%$ \\
\hline Stihl T4 (E20 engine) & 26.3 & $-37 \%$ & 68.8 & $-33 \%$ \\
\hline Numerical average & 29.6 & & 70.5 & \\
\hline \multicolumn{5}{|c|}{$\mathrm{NO}_{\mathrm{X}}$ emissions } \\
\hline Stihl T1 (E0 engine) & 3.3 & & 3.7 & \\
\hline Stihl T2 (E10 engine) & 4.1 & $11 \%$ & 4.8 & $39 \%$ \\
\hline Stihl T3 (E15 engine) & 3.2 & $116 \%$ & 2.5 & $184 \%$ \\
\hline Stihl T4 (E20 engine) & 2.6 & $70 \%$ & 3.0 & $114 \%$ \\
\hline Numerical average & 3.3 & & 3.5 & \\
\hline \multicolumn{5}{|c|}{$\mathrm{HC}+\mathrm{NO}_{\mathrm{X}}$ emissions } \\
\hline Stihl T1 (E0 engine) & 36.9 & & 80.1 & \\
\hline Stihl T2 (E10 engine) & 33.9 & $-9 \%$ & 70.4 & $-15 \%$ \\
\hline Stihl T3 (E15 engine) & 31.7 & $-14 \%$ & 73.7 & $-10 \%$ \\
\hline Stihl T4 (E20 engine) & 28.9 & $-27 \%$ & 71.8 & $-27 \%$ \\
\hline Numerical average & 32.9 & & 74.0 & \\
\hline \multicolumn{5}{|c|}{ CO emissions } \\
\hline Stihl T1 (E0 engine) & 347 & & 591 & \\
\hline Stihl T2 (E10 engine) & 285 & $-7 \%$ & 461 & $-20 \%$ \\
\hline Stihl T3 (E15 engine) & 408 & $-39 \%$ & 712 & $-40 \%$ \\
\hline Stihl T4 (E20 engine) & 335 & $-48 \%$ & 603 & $-40 \%$ \\
\hline Numerical average & 344 & & 592 & \\
\hline
\end{tabular}

Table 3.13. Change in exhaust temperature with ethanol blends for hottest engine condition for six pilot study engines

\begin{tabular}{|c|c|c|c|c|}
\hline \multirow{3}{*}{ Engine/equipment } & \multirow{3}{*}{$\begin{array}{c}\text { Baseline } \\
\text { E0 }\end{array}$} & \multirow{2}{*}{\multicolumn{3}{|c|}{$\begin{array}{c}\text { Maximum exhaust temperature } \\
\text { increase from E0 } \\
\text { Rise in degrees Celsius }\end{array}$}} \\
\hline & & & & \\
\hline & & E10 & E15 & E20 \\
\hline Honda EB3000c generator & 654 & 24 & 33 & 41 \\
\hline 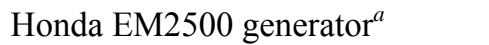 & 667 & 16 & & 31 \\
\hline Briggs and Stratton generator & 689 & 33 & 19 & 42 \\
\hline Kohler generator & 835 & 22 & 42 & 69 \\
\hline Stihl line trimmer & 726 & 42 & 47 & 38 \\
\hline Poulan blower & 542 & 29 & 37 & 54 \\
\hline Numerical average (new engines) & 689 & 30 & 36 & 49 \\
\hline
\end{tabular}

${ }^{a}$ Field-aged Honda generator not tested on E15, not included in numerical average. 


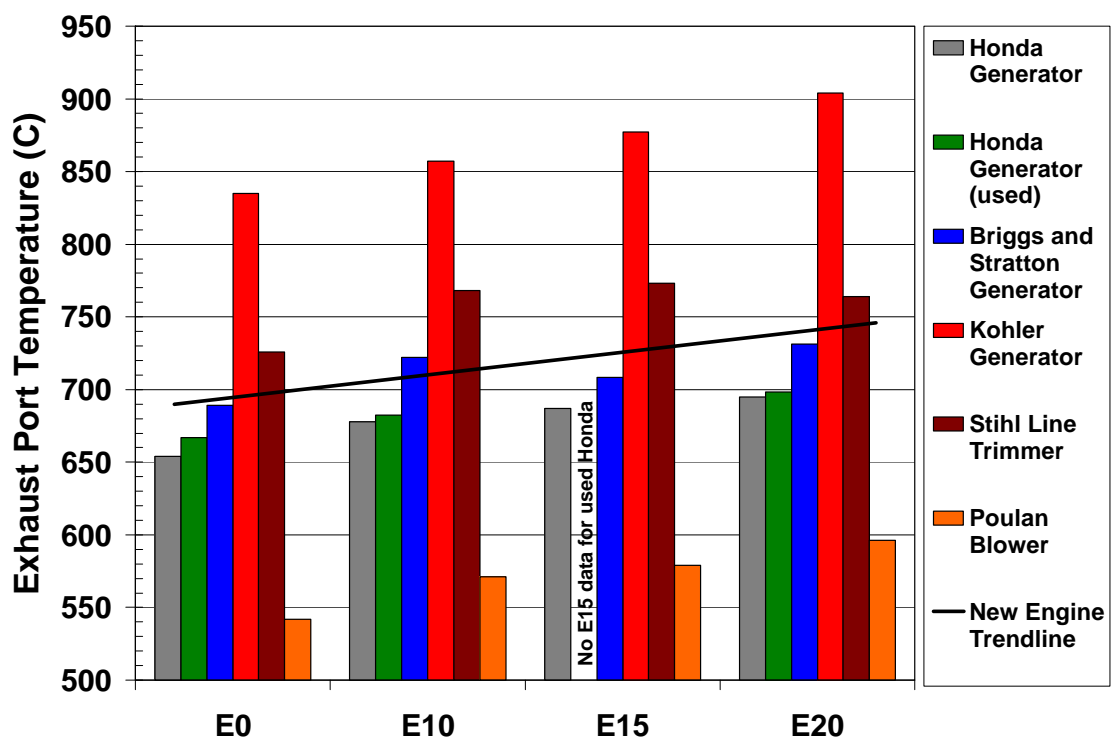

Fig. 3.15. Exhaust port temperature for pilot study engines at hottest condition versus ethanol blend level.

The V-twin Kohler was found to have uneven cylinder-to-cylinder fuel balance, which causes asymmetrical exhaust manifold temperatures. The exhaust manifold temperature results for both cylinders and for all test modes and fuels are shown in Fig. 3.16. To confirm this apparent fueling

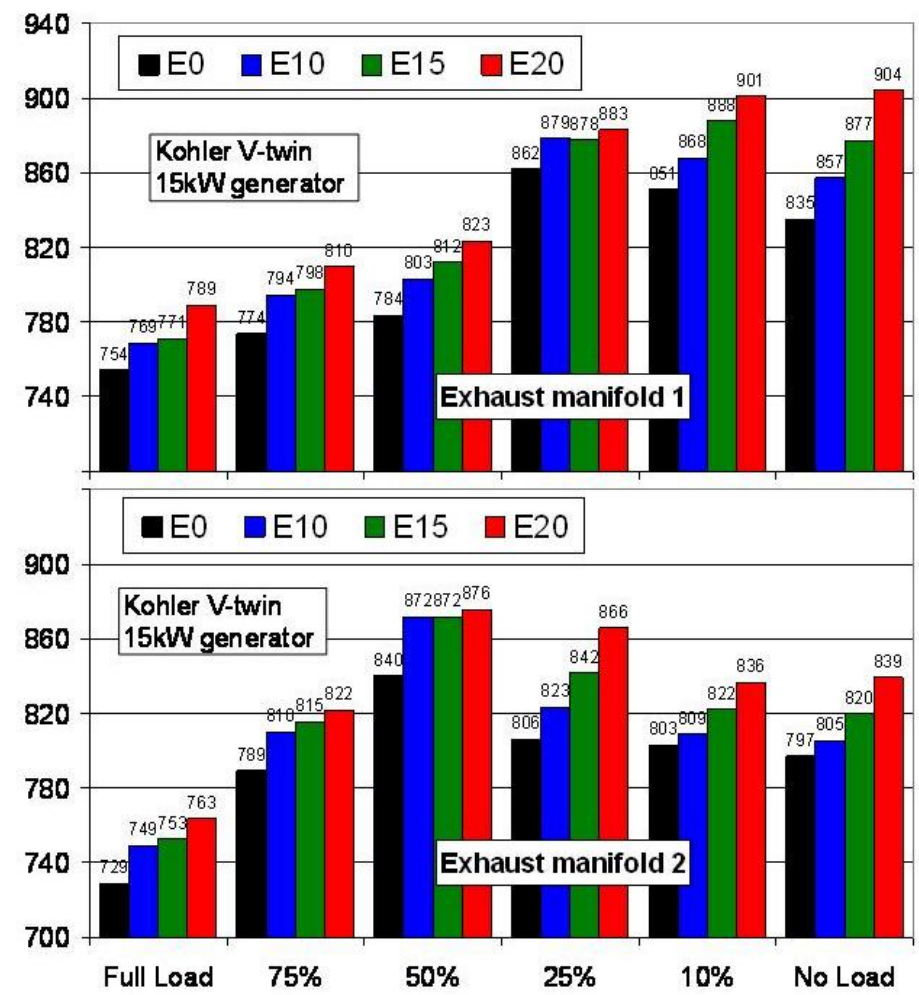

Fig. 3.16. Exhaust temperature versus mode for all fuels and individual cylinders of Kohler generator. Enrichment at higher loads cools both exhaust manifolds, but uneven fuel:air distribution leads to higher no-load temperatures in cylinder 1 from a less-rich condition than cylinder 2. Cylinder 2 is hottest at half load. 
imbalance, the $\mathrm{CO}$ concentration for each cylinder was measured individually at three operating conditions, as shown in Fig. 3.17 (with E0 fuel). The results indicate uneven distribution of fuel between the two cylinders and explain the unusual manifold temperature results shown in Fig. 3.16.

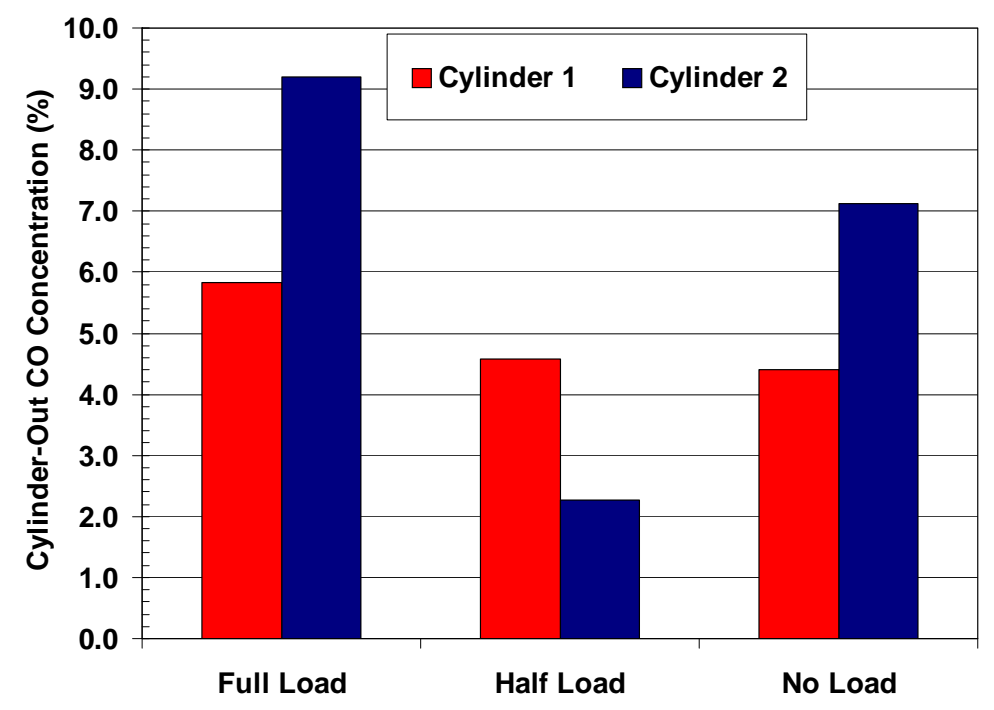

Fig. 3.17. Individual cylinder CO concentration for E0 fueling at three loads for Kohler generator.

The highest temperature in cylinder one (and overall for this engine) occurs at the no-load or fast idle (standby) condition. As electrical loads are applied and the governor opens the throttle to increase air flow and engine power in mode 1 (full load), the carburetor is also decreasing the net fuel:air equivalence ratio (overall richer combustion). Richer combustion can increase engine power and also cool the engine. The uneven cylinder-to-cylinder distribution results in much richer combustion in cylinder 2 at the fast-idle and full-load conditions, but much leaner (less rich) combustion at half load. Cylinder 1 has relatively consistent fueling, with $\mathrm{CO}$ emissions in the $4.5 \%$ to $6 \%$ range from fast idle to full load, while the CO concentration from cylinder 2 was only $2 \%$ at half load with E0 fuel, leading to the highest temperatures for this cylinder at that condition. The potential severity of this problem for 2-cylinder engines is uncertain, as the extent of engine-to-engine variability is unknown at this time.

Carbon monoxide emissions vary widely in cylinder 2 as a function of load while remaining fairly consistent in cylinder 1, indicating a much broader variation of fuel:air distribution in cylinder 2. The less rich cylinder (lower CO emissions) is always hotter (see Fig. 3.16).

\subsubsection{Full-life study temperature results}

As in the ORNL/NREL pilot study, exhaust temperature, oil temperature (where applicable), and several surface temperatures were measured on all small engines tested in the full-life study at TRC. General observations are as follows.

- In most cases, the exhaust temperature increased with higher ethanol content.

- Engine-to-engine differences on E0 fuel were fairly large for the residential engines - in some cases as large as the changes due to introduction of the ethanol blends.

- In general, engines exhibited lower exhaust temperatures on all fuels at full life in comparison to the new condition. 
- The relative change in temperature as ethanol increases appears more distinct at the full-life condition for most engines.

- As with the engines tested at ORNL and NREL, the largest temperature change noted in any of the engines was in the exhaust.

- Full-life testing revealed no engine failures that could be attributed to increased thermal stress on any of the engines.

Table 3.14 shows E0 baseline temperatures for the highest temperature mode and the temperature change observed with the respective ethanol blend run in each engine tested in the full-life study. The highest temperature for the Class I engines was mode 6 , the fast-idle or stand-by condition. The hottest condition for the Class IV engines was mode 1, or the full-power condition. Figures 3.18 and 3.19 display temperature data from the Briggs and Stratton engines and Stihl line trimmers in graphic representation. These figures are repeated in Appendix D along with similar figures showing data from the other two engine types tested at TRC.

Results for the commercial Class I Honda generators demonstrate that the engine-to-engine differences on E0 are not as large as those for the residential power washer engines. The decrease in exhaust temperature for the Honda generator run on E20 was likely due to the erratic operation of this unit at light loads in the new condition. Operators reported the engine speed fluctuating due to unstable governor operation with E20. This problem did not recur during half-life or full-life emissions tests on this engine.

Despite the dearth of full-life data on the Weed Eater Featherlite blowers due to three engine failures, the results still show a general decrease in exhaust temperature with age and maintain the increase in operating temperature with increasing ethanol.

All Stihl engines ran considerably cooler at the full-life condition but still showed a slight increase in exhaust temperature with ethanol addition. During the full-life dynamometer tests, it was noted that all four Stihl engines had lost some $30 \%$ to $35 \%$ of their rated power in mode 1, likely contributing to the increase in brake-specific emissions and lower exhaust temperature. Consultation with Stihl indicated that normal power loss at full life is typically less than $10 \%$ when the maintenance outlined in the owner's manual is closely followed, including valve adjustment and cleaning of the combustion chamber. A final set of E0 tests on these four engines was conducted after recommended cleaning and valve adjustment. Three of the trimmers returned to normal full-life power specification (trimmers 1, 2, and 4, aged on E0, E10, and E20, respectively), exhibiting mode 1 power at $90 \%$ to $95 \%$ of the power rating when new. The E15 unit, trimmer 3, was not able to make normal full-life power, exhibiting a power loss of about $18 \%$. This unit was retested after carburetor and air cleaner swaps and rechecking valve adjustment, but power output did not recover. The engine started and ran normally except for the power loss. Reasons for this engine's power loss are not known at this time. The four units were returned to Stihl for examination. 
Table 3.14. Change in exhaust temperature for engines in full-useful-life (full-life) study for hottest engine condition. Class I engines at fast idle condition (mode 6), Class IV engines at rated power condition (mode 1) [Exhaust port temperature $\left({ }^{\circ} \mathrm{C}\right)$ ]

\begin{tabular}{|c|c|c|c|c|}
\hline \multirow[b]{2}{*}{ Engine/equipment } & \multicolumn{2}{|c|}{ New (mode 6) } & \multicolumn{2}{|c|}{ Full life (mode 6) } \\
\hline & New E0 temp. & $\begin{array}{l}\text { Change from } \\
\text { E0 to ethanol } \\
\text { blend }^{a}\end{array}$ & $\begin{array}{l}\text { Full-life E0 } \\
\text { temp. }\end{array}$ & $\begin{array}{c}\text { Change from } \\
\text { E0 to ethanol } \\
\text { blend }^{a}\end{array}$ \\
\hline \multicolumn{5}{|c|}{ Briggs and Stratton power washers (residential Class I) } \\
\hline Briggs PW1 (E0 engine) & 650 & & 613 & \\
\hline Briggs PW2 (E10 engine) & 654 & 25 & 547 & 12 \\
\hline Briggs PW3 (E15 engine) & 654 & 10 & 607 & 25 \\
\hline Briggs PW4 (E20 engine) & 680 & 0 & 609 & 28 \\
\hline Briggs PW5 (alternate) & 692 & & & \\
\hline Briggs PW6 (alternate) & 540 & & & \\
\hline Numerical average (PW1-4) & 660 & & 594 & \\
\hline \multicolumn{5}{|c|}{ Honda generators (commercial Class I) } \\
\hline Honda G1 (E0 engine) & 742 & & 700 & \\
\hline Honda G2 (E10 engine) & 755 & 0 & 722 & 9 \\
\hline Honda G3 (E15 engine) & 747 & 10 & 715 & 28 \\
\hline Honda G4 (E20 engine) $)^{b}$ & 761 & -35 & 717 & 23 \\
\hline Numerical average & 751 & & 713 & \\
\hline \multicolumn{5}{|c|}{ Weed Eater blowers (residential Class IV) } \\
\hline Engine/equipment & \multicolumn{2}{|c|}{ New (mode 1$)$} & \multicolumn{2}{|c|}{ Full-life (mode 1) } \\
\hline Weed Eater B1 & 574 & & & \\
\hline Weed Eater B2 (E0 engine) & 576 & & & \\
\hline Weed Eater B3 (E15 engine) ${ }^{C}$ & 580 & 14 & & \\
\hline Weed Eater B4 & 577 & & & \\
\hline Weed Eater B5 (E10 engine) & 574 & 6 & 551 & 23 \\
\hline Weed Eater B6 (E20 engine) $^{d}$ & 580 & 21 & 537 & 5 \\
\hline Weed Eater B7 (E15 engine) & 563 & 54 & & \\
\hline Weed Eater B8 (E20 engine) & 558 & & & \\
\hline Numerical average & 573 & & 544 & \\
\hline \multicolumn{5}{|c|}{ Stihl line trimmers (commercial Class IV) } \\
\hline Stihl T1 (E0 engine) & 717 & & 675 & \\
\hline Stihl T2 (E10 engine) & 725 & 8 & 669 & 19 \\
\hline Stihl T3 (E15 engine) & 688 & 50 & 628 & 24 \\
\hline Stihl T4 (E20 engine) & 761 & 28 & 642 & 43 \\
\hline Numerical average & 723 & & 653 & \\
\hline
\end{tabular}

${ }^{\text {a }}$ Ethanol blend denotes E10, E15, or E20.

${ }^{\mathrm{b}}$ Honda G4 experienced unstable speed on governor at light loads with E20 when new.

${ }^{\mathrm{c}}$ Replaced B7 as E15 blower after B7 failure.

${ }^{\mathrm{d}}$ Replaced B8 as E20 blower because B8 would not idle with E20. 


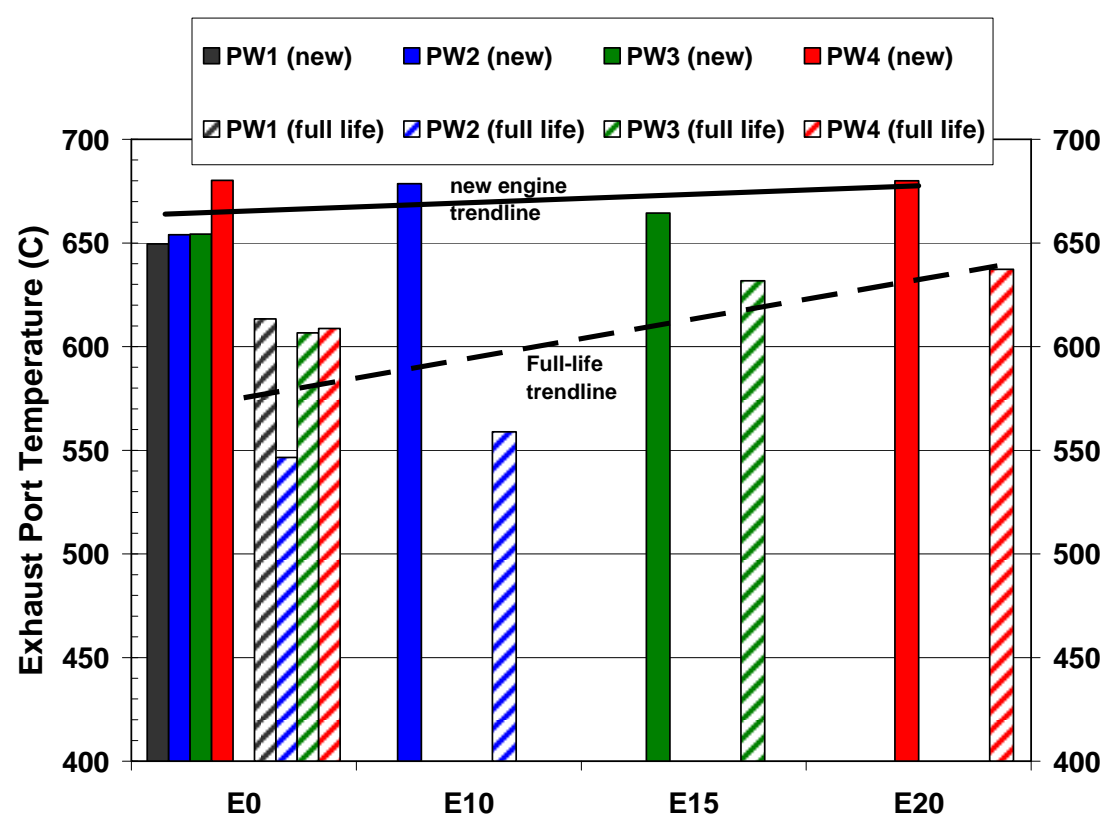

Fig. 3.18. Exhaust port temperature for Briggs and Stratton power washer engines at mode 6 condition versus ethanol blend level. Solid colors represent tests at the new condition while striped bars of the same color represent the same engine at the full-useful-life (full-life) condition. Exhaust temperature increases for all engines with ethanol addition.

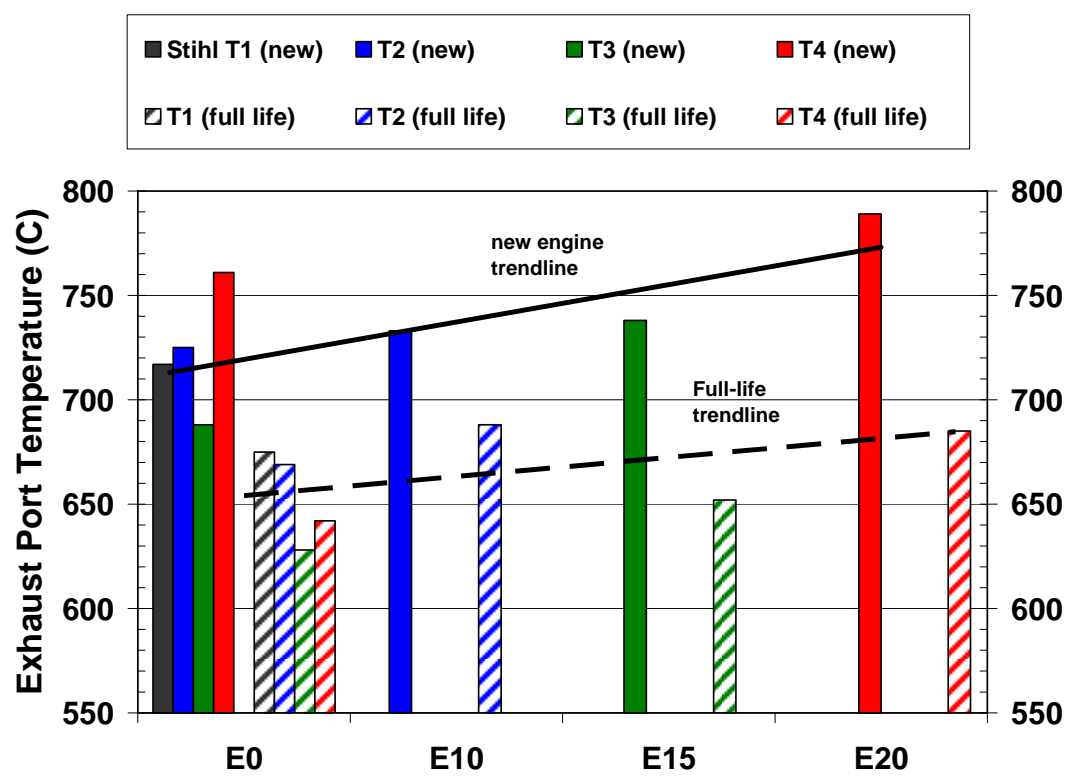

Fig. 3.19. Exhaust port temperature for Class IV Stihl line trimmer engines at hottest condition (mode 1) at new and full-useful-life (full-life) condition. Solid colors represent tests at the new condition while striped bars of the same color represent the same engine at the full-life condition. Full-life temperatures were considerably cooler for all Stihl engines. 


\section{NEXT STEPS}

Given the importance of expanding the nation's use of renewable fuels and the new renewable fuel mandate set forth in the Energy Independence and Security Act of 2007, DOE and others recognize the need to consider a variety of means for bringing such fuels to market. While ethanol is the most widely used renewable fuel in the United States, the E10 market - which takes up the vast majority of ethanol used today - will be saturated in the near future. Given that reality, DOE is working to expand the distribution and use of E85 and to simultaneously investigate the potential of using intermediate ethanol blends (e.g., E15, E20) in conventional vehicles and engines.

This report summarizes findings to date from DOE's first phase of intermediate ethanol blends testing on vehicles and other engines. Recognizing the need for a wide range of additional tests, DOE is sponsoring a number of other studies. Current studies, some of which are being conducted in partnership with other organizations, are summarized below. Additional studies may be conducted as needed, subject to available funding.

\subsection{EMISSIONS AND CATALYST TEMPERATURE}

This report provides results of immediate effects of mid-level ethanol blends on vehicle and small engine emissions and catalyst temperatures.

\subsection{EMISSIONS OF VARIOUS GASOLINES AND ETHANOL BLENDS}

This task, performed in collaboration with EPA and CRC, will assess the impacts of varying Reid vapor pressure (RVP), T50, T90, and aromatic content of gasoline and multiple match-blended ethanol/gasoline fuels on vehicle tailpipe emissions. Data on criteria pollutants $\left[\mathrm{HC}, \mathrm{CO}, \mathrm{NO}_{\mathrm{X}}\right.$, and particulate matter (PM)], ethanol, and carbonyl compounds will be collected. Detailed HC speciation data will be collected for all vehicles tested in this task. Detailed PM and semi-volatile organic compound data will be collected for a subset of the fuels.

\subsection{EVAPORATIVE EMISSIONS}

This study, being conducted in collaboration with CRC (Project E-77), will measure evaporative emissions associated with testing gasoline fuels of varying RVP (volatility) and ethanol blends. Fuels with defined vapor pressures and ethanol content ranging from $0 \%$ to $20 \%$ will be tested on multiple model year vehicles. Static permeation, running loss, hot soak, and diurnal emissions will be measured.

\subsection{FULL-USEFUL-LIFE EMISSIONS}

This task, in collaboration with CRC (Project E-87), will assess the impact of intermediate ethanol blends on tailpipe emissions over the full useful life of vehicles. In Phase I, the study will initially screen 25 vehicles for catalyst performance and key temperatures during open-loop (WOT) operation. Full-life studies on numerous engine families are planned in Phase II. 


\subsection{DRIVEABILITY}

This task, conducted in collaboration with CRC (Project CM-138), evaluated impacts of intermediate blends on the driveability of six late-model non-FFVs and of various E85 fuels in 20 FFVs. The standard driveability test, developed by CRC, was used. Fuels tested in the study include E0, E15, and E20 with prescribed vapor pressures. The final report for this study is available on the CRC web site. ${ }^{*}$ Additional driveability studies may be conducted in the future.

\subsection{FUEL SYSTEM MATERIALS COMPATIBILITY}

This task, conducted in collaboration with CRC (Project AVFL-15), will evaluate the durability of wetted components of fuel systems in non-FFVs when exposed to different ethanol blends. This study will measure effects on all materials found in the fuel system, including plastics, elastomers, Orings, and hose materials.

\subsection{FUTURE REPORTS}

As results from these studies become available, DOE will issue additional reports with analyses as well as core data.

DOE will continue to work closely with EPA, industry partners, and others to ensure that testing is sound and targeted at providing data needed to assess the effects of intermediate ethanol blends on conventional vehicles as well as other engines.

\footnotetext{
* "2008 CRC Cold-Start and Warm-Up E85 and E15/E20 Driveability Program - Final Report," CRC Report No. 652, October 2008.
} 
APPENDICES 



\section{APPENDIX A \\ VEHICLE TEST EQUIPMENT, PROCEDURES, AND RELEVANT VEHICLE EMISSIONS STANDARDS}

The equipment used during this study can be broken down into the following categories.

Measurement equipment

- Emissions

- Exhaust and catalyst temperatures

Test cell equipment

- Transportation Research Center (TRC)

- Oak Ridge National Laboratory (ORNL)

- National Renewable Energy Laboratory (NREL)/ Colorado Department of Public Health and Environment (CDPHE)

\section{A.1 EMISSIONS MEASUREMENT}

All laboratories measured emissions via full-flow dilution per CFR 40 part 86 guidelines. Phase concentrations of $\mathrm{CO}$, oxides of nitrogen $\left(\mathrm{NO}_{\mathrm{X}}\right)$, total hydrocarbons (THC), $\mathrm{CH}_{4}$, and $\mathrm{CO}_{2}$ were measured by conventional analyzers. Modal emissions (second-by-second gas concentrations) at engine-out, tailpipe, and tunnel locations were recorded at ORNL, and modal tunnel data were collected at TRC. All available data from each vehicle's Engine Control Unit (ECU), such as engine revolutions per minute, intake manifold pressure, etc., were collected at ORNL and CDPHE via the Assembly Line Diagnostic Link (ALDL) for subsequent analysis.

All labs sampled aldehydes (including formaldehyde and acetaldehyde) using dilution tunnel sample taps with gas drawn through dinitrophenylhydrazine- (DNPH)-treated silica gel cartridges at a rate of approximately $1 \mathrm{~L} / \mathrm{min}^{*}$. DNPH cartridges were then post-processed by eluting with acetonitrile and analyzing by high-performance liquid chromatography. Aldehyde emissions are important for several reasons. Formaldehyde is a regulated pollutant and acetaldehyde, although not yet regulated by the U.S. Environmental Protection Agency (EPA), is listed by EPA as a hazardous air pollutant. In addition, these oxygenated compounds are reactive in the atmosphere and must be included when calculating non-methane organic gas (NMOG) emissions. The NMOG calculation method is described in Sect. A.3.

Exhaust gas ethanol concentration was measured by all laboratories using the Innova Photoacoustic Multi-gas Analyzer supplied by California Analytical Instruments. This method, developed and documented by Loo and Parker ${ }^{\dagger}$ and now accepted by EPA, was used to batch sample individual phase emissions for ethanol concentration. Because this method includes the coupled effects of other gas species on ethanol measurement, the instrument must be calibrated and configured to measure these interfering species. Consequently, appropriate optical filters must be installed and calibrated to measure interference gases such as water vapor, ammonia, and $\mathrm{CO}_{2}$, and gas sampling and interference corrections must be enabled in the instrument during operation.

Unfortunately, for the data acquired at TRC using two new instruments, these interference measurements were not properly enabled so errors in measurement of ethanol in the exhaust were

\footnotetext{
${ }^{*}$ Siegl, W. O., J. F. O. Richert, T. E. Jensen, D. Schuetzle, S. J. Swarin, J. F. Loo, A. Prostak, D. Nagy, A. M. Schlenker, "Improved Emissions Speciation Methodology for Phase II of the Auto/Oil Air Quality Improvement Research Program-Hydrocarbons and Oxygenates," Society of Automotive Engineers Technical Series 930142 (1993).

†Loo, Jeffrey F., and David T. Parker, "Evaluation of a Photoacoustic Gas Analyzer for Ethanol Vehicle Emissions Measurement," Society of Automotive Engineers, 2000-01-0794 (2000).
} 
experienced. Estimates of ethanol gas concentrations for the six vehicles tested at TRC were based on volume percent ethanol in the gasoline and measured THC emissions. This estimation method was developed using exhaust ethanol data acquired from the NREL dataset at both $50^{\circ}$ and $75^{\circ} \mathrm{F}$. This dataset included 24 points - three vehicles, four fuels, and two temperatures. These data showed strong correlation with a coefficient of determination, $\mathrm{R}^{2}$, of greater than $95 \%$. While not as accurate as direct ethanol measurement, this method is believed to provide a reasonable estimate for the purposes of NMOG calculation. This method was also used to estimate ethanol emissions for the vehicles tested at ORNL. The relatively high dilution ratio used for ORNL testing led to ethanol measurements near the detection limit of the Innova. This problem was exacerbated by apparent "hang up" of the ethanol in the sample system.

Hydrocarbon (HC) speciation was also performed for selected tests at ORNL and for all Phase 1 measurements at NREL/CDPHE. This measurement was accomplished at both laboratories by drawing dilute tunnel gas into an evacuated canister of passivated stainless-steel construction. This sample gas was then analyzed by gas chromatography/mass spectrometry for pollutant quantification and identification. An analysis of this data was not available for this report.

\section{A.1.1 Exhaust and Catalyst Temperature Measurements}

A wide-range universal exhaust gas oxygen sensor (UEGO) was used on each vehicle to record real-time fuel:air equivalence ratio. This information is useful to understand how each test vehicle's fuel control system responded to the oxygenated fuels.

Several key exhaust temperatures were also measured on each vehicle at the following locations.

- Engine-out or precatalyst, measured using 1/8 in. thermocouple located upstream of catalyst core or in exhaust manifold.

- Catalyst core, measured using 1/16 in. or 1/8 in. thermocouple installed directly into catalyst core at 1 in. from leading face.

- Between 1st and 2nd catalysts (for vehicles with dual catalyst configuration), measured using $1 / 8$ in. thermocouple located between catalysts.

- Second catalyst core, measured using $1 / 16$ in. or $1 / 8$ in. thermocouple installed directly into second catalyst core at $1 \mathrm{in}$. from leading face.

- Catalyst outlet, measured using 1/8 in. thermocouple located 6 in. downstream of catalyst outlet.

Each vehicle's exhaust system was removed so that thermocouples, UEGO ports, and exhaust sample ports could be installed. Figure A.1 shows an example exhaust system modified for this program from a 4-cylinder Toyota Camry. Only the exhaust manifold and first catalyst are shown. Similar temperature and sample ports were installed in the second catalyst and outlet pipe.

\section{A.1.2 Vehicle Laboratory at TRC}

The chassis dynamometer used at TRC was an AVL 48-in. (1.22-m), dual-axle 2-wheel drive/4-wheel drive motor/brake unit.

Emissions were measured using Horiba 200 series analyzers.

- $\mathrm{CO}_{2}$ and $\mathrm{CO}$ were measured using non-dispersive infrared (NDIR) instruments.

- $\mathrm{NO}_{\mathrm{X}}$ was measured by a chemiluminescence detector.

- THC was measured using a flame ionization detector (FID).

- $\mathrm{CH}_{4}$ was measured using a gas chromatography analyzer. 


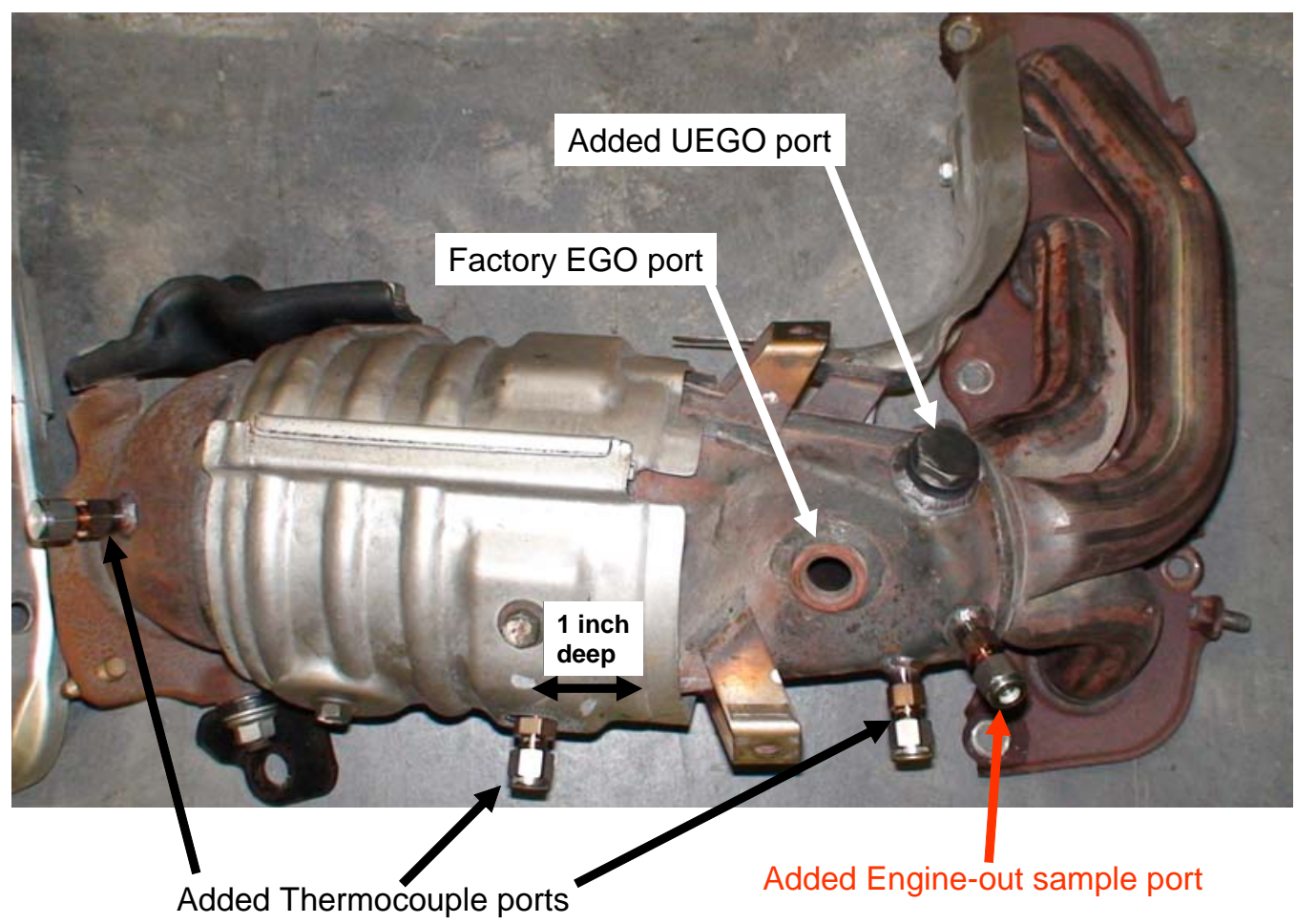

Fig. A.1. Example of vehicle exhaust system instrumentation, including universal exhaust gas oxygen sensor (UEGO) and temperature and exhaust gas sample ports.

\section{A.1.3 Vehicle Laboratory at ORNL}

The chassis dynamometer at ORNL's Fuels, Engines, and Emissions Research Center was of the twin-roll type [21.625 in. in diameter $(0.55 \mathrm{~m})$ ] with an eddy current brake.

Conventional emissions measurements were conducted with analyzers from California Analytical Instruments.

- $\mathrm{CO}_{2}$ and $\mathrm{CO}$ were measured using NDIR

- $\mathrm{NO}_{\mathrm{X}}$ was measured by chemiluminescence detector

- THC and $\mathrm{CH}_{4}$ were measured using a FID with methane cutter.

\section{A.1.4 Vehicle Laboratory at CDPHE}

The chassis dynamometer at CDPHE's Aurora Emissions Technical Center was a Horiba 48-in. (1.22-m) independent-axle, 2-wheel drive motor/brake unit.

Emissions were measured using Horiba series 200 emissions analyzers.

- $\mathrm{CO}_{2}$ and $\mathrm{CO}$ were measured using NDIR

- $\mathrm{NO}_{\mathrm{X}}$ was measured by chemiluminescence detector

- $\quad \mathrm{THC}$ and $\mathrm{CH}_{4}$ were measured using a flame ionization detector with methane cutter.

\section{A.2 TEST PROCEDURES}

The test procedures for each different fuel tested consisted of the following.

- Emissions and fuel economy testing prep cycles

- Vehicle emissions testing 
- Emissions control system temperature testing

- Statistical analysis of emissions and fuel economy data

The following fuel testing sequence was followed for all vehicles.

1. E0 baseline

2. $\mathrm{E} 20$

3. E10

4. E15

5. E0 repeat

Initial E0 testing was conducted to obtain a performance baseline before introduction of ethanol blended fuels. E20 fuel was tested immediately following E0 to precipitate any possible malfunction indicator light (MIL) occurrences due to fuel trim effects or clogged filters resulting from the increased solvency of E20 fuel. Repetition of E0 fueling at the conclusion of emissions testing was to test for any drift in the E0 data over time and to see whether the short-term exposure to intermediate ethanol blends or the wide-open-throttle (WOT) testing might have caused any notable change to the emissions control system function.

\section{A.2.1 Emissions Test Preparatory cycles}

Before the start of testing, each vehicle was inspected to ensure all emission control hardware was intact, and an ECU scan was conducted to confirm no on-board diagnostic (OBDII) faults were present. Each vehicle then underwent an initial crankcase oil, oil filter, and air filter replacement. Engine oil and filters were per the manufacturer's recommendations. Each vehicle was then driven through three US06 drive cycles to stabilize the engine oil by eliminating the higher volatility components that may have an effect on vehicle emissions. Each vehicle's ECU was again scanned before initiation of testing to confirm there were no existing or pending OBDII faults. The following list summarizes the vehicle preparation procedure.

\section{A.2.1.1 Initial acquisition preparation}

1. Check for pending and existing OBDII faults. Consult program technical monitor if any exist.

2. Change oil, oil filter, and air filter using OEM recommended product.

3. Record oil sump level in vehicle log book.

4. Condition new oil by running three consecutive US06 test cycles on market gasoline.

5. Record oil sump level following oil conditioning.

6. Recheck for any existing or pending MIL codes.

\section{A.2.1.2 Baseline emissions and fuel economy check}

Following initial preparation, vehicles at CDPHE and ORNL were tested on the Federal Test Procedure (FTP) and Highway Fuel Economy Test protocols to determine city and highway fuel economy for comparison to published EPA data. Provided these evaluations yielded fuel economy results within $10 \%$ of EPA database values, dynamometer setup and vehicle operation were considered to be acceptable. 


\section{A.2.1.3 Fuel change and adaptation to new fuel}

Following the initial acquisition preparation, each vehicle was fueled with the appropriate test fuel and adapted according to the fuel change protocol described below. This fuel change protocol was performed for every fuel change throughout the test program.

1. Drain tank using in-tank fuel pump.

2. Key on for $30 \mathrm{~s}$.

3. Confirm gauge reading and allow vehicle to register new fueling event.

4. Add half tank of new test fuel.

5. Drive 550 ( $5 \mathrm{~min}$ at $50 \mathrm{mph}$ ), then run double US06 test cycles.

6. Drain tank using in-tank fuel pump.

7. Key on for $30 \mathrm{~s}$.

8. Confirm gauge reading and allow vehicle to register new fueling event.

9. Add half tank of new test fuel.

10. Proceed to vehicle emissions testing.

\section{A.2.1.4 Vehicle emissions testing}

After completion of the test preparation cycles, emissions tests were performed using the LA92 drive cycle. The LA92, also known as the unified cycle, is used for in-use emissions testing in some areas of the country. Acceleration rates and speeds for the LA92 are higher than those of the FTP but lower than those of the US06, and thus it is generally considered to be more typical of real-world driving, even though the FTP and US06 are certification tests and the LA92 is not. The LA92 cycle was chosen for the current test program because it is being used in a joint EPAct/DOE program.

\section{A.2.1.5 LA92 drive cycle}

The LA92 is a three-phase test, much like the FTP, and the FTP weighting factors for each phase were used in the calculation of composite results. The entire 1,736-s drive cycle of the LA92 is shown in Fig. A.2.

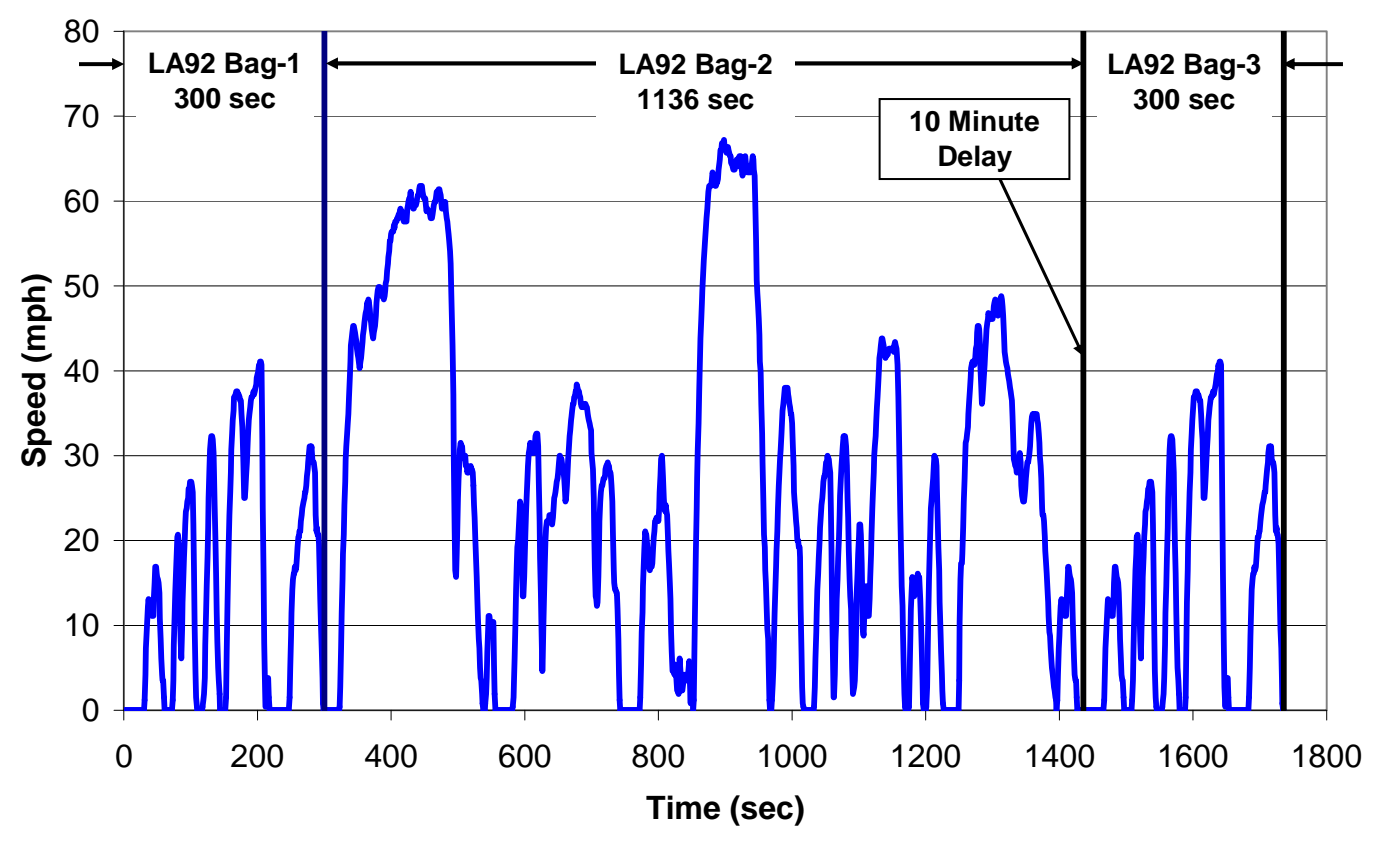

Fig. A.2. LA92 drive cycle. 
Phase 1

The first phase of the LA92 is $300 \mathrm{~s}$, compared with $505 \mathrm{~s}$ for the standard FTP. Consequently, LA92 Phase 1 emissions are more dominated by cold-start transient and tend to be much higher than the FTP on a gram-per-mile basis. The 300-s Phase 1 includes numerous moderate accelerations with a maximum speed of just over $40 \mathrm{mph}$.

Phase 2

Phase 2 is $1,136 \mathrm{~s}$ and includes two moderate-to-heavy accelerations with top speeds just over $60 \mathrm{mph}$.

Phase 3

Phase 3 is a repeat of Phase 1, but with a 10-min engine-off soak after Phase 2. Therefore, Phase 3 contains a hot start instead of a cold start.

\section{A.2.1.6 Vehicle emissions test procedure}

The following protocol was executed after the preparation cycles and before the first emissions test run on each fuel. The second and third emissions tests followed consecutively without a repeat of the entire preparation cycle.

1. Vehicle precondition: Drive $5 \mathrm{~min}$ at $50 \mathrm{mph}$; then, complete LA4 ${ }^{*}$ test cycle followed by LA92 test cycle. Idle vehicle in Park for 2 min following completion of LA92, then key off.

2. Note: Vehicle precondition must be performed following overnight vehicle soak at intended test temperature.

3. Soak vehicle overnight.

4. Execute LA92 emissions test protocol.

5. Idle vehicle in Park for 2 min following each test; then, key off.

6. Push vehicle (with key in off position) from chassis dynamometer to parking/staging area.

7. Subsequent vehicle tests at the same test conditions may be performed with only an LA92 precondition. Previous vehicle tests may be used as preconditions provided test temperatures are equivalent.

8. Check for existing or pending OBDII faults following each LA92 test and record results in vehicle log book.

This protocol was agreed upon following consultation with several technical peers.

At the conclusion of all emissions tests for a given fuel, WOT test protocols were conducted to evaluate each vehicle's control system fuel trim strategy during enrichment (i.e., WOT operation).

\section{A.2.2 Catalyst Temperature Test Procedure}

Exhaust and catalyst temperature testing was subdivided into three categories.

- WOT excursion on level ground

- WOT hill climb

- Closed-loop at high engine load

\section{A.2.2.1 Wide-open-throttle excursion on level ground}

The WOT protocol used predominantly in this test series to evaluate open-loop enrichment effects was based on the EPA mobile source air toxics sulfur purge cycle originally developed under

${ }^{*}$ The LA4 is a 1,372 s cycle that consists of the first two phases of the Federal Test Procedure. 
the CRC E-60 program. The CRC WOT protocol was slightly modified for this program. The original CRC E-60 protocol called for WOT accelerations starting from $30 \mathrm{mph}$, whereas the modified protocol used a standing start WOT acceleration to allow longer time at WOT conditions. Because this longer WOT excursion would likely produce higher dilution tunnel temperatures, a 90-s idle period $(0 \mathrm{mph})$ was added between successive WOTs. This modified protocol is depicted in Fig. A.3.

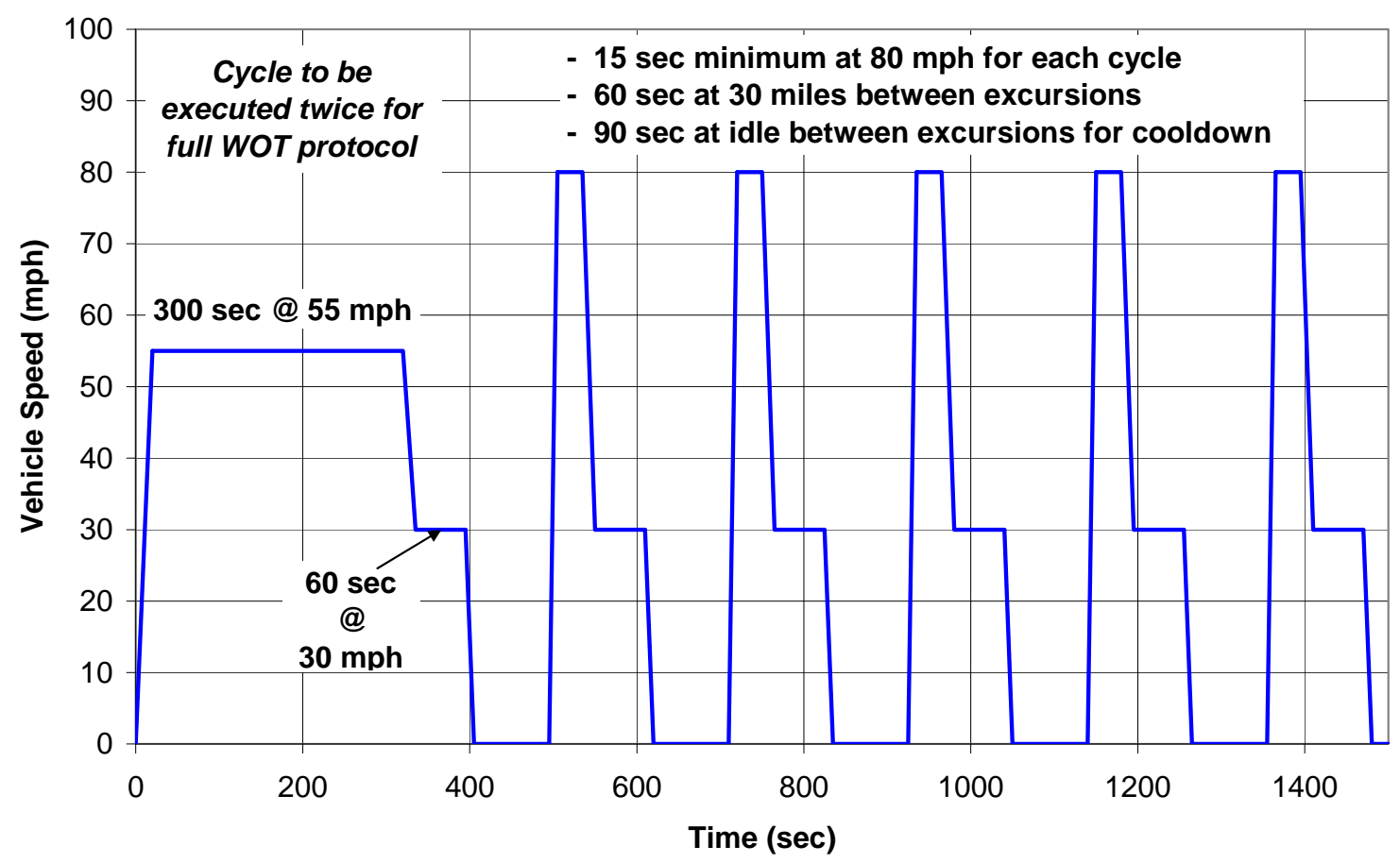

Fig. A.3. Modified Coordinating Research Council E-60 wide-open-throttle drive cycle.

The modified CRC WOT cycle was executed for each vehicle at all three test sites following fuel adaptation and after all LA92 emissions tests on a given fuel were complete. The total procedure consisted of the following.

1. $5 \mathrm{~min}$ at $55-\mathrm{mph}$ constant speed section to stabilize engine and exhaust temperatures.

2. $1 \mathrm{~min}$ at $30 \mathrm{mph}$ and $90 \mathrm{~s}$ at idle.

3. Accelerate vehicle at WOT to a final maximum speed of $80 \mathrm{mph}$.

4. Hold $80 \mathrm{mph}$ maximum speed for a minimum of $15 \mathrm{~s}$.

5. Note: Drive cycle followed included a total of $40 \mathrm{~s}$ for both WOT and 80-mph hold. This approach met the above requirements for all vehicles tested in this program.

6. Decelerate vehicle to $30 \mathrm{mph}$ and hold for $60 \mathrm{~s}$.

7. Decelerate vehicle to $0 \mathrm{mph}$ and hold for $90 \mathrm{~s}$.

8. Repeat steps 3-7 for a total of five WOT excursions to $80 \mathrm{mph}$.

9. Repeat steps $1-8$ one additional time to complete WOT protocol.

All tests were run using EPA's recommended vehicle test weights on simulated level ground. This protocol allowed for sustained WOT operation on the order of 20 to $30 \mathrm{~s}$ at CDPHE and slightly less time at ORNL and TRC due to altitude differences.

\section{A.2.2.2 Wide-open-throttle hill climb}

The second WOT protocol used on selected vehicles in this program was developed to allow for more sustained WOT operation. This expanded protocol included a 7\% grade combined with the 
vehicle's gross combined weight rating (GCWR; i.e., maximum gross vehicle weight plus maximum tow weight). A grade of $7 \%$ was chosen as this represents the most aggressive sustained grade in the U.S. highway system (e.g., Vail pass in Colorado). The maximum gross combined vehicle weight was used as this load represents the worst-case, real-world condition allowable per the vehicle

manufacturer's recommendation. This WOT hill climb protocol was developed to more fully explore selected vehicles' response to extended WOT operation and thereby more extensively determine ethanol effects at extreme operating conditions. Throughout hill climb testing, a single 24-in. Hartzell fan was used for radiator cooling (as was typical for all testing), while two additional Hartzell fans were oriented to circulate air under the vehicle to simulate road air cooling. Such cooling fans most likely circulate less air around the vehicle than a full wind tunnel but were considered sufficient based on exhaust component temperature observations.

The WOT hill climb protocol started with a 5-min/50-mph warm-up cycle similar to the E-60 protocol described previously. After this warm-up, a single WOT excursion was executed. This WOT excursion was intended to last for $5 \mathrm{~min}$, but actual runtime was expected to be limited by vehicle power-to-weight ratio combined with the dynamometer speed limit of $80 \mathrm{mph}$.

\section{A.2.2.3 Closed-loop at high engine load}

Following the hill climb WOT procedure, a constant speed section was included to evaluate ethanol effects just below the engine load point where fuel enrichment occurs for hardware protection. A graphical description of the entire hill climb and edge of hardware protection test cycle is shown in Fig. A.4, including both the WOT and constant speed sections. A sample vehicle speed trace for one of the test vehicles is also included in Fig. A.4.

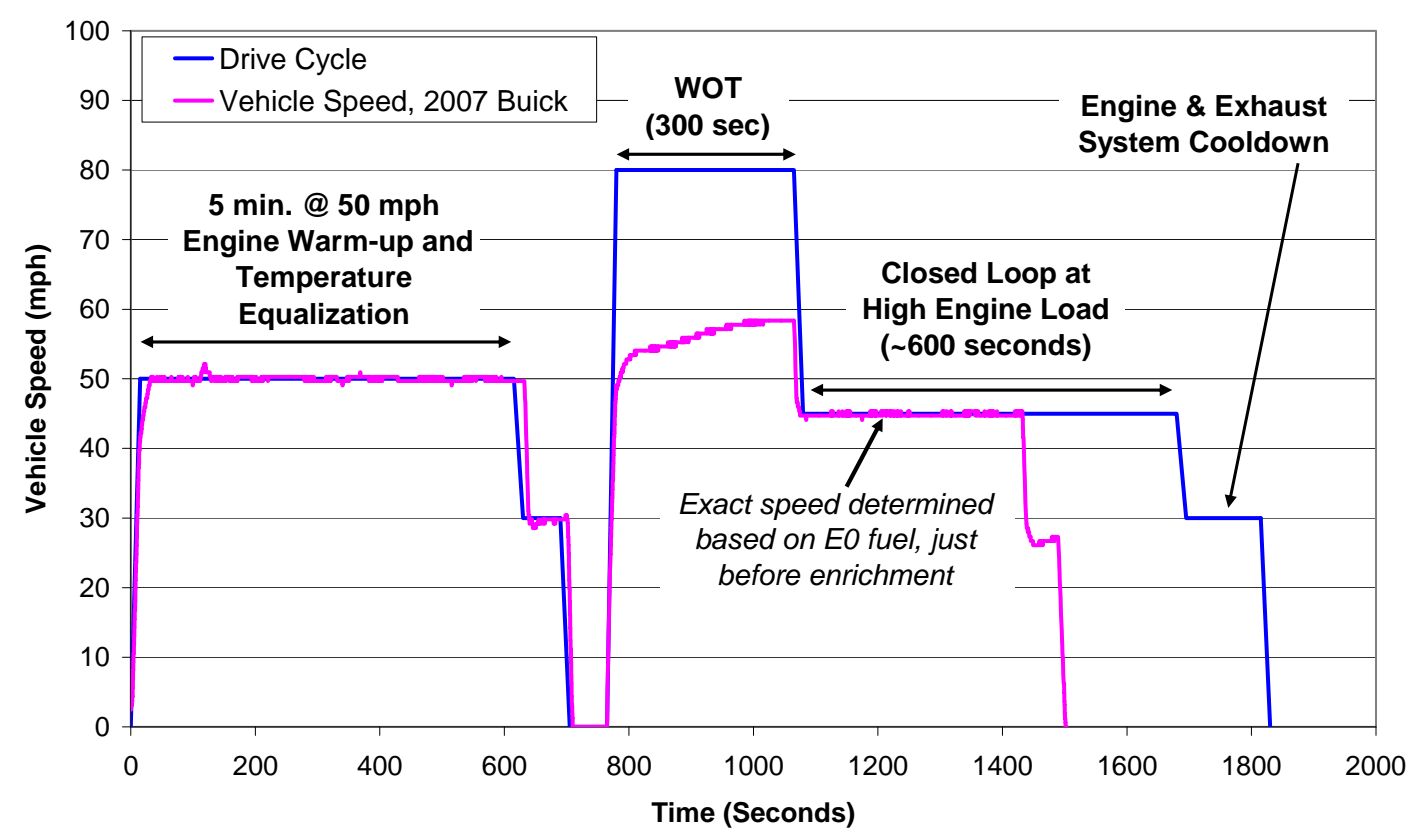

Fig. A.4. Wide-open-throttle (WOT) hill climb and edge of fuel enrichment drive cycle with vehicle speed data from 2007 Buick. 
The actual vehicle speed used during this steady-state phase of the drive cycle was determined for each vehicle tested using E0 fuel and holding the maximum speed achievable before the fuel control went into enrichment. This phase used the same conditions, 7\% grade and maximum gross combined vehicle weight as included in the WOT hill climb. The drive cycle of Fig. A.4 shows a duration for this phase of $10 \mathrm{~min}$; however, actual duration was limited to that needed to achieve a stable catalyst temperature. Vehicles were tested on this protocol using only E0 and E20 fuels.

\section{A.3 NON-METHANE ORGANIC GAS CALCULATION METHOD}

The method described assumes an FID (flame ionization detector) is used for hydrocarbon (HC) measurement. The method could be readily adapted to Fourier transform infrared spectroscopy or another HC measurement method.

\section{A.3.1 Required Data}

\section{Pollutant concentrations}

THC: $\quad$ Total hydrocarbons as indicted by bench FID instrument; value in $\mathrm{ppmC}_{1}$ (parts per million, carbon) concentration [ppmC]

$\mathrm{CH}_{4}$ : $\quad$ Methane measurement from dedicated methane bench FID instrument (or equivalent); value in ppmC concentration $[\mathrm{ppmC}]$

$\mathrm{C}_{2} \mathrm{H}_{5} \mathrm{OH}$ : Ethanol content of exhaust gas, measured either by photoacoustic analyzer or impinger method; value in molar concentration [ppm]

$\mathrm{CH}_{3} \mathrm{CHO}$ : Acetaldehyde measured by high-performance liquid chromatography (HPLC) or similar method; value in molar concentration [ppm]

HCHO: $\quad$ Formaldehyde measured by HPLC or similar method; value in molar concentration [ppm]

\section{$\underline{\text { FID response factors }}$}

FID instrument response is calibrated for HC-only gas - typically propane. Because its response is different for oxygenated hydrocarbons and methane, its output must be corrected to account for the presence of these compounds in the measured exhaust. Measured response factors are determined for each compound known to be present and known to affect FID response. Relevant response factors for the current experiment are identified as follows:

$\mathrm{r}\left(\mathrm{CH}_{4}\right)$ : $\quad$ FID response factor to methane (generally $>1$ ).

$\mathrm{r}\left(\mathrm{C}_{2} \mathrm{H}_{5} \mathrm{OH}\right)$ : FID response factor to ethanol (generally $<1$ ).

$\mathrm{r}\left(\mathrm{CH}_{3} \mathrm{CHO}\right)$ : FID response factor to acetaldehyde (generally $<1$ ).

The response factor for formaldehyde is not included in the above. Per CFR recommendations, this response factor is assumed to be zero.

Response factors should be measured directly on the FID instrument being used for HC measurement. Note that FID response to ethanol may be slow due to ethanol adsorption on walls of supply tubing. This must be taken into account when determining FID response and when determining sample time for THC measurement to be certain an accurate response to ethanol is obtained.

\section{A.3.2 FID Correction}

First the FID measurement must be corrected for the presence of methane and (known) oxygenated hydrocarbons in the exhaust gas. This correction is typically done on a ppmC basis as follows. 
Calculated NONMHC (non-oxygenated non-methane hydrocarbon)

$$
\begin{aligned}
\text { NONMHC }=\text { THCconc }- & {[\mathrm{r}(\mathrm{CH} 4) * \mathrm{CH} 4 \text { conc }]-[\mathrm{r}(\mathrm{C} 2 \mathrm{H} 5 \mathrm{OH}) * 2 * \mathrm{C} 2 \mathrm{H} 5 \mathrm{OH} \text { conc }] } \\
- & {\left[\mathrm{r}\left(\mathrm{CH}_{3} \mathrm{CHO}\right) * 2 * \mathrm{CH}_{3} \mathrm{CHO}_{\text {conc }}\right] . }
\end{aligned}
$$

The above pollutant concentrations must be in ppmC units, hence, the factor 2 for ethanol and acetaldehyde. Ethanol or acetaldehyde concentrations in the above equation should be in parts per million on a volume (molar) basis. If impingers or DNPH cartridges were used and initial results are on a mass basis, they must be converted back to a parts-per-million basis for the above calculation.

\section{A.3.3 Non-Methane Organic Gas (NMOG) Calculation}

Oxygenated hydrocarbons are then added back to the NONMHC value to yield NMOG emissions. This calculation is done on a gram basis by multiplying each pollutant concentration by its respective density. Pollutant values are then summed, multiplied by the total volume of the sampled exhaust ( $\mathrm{V}_{\mathrm{MIX}}$ ), and normalized by the miles driven.

$$
\begin{aligned}
\mathrm{NMOG} & =\left\{\left[\mathrm{NONMHC}_{\text {conc }} * \mathrm{NONMHC}_{\text {dens }}\right]+\left[\mathrm{C}_{2} \mathrm{H}_{5} \mathrm{OH}_{\text {conc }} * \mathrm{C}_{2} \mathrm{H}_{5} \mathrm{OH}_{\text {dens }}\right]\right. \\
& \left.+\left[\mathrm{CH} 3 \mathrm{CHO}_{\text {conc }} * \mathrm{CH} 3 \mathrm{CHO}_{\text {dens }}\right]+\left[\mathrm{HCHO}_{\text {conc }} * \mathrm{HCHO}_{\text {dens }}\right]\right\} \\
& * 1 \mathrm{e}-6 * \mathrm{~V}_{\mathrm{MIX}} / \text { miles. }
\end{aligned}
$$

This calculation gives NMOG on a gram/mile basis. Pollutant concentrations are in parts per million. Again, if the initial results are on a mass-per-volume basis (as is often the case for acetaldehyde and formaldehyde), the calculation will have to be modified to obtain the appropriate units.

Density used for NONMHC is that typically assumed for HC-only exhaust, as recommended in the CFR. Assuming $\mathrm{V}_{\mathrm{MIX}}$ is measured in cubic feet, the following values for pollutant densities can be calculated. Per CFR, calculations are based on standard temperature and pressure of $20^{\circ} \mathrm{C}\left(68^{\circ} \mathrm{F}\right)$ and $1 \mathrm{~atm}$.

NONMHC: $16.33 \mathrm{~g} / \mathrm{ft}^{3}(13.88 \mathrm{~g} / \mathrm{mole})$

$\mathrm{C}_{2} \mathrm{H}_{5} \mathrm{OH}: \quad 54.23 \mathrm{~g} / \mathrm{ft}^{3}(46.07 \mathrm{~g} / \mathrm{mole})$

$\mathrm{CH}_{3} \mathrm{CHO}: \quad 51.85 \mathrm{~g} / \mathrm{ft}^{3}(44.05 \mathrm{~g} / \mathrm{mole})$

HCHO: $\quad 35.34 \mathrm{~g} / \mathrm{ft}^{3}(30.03 \mathrm{~g} / \mathrm{mole})$

$\mathrm{CH}_{4}: \quad 18.88 \mathrm{~g} / \mathrm{ft}^{3}(16.04 \mathrm{~g} / \mathrm{mole})$

\section{A.4 RELEVANT VEHICLE EMISSIONS STANDARDS}

Emissions from vehicles have been regulated by EPA and the California Air Resources Board since the early 1970s. Tier 0 refers to standards that were phased-in during the 1970 s as a result of the 1970 Clean Air Act. These standards were amended in the late 1970s and first met in 1981. Tier 0 standards were in force until 1994. Tier 1 standards were phased-in from 1994 through 1996. Table A.1 shows the Tier 0, Tier 1, and Low Emission Vehicle (LEV) program emissions standards. Table A.2 gives the footnotes (i.e., numbers in brackets [x]) for Table A.1, and Table A.3 defines the acronyms used in Tables A.1, A.4, and A.5.

Phase-in of Tier 2 standards began in 2004, although some manufacturers had the option of early compliance under the NLEV program. Full useful life for Tier 2 vehicles is 100,000 miles, 120,000 miles, or 150,000 miles, depending on a number of factors. The rule is described in detail in 
the Federal Register/Vol. 65, No. 28. Tier 2 full-useful-life standards are shown in Table A.4, and Tier 2 50,000 mile standards are shown in Table A.5. It is important to note that these standards are for vehicles driven on the FTP. As such, standards are provided for reference only, vehicles tested on the LA92 cycle are not necessarily required to meet these standards.

\section{Table A.1. Federal certification exhaust emission standards for light-duty vehicles and light-duty trucks}

[All emissions in grams/mile on Federal Test Procedure (source: www.epa.gov/otaq/standards.htm)]

\begin{tabular}{|c|c|c|c|c|c|c|c|c|c|c|c|c|c|c|c|c|}
\hline & \multirow{3}{*}{$\begin{array}{c}\text { Vehicle } \\
\text { Type }\end{array}$} & \multirow{3}{*}{$\begin{array}{l}\text { Emission } \\
\text { Category }\end{array}$} & \multicolumn{14}{|c|}{ Vehicle Useful Life } \\
\hline & & & \multicolumn{7}{|c|}{5 Years / 50,000 Miles } & \multicolumn{7}{|c|}{10 Years / 100,000 Miles } \\
\hline & & & $\mathrm{THC}^{[2,5,39]}$ & $\mathrm{NMHC}^{[3]}$ & NMOG & $\mathrm{CO}^{[35,39]}$ & $\mathrm{NOx}$ & $\mathrm{PM}^{[2 \mid]}$ & $\mathrm{HCHO}$ & $\mathrm{THC}^{[2.5]}$ & $\mathrm{NMHC}^{[3]}$ & NMOG & $\mathrm{CO}^{[38]}$ & NOx & $\mathrm{PM}^{[23]}$ & $\mathrm{HCHO}$ \\
\hline \multirow[t]{6}{*}{ Federal } & \multirow{2}{*}{\begin{tabular}{|l} 
LDV \\
$|37,40,43|$ \\
\end{tabular}} & Tier 0 & 0.41 & $\begin{array}{ll}{[6]} & 0.34 \\
\end{array}$ & - & 3.4 & 1.0 & (1) 0.20 & - & & & & & & & \\
\hline & & Tier 1 & ${ }^{[28]} 0.41$ & 0.25 & - & 3.4 & ${ }^{[7]} 0.4$ & 0.08 & - & - & 0.31 & - & 4.2 & 0.6 & 0.10 & $=$ \\
\hline & \multirow{2}{*}{\begin{tabular}{|l} 
LDT1 \\
{$[37,40,43]$}
\end{tabular}} & Tier $0^{[26]}$ & & & & & & & & 0.80 & ${ }^{[6]} 0.67$ & - & 10 & 1.2 & ${ }^{[4]} 0.26$ & - \\
\hline & & Tier 1 & - & 0.25 & - & 3.4 & 0.4 & 0.08 & - & {$[26,28] \quad 0.80$} & 0.31 & - & 4.2 & ${ }^{[0]} 0.6$ & 0.10 & - \\
\hline & \multirow{2}{*}{$\begin{array}{l}\text { LDT2 } \\
{[37,40,43]}\end{array}$} & Tier $0^{[26]}$ & & & & & & & & 0.80 & ${ }^{[6]} 0.67$ & - & 10 & 1.7 & ${ }^{[4]} 0.13$ & - \\
\hline & & Tier 1 & - & 0.32 & - & 4.4 & ${ }^{[8]} 0.7$ & 0.08 & - & {$[26.28] \quad 0.80$} & 0.40 & - & 5.5 & 0.97 & 0.10 & - \\
\hline \multirow{12}{*}{$\begin{array}{l}\text { Federal } \\
\text { National } \\
\text { Low } \\
\text { Emission } \\
\text { Vehicle } \\
\text { (NLEV) } \\
\text { Program }\end{array}$} & \multirow{4}{*}{$\begin{array}{l}\text { LDV } \\
{[36,40,41]}\end{array}$} & TLEV & [28] 0.41 & - & ${ }^{[1,31]} 0.125$ & 3.4 & [34] 0.4 & 0.08 & 0.015 & - & - & ${ }^{(1,31)} 0.156$ & 4.2 & [34] 0.6 & (32) 0.08 & 0.018 \\
\hline & & $\mathrm{LEV}^{[42]}$ & ${ }^{[28]} 0.41$ & $=$ & ${ }^{[1.31]} 0.075$ & 3.4 & ${ }^{[34]} 0.2$ & 0.08 & 0.015 & - & - & ${ }^{[1.31]} 0.090$ & 4.2 & ${ }^{[34]} 0.3$ & {$\left[\begin{array}{ll}{[32]} & 0.08 \\
\end{array}\right.$} & 0.018 \\
\hline & & ULEV $^{[42]}$ & ${ }^{[28]} 0.41$ & - & ${ }^{[1,31]} 0.040$ & 1.7 & ${ }^{[34]} 0.2$ & 0.08 & 0.008 & - & - & ${ }^{[1,31]} 0.055$ & 2.1 & ${ }^{[34]} 0.3$ & ${ }^{[32]} \quad 0.04$ & 0.011 \\
\hline & & ZEV & 0.00 & 0.00 & \begin{tabular}{|l|}
0.000 \\
\end{tabular} & 0.0 & [34] 0.0 & 0.00 & 0.000 & 0.00 & 0.000 & \begin{tabular}{|l|}
0.000 \\
\end{tabular} & 0.0 & [34] 0.0 & 0.00 & 0.000 \\
\hline & \multirow{4}{*}{$\begin{array}{l}\text { LDT1 } \\
{[36,40,41]}\end{array}$} & TLEV & - & - & ${ }^{[1,31]} 0.125$ & 3.4 & ${ }^{[34]} 0.4$ & 0.08 & 0.015 & {$[26,28] \quad 0.80$} & - & ${ }^{[1,3]]} 0.156$ & 4.2 & [34] 0.6 & 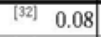 & 0.018 \\
\hline & & LEV $^{[42]}$ & - & - & ${ }^{[1,31]} 0.075$ & 3.4 & ${ }^{[34]} 0.2$ & 0.08 & 0.015 & ${ }^{[26,28]} 0.80$ & - & ${ }^{[1,31]} 0.090$ & 4.2 & [34] 0.3 & [32] 0.08 & 0.018 \\
\hline & & ULEV $^{[42]}$ & - & - & ${ }^{(1,31]} 0.040$ & 1.7 & ${ }^{[34]} 0.2$ & 0.08 & 0.008 & $\begin{array}{ll}26,28] & 0.80 \\
\end{array}$ & & ${ }^{[1,31]} 0.055$ & 2.1 & ${ }^{[36]} 0.3$ & $\begin{array}{ll}{ }^{[32]} & 0.04 \\
\end{array}$ & 0.011 \\
\hline & & ZEV & 0.00 & 0.00 & 0.000 & 0.0 & ${ }^{[34]} 0.0$ & 0.00 & 0.000 & 0.00 & 0.000 & 0.000 & 0.0 & ${ }^{[34]} 0.0$ & 0.00 & 0.000 \\
\hline & \multirow{4}{*}{$\begin{array}{l}\text { LDT2 } \\
{[36,40,41]}\end{array}$} & TLEV & - & - & ${ }^{[1,31]} 0.160$ & 4.4 & ${ }^{[34]} 0.7$ & 0.08 & 0.018 & {$[26.28] \quad 0.80$} & - & ${ }^{[1,31]} 0.200$ & 5.5 & ${ }^{[34]} 0.9$ & \begin{tabular}{ll|}
{$[32]$} & 0.10 \\
\end{tabular} & 0.023 \\
\hline & & $\mathrm{LEV}^{[42]}$ & - & - & ${ }^{[1,31]} 0.100$ & 4.4 & ${ }^{[34]} 0.4$ & 0.08 & 0.018 & ${ }^{[26,28]} 0.80$ & - & ${ }^{[1.31]} 0.130$ & 5.5 & ${ }^{[34]} 0.5$ & {$[32] \quad 0.10$} & 0.023 \\
\hline & & ULEV $^{[42]}$ & - & - & ${ }^{[1,31]} 0.050$ & 2.2 & {$\left[\begin{array}{ll}{[34]} & 0.4\end{array}\right.$} & 0.08 & 0.009 & {$[26,28] \quad 0.80$} & - & ${ }^{[1,31]} 0.070$ & 2.8 & [34] 0.5 & [32] 0.05 & 0.013 \\
\hline & & ZEV & 0.00 & 0.00 & 0.000 & 0.0 & [34] 0.0 & 0.00 & 0.000 & 0.00 & 0.000 & 0.000 & 0.0 & [3]] 0.0 & 0.00 & 0.000 \\
\hline \multirow{12}{*}{$\begin{array}{l}\text { Federal } \\
\text { Clean } \\
\text { Fueled } \\
\text { Vehicle } \\
\text { (CFV) } \\
\text { Program }\end{array}$} & \multirow{4}{*}{$\begin{array}{l}\text { LDV } \\
{[37,40,41]}\end{array}$} & LEV & 0.41 & - & [50] 0.075 & 3.4 & [34] 0.2 & - & 0.015 & - & - & 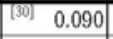 & 4.2 & [34] 0.3 & (II) 0.08 & 0.018 \\
\hline & & ILEV $^{[33]}$ & ${ }^{[28]} 0.41$ & - & 0.075 & 3.4 & ${ }^{[34]} 0.2$ & - & 0.015 & - & - & 0.090 & 4.2 & ${ }^{[34]} 0.3$ & [10] 0.08 & 0.018 \\
\hline & & ULEV & ${ }^{[28]} 0.41$ & - & ${ }^{[30]} 0.040$ & 1.7 & ${ }^{[34]} 0.2$ & - & 0.008 & - & - & [30] 0.055 & 2.1 & [36] 0.3 & $\begin{array}{ll}10] & 0.04 \\
\end{array}$ & 0.011 \\
\hline & & ZEV & 0.00 & 0.00 & \begin{tabular}{|r|}
0.000 \\
\end{tabular} & 0.0 & ${ }^{[34]} 0.0$ & 0.00 & 0.000 & 0.00 & 0.000 & 0.000 & 0.0 & [34] 0.0 & 0.00 & 0.000 \\
\hline & \multirow{4}{*}{\begin{tabular}{|l} 
LDT1 \\
{$[37,40,41]$}
\end{tabular}} & LEV & - & - & 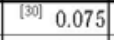 & 3.4 & ${ }^{[34]} 0.2$ & - & 0.015 & {$[26.28] 0.80$} & - & 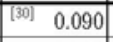 & 4.2 & ${ }^{[34]} 0.3$ & $\begin{array}{ll}{[10]} & 0.08 \\
\end{array}$ & 0.018 \\
\hline & & ILEV $^{[33]}$ & - & - & 0.075 & 3.4 & $\begin{array}{lll}{[34]} & 0.2\end{array}$ & - & 0.015 & ${ }^{[26,28]} 0.80$ & - & 0.090 & 4.2 & ${ }^{[34]} 0.3$ & $\begin{array}{ll}{[10]} & 0.08 \\
\end{array}$ & 0.018 \\
\hline & & ULEV & - & - & ${ }^{[30]} 0.040$ & 1.7 & ${ }^{[34]} 0.2$ & - & 0.008 & ${ }^{[26,28]} 0.80$ & & ${ }^{[30]} 0.055$ & 2.1 & [34] 0.3 & [10] 0.04 & 0.011 \\
\hline & & ZEV & 0.00 & 0.00 & 0.000 & 0.0 & ${ }^{[34]} 0.0$ & 0.00 & 0.000 & 0.00 & 0.000 & \begin{tabular}{|l|}
0.000 \\
\end{tabular} & 0.0 & [3] 0.0 & 0.00 & 0.000 \\
\hline & \multirow{4}{*}{\begin{tabular}{|l} 
LDT2 \\
{$[37,40,41]$}
\end{tabular}} & LEV & - & - & 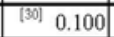 & 4.4 & \begin{tabular}{ll|}
{$[34]$} & 0.4 \\
\end{tabular} & - & 0.018 & {$[26,28] 0.80$} & - & \begin{tabular}{|l|l|}
{$[30]$} & 0.130 \\
\end{tabular} & 5.5 & [34] 0.5 & $\begin{array}{ll}{[10]} & 0.08\end{array}$ & 0.023 \\
\hline & & ILEV $^{[33]}$ & - & - & 0.100 & 4.4 & ${ }^{[34]} 0.4$ & - & 0.018 & ${ }^{[26,28]} 0.80$ & - & 0.130 & 5.5 & ${ }^{[34]} 0.5$ & {$[10] \quad 0.08$} & 0.023 \\
\hline & & ULEV & - & - & ${ }^{[30]} 0.050$ & 2.2 & ${ }^{[34]} 0.4$ & - & 0.009 & ${ }^{[26,28]} 0.80$ & - & [30] 0.070 & 2.8 & ${ }^{[34]} 0.5$ & {$[10] \quad 0.04$} & 0.013 \\
\hline & & ZEV & 0.00 & 0.00 & 0.000 & 0.0 & ${ }^{[34]} 0.0$ & 0.00 & 0.000 & 0.00 & 0.000 & 0.000 & 0.0 & ${ }^{[34]} 0.0$ & 0.00 & 0.000 \\
\hline
\end{tabular}


Table A.2. Footnotes used in Table A.1

(Source: www.epa.gov/otaq/standards.htm)

Footnotes to the tables of emission standards

1. NMHC FOR DIESEL CYCLE VEHICLES

2. THCE FOR METHANOL VEHICLES

3. THCE FOR TIER 0 METHANOL VEHICLES, NMHCE FOR OTHER ALCOHOL VEHICLES

4. APPLIES TO DIESEL VEHICLES ONLY

5. DOES NOT APPLY TO CNG VEHICLES

6. CNG VEHICLES ONLY

7. 1.0 FOR DIESEL-FUELED VEHICLES THROUGH 2003 MODEL YEAR

8. DOES NOT APPLY TO DIESEL-FUELED VEHICLES

9. 1.25 FOR DIESEL-FUELED VEHICLES THROUGH 2003 MODEL YEAR

10. DIESEL-FUELED VEHICLES ONLY

11. METHANOL AND ETHANOL VEHICLES ONLY

12. GASOLINE VEHICLES ONLY

13. 0.7 THROUGH MODEL YEAR 1997

14. 1.0 THROUGH MODEL YEAR 1997

15. 1.1 THROUGH MODEL YEAR 1997

16. 1.5 THROUGH MODEL YEAR 1997

17. 1.3 THROUGH MODEL YEAR 1997

18. 1.8 THROUGH MODEL YEAR 1997

19. 2.0 THROUGH MODEL YEAR 1997

20. 2.8 THROUGH MODEL YEAR 1997

21. 1.48 FOR DIESEL-FUELED VEHICLES

22. 2.07 FOR DIESEL-FUELED VEHICLES

23. OTHER EQUIVALENT SCHEDULES ALLOWED.

24. PC/LDV MAY BE COMBINED WITH LDT1 \& LDT2 FOR TIER 1 PHASE-IN

25. PC/LDV \& LDT1 COMBINED WITH LDT2 FOR SFTP PHASE-IN

26. STANDARDS APPLY AT A USEFUL LIFE OF 11 YEARS / 120,000 MILES

27. GASOLINE AND DIESEL VEHICLES ONLY

28. TOTAL HC COMPLIANCE STATEMENT ALLOWED (IN LIEU OF TEST DATA)

29. PARTICULATES COMPLIANCE STATEMENT ALLOWED FOR NON-DIESEL CYCLE VEHICLES (IN LIEU OF SUPPLYING ACTUAL TEST DATA)

30. SPECIAL NMOG STANDARDS APPLY TO DUAL \& FLEXIBLE FUEL VEHICLES, SEE 40 CFR $88.104-94$ (h) \& (1)

31. DUAL \& FLEXIBLE FUEL VEHICLES MAY MEET NEXT HIGHER (LESS STRINGENT) NMOG STANDARD WHEN OPERATING ON GASOLINE.

32. $0.10 \mathrm{GM} /$ MILE PARTICULATE STANDARD APPLIES TO NON-DIESEL VEHICLES

33. SPECIAL EVAPORATIVE REQUIREMENTS APPLY (5.0 GRAMS MAX WITH THE EVAPORATIVE SYSTEM DISCONNECTED)

34. HIGHWAY NOx EMISSIONS SHALL NOT EXCEED 1.33 TIMES THE APPLICABLE FTP (CITY) NOx STANDARDS

35. COLD CO EMISSIONS FOR GASOLINE FUELED VEHICLES SHALL NOT EXCEED 10.0 GR/MI (LDV, LDT1, LDT2) OR 12.5 GM/MI (LDT3 \& LDT4) AT 50K MILES

36. CALIFORNIA OBD-II SYSTEM REQUIRED, REF 40 CFR 86.1717-99

37. FEDERAL OBD SYSTEM REQUIRED BEGINNING WITH 1994 MODEL YEAR VEHICLES, REF 40 CFR 86.1806-01

38. IDLE CO EMISSIONS FROM GASOLINE, METHANOL, CNG \& LPG TRUCKS SHALL NOT EXCEED 0.50 PERCENT EXHAUST GAS AT 120K MILES/11 YEARS COMPLIANCE STATEMENT ALLOWED (IN LIEU OF ACTUAL TEST DATA)

39. CERTIFICATION SHORT TEST (CST) EMISSIONS FROM GASOLINE VEHICLES SHALL NOT EXCEED 100 PPM HC OR 0.50 PERCENT EXHAUST GAS CO AT IDLE AND 2500 RPM AT 4K MILES: COMPLIANCE STATEMENT ALLOWED (IN LIEU OF DATA)

40. TIER 1, NLEV \& CFV VEHICLES MUST MEET TIER 1 EMISSION STANDARDS AT HIGH ALTITUDE: TIER 0 VEHICLES MUST MEET SPECIAL HIGH ALTITUDE STANDARDS: COMPLIANCE STATEMENT ALLOWED (IN LIEU OF ACTUAL TEST DATA)

41. NLEV AND CFV (LDV, LDT1, LDT2) VEHICLES MUST MEET SPECIAL 50 DEG F EMISSION STANDARDS AT 4K MILES (NOT APPLICABLE TO DIESEL, CNG, OR HYBRID ELECTRIC VEHICLES): REF. 40 CFR 86.1708 \& 1709-99 (b) (1) (iv)

42. SPECIAL INTERIM IN-USE EMISSION STANDARDS APPLY TO 1999 LEV AND 1999 TO 2002 ULEV VEHICLES; REF. 40 CFR 86.1808 \& 1809-99(C) AS CORRECTED IN EPA GUIDANCE LETTER VPCD-98-03, APRIL 8, 1998.

43. TIER 0 AND TIER 1 EMISSION STANDARDS DO NOT APPLY TO ETHANOL VEHICLES 
Table A.3. Acronyms used in Tables A.1, A.4, and A.5

\begin{tabular}{|c|c|}
\hline Acronym & Definition \\
\hline ALVW & adjusted loaded vehicle weight ([VCW+GWVR]/2) \\
\hline CFV & Clean Fueled Vehicle (Program) \\
\hline $\mathrm{CO}$ & carbon monoxide \\
\hline GVWR & gross vehicle weight rating \\
\hline $\mathrm{HCHO}$ & Formaldehyde \\
\hline HLDT & heavy light-duty truck \\
\hline ILEV & inherently low-emission vehicle \\
\hline LDT1 & light-duty truck $1(\mathrm{GVWR} \leq 6,000 \mathrm{lb}, \mathrm{LVW}<3,750 \mathrm{lb})$ \\
\hline LDT2 & light-duty truck $2(\mathrm{GVWR} \leq 6,000 \mathrm{lb}, 3,751 \leq \mathrm{LVW} \leq 5,750 \mathrm{lb})$ \\
\hline LDT3 & light-duty truck $3(6,000<\mathrm{GVWR} \leq 8,500 \mathrm{lb}, \mathrm{ALVW} \leq 5,750 \mathrm{lb})$ \\
\hline LDT4 & light-duty truck $4(6,000<\mathrm{GVWR} \leq 8,500 \mathrm{lb}, 5,750<\mathrm{ALVW} \leq 3,450 \mathrm{lb})$ \\
\hline LDV & light-duty vehicle (passenger car) \\
\hline LEV & low-emission vehicle \\
\hline LVW & loaded vehicle weight $(\mathrm{VCW}+300 \mathrm{lb})$ \\
\hline MDPV & medium-duty passenger vehicle \\
\hline NLEV & National Low Emission Vehicle (Program) \\
\hline NMHC & non-methane hydrocarbons \\
\hline NMOG & non-methane organic gas \\
\hline $\mathrm{NO}_{\mathrm{X}}$ & oxides of nitrogen \\
\hline PM & particulate matter \\
\hline THC & total hydrocarbons \\
\hline TLEV & transitional low-emission vehicle \\
\hline ULEV & ultra-low-emission vehicle \\
\hline $\mathrm{VCW}$ & $\begin{array}{l}\text { vehicle curb weight - weight of vehicle with full tanks and components included but without } \\
\text { passengers or luggage (load) }\end{array}$ \\
\hline ZEV & zero emission vehicle \\
\hline
\end{tabular}


Table A.4. Tier 2 and interim non-Tier 2 full-useful-life exhaust emissions standards

[All emissions in grams/mile (source: www.epa.gov/otaq/standards.htm)]

\begin{tabular}{|c|c|c|c|c|c|c|}
\hline Bin No. & $\mathrm{NO}_{\mathrm{X}}$ & NMOG & $\mathrm{CO}$ & $\mathrm{HCHO}$ & PM & Notes \\
\hline $11 \ldots \ldots \ldots \ldots \ldots \ldots \ldots \ldots$ & 0.9 & 0.280 & 7.3 & 0.032 & 0.12 & a, c \\
\hline $10 \ldots \ldots \ldots \ldots \ldots \ldots \ldots \ldots$ & 0.6 & $0.156 / 0.230$ & $4.2 / 6.4$ & $0.018 / 0.027$ & 0.08 & $a, b, d$ \\
\hline $9 \quad \ldots \ldots \ldots \ldots \ldots \ldots \ldots \ldots$ & 0.3 & $0.090 / 0.180$ & 4.2 & 0.018 & 0.06 & $a, b, e$ \\
\hline 8 . & 0.20 & $0.125 / 0.156$ & 4.2 & 0.018 & 0.02 & $\mathrm{~b}, \mathrm{f}$ \\
\hline … & 0.15 & 0.090 & 4.2 & 0.018 & 0.02 & \\
\hline 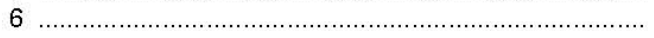 & 0.10 & 0.090 & 4.2 & 0.018 & 0.01 & \\
\hline 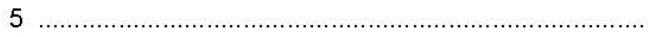 & 0.07 & 0.090 & 4.2 & 0.018 & 0.01 & \\
\hline 4 , & 0.04 & 0.070 & 2.1 & 0.011 & 0.01 & \\
\hline З 3 & 0.03 & 0.055 & 2.1 & 0.011 & 0.01 & \\
\hline 2 ㅅ․ & 0.02 & 0.010 & 2.1 & 0.004 & 0.01 & \\
\hline 1 & 0.00 & 0.000 & 0.0 & 0.000 & 0.00 & \\
\hline
\end{tabular}

Notes:

a This bin and its corresponding intermediate life bin are deleted at end of 2006 model year (end of 2008 model year for HLDTs and MDPVs).

b Higher NMOG, CO and HCHO values apply for HLDTs and MDPVs only.

$c$ This bin is only for MDPVs.

Optional NMOG standard of $0.280 \mathrm{~g} / \mathrm{mi}$ applies for qualifying LDT4s and qualifying MDPVs only.

e Optional NMOG standard of $0.130 \mathrm{~g} / \mathrm{mi}$ applies for qualifying LDT2s only.

f Higher NMOG standard deleted at end of 2008 model year.

Table A.5. Tier 2 and interim non-Tier 2 intermediate full-useful-life (50,000 mile) exhaust emissions standards

[All emissions in grams/mile (source: www.epa.gov/otaq/standards.htm)]

\begin{tabular}{|c|c|c|c|c|c|c|}
\hline Bin No. & $\mathrm{NO}_{\mathrm{X}}$ & NMOG & $\mathrm{CO}$ & $\mathrm{HCHO}$ & PM & Notes \\
\hline 1 & $\begin{array}{r}0.6 \\
0.4 \\
0.2 \\
0.14 \\
0.11 \\
0.08 \\
0.05\end{array}$ & $\begin{array}{r}0.195 \\
0.125 / 0.160 \\
0.075 / 0.140 \\
0.100 / 0.125 \\
0.075 \\
0.075 \\
0.075\end{array}$ & $\begin{array}{r}5.0 \\
3.4 / 4.4 \\
3.4 \\
3.4 \\
3.4 \\
3.4 \\
3.4\end{array}$ & $\begin{array}{r}0.022 \\
0.015 / 0.018 \\
0.015 \\
0.015 \\
0.015 \\
0.015 \\
0.015\end{array}$ & 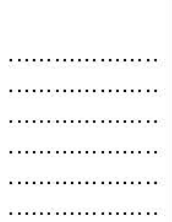 & $\begin{array}{r}a c f h \\
a b d f g h \\
a b c f h \\
b \text { f h } 1 \\
f h \\
\\
f h \\
f h\end{array}$ \\
\hline
\end{tabular}

Notes:

a This bin deleted at end of 2006 model year (end of 2008 model year for HLDTs and MDPVS ).

b Higher NMOG, CO and HCHO values apply for HLDTs and MDPVs only.

c This bin is only for MDPVs.

a Optional NMOG standard of $0.195 \mathrm{~g} / \mathrm{mi}$ applies for qualifying LDT4s and qualifying MDPVs only

e Optional NMOG standard of $0.100 \mathrm{~g} / \mathrm{mi}$ applies for qualifying LDT2s only.

f The full useful life PM standards from Table S04-1 also apply at intermediate useful life.

$\mathrm{g}$ Intermediate life standards of this bin are optional for diesels.

$\mathrm{h}$ Intermediate life standards are optional for vehicles certified to a useful life of 150,000 miles.

i Higher NMOG standard deleted at end of 2008 model year. 


\section{APPENDIX B \\ SMALL NON-ROAD ENGINE TEST EQUIPMENT, PROCEDURES, AND RELEVANT EMISSIONS STANDARDS}

The equipment used during the small non-road engine (SNRE) studies can be broken down into the following.

Measurement equipment

- Emissions

- Temperatures

Test cell equipment

- Oak Ridge National Laboratory (ORNL)

- National Renewable Energy Laboratory (NREL)

- Transportation Research Center (TRC)

\section{B.1 EMISSIONS MEASUREMENT}

All laboratories measured emissions using emissions benches equipped with conventional automotive emissions analyzers, such as the following:

- heated flame ionization detector for total hydrocarbons (THC),

- heated chemiluminescence detector for oxides of nitrogen $\left(\mathrm{NO}_{\mathrm{X}}\right){ }^{*}$

- non-dispersive infrared detectors for $\mathrm{CO}$ and $\mathrm{CO}_{2}$, and

- Innova Multigas Photoacoustic Analyzer for ethanol.

Additional details specific to each laboratory about emissions measurements are below.

\section{B.1.1 ORNL—Fuels, Engines, and Emissions Research Center}

Engine-out concentrations and mass rates of $\mathrm{NO}_{\mathrm{X}}, \mathrm{THC}, \mathrm{CO}$, and $\mathrm{CO}_{2}$ were measured at each mode using a raw emissions bench and a full-flow dilution tunnel and a second tunnel bench, respectively.

Brake-specific emissions were estimated by assuming a constant generator efficiency of $90 \%$. The electrical load on the generator was manipulated with resistive load banks and other electrical appliances to approximate each load point. Current, voltage, and engine speed were manually recorded at each mode. Electrical load was divided by 0.9 to estimate engine brake horsepower. Although actual generator efficiency varies with load, measuring this efficiency was beyond the scope of this project. The assumption of $90 \%$ is conservative in that it tends to increase the calculated brake-specific emissions (assuming lower efficiency would decrease the calculated brake-specific emissions). Since the same efficiency was applied across all loads and all fuels, the relative change associated with the ethanol blends is not affected by this assumption.

Particulate samples were collected from the full-flow tunnel for extended sampling times with the larger Class II engines. Total particulate sample volume was recorded with a dry gas meter, and the sample time for each mode was set per cycle G2 in Table B.1.

\footnotetext{
${ }^{*} \mathrm{NO}_{\mathrm{X}}$ measurement at NREL was by non-dispersive ultraviolet.
} 
Table B.1. ISO 8178 emission test cycles

\begin{tabular}{|l|c|c|c|c|c|c|c|c|c|c|c|}
\hline \multirow{2}{*}{ Test cycle } & \multicolumn{10}{|c|}{ Mode weighting factors from ISO 8178 test cycle } \\
\cline { 2 - 12 } & $\mathbf{1}$ & $\mathbf{2}$ & $\mathbf{3}$ & $\mathbf{4}$ & $\mathbf{5}$ & $\mathbf{1}$ & $\mathbf{2}$ & $\mathbf{3}$ & $\mathbf{4}$ & $\mathbf{5}$ & $\mathbf{6}$ \\
\hline \hline Torque, \% & 100 & 75 & 50 & 25 & 10 & 100 & 75 & 50 & 25 & 10 & 0 \\
\hline & \multicolumn{7}{|c|}{ Rated speed } & \multicolumn{7}{|c|}{ Intermediate speed } & $\begin{array}{c}\text { Low } \\
\text { idle }\end{array}$ \\
\hline G1 & - & - & - & - & - & 0.90 & 0.20 & 0.29 & 0.30 & 0.07 & 0.05 \\
\hline G2 & 0.09 & 0.20 & 0.29 & 0.30 & 0.07 & - & - & - & - & - & 0.05 \\
\hline G3 & 0.85 & - & - & - & - & - & - & - & - & - & 0.15 \\
\hline
\end{tabular}

Aldehydes were measured using dinitrophenylhydrazine- (DNPH)-treated silica gel cartridges, using the same sample times as those for particulates. Only the larger Class II engines were able to generate adequate sample for these measurements via full flow dilution.

A microdilution tunnel with constant dilution ratio was used for dilute sampling of the Class I engines, such that ethanol concentration could be measured with the Innova.

Composite emissions were computed using weighted averages of each mode, per cycle $\mathrm{G} 2$ in Table B.1.

\section{B.1.2 NREL-ReFUEL Laboratory}

Emissions were measured using a portable emissions measurement system (PEMS) at the ReFUEL laboratory. Concentrations of $\mathrm{NO}_{\mathrm{X}}, \mathrm{THC}, \mathrm{CO}$, and $\mathrm{CO}_{2}$ were measured at each mode.

Brake-specific emissions were estimated via the following engineering assumptions about power output and exhaust flow rate.

- For the 2-stroke Poulan engine, a peak volumetric efficiency of 35\% was assumed at full load, and rated power was assumed. The volumetric efficiency and brake power at idle were assumed to be $20 \%$ of the peak.

- For the 4-stroke Stihl engine, the peak volumetric efficiency was assumed to be $80 \%$, and again, rated power was assumed. The idle load was again assumed to be $20 \%$ of the peak, and the volumetric efficiency at idle was assumed to be $80 \%$ of the maximum.

Composite emissions were computed at NREL using weighted averages of each mode, per cycle G3 in Table B.1 for handheld engines.

\section{B.1.3 TRC Full-Useful-Life (Full-Life) Study}

Mass rates of $\mathrm{NO}_{\mathrm{X}}, \mathrm{THC}, \mathrm{CO}$, and $\mathrm{CO}_{2}$ were measured at each mode using a full-flow dilution tunnel and a tunnel bench.

Brake-specific emissions were calculated directly from dynamometer horsepower on dynamometer tested engines (Class I residential power washer engines and Class IV line trimmer engines).

Brake-specific engine-generator emissions were estimated by assuming a constant generator efficiency of $80 \%$, based on guidance from Honda. While the actual generator efficiency is a function of electrical load, the load/efficiency curve was considered proprietary by Honda. Measuring this generator efficiency as a function of load was beyond the scope of this project and not necessary. As the same efficiency was applied to all modes for calculating brake-specific emissions, the relative change in emissions with ethanol fuel was unaffected. The electrical load on the generator was 
manipulated with resistive load banks to approximate each load point per cycle G2 in Table B.1. Current, voltage, and engine speed were manually recorded at each mode. Electrical load was divided by 0.8 to estimate engine brake horsepower.

Brake-specific blower engine emissions were estimated by assuming all engines made the same mode 1 power, measured on the dynamometer with four sacrificial engines early in the program. Because of engine failures associated with difficulties of dynamometer testing of the residential Class IV engines, the engine loads were provided by the blower wheel for the aging as well as the actual emissions tests.

Particulate samples were collected from the full-flow tunnel for all engines. Total particulate sample volume was computed based on the sample flow rate, which was controlled by a mass flow controller for weighting the composite particulate matter (PM) emissions per cycle G2 in Table B.1. Aldehydes were measured using DNPH-treated silica gel cartridges, using the same weighting approach as that for particulates, controlling flow rate with a mass flow controller.

\section{B.2 TEMPERATURE MEASUREMENT}

During break-in and all emissions and durability testing, the following temperatures were recorded (as applicable).

- Exhaust port

- Exhaust manifold

- Cylinder head

- Muffler

- Oil temperature

- Cylinder jug

- Exhaust outlet to atmosphere

Type K thermocouples were used, and temperatures at all sites were recorded on computer-based data acquisition systems.

\section{B.3 TEST CELL EQUIPMENT}

\section{B.3.1 ORNL-Fuels, Engines, and Emissions Research Center}

The following equipment was used in SNRE testing at ORNL.

- Computer-based data acquisition system - used to record the following:

- temperature,

- fuel:air equivalence ratio,

- gravimetric fuel mass, and

— emissions data.

- Inductive Tachometer (Tiny Tach) —Used to measure engine speed when available. Engine speed was recorded manually on a log sheet.

- Generator load was provided by resistive load banks and augmented when necessary by electrical appliances. Electrical load (volts and amps) was recorded manually on a log sheet.

\section{B.3.2 NREL-ReFUEL Laboratory}

The following equipment was used in testing emissions and temperature at the ReFUEL Laboratory. 
- Computer-based data acquisition system — used to record the following:

- temperature and

- engine speed data.

- Semtech PEMS — used for measuring exhaust concentrations of $\mathrm{HC}, \mathrm{CO}$, and $\mathrm{NO}_{\mathrm{X}}$.

\section{B.3.3 TRC Full-Life Study}

The TRC emissions laboratory is equipped with two SNRE dynamometers, sized for Class I and Class IV engines. Full-flow dilution was used for measuring emissions, as described above.

Additional hardware for extended aging operations includes computer-controlled aging stands. Specifics of equipment used for each engine follow.

- $\quad$ Briggs and Stratton power washer engines

- Emissions were measured on the dynamometer according to CFR guidelines. Two protocols were used and will be described in more detail in Sect. C.4.

- Engines were aged using the power washer to provide the aging load by use of a closed-loop water system. Spray wands were held in a special fixture and a computer-controlled pneumatic actuator activated the spray trigger using a 2-mode cycle.

- $\quad$ tihl line trimmer engines

- Engines were emissions tested on the dynamometer according to CFR guidelines. Stihl engineers provided a special dynamometer fixture to facilitate testing on the dynamometer.

- Engines were aged with the line guard removed and the line extended to create additional windage loads. Line length was adjusted so that the engines would run at 8,000 RPM in mode 1. A computer-controlled pneumatic actuator was used to cycle the throttle trigger during the aging program.

- Weed Eater leaf blowers - were initially tested on the dynamometer, but this resulted in catastrophic engine failures due to the lack of an appropriate Class IV-engine-test fixture for this engine. Average mode 1 power measurements on the initial four engines were used to estimate blower power for all subsequent engine tests. The blower wheel was used as the engine brake for both the aging load and the emissions testing. A computer-controlled pneumatic actuator was used to cycle the throttle trigger during the aging program.

- Honda generators - used an electrical load bank for the aging load as well as for emulating the 6-mode emissions test. The same load bank was used for emissions testing of all four generators, but each generator had a dedicated load bank during aging. A computer-driven control system switched loads on the load banks automatically so that each mode was held for the appropriate time duration for the entirety of the aging protocol.

\section{B.4 TEST PROCEDURES}

Engines at all sites were instrumented with thermocouples. Engine break-in was conducted using E0 (federal certification gasoline). The new engines were run at moderate load for $40 \mathrm{~min}$ to $10 \mathrm{hr}$ (nominally $1-4 \%$ of full-life) before the first emissions tests were conducted. None of the engine manuals specified a break-in time or procedure.

\section{B.4.1 Testing at ORNL}

The basic procedure for emissions testing at ORNL was as follows.

\section{Engine instrumentation and preparation}

Each engine was instrumented for temperature with thermocouples. In addition, a wide-range universal exhaust gas oxygen sensor was installed in the muffler to measure the fuel:air equivalence 
ratio, and a sample port was installed in the exhaust manifold for monitoring engine-out emissions concentrations. Most of the engines were instrumented for engine speed using an inductive-spark pickup tachometer.

\section{Engine break-in}

Break-in was conducted at moderate load or on the appropriate emissions test cycle for $2 \mathrm{hr}$. Exceptions were the field-aged Honda generator (no break-in needed) and the Kohler generator, which was subjected to a $10-$ hr break-in given its $1,000-$ hr full life.

\section{Emissions testing}

The 6-mode gaseous emissions test (G2 procedure from Table B.1) used the following process.

1. Warm engine at $50 \%$ load for $20 \mathrm{~min}$.

2. Switch to mode 1 . Stabilize engine for $10 \mathrm{~min}$, then collect data for $10 \mathrm{~min}$.

3. Repeat step 2 for modes 2-6.

4. Switch to E20 (or E10 or E15); repeat steps 1-3.

5. Repeat E0 test at end.

For full-flow tunnel sampling of PM and aldehydes, each mode was timed according to the 6-mode weighting factors. To collect adequate PM mass, 3,000-s and 6,000-s total sampling times were used. Each mode change was followed by $10 \mathrm{~min}$ of stabilization. Mode sample times are listed below.

- $\quad$ Mode $1(9 \%$ of 6,000$)$ for $540 \mathrm{~s}$.

- Mode $2(20 \%)$ for $1,200 \mathrm{~s}$.

- Mode $3(29 \%)$ for $1,740 \mathrm{~s}$.

- Mode $4(30 \%)$ for $1,800 \mathrm{~s}$.

- Mode 5 (7\%) for $420 \mathrm{~s}$.

- Mode $6(5 \%)$ for $300 \mathrm{~s}$.

\section{B.4.2 Testing at NREL}

The basic procedure for emissions testing at NREL was as follows.

\section{Engine instrumentation and preparation}

Each engine was instrumented for temperature with thermocouples. In addition, each engine was instrumented for engine speed and operating time (hour meter). Time of operation on each fuel and each test cycle was recorded.

\section{Engine break-in}

Break-in was conducted by running the appropriate 2-mode cycle for $40 \mathrm{~min}$.

3. Emissions testing

The basic emissions testing procedure at NREL was as follows.

- Operate on aging cycle for a minimum of $40 \mathrm{~min}$ to stabilize engine.

- Perform emissions certification cycle, in duplicate.

- Change fuel to ethanol blend (E10, E15, or E20), being sure to drain tank and fuel lines completely.

- Repeat emissions testing per the above protocol for each fuel blend (E10, E15, E20). 
NREL also tested the Poulan blower to full life after testing E0, E10, E15, and E20 for a total of about $12 \mathrm{hr}$. The aging cycle at NREL with the Poulan blower was as follows.

- Operate on aging cycle for $8 \mathrm{hr}$ on each fuel, starting with E0.

- Record temperatures and speed and note operation.

- Return to E0.

\section{B.4.3 Testing at TRC—Full-Life Testing of Class I and Class IV Engines}

Initially, four of each type of equipment were to be tested. Following baseline emissions measurement on each engine with E0, one engine of each type was then dedicated to one of four fuels (E0, E10, E15, or E20) for aging. However, due to the inherent engine-to-engine differences in the residential engines, more than four engines were baselined in an attempt to evaluate four similar engines in the aging program. Six power washer engines and eight Weed Eater leaf blowers were baselined. Table B.2 provides details on the engines and fuels tested at TRC.

General procedure. The general approach for each four-engine, four-fuel combination at TRC was as follows.

1. Engine instrumentation-Engines at TRC were instrumented for numerous temperatures with thermocouples.

2. Break-in for $2 \mathrm{hr}$ (E0 fuel, all engines).

3. Applicable emissions certification cycle (3-4 consecutive tests, E0 fuel, all engines).

4. Fuel switch, dedicated ethanol blend fuel per engine (3 engines).

5. Applicable emissions certification cycle (3-4 consecutive tests, dedicated ethanol blend fuel per engine).

6. Durability cycle for half of full life, dedicated ethanol blend fuel. ${ }^{*}$

7. Applicable emissions certification cycle, dedicated ethanol blend fuel (3-4 consecutive tests).

8. Durability cycle for remainder of full life, dedicated ethanol blend fuel.

9. Applicable emissions certification cycle, dedicated ethanol blend fuel (3-4 consecutive tests).

10. Fuel switch (three engines back to E0), applicable emissions certification cycle (3-4 consecutive tests, E0 fuel).

Engine oil for the pressure washers and generators was changed per manufacturer's recommendations. Samples of each oil drain were stored for potential future analysis.

\section{B.4.4 Specific Test Protocols in Full-Life Study}

Table B.2 provides additional detail on the specific test protocols for each engine in the full-life study.

\section{B.4.4.1 Briggs and Stratton Quattro engine (Troy-Bilt power washer, Class I residential, 125-hr life)}

The power washer engines were aged using a 2-mode test. This approach was used such that all four engines could be aged simultaneously using the power washer as the engine load, and it was deemed similar to actual field use of this machine.

\footnotetext{
*For the engines that survived the full-useful-life (full-life) durability test (50-500 hr, depending on engine type and application), the emissions test protocol was repeated at half-life and again at full-life hours. Full-life tests were conducted first on the respective fuel for each engine, followed by a final E0 test.
} 
Table B.2. Summary of engine, fuel, and emissions test protocols for full-useful-life (full-life) testing [Hashed areas indicate no data collected. Ethanol blend denotes fuel tested at that condition (E0, E10, E15, or E20)]

\begin{tabular}{|c|c|c|c|c|c|c|}
\hline \multirow{2}{*}{\multicolumn{2}{|c|}{$\begin{array}{c}\text { Engine/equipment } \\
\text { (emissions test protocol) }\end{array}$}} & \multicolumn{2}{|c|}{ New $^{a}$} & \multirow{3}{*}{$\begin{array}{c}\text { Half life } \\
\text { E0 }\end{array}$} & \multicolumn{2}{|c|}{ Full life } \\
\hline & & \multirow{2}{*}{$\begin{array}{c}\text { E0 baseline } \\
\text { E0 }\end{array}$} & \multirow{2}{*}{$\begin{array}{c}\begin{array}{c}\text { Ethanol } \\
\text { blend }\end{array} \\
\text { E0 }\end{array}$} & & \multirow{2}{*}{$\begin{array}{c}\begin{array}{c}\text { Ethanol } \\
\text { blend }\end{array} \\
\text { E0 }\end{array}$} & \multirow{2}{*}{$\begin{array}{c}\text { Baseline } \\
\text { E0 }\end{array}$} \\
\hline \multirow{6}{*}{$\begin{array}{l}\text { Briggs and } \\
\text { Stratton power } \\
\text { washer (6-mode } \\
\text { dyno test, TRC } \\
\text { Protocol) })^{b}\end{array}$} & PW1 & & & & & \\
\hline & PW2 & E0 & E10 & E10 & E10 & E0 \\
\hline & PW3 & E0 & E15 & E15 & E15 & E0 \\
\hline & PW4 & E0 & E20 & E20 & E20 & E0 \\
\hline & PW5 & E0 & & & & \\
\hline & PW6 & E0 & & & & \\
\hline \multirow{6}{*}{$\begin{array}{l}\text { Briggs and } \\
\text { Stratton power } \\
\text { washer (6-mode } \\
\text { dyno test, BASCO } \\
\text { Protocol) })^{C}\end{array}$} & PW1 & & & & E0 & E0 \\
\hline & PW2 & & & & E10 & E0 \\
\hline & PW3 & & & & E15 & E0 \\
\hline & PW4 & & & & E20 & E0 \\
\hline & PW5 & E0 & & & & \\
\hline & PW6 & & & & & \\
\hline \multirow{4}{*}{$\begin{array}{l}\text { Honda generator } \\
\text { (6-mode test, } \\
\text { generator as engine } \\
\text { brake) }\end{array}$} & G1 & E0 & E0 & E0 & E0 & E0 \\
\hline & G2 & E0 & E10 & E10 & E10 & E0 \\
\hline & G3 & E0 & E15 & E15 & E15 & E0 \\
\hline & G4 & E0 & E20 & E20 & E20 & E0 \\
\hline \multirow{8}{*}{$\begin{array}{l}\text { Weed Eater blower } \\
\text { (2-mode test, } \\
\text { blower wheel as } \\
\text { engine brake) }\end{array}$} & $\overline{\mathrm{B} 2^{d, e}}$ & $\overline{\text { E0 }}$ & $\bar{E}$ E0 & E0 & & \\
\hline & $\mathrm{B}^{d}$ & E0 & E10 & E10 & E10 & E0 \\
\hline & $\mathrm{B} 7^{\mathrm{d} f \mathrm{f}}$ & E0 & E15 & & & \\
\hline & $\mathrm{B}^{f, g}$ & E0 & E15 & & & \\
\hline & $\mathrm{B} 8^{d, h}$ & E0 & $\mathrm{E} 20^{h}$ & & & \\
\hline & $\mathrm{B} 6^{i}$ & E0 & E20 & E20 & E20 & E0 \\
\hline & $\mathrm{B} 1$ & E0 & & & & \\
\hline & $\mathrm{B} 4$ & E0 & & & & \\
\hline \multirow{4}{*}{$\begin{array}{l}\text { Stihl Line } \\
\text { Trimmer (2-mode } \\
\text { dyno test) }\end{array}$} & T1 & $\overline{\mathrm{E} 0}$ & E0 & E0 & E0 & E0 \\
\hline & $\mathrm{T} 2$ & E0 & E10 & E10 & E10 & E0 \\
\hline & $\mathrm{T} 3$ & E0 & E15 & E15 & E15 & E0 \\
\hline & $\mathrm{T} 4$ & E0 & E20 & E20 & E20 & E0 \\
\hline
\end{tabular}

${ }^{a}$ New refers to engines following $2 \mathrm{hr}$ initial break-in.

${ }^{b}$ TRC protocol allowed engine to run on governor in mode 1 , similar to power washer operation in spray mode.

${ }^{c}$ BASCO protocol involved override of governor for wide-open throttle operation in mode 1 . Because BASCO protocol not initially run on PW1-PW4 in new condition, PW5 tested on BASCO protocol for new engine comparison. PW5 failed during E10 testing on BASCO protocol.

${ }^{d}$ Engine initially selected for aging program (B2-E0, B5-E10, B7-E15, B8-E20).

${ }^{e} \mathrm{~B} 2$ failed before full life (50 hr).

${ }^{f}$ Failed before half life.

${ }^{g} \mathrm{~B} 3$ replaced $\mathrm{B} 7$ as $\mathrm{E} 15$ engine after $\mathrm{B} 7$ failure.

${ }^{h}$ No E20 emissions data obtained from B8 (would not idle).

${ }^{i} \mathrm{~B} 6$ replaced $\mathrm{B} 8$ as $\mathrm{E} 20$ engine when $\mathrm{B} 8$ would not idle on E20. 
TRC protocol. Emissions tests on the power washer engines were conducted using the TRC protocol at the new, half-life, and full-life condition. The TRC protocol is a 6-mode emissions test and was conducted on the engine dynamometer per CFR guidelines. The mode 1 load was determined using the installed governor to control engine speed, and dynamometer load was set to match the observed engine speed when the power washer was in spray mode on the aging stand.

BASCO protocol. Briggs and Stratton Company (BASCO) was consulted on the proper protocol for testing this Class I engine and provided guidance that the correct mode 1 load should be determined by physically overriding the governor and fixing the throttle in the full-open position. Because this information was obtained after the initial baseline and start of the aging process, it was decided to run this revised 6-mode protocol (named BASCO protocol) at the end of the aging program and to continue using the TRC protocol, still a representative test because it could be considered a measure of in-use emissions. As presented in Table B.2, PW1-PW4 were tested on the TRC protocol at the new, half-life, and full-life conditions but only tested on the BASCO protocol at the full-life condition.

To obtain reference emissions on a new engine with the BASCO protocol, PW5 was retested at the end of the program. The initial intent of this program modification was to test PW5 on both the TRC and BASCO protocols using all four fuels; however, during the E10 testing, the engine began to run very erratically. Reasons for the engine problem are unknown.

\section{Power washer aging and emissions general procedure.}

1. Engine break-in

- 2-mode 85/15.

- 10 -min cycle.

- $2 \mathrm{hr}$.

2. Baseline emissions test (dyno)-TRC protocol

- 20-min warm-up at wide-open throttle (WOT).

- 6-mode test-5-min stabilization with 1-min sampling.

- E0 and ethanol blend fuels.

3. Aging (power washer)

- 2-mode 85/15.

- 10 -min cycle.

4. Half-life emissions test (dyno)-TRC protocol

- 20-min warm-up at WOT.

- 6-mode test-5-min stabilization with 1-min sampling.

- Ethanol blend fuels.

5. Aging (power washer)

- 2-mode 85/15.

- 10-min cycle.

6. Full-life emissions test (dyno) - TRC and BASCO protocols

- 20-min warm-up at WOT.

- 6-mode test-5-min stabilization with 1-min sampling.

- E0 and ethanol blend fuels. 


\section{B.4.4.2 Honda EB 3000c generator test protocols-(GX200 Class I Commercial, 500 H life)}

Honda test procedure. Following 2 hr of E0 break-in (using the 6-mode test) on the load bank aging stand, the four engines were baseline emissions tested on E0, using a simulated 6-mode test in which the electrical load was selected to closely match the six desired engine modes. Denoted G1-G4, (generator 1-generator 4), the units were assigned one of the four fuels tested (E0, E10, E15, E20) as presented in Table B.2.

\section{Honda test protocol.}

1. Break-in - mode 3 for $2 \mathrm{hr}$.

2. Baseline emissions test-10-min warm-up at mode 1, 6-mode test, $10 \mathrm{~min}$ at each mode, 1-min sample. E0 and ethanol blend fuels.

3. Aging - 6-mode operation, time at each mode per EPA weighting, 1-hr cycle time.

4. Half-life emissions test-10-min warm-up at mode 1, 6-mode test, $10 \mathrm{~min}$ at each mode, 1-min sample. Ethanol blend fuels.

5. Aging - 6-mode operation, time at each mode per EPA weighting, 1-hr cycle time.

6. Full-life emissions test-10-min warm-up at mode 1, 6-mode test, 10 min at each mode, 1-min sample. E0 and ethanol blend fuels.

\section{B.4.4.3 Weed Eater Featherlite leaf blower protocol-(Class IV Residential, $50 \mathrm{H}$ life)}

Initial attempts to test the blower engines on the dynamometer were unsuccessful. Through industry consultation it was learned that a special engine-specific dynamometer fixture for Class IV engines is necessary to avoid catastrophic engine failures. Tests of four blowers did provide a reasonable estimate of actual shaft horsepower for this engine type, and this measurement was used in calculating brake-specific emissions when the replacement blowers were emissions tested. Emissions tests used the blower wheel as the engine brake, similar to the aging stand.

\section{Weed Eater test protocol.}

1. Break-in

- 2-mode 85/15.

- 6-min cycle, $2 \mathrm{hr}$.

- Baseline emissions test-Eight leaf blowers, denoted B1-B8, were baselined on E0, and then four were selected for the aging program (B2, B5, B7, and B8).

- 8-min warm-up at WOT.

- 85/15 2-mode test (6-min cycle).

2. Aging

- 2-mode 85/15.

- 6-min cycle.

3. Half-life emissions test

- 8-min warm-up at WOT.

- 85/15 2-mode test (6-min cycle).

4. Aging

- 2-mode 85/15.

- 6-min cycle.

5. Full-life emissions test

- 8-min warm-up at WOT.

- 85/15 2-mode test (6-min cycle). 


\section{B.4.4.4 Stihl line trimmer protocol—(Class IV Commercial, $300 \mathrm{H}$ life)}

Denoted T1-T4 (trimmer 1-trimmer 4), the units were assigned one of the four fuels tested (E0, E10, E15, E20) as presented in Table B.2. Stihl provided a proprietary dynamometer fixture to facilitate proper dynamometer emissions tests on these engines that would avoid the failures experienced with the leaf blower engines. After baseline testing of all four engines with E0 and the other three engines with their respective ethanol blends, the engines were aged on the aging stand using the extended line windage as a brake. The trimmer guards were removed and trimmer line length was adjusted to achieve the desired 8,000 RPM engine speed at full load. At half life (150 hr) the engines were emissions tested on the dynamometer with only their respective ethanol blends, then returned to the aging stand to accumulate $300 \mathrm{hr}$. End-of-life emissions tests were conducted on the ethanol blend, then each of the three dedicated ethanol blend engines was retested with E0. All four engines survived the aging protocol and were able to be emissions tested at each interval.

\section{Stihl protocol.}

1. Break-in (trimmer stand) - 2-mode 85/15, 6-min cycle, $2 \mathrm{hr}$.

2. Baseline emissions test (dyno) -8-min warm-up at WOT, 85/15 2-mode test (5 min per mode, 1min sample).

3. Aging (trimmer stand)-2-mode 85/15, 6-min cycle, $2 \mathrm{hr}$.

4. Half-life emissions test (dyno) - 8-min warm-up at WOT, 85/15 2-mode test (6-min cycle).

5. Aging (dyno)-2-mode 85/15, 6-min cycle.

6. Full-life emissions test (dyno)-8-min warm-up at WOT, 2-mode 85/15 (5 min per mode, 1-min sample).

\section{B.5 RELEVANT SNRE EMISSIONS STANDARDS}

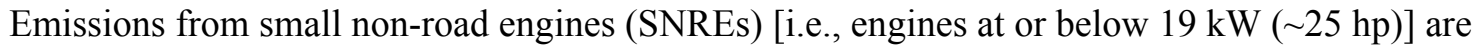
regulated by EPA according to application, size, and useful life rating. Table B.3 shows Phase 1 and Phase 2 standards for SNREs used in non-handheld applications (Class I, Class II, Class I-A and Class I-B). Table B.4 shows the Phase 1 and Phase 2 standards for SNREs used in handheld applications (Class III, Class IV, and Class V). In September 2008, EPA finalized new rules for these classes of engines. The new rules include the first evaporative emission standards for both non-handheld and handheld applications. The new rules also include Phase 3 exhaust emission standards for SNREs used in non-handheld applications. Most of the new standards take effect in 2011 or 2012. The new standards are not provided here but can be reviewed at www.epa.gov/otaq/equip-ld.htm.

Table B.3. Phase 1 and Phase 2 non-handheld engine emission standards

\begin{tabular}{|c|l|l|l|c|c|}
\hline Phase & Class & \multicolumn{1}{|c|}{$\begin{array}{c}\text { Displacement } \\
\text { (cc) }\end{array}$} & Model year & $\begin{array}{c}\text { HC + NO } \\
\text { (g/kW-hr) }\end{array}$ & $\begin{array}{c}\text { CO } \\
\text { (g/kW-hr) }\end{array}$ \\
\hline \multirow{2}{*}{1} & I & $<225$ & 1997 & 16.1 & 519 \\
\cline { 2 - 6 } & II & $\geq 225$ & 1997 & 13.4 & 519 \\
\hline \multicolumn{5}{|l|}{} \\
\hline \multirow{6}{*}{2} & I-A & $<66$ & 2001 & 50 & 610 \\
\cline { 2 - 6 } & I-B & $66 \leq \mathrm{cc}<100$ & 2001 & 40 & 610 \\
\cline { 2 - 6 } & I & $100 \leq \mathrm{cc}<225$ & August $2007^{a}$ & 16.1 & 610 \\
\cline { 2 - 6 } & II & cc $\geq 225$ & 2001 & 18.0 & 610 \\
& & 2002 & 16.6 & \\
& & 2003 & 15.0 & \\
& & 2004 & 12.1 & \\
\hline
\end{tabular}

${ }^{a}$ Effective date. If a new engine family was introduced after August 1, 2003, it was required to meet the Phase 2 standards at that time. 
Table B.4. Phase 1 and Phase 2 handheld engine emission standards

\begin{tabular}{|c|c|c|c|c|c|c|}
\hline Phase & Class & $\begin{array}{c}\text { Displacement } \\
\text { (cc) }\end{array}$ & $\begin{array}{l}\text { Model } \\
\text { Year }\end{array}$ & $\begin{array}{c}\text { HC } \\
\text { (g/kW-hr) }\end{array}$ & $\begin{array}{c}\mathrm{NO}_{\mathrm{X}} \\
\text { (g/kW-hr) }\end{array}$ & $\begin{array}{c}\text { CO } \\
\text { (g/kW-hr) }\end{array}$ \\
\hline \multirow[t]{3}{*}{1} & III & $<20$ & 2001 & 295 & 5.36 & 805 \\
\hline & IV & $20 \leq \mathrm{cc}<50$ & 2001 & 241 & 5.36 & 805 \\
\hline & $\mathrm{V}$ & $\geq 50$ & 2001 & 161 & 5.36 & 603 \\
\hline & & & & \multicolumn{2}{|c|}{$\begin{array}{c}\mathrm{HC}+\mathrm{NO}_{\mathrm{X}} \\
(\mathrm{g} / \mathrm{kW}-\mathrm{hr})\end{array}$} & $\begin{array}{c}\text { CO } \\
\text { (g/kW-hr) }\end{array}$ \\
\hline \multirow[t]{3}{*}{2} & III & $<20$ & $\begin{array}{l}2002 \\
2003 \\
2004 \\
2005 \\
\end{array}$ & \multicolumn{2}{|c|}{$\begin{array}{c}238 \\
175 \\
113 \\
50\end{array}$} & 805 \\
\hline & IV & $20 \leq \mathrm{cc}<50$ & $\begin{array}{l}2002 \\
2003 \\
2004 \\
2005\end{array}$ & & & 805 \\
\hline & $\mathrm{V}$ & $\geq 50$ & $\begin{array}{l}2004 \\
2005 \\
2006 \\
2007\end{array}$ & \multicolumn{2}{|c|}{$\begin{array}{c}143 \\
119 \\
96 \\
72\end{array}$} & 603 \\
\hline
\end{tabular}

For the Phase 1 standards, manufacturers were required to demonstrate compliance when the engines were new. Beginning with the Phase 2 standards, manufacturers must demonstrate compliance over a full-useful-life period. Manufacturers are required to select the full-useful-life period (from those specified in Table B.5) that most closely approximates the useful lives of the equipment into which the engines are to be installed.

Table B.5. Full useful life periods for Phase 2 SNREs

\begin{tabular}{|l|c|l|c|c|c|}
\hline Application & Class & $\begin{array}{c}\text { Displacement } \\
\text { (cc) }\end{array}$ & $\begin{array}{c}\text { Low-hour } \\
\text { period }\end{array}$ & $\begin{array}{c}\text { Medium-hour } \\
\text { period }\end{array}$ & $\begin{array}{c}\text { High-hour } \\
\text { period }\end{array}$ \\
\hline \multirow{3}{*}{ Non-handheld } & I-A & $<66$ & 50 & 125 & 300 \\
\cline { 2 - 6 } & I-B & $66 \leq \mathrm{cc}<100$ & 125 & 250 & 500 \\
\cline { 2 - 6 } & I & $100 \leq \mathrm{cc}<225$ & 125 & 250 & 500 \\
\cline { 2 - 6 } & II & $\mathrm{cc} \geq 225$ & 250 & 500 & 1,000 \\
\hline \multirow{3}{*}{ Handheld } & III & $<20$ & 50 & 125 & 300 \\
\cline { 2 - 6 } & IV & $20 \leq \mathrm{cc}<50$ & 50 & 125 & 300 \\
\cline { 2 - 6 } & $\mathrm{V}$ & $\geq 50$ & 50 & 125 & 300 \\
\hline
\end{tabular}





\section{APPENDIX C}

\section{INDIVIDUAL VEHICLE EMISSIONS RESULTS}

Figures in this appendix show the average emissions from each vehicle tested. (Table C.1 is a listing of the vehicles, figure numbers, and other pertinent information.) Figure C.1 shows the nonmethane organic gas (NMOG), non-methane hydrocarbons (NMHC), carbon monoxide (CO), oxides of nitrogen $\left(\mathrm{NO}_{\mathrm{X}}\right)$, and fuel economy (FE) for the 2007 Chrysler Town and Country, while Fig. C.2 shows the ethanol, acetaldehyde, and formaldehyde emissions for the same vehicle. Similarly, for the remaining vehicles, the odd-numbered figures show the $\mathrm{NMOG}, \mathrm{NHMC}, \mathrm{CO}, \mathrm{NO}_{\mathrm{X}}$, and $\mathrm{FE}$, while the even-numbered figures show the ethanol, acetaldehyde, and formaldehyde. In all figures, $\mathrm{CO}$ emissions are divided by 10 and FE is divided by 100 to permit plotting on a common axis with the other emissions. All results are the average of at least 3 composite LA92 results at $75^{\circ} \mathrm{F}$.

Table C.1. List of Appendix C figures

\begin{tabular}{|l|l|l|l|l|}
\hline \multicolumn{1}{|c|}{$\begin{array}{c}\text { Figure } \\
\text { numbers }\end{array}$} & \multicolumn{1}{|c|}{$\begin{array}{c}\text { OEM } \\
\text { (make) }\end{array}$} & \multicolumn{1}{|c|}{ Model } & Year & \multicolumn{1}{|c|}{ Test site } \\
\hline C.1-C.2 & Chrysler & Town \& Country & 2007 & NREL/CDPHE \\
\hline C.3-C.4 & Ford & F150 & 2007 & TRC \\
\hline C.5-C.6 & Ford & F150 & 2003 & TRC \\
\hline C.7-C.8 & Ford & Taurus & 2003 & TRC \\
\hline C.9-C.10 & GM (Buick) & Lucerne & 2007 & NREL/CDPHE \\
\hline C.11-C.12 & GM (Buick) & LeSabre & 2003 & NREL/CDPHE \\
\hline C.13-C.14 & GM & Silverado & 2007 & TRC \\
\hline C.15-C.16 & Honda & Accord & 2007 & TRC \\
\hline C.17-C.18 & Nissan & Altima & 2003 & TRC \\
\hline C.19-C.20 & Toyota & Camry & 2007 & ORNL \\
\hline C.21-C.22 & Toyota & Camry & 2003 & ORNL \\
\hline C.23-C.24 & Chrysler & PT Cruiser & 2001 & NREL/CDPHE \\
\hline C.25-C.26 & Ford & Crown Victoria & 1999 & NREL/CDPHE \\
\hline C.27-C.28 & Honda & Civic & 1999 & ORNL \\
\hline C.29-C.30 & Toyota & Corolla & 1999 & NREL/CDPHE \\
\hline C.31-C.32 & VW & Golf GTI & 2004 & ORNL \\
\hline
\end{tabular}

Abbreviations: OEM = original equipment manufacturer, NREL = National Renewable Energy Laboratory, CDPHE $=$ Colorado Department of Public Health and Environment, TRC $=$ Transportation Research Center, ORNL = Oak Ridge National Laboratory. 


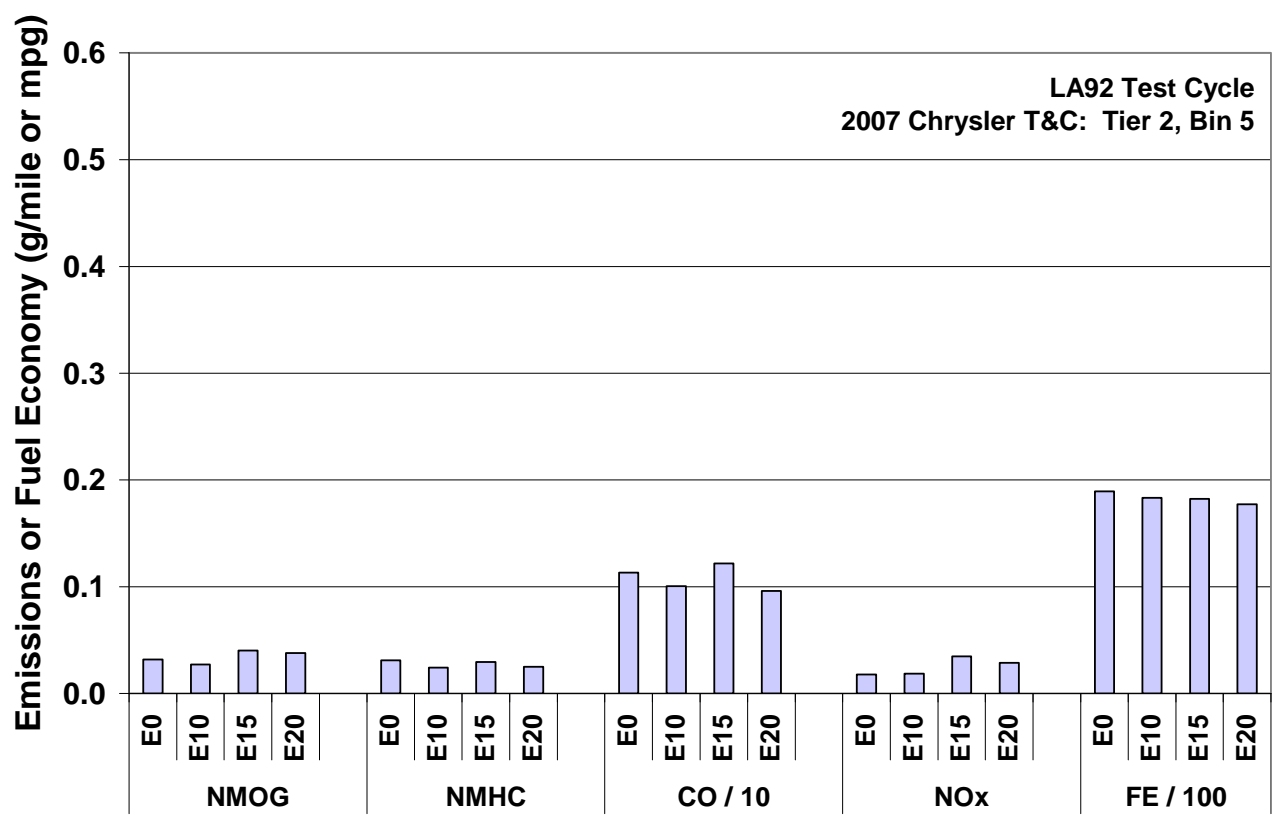

Fig. C.1. Non-methane organic gas (NMOG), non-methane hydrocarbons (NMHC), carbon monoxide (CO), oxides of nitrogen ( $\mathrm{NO}_{\mathrm{X}}$ ), and fuel economy (FE) for 2007 Chrysler Town and Country on LA92 cycle. Bars show average of 3 tests at $75^{\circ} \mathrm{F}$.

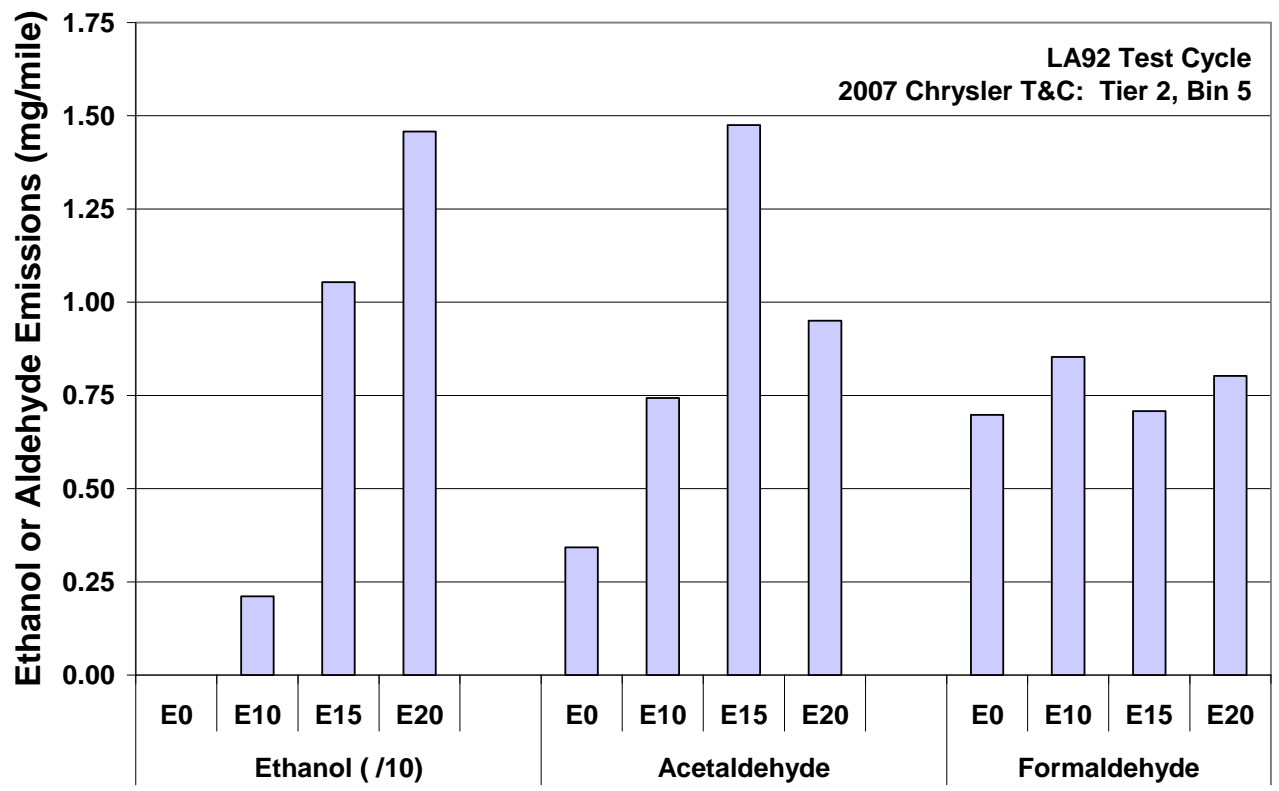

Fig. C.2. Ethanol, acetaldehyde, and formaldehyde emissions for 2007 Chrysler Town and Country on LA92 cycle. Bars show average of 3 tests at $75^{\circ} \mathrm{F}$. 


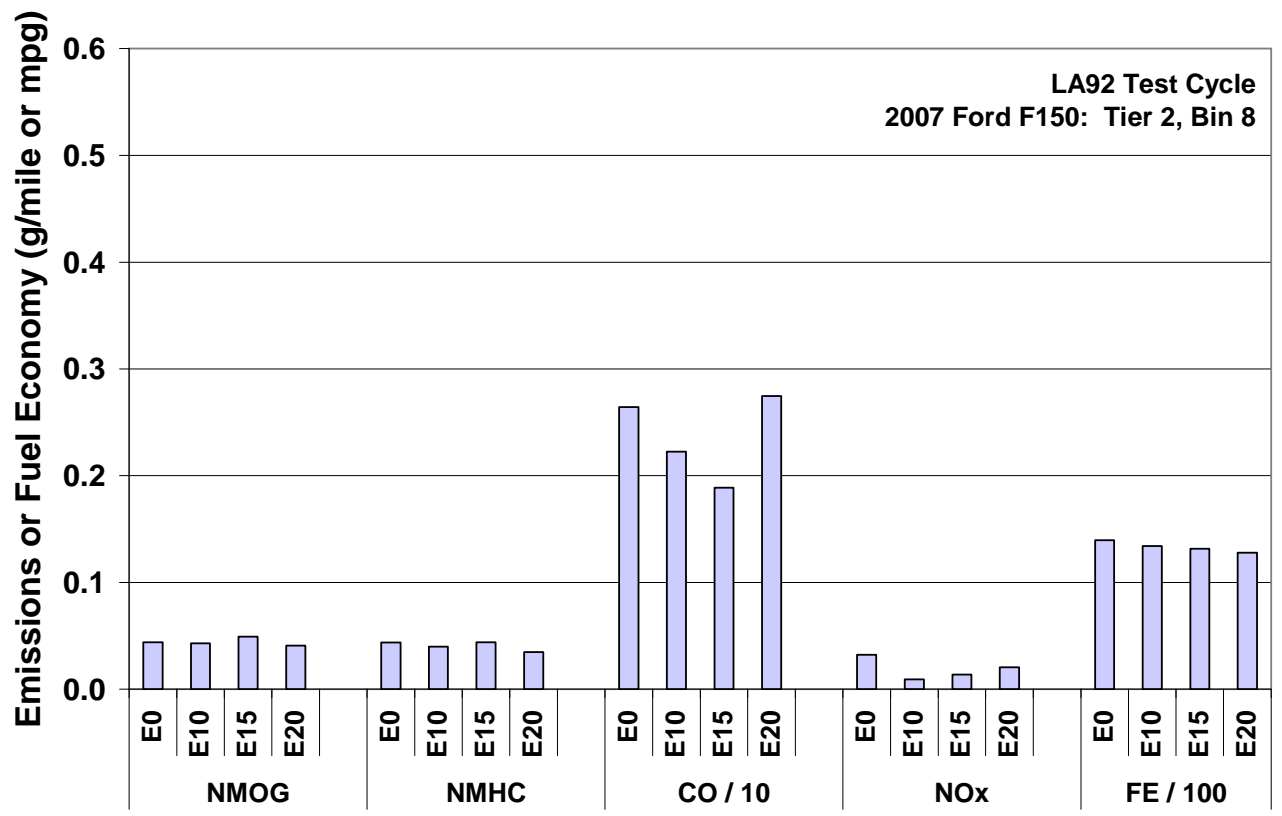

Fig. C.3. Non-methane organic gas (NMOG), non-methane hydrocarbons (NMHC), carbon monoxide (CO), oxides of nitrogen ( $\mathrm{NO}_{\mathrm{X}}$ ), and fuel economy (FE) for 2007 Ford F150 on LA92 cycle. Bars show average of 3 tests at $75^{\circ} \mathrm{F}$.

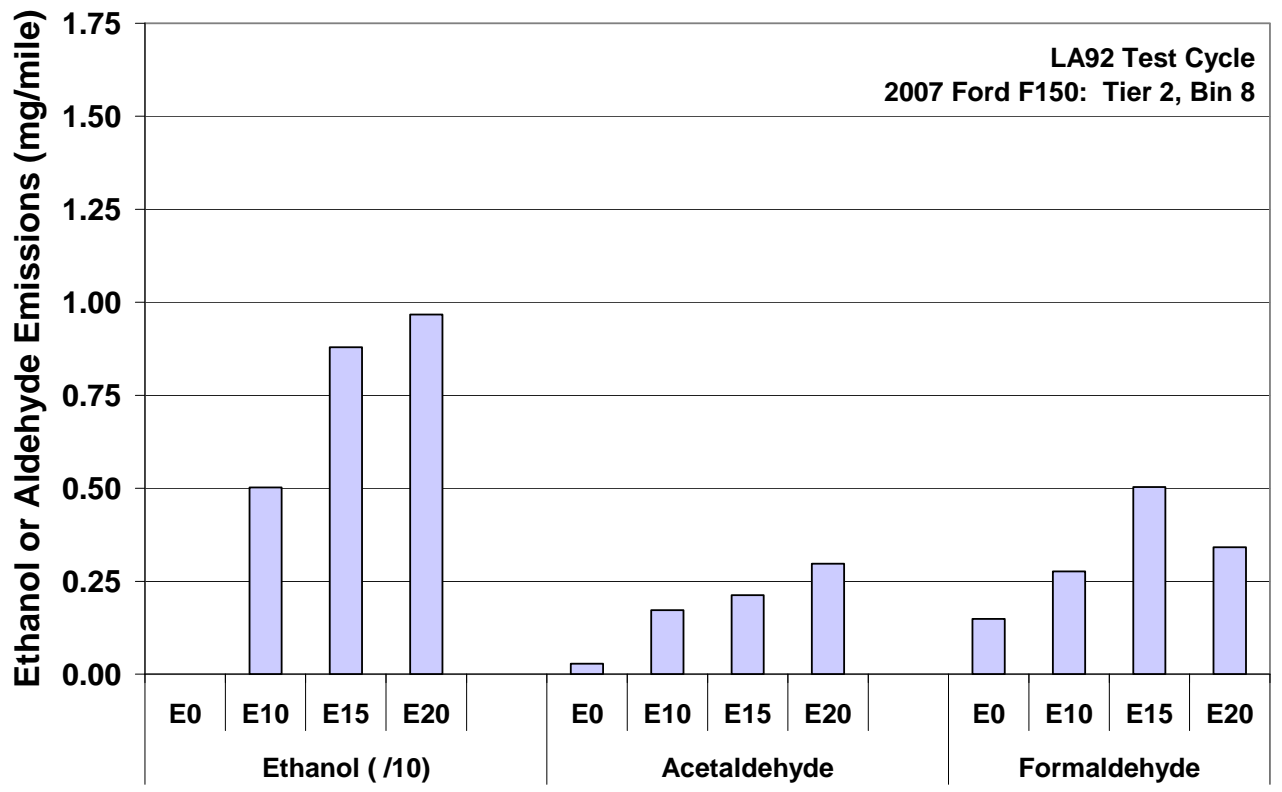

Fig. C.4. Ethanol, acetaldehyde, and formaldehyde emissions for 2007 Ford F150 on LA92 cycle. Bars show average of 3 tests at $75^{\circ} \mathrm{F}$. 


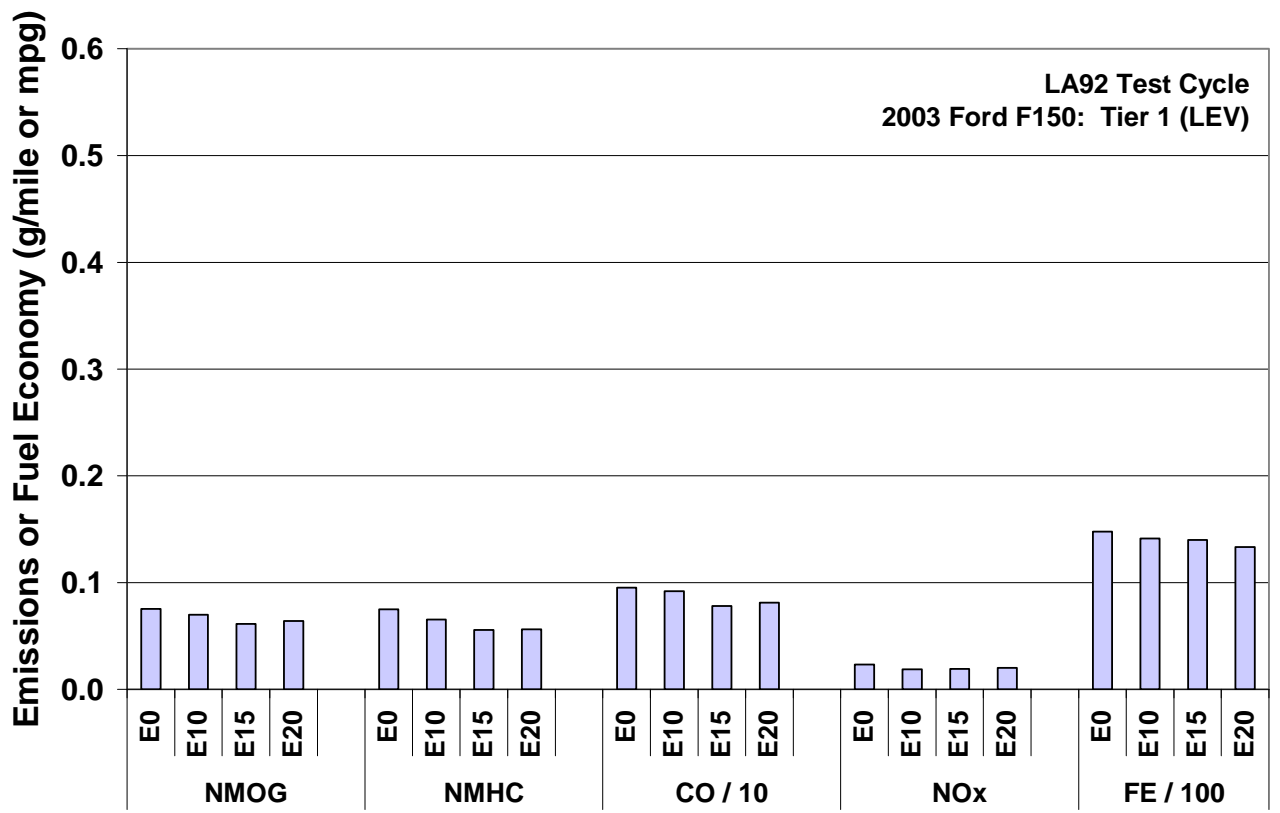

Fig. C.5. Non-methane organic gas (NMOG), non-methane hydrocarbons (NMHC), carbon monoxide (CO), oxides of nitrogen ( $\mathrm{NO}_{\mathrm{X}}$ ), and fuel economy (FE) for 2003 Ford F150 on LA92 cycle. Bars show average of 3 tests at $75^{\circ} \mathrm{F}$.

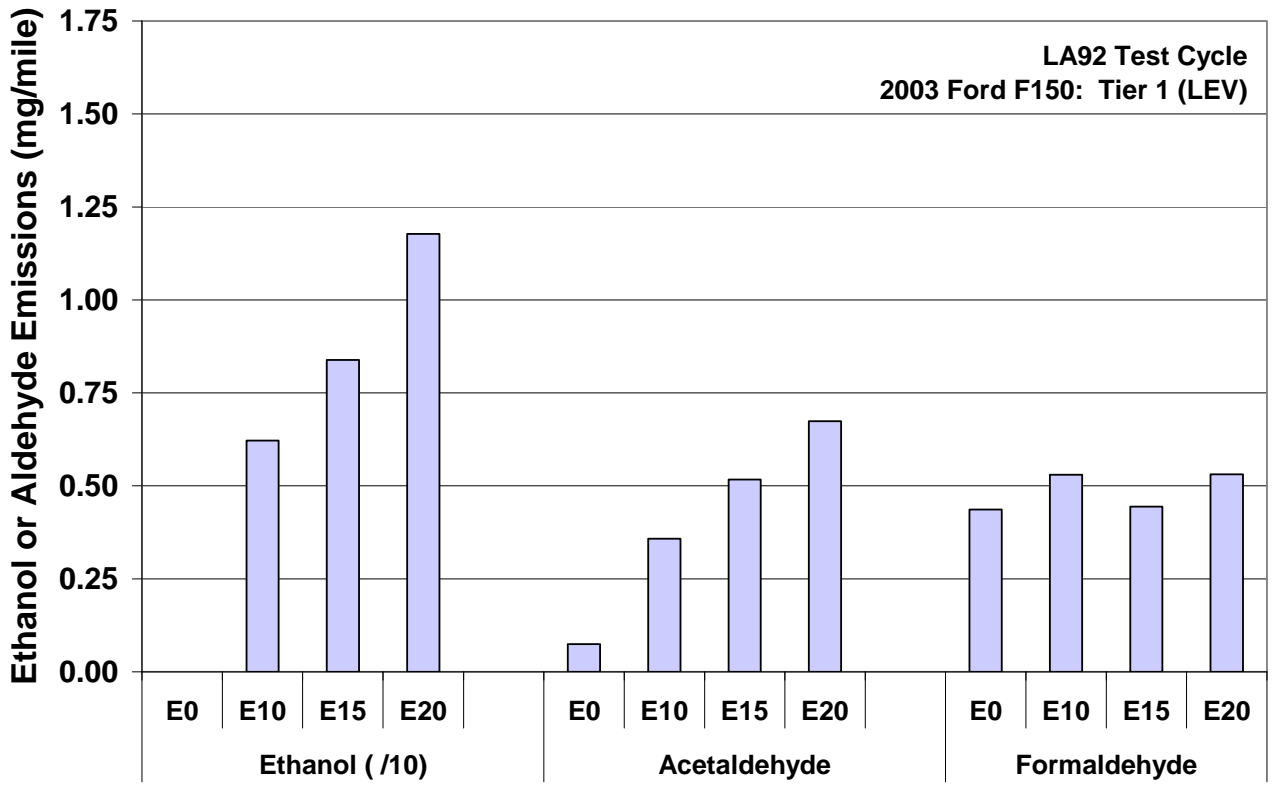

Fig. C.6. Ethanol, acetaldehyde, and formaldehyde emissions for 2003 Ford F150 on LA92 cycle. Bars show average of 3 tests at $75^{\circ} \mathrm{F}$. 


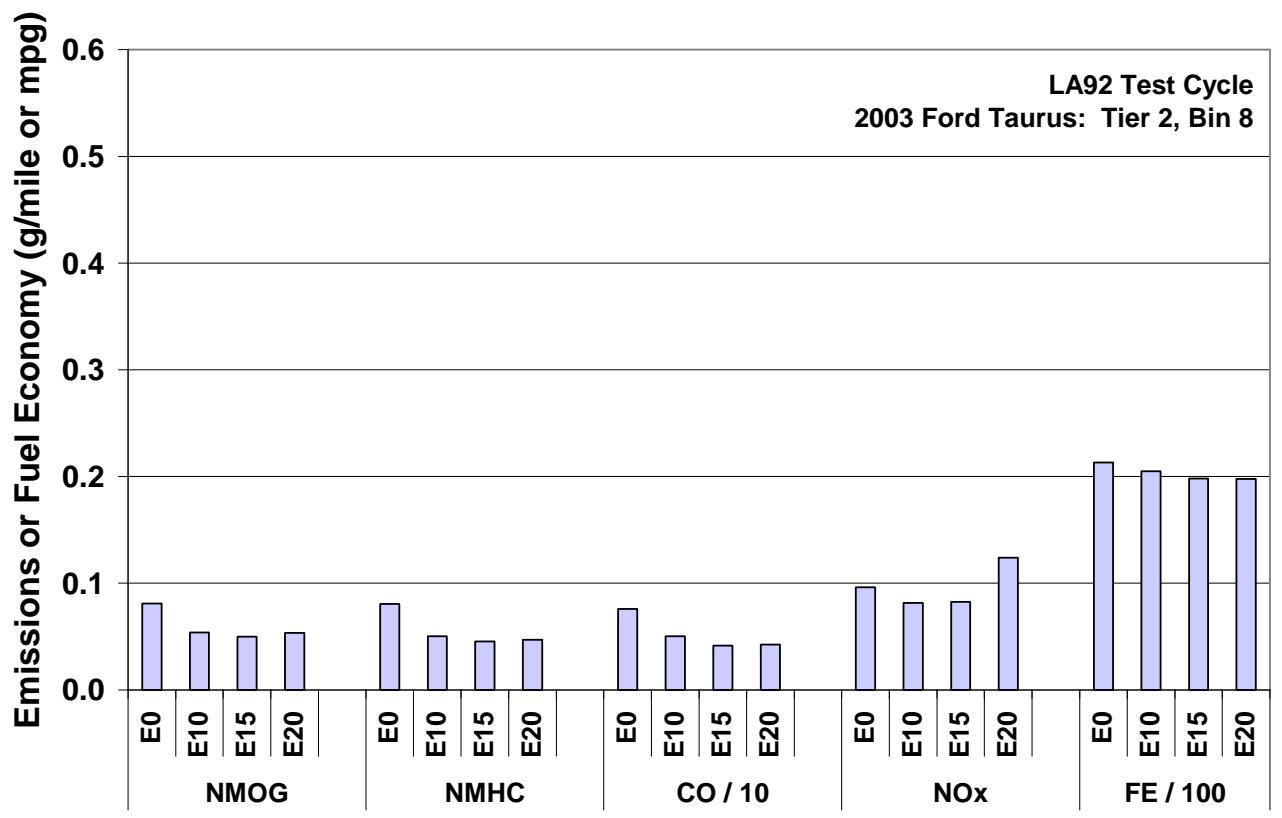

Fig. C.7. Non-methane organic gas (NMOG), non-methane hydrocarbons (NMHC), carbon monoxide (CO), oxides of nitrogen ( $\mathrm{NO}_{\mathrm{X}}$ ), and fuel economy (FE) for 2003 Ford Taurus on LA92 cycle. Bars show average of 3 tests at $75^{\circ} \mathrm{F}$.

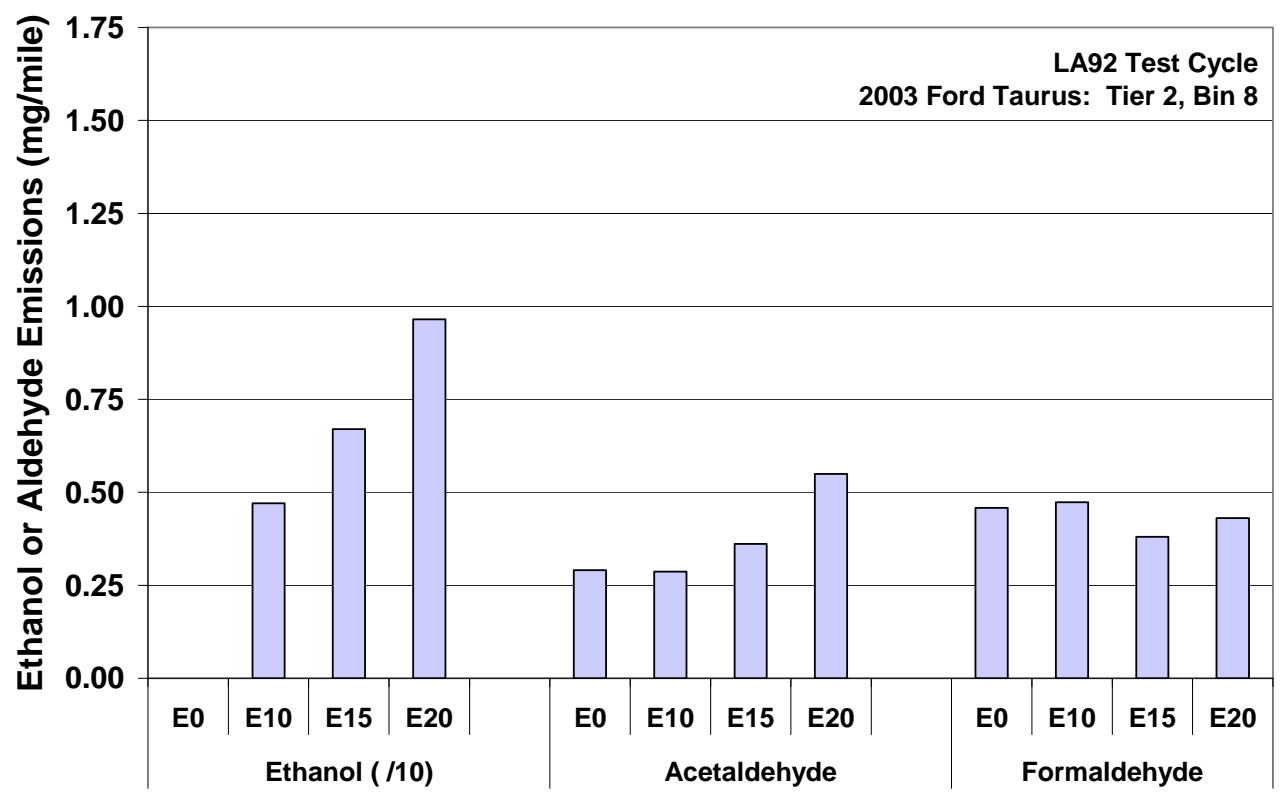

Fig. C.8. Ethanol, acetaldehyde, and formaldehyde emissions for 2003 Ford Taurus on LA92 cycle. Bars show average of 3 tests at $75^{\circ} \mathrm{F}$. 


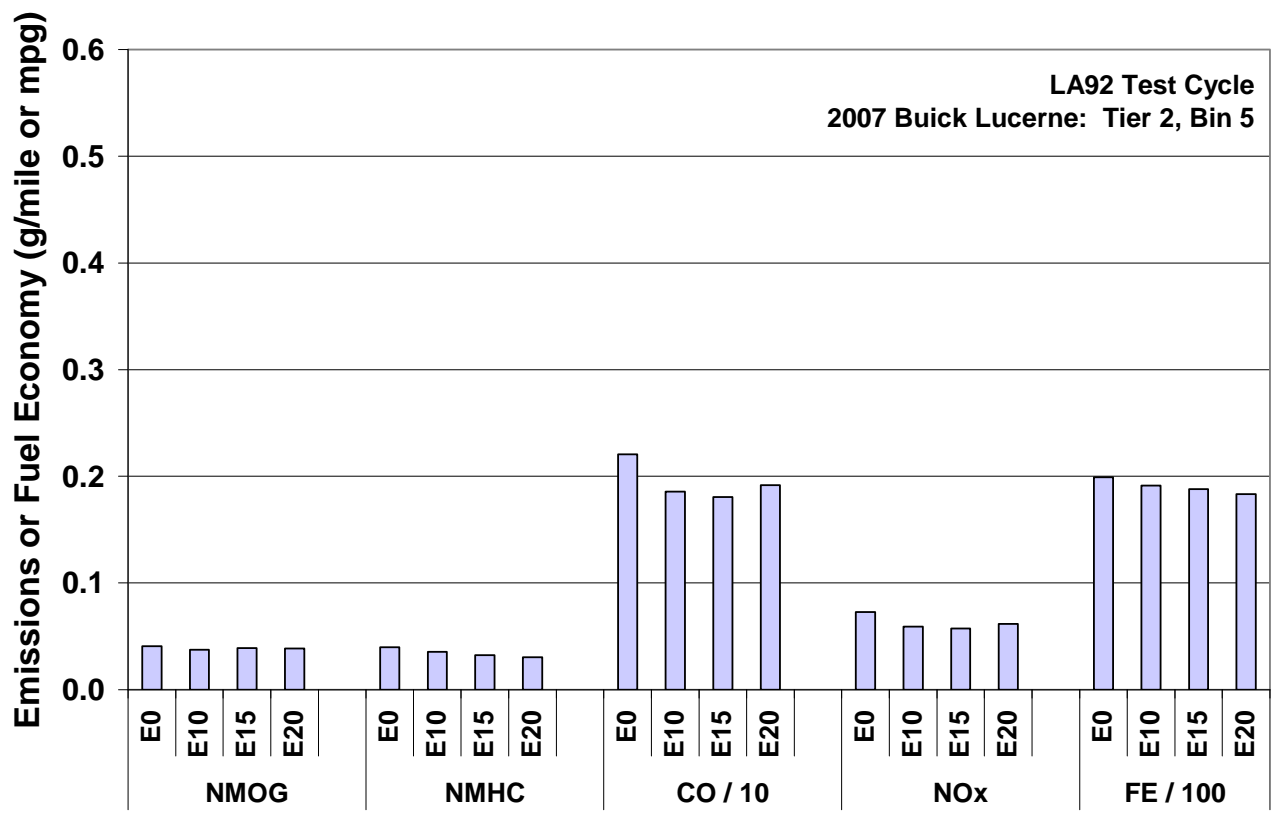

Fig. C.9. Non-methane organic gas (NMOG), non-methane hydrocarbons (NMHC), carbon monoxide (CO), oxides of nitrogen ( $\mathrm{NO}_{\mathrm{X}}$ ), and fuel economy (FE) for 2007 Buick Lucerne on LA92 cycle. Bars show average of 3 tests at $75^{\circ} \mathrm{F}$.

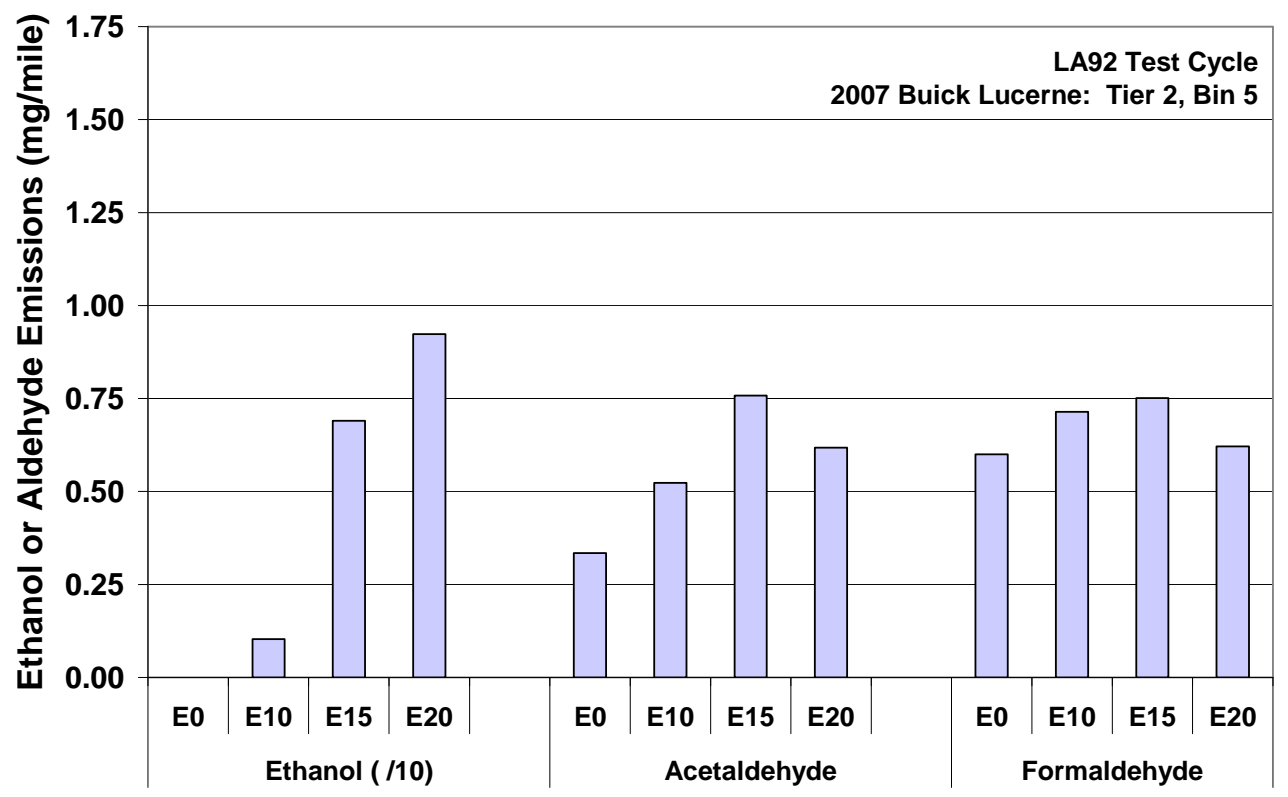

Fig. C.10. Ethanol, acetaldehyde, and formaldehyde emissions for 2007 Buick Lucerne on LA92 cycle. Bars show average of 3 tests at $75^{\circ} \mathrm{F}$. 


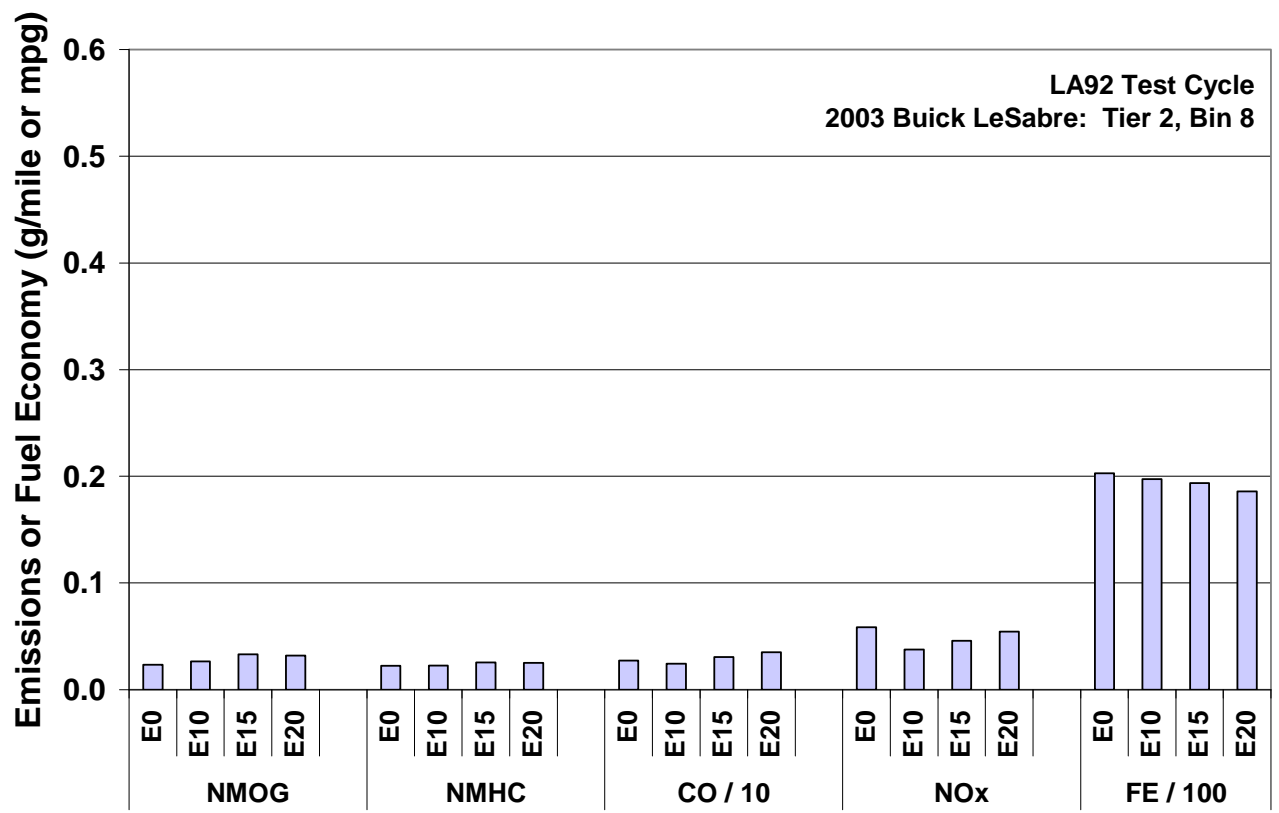

Fig. C.11. Non-methane organic gas (NMOG), non-methane hydrocarbons (NMHC), carbon monoxide (CO), oxides of nitrogen ( $\mathrm{NO}_{\mathrm{X}}$ ), and fuel economy (FE) for 2003 Buick LeSabre on LA92 cycle. Bars show average of 3 tests at $75^{\circ} \mathrm{F}$.

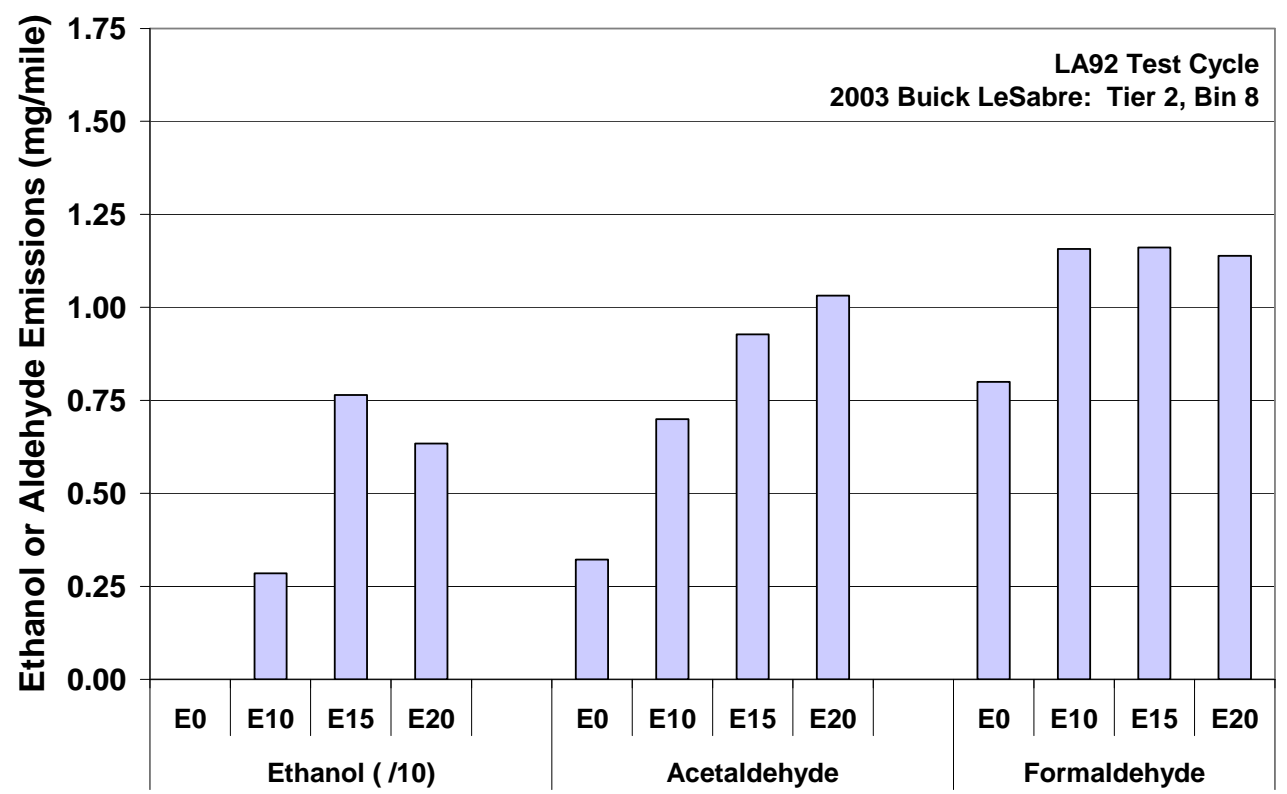

Fig. C.12. Ethanol, acetaldehyde, and formaldehyde emissions for 2003 Buick LeSabre on LA92 cycle. Bars show average of 3 tests at $75^{\circ} \mathrm{F}$. 


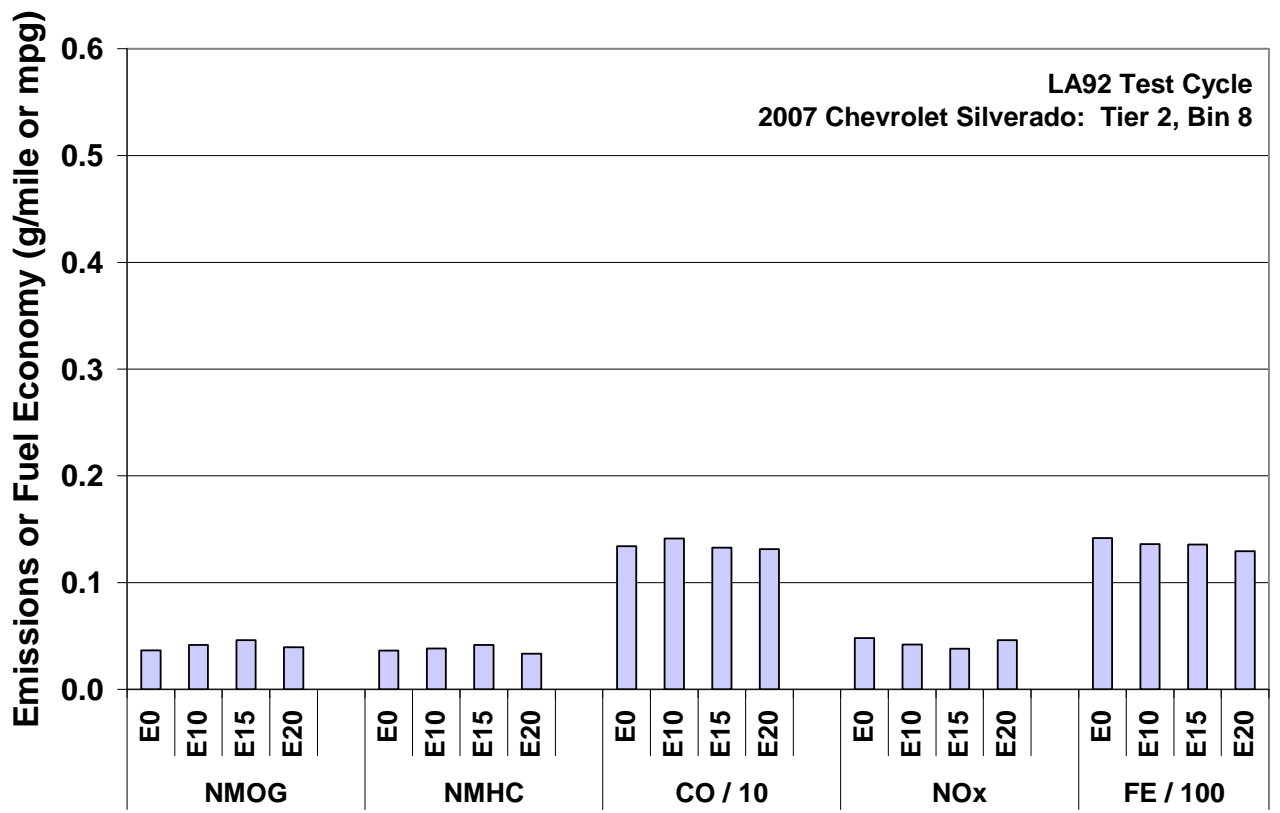

Fig. C.13. Non-methane organic gas (NMOG), non-methane hydrocarbons (NMHC), carbon monoxide (CO), oxides of nitrogen ( $\mathrm{NO}_{\mathrm{X}}$ ), and fuel economy (FE) for 2007 Chevrolet Silverado on LA92 cycle. Bars show average of 3 tests at $75^{\circ} \mathrm{F}$.

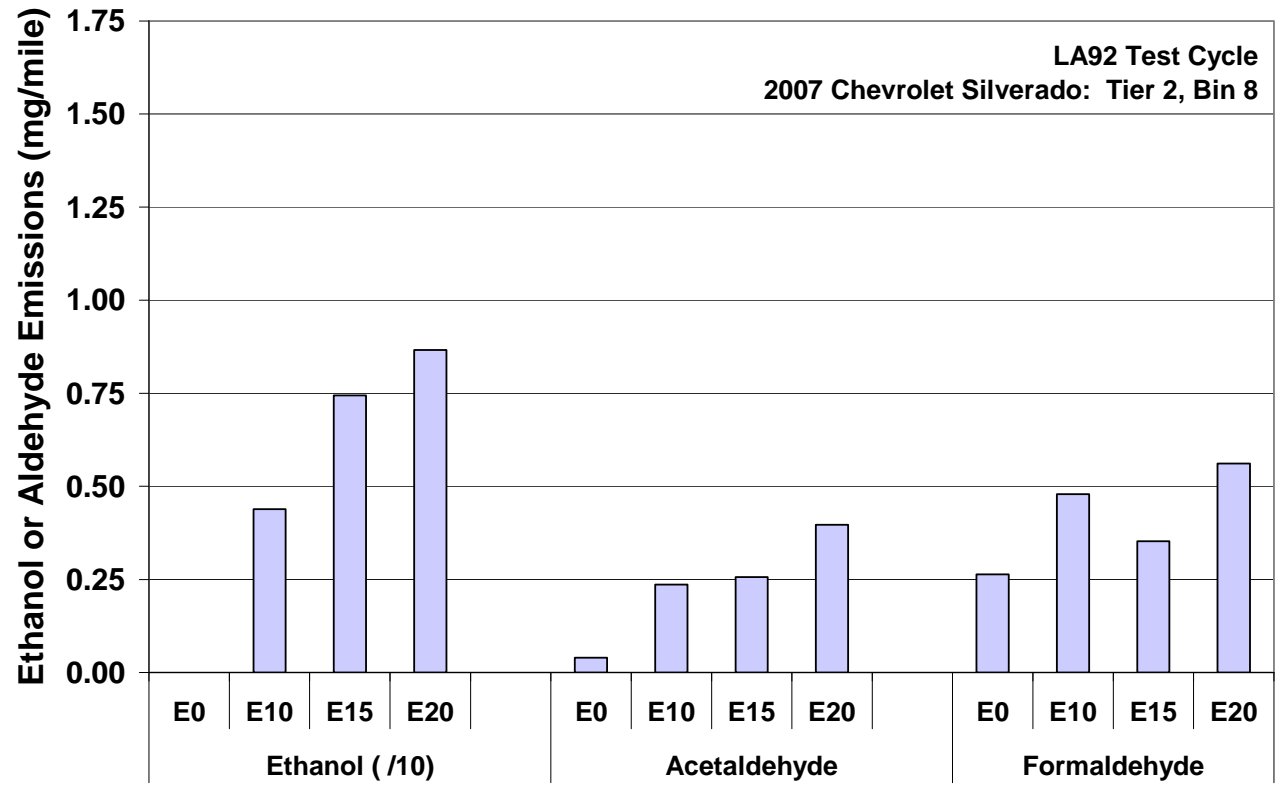

Fig. C.14. Ethanol, acetaldehyde, and formaldehyde emissions for 2007 Chevrolet Silverado on LA92 cycle. Bars show average of 3 tests at $75^{\circ} \mathrm{F}$. 


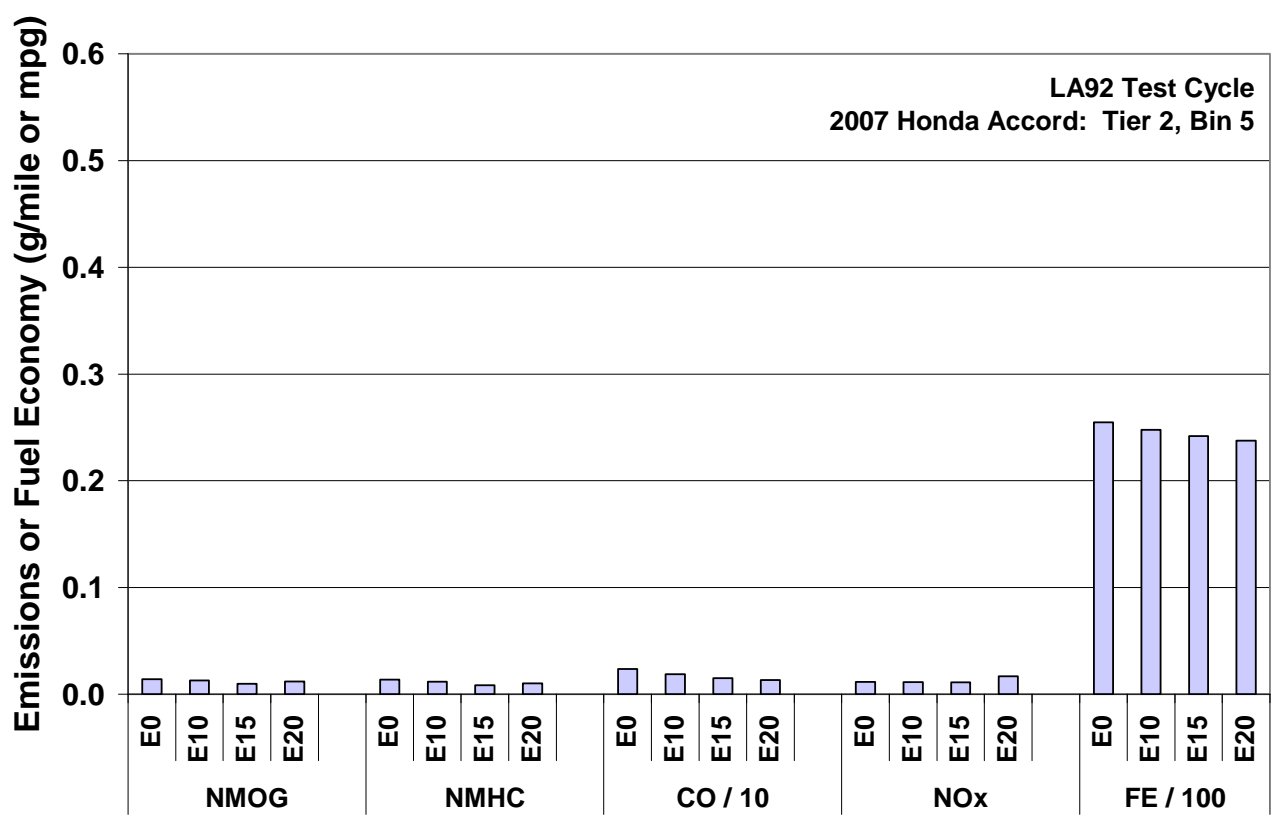

Fig. C.15. Non-methane organic gas (NMOG), non-methane hydrocarbons (NMHC), carbon monoxide (CO), oxides of nitrogen ( $\mathrm{NO}_{\mathrm{x}}$ ), and fuel economy (FE) for 2007 Honda Accord on LA92 cycle. Bars show average of 3 tests at $75^{\circ} \mathrm{F}$.

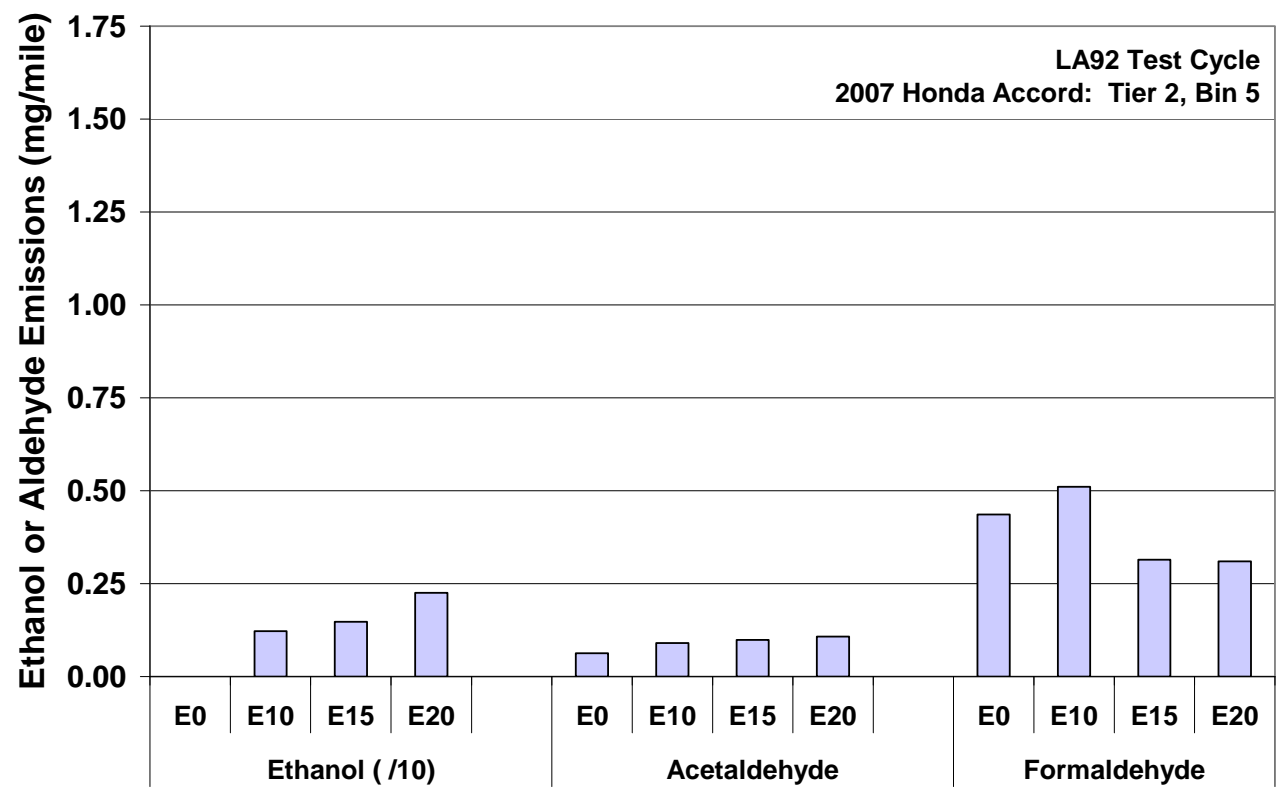

Fig. C.16. Ethanol, acetaldehyde, and formaldehyde emissions for 2007 Honda Accord on LA92 cycle. Bars show average of 3 tests at $75^{\circ} \mathrm{F}$. 


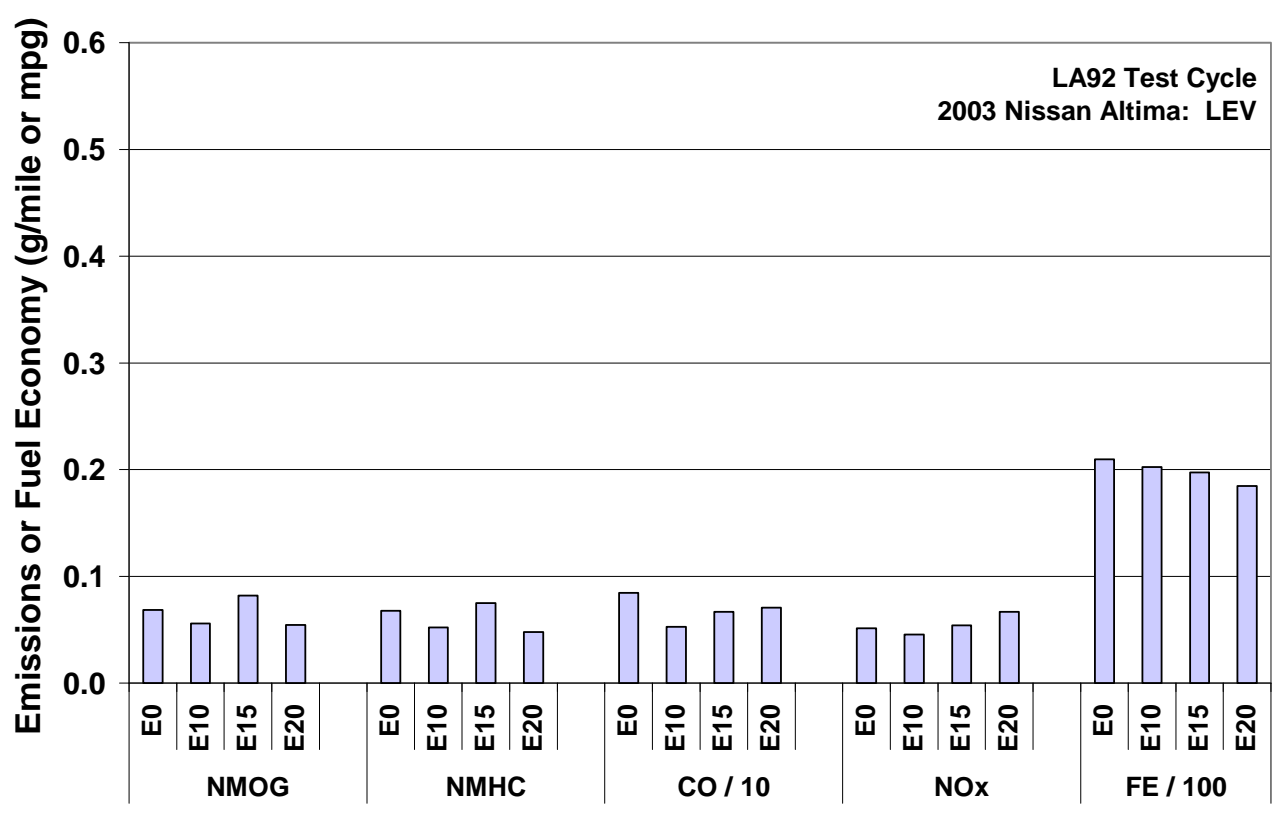

Fig. C.17. Non-methane organic gas (NMOG), non-methane hydrocarbons (NMHC), carbon monoxide (CO), oxides of nitrogen $\left(\mathrm{NO}_{\mathrm{X}}\right)$, and fuel economy (FE) for 2003 Nissan Altima on LA92 cycle. Bars show average of 3 tests at $75^{\circ} \mathrm{F}$.

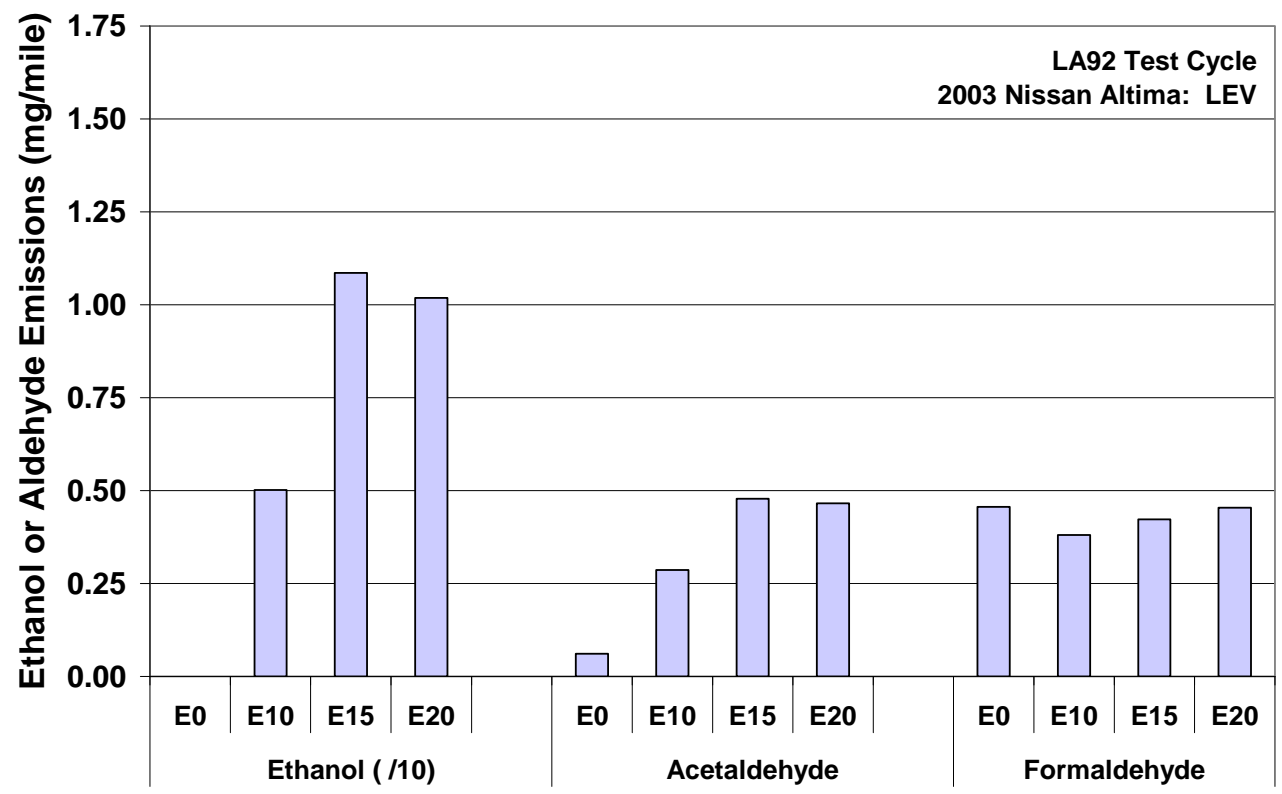

Fig. C.18. Ethanol, acetaldehyde, and formaldehyde emissions for 2003 Nissan Altima on LA92 cycle. Bars show average of 3 tests at $75^{\circ} \mathrm{F}$. 


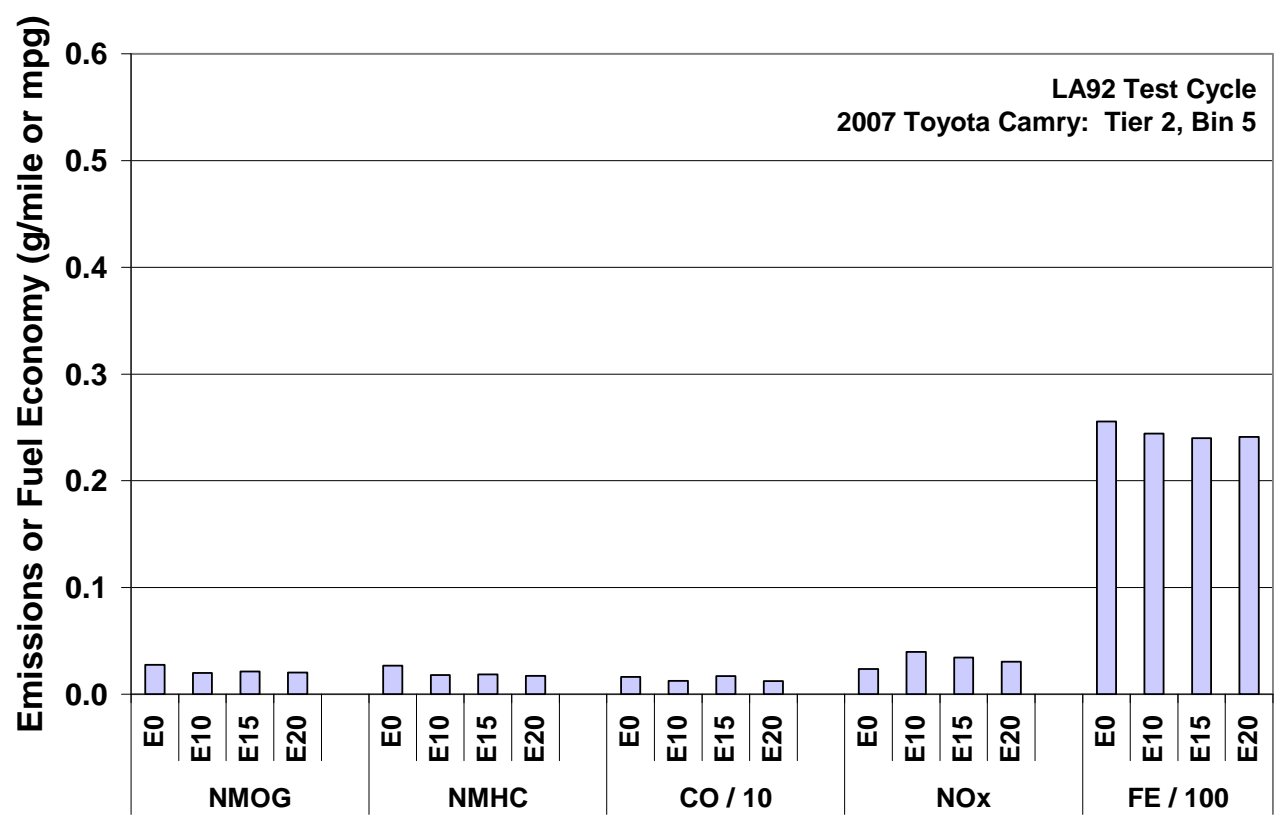

Fig. C.19. Non-methane organic gas (NMOG), non-methane hydrocarbons (NMHC), carbon monoxide (CO), oxides of nitrogen $\left(\mathrm{NO}_{\mathrm{X}}\right)$, and fuel economy (FE) for 2007 Toyota Camry on LA92 cycle. Bars show average of 3 tests at $75^{\circ} \mathrm{F}$.

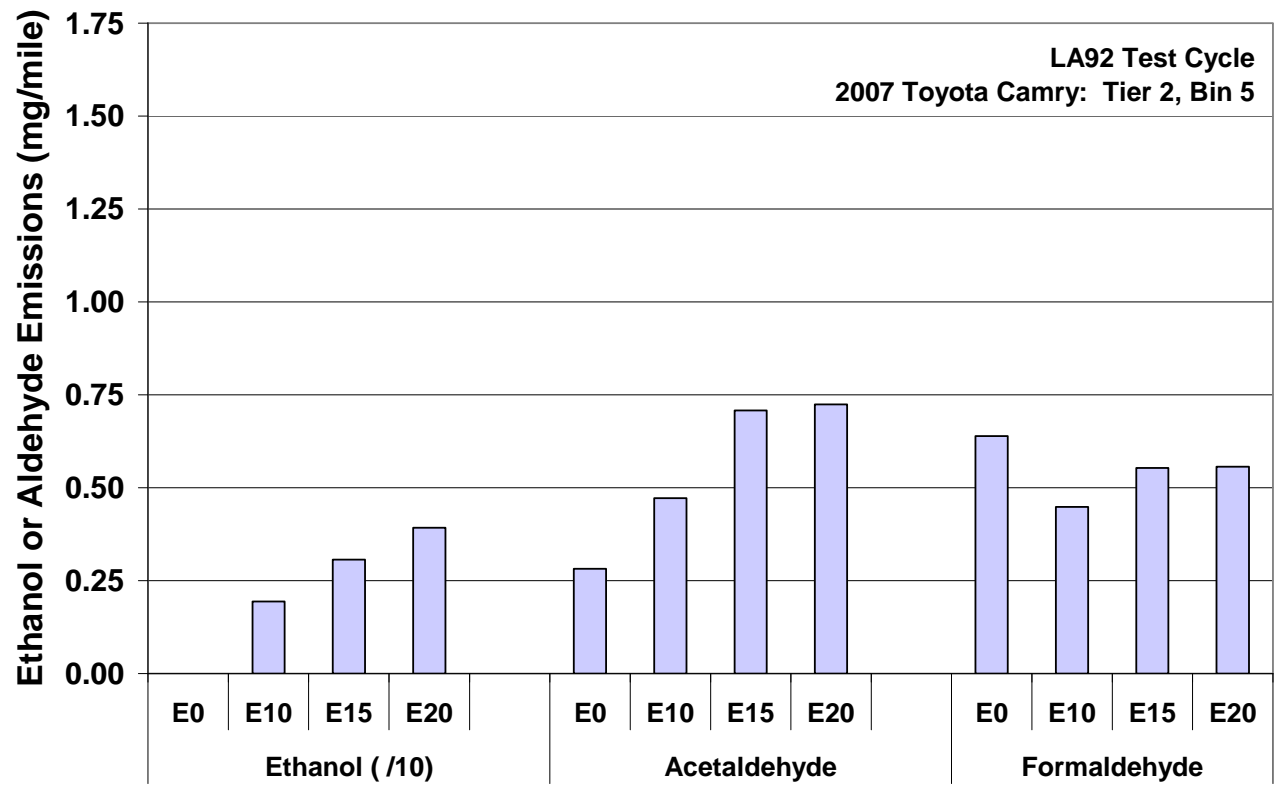

Fig. C.20. Ethanol, acetaldehyde, and formaldehyde emissions for 2007 Toyota Camry on LA92 cycle. Bars show average of 3 tests at $75^{\circ} \mathrm{F}$. 


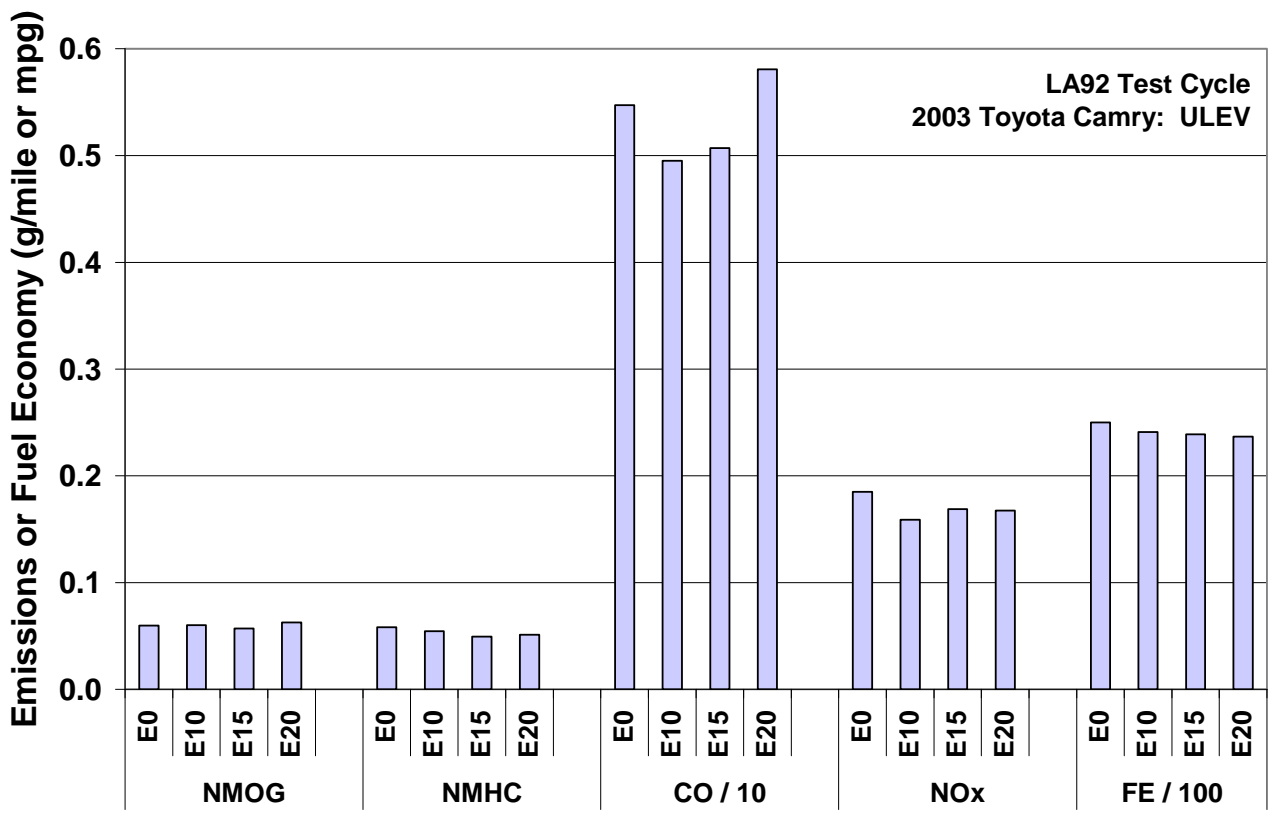

Fig. C.21. Non-methane organic gas (NMOG), non-methane hydrocarbons (NMHC), carbon monoxide (CO), oxides of nitrogen ( $\mathrm{NO}_{\mathrm{X}}$ ), and fuel economy (FE) for 2003 Toyota Camry on LA92 cycle. Bars show average of 3 tests at $75^{\circ} \mathrm{F}$.

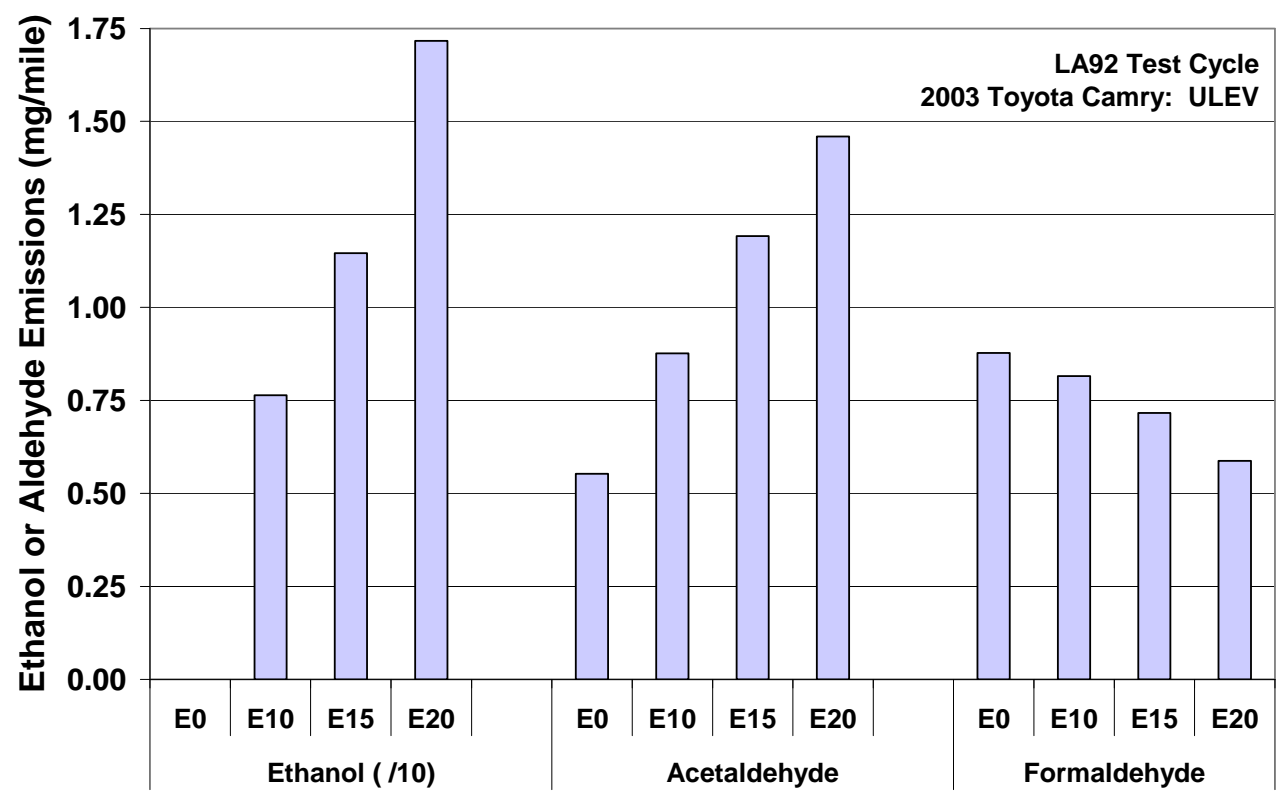

Fig. C.22. Ethanol, acetaldehyde, and formaldehyde emissions for 2003 Toyota Camry on LA92 cycle. Bars show average of 3 tests at $75^{\circ} \mathrm{F}$. 


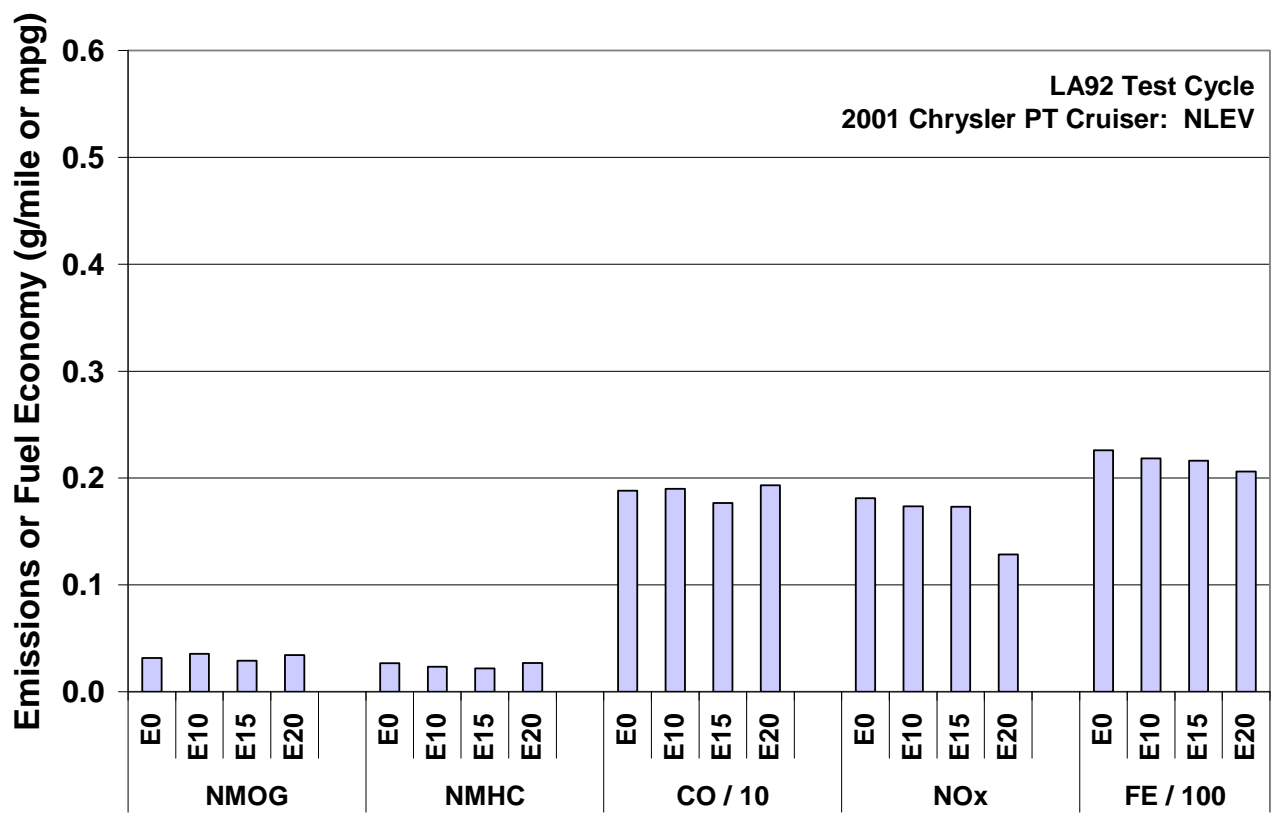

Fig. C.23. Non-methane organic gas (NMOG), non-methane hydrocarbons (NMHC), carbon monoxide (CO), oxides of nitrogen ( $\mathrm{NO}_{\mathrm{X}}$ ), and fuel economy (FE) for 2001 Chrysler PT Cruiser on LA92 cycle. Bars show average of 3 tests at $75^{\circ} \mathrm{F}$.

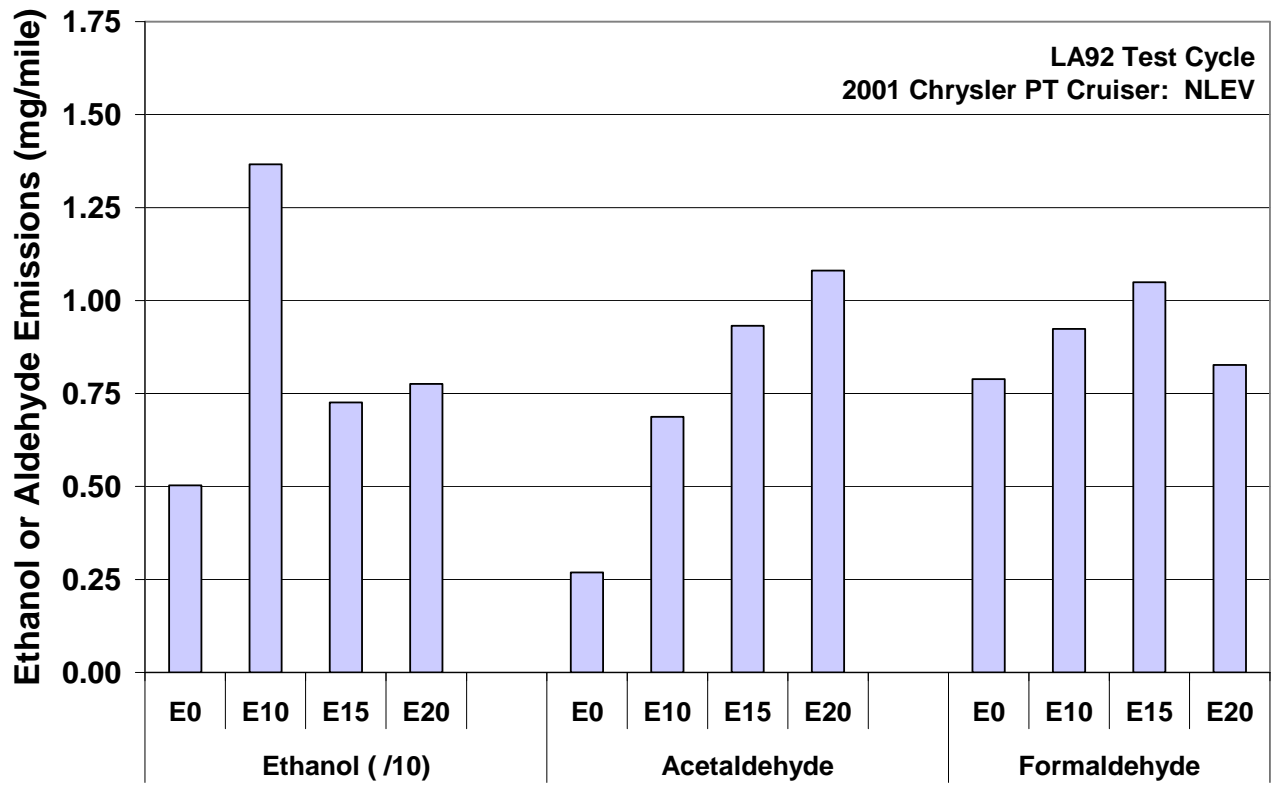

Fig. C.24. Ethanol, acetaldehyde, and formaldehyde emissions for 2001 Chrysler PT Cruiser on LA92 cycle. Bars show average of 3 tests at $75^{\circ} \mathrm{F}$. 


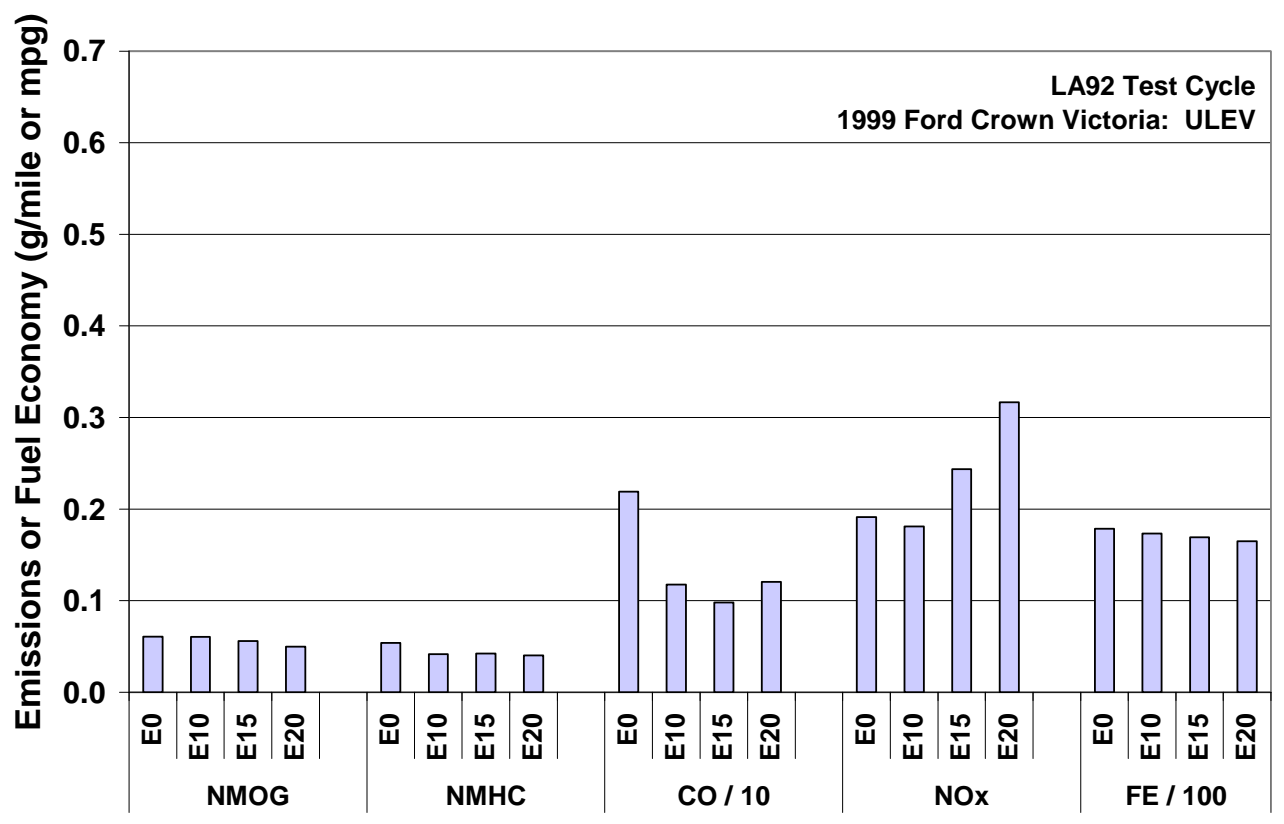

Fig. C.25. Non-methane organic gas (NMOG), non-methane hydrocarbons (NMHC), carbon monoxide (CO), oxides of nitrogen ( $\left.\mathrm{NO}_{\mathrm{X}}\right)$, and fuel economy (FE) for 1999 Ford Crown Victoria on LA92 cycle. Bars show average of 3 tests at $75^{\circ} \mathrm{F}$.

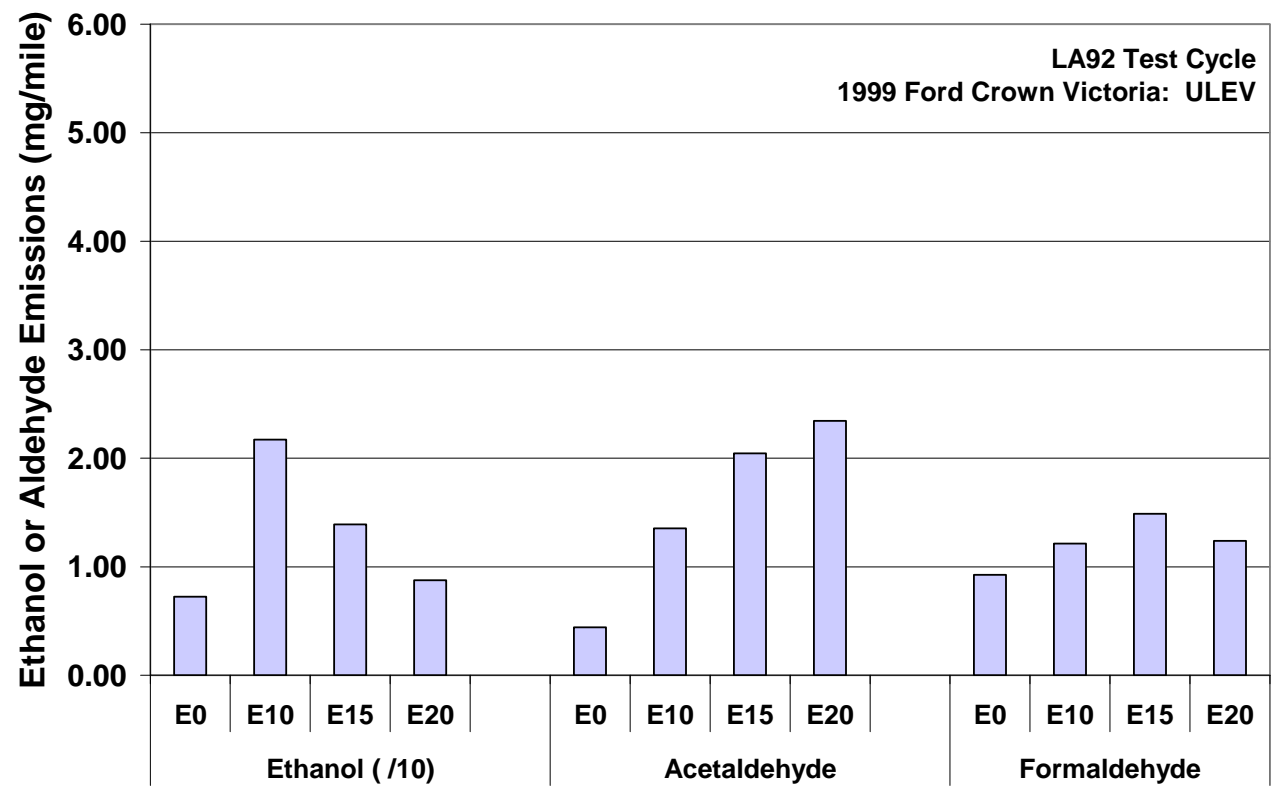

Fig. C.26. Ethanol, acetaldehyde, and formaldehyde emissions for 1999 Ford Crown Victoria on LA92 cycle. Bars show average of 3 tests at $75^{\circ} \mathrm{F}$. 


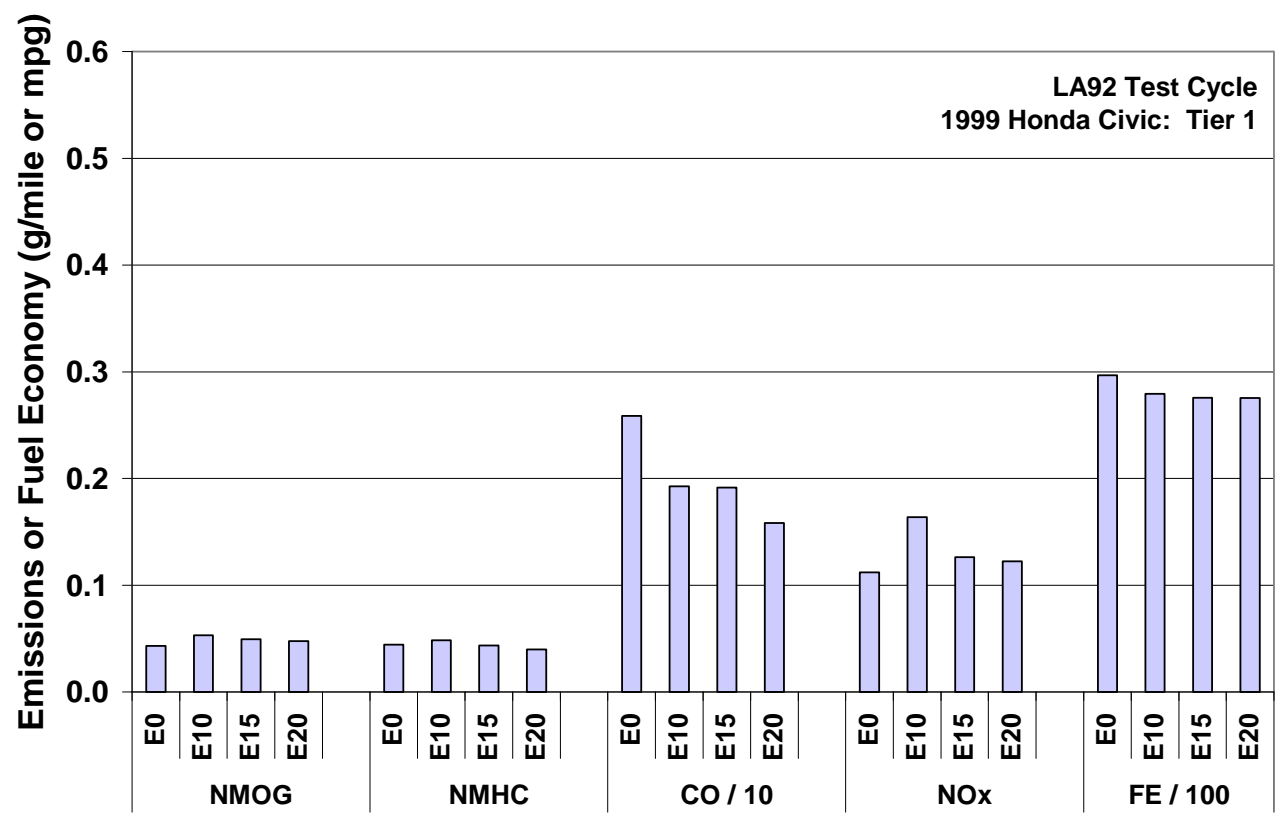

Fig. C.27. Non-methane organic gas (NMOG), non-methane hydrocarbons (NMHC), carbon monoxide (CO), oxides of nitrogen ( $\mathrm{NO}_{\mathrm{X}}$ ), and fuel economy (FE) for 1999 Honda Civic on LA92 cycle. Bars show average of 3 tests at $75^{\circ} \mathrm{F}$.

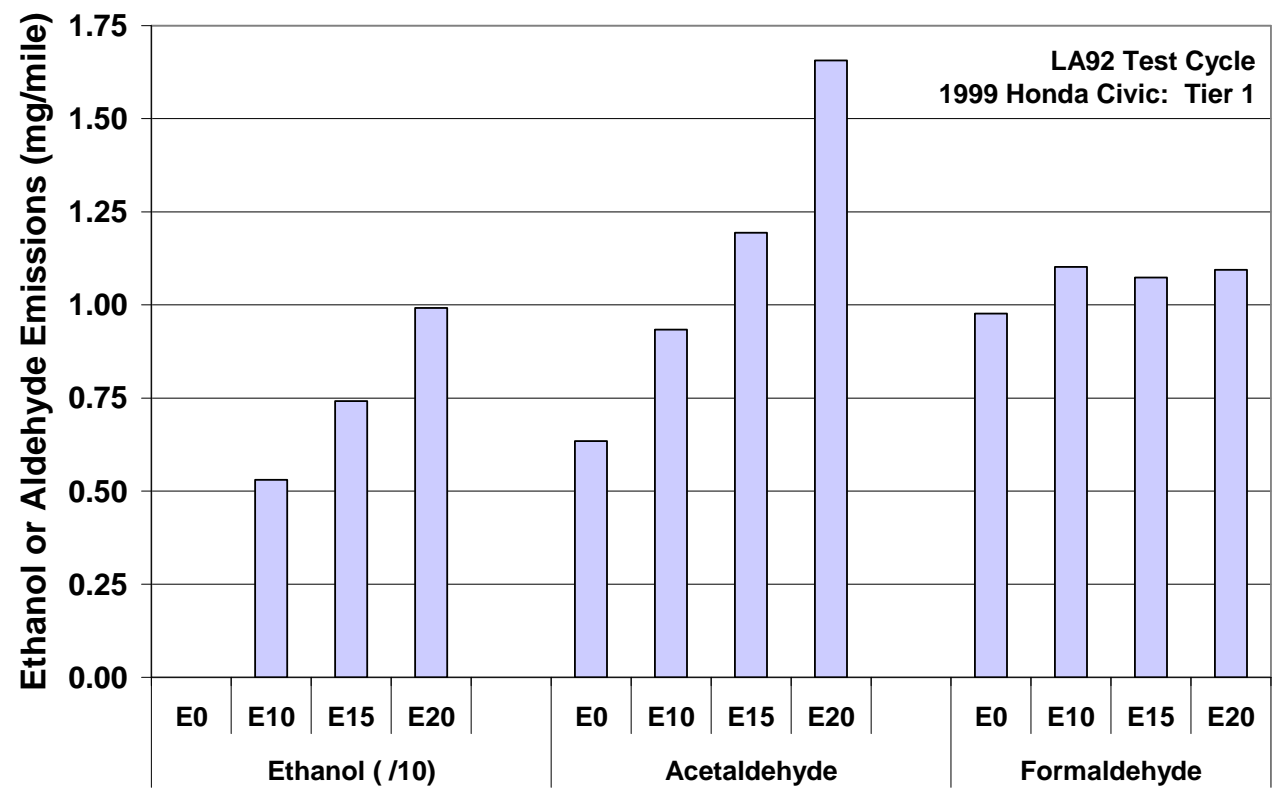

Fig. C.28. Ethanol, acetaldehyde, and formaldehyde emissions for 1999 Honda Civic on LA92 cycle. Bars show average of 3 tests at $75^{\circ} \mathrm{F}$. 


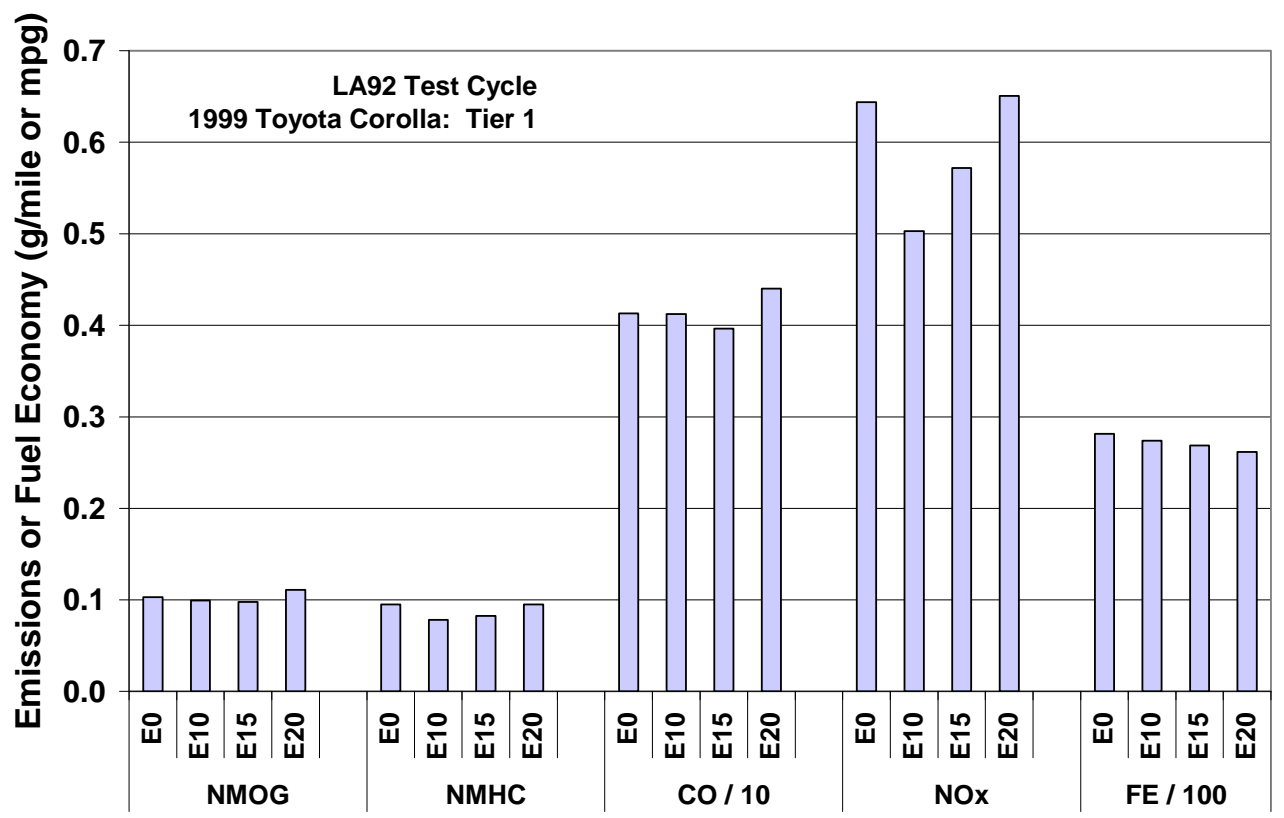

Fig. C.29. Non-methane organic gas (NMOG), non-methane hydrocarbons (NMHC), carbon monoxide (CO), oxides of nitrogen $\left(\mathrm{NO}_{\mathrm{X}}\right)$, and fuel economy (FE) for 1999 Toyota Corolla on LA92 cycle. Bars show average of 3 tests at $75^{\circ} \mathrm{F}$.

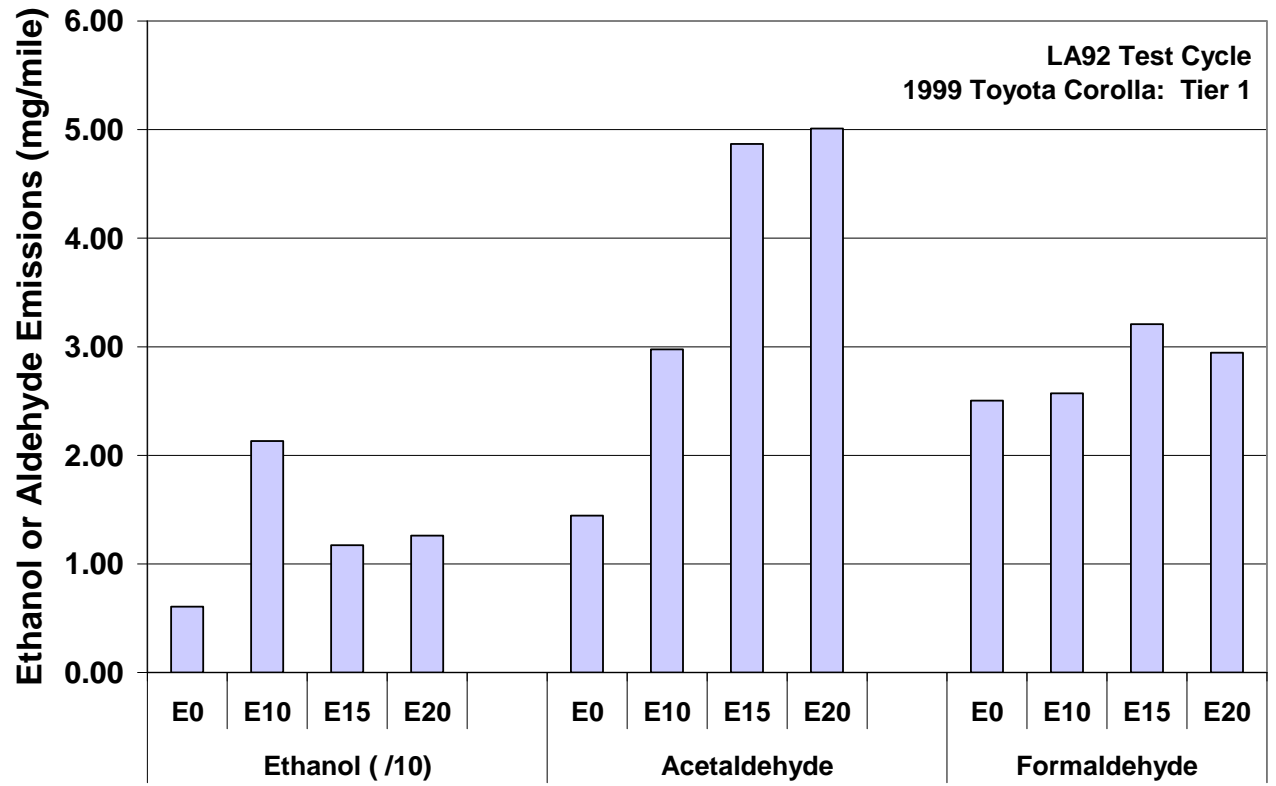

Fig. C.30. Ethanol, acetaldehyde, and formaldehyde emissions for 1999 Toyota Corolla on LA92 cycle. Bars show average of 3 tests at $75^{\circ} \mathrm{F}$. 


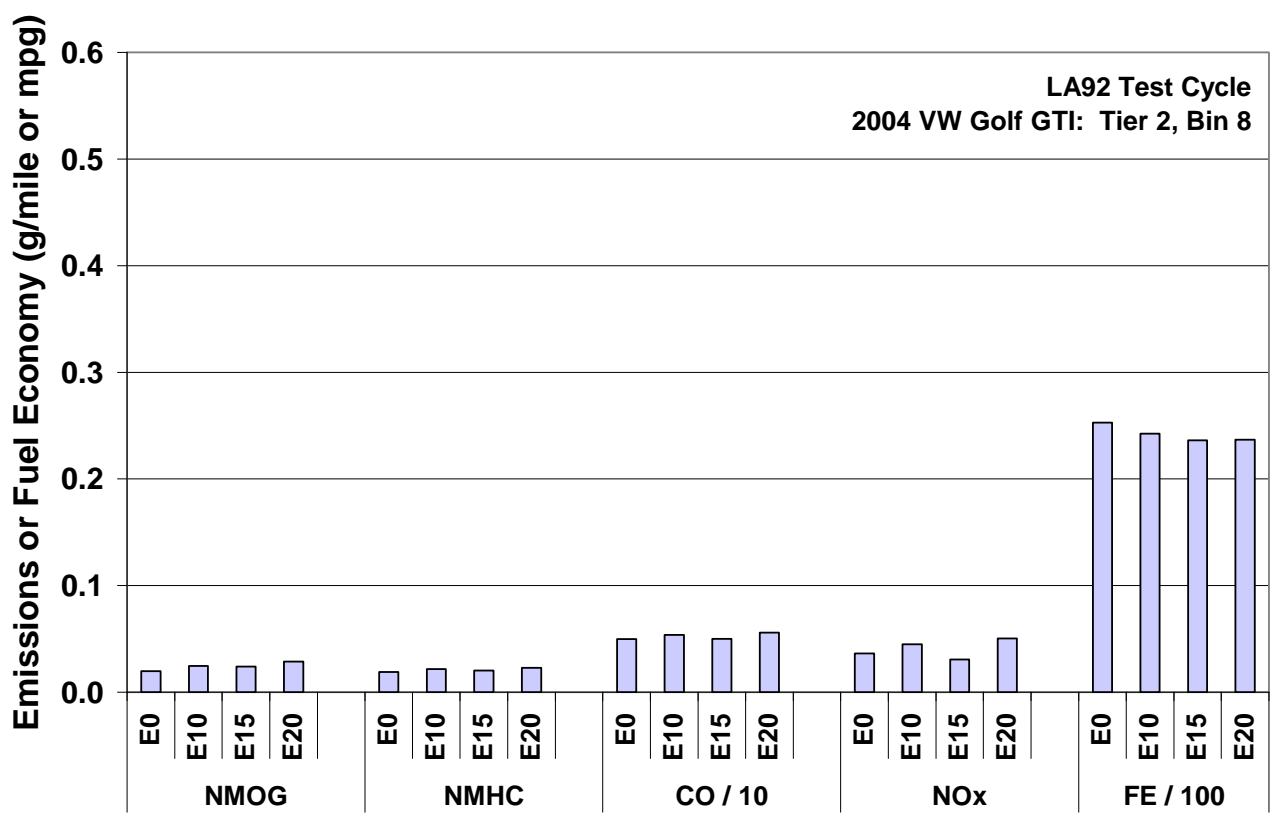

Fig. C.31. Non-methane organic gas (NMOG), non-methane hydrocarbons (NMHC), carbon monoxide (CO), oxides of nitrogen ( $\mathrm{NO}_{\mathrm{X}}$ ), and fuel economy (FE) for 2004 Volkswagen Golf GTI on LA92 cycle. Bars show average of 3 tests at $75^{\circ} \mathrm{F}$.

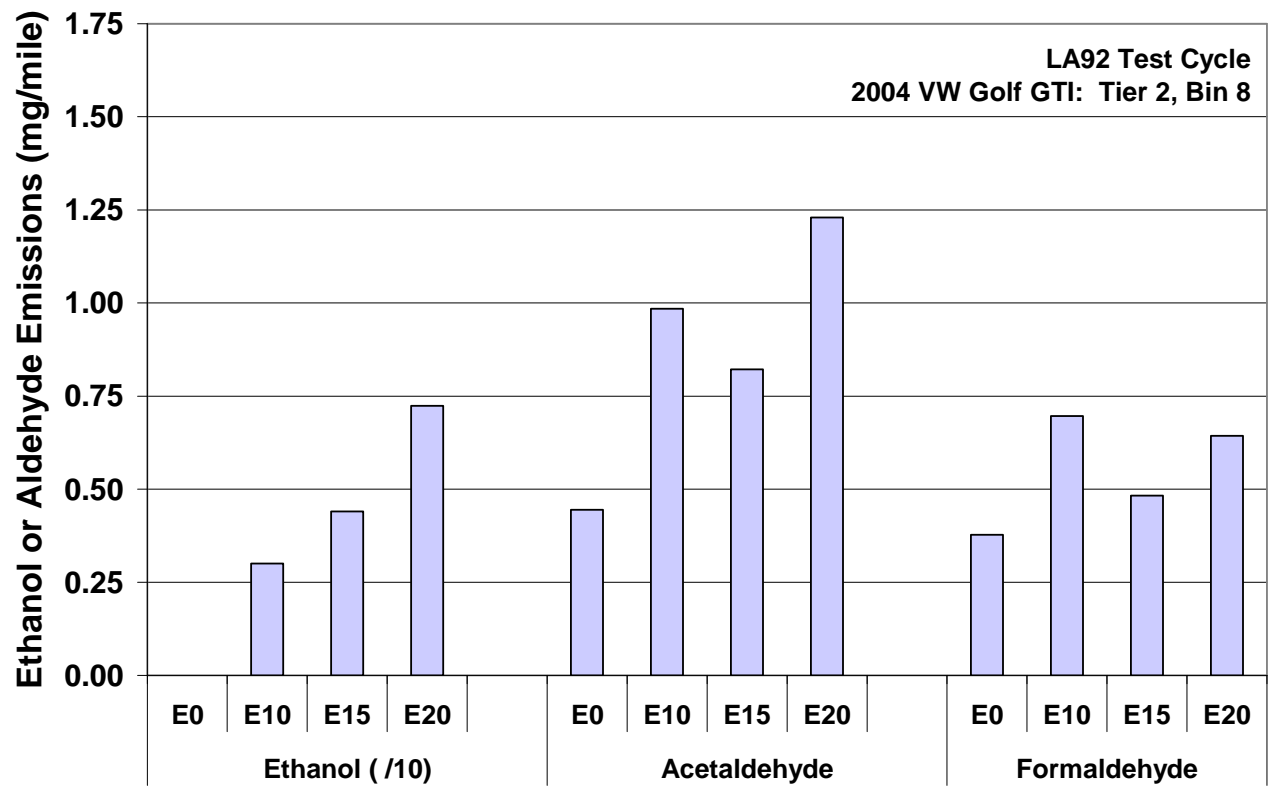

Fig. C.32. Ethanol, acetaldehyde, and formaldehyde emissions for 2004 Volkswagen Golf GTI on LA92 cycle. Bars show average of 3 tests at $75^{\circ} \mathrm{F}$. 


\section{APPENDIX D}

\section{SMALL ENGINE FULL-USEFUL-LIFE TESTING}

\section{D.1 EMISSIONS}

The following figures and tables show the full set of exhaust emissions data for the full-useful-life (full-life) small, non-road engine (SNRE) testing at the Transportation Research Center (TRC). Figures show the brake-specific emissions for the composite of the appropriate 6-mode (Class I engines) or 2-mode (Class IV engines) test. Data from the new condition are shown for all engines with E0 fuel and then each engine on its respective ethanol blend (E10, E15, or E20). When available, full-life data are also shown on the same figure. Trendlines are simple linear regressions for the new or full-life condition, as noted in the figures. The dedicated E0 engine results are shown for reference but were not used in the trendline regression since these engines ran only the E0 fuel. Figures are arranged first by engine type, then by emissions constituent. The $\mathrm{HC}$ emissions results shown here are as indicated by the flame ionization detector (FID) and do not include any correction for oxygenated compounds in the exhaust such as ethanol or aldehydes.

Figures D. 1 through D.4 show the hydrocarbon $(\mathrm{HC})$, oxides of nitrogen $\left(\mathrm{NO}_{\mathrm{X}}\right), \mathrm{HC}+\mathrm{NO}_{\mathrm{X}}$, and $\mathrm{CO}$ emissions for the Class I Briggs and Stratton power washer engines on the TRC protocol. The Briggs and Stratton engines were emissions tested on the dynamometer using two different 6-mode protocols. On the TRC protocol, mode 1 for the Briggs and Stratton engine was under governor control to match the spray condition used during aging. Similar plots are shown in Figs. D5 through D.8 for the same engines on the BASCO protocol. On the BASCO protocol, the throttle was mechanically fixed to the wide-open position, overriding the governor for mode 1 . This protocol was only run on PW1-PW4 at the full-life condition; thus, PW5 with E0 fuel was also tested on the BASCO protocol for a new engine baseline comparison.

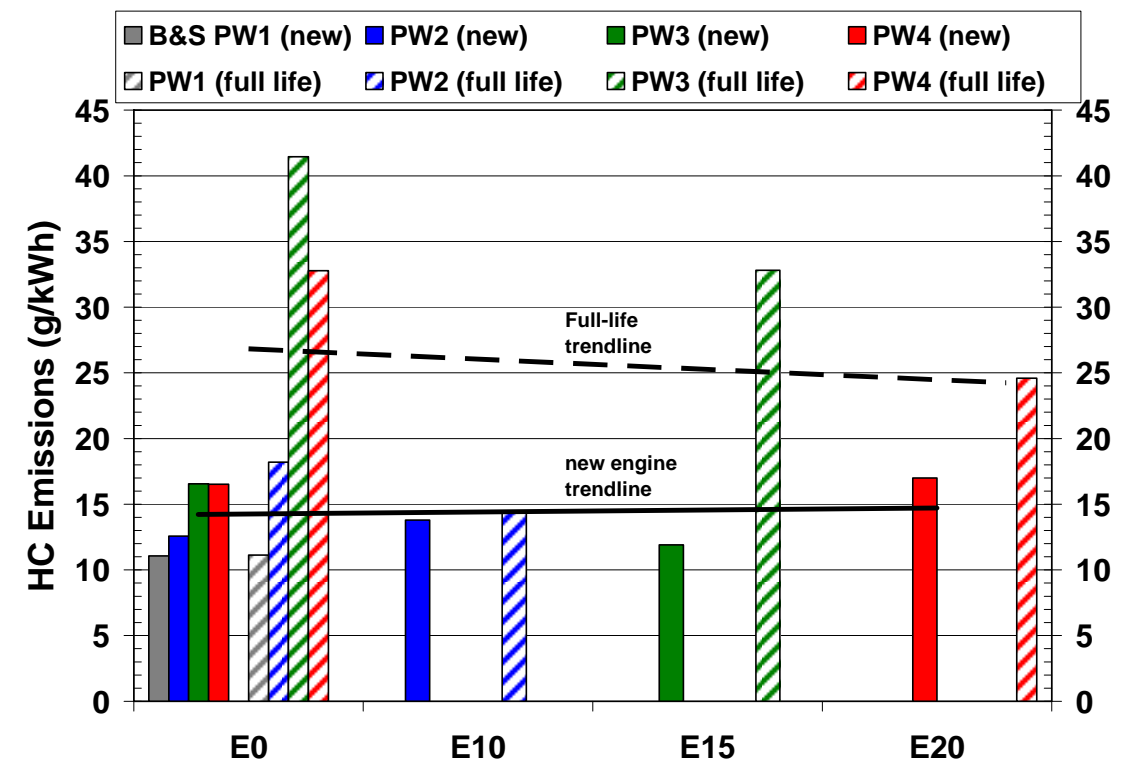

Fig. D.1. Hydrocarbon (HC) emissions for Class I Briggs and Stratton power washer engines on Transportation Research Center protocol at new and full-useful-life (full-life) condition. Solid colors represent tests in the new condition while striped bars of the same color represent the same engine at the full-life condition. 


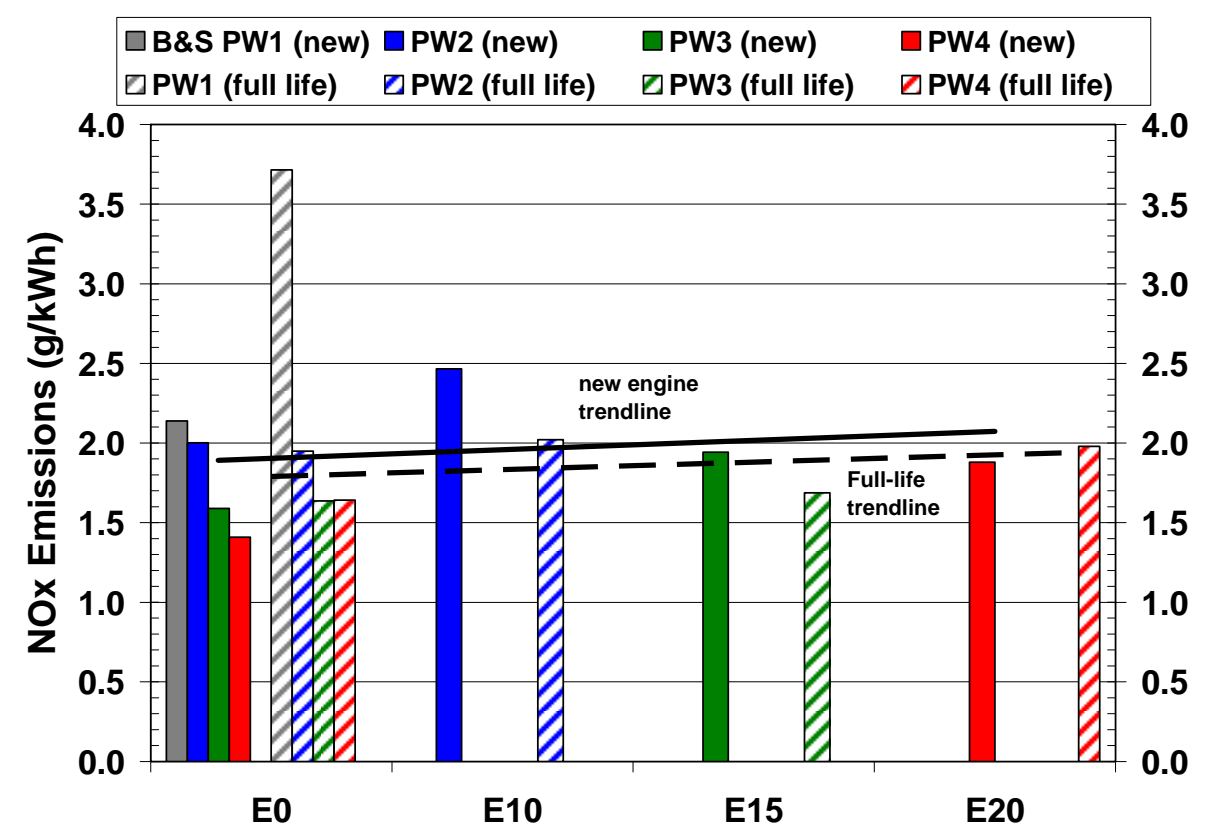

Fig. D.2. Nitrogen oxide $\left(\mathrm{NO}_{\mathrm{x}}\right)$ emissions for Class I Briggs and Stratton power washer engines on the Transportation Research Center protocol at new and fulluseful-life (full-life) condition. Solid colors represent tests in the new condition while striped bars of the same color represent the same engine at the full-life condition.

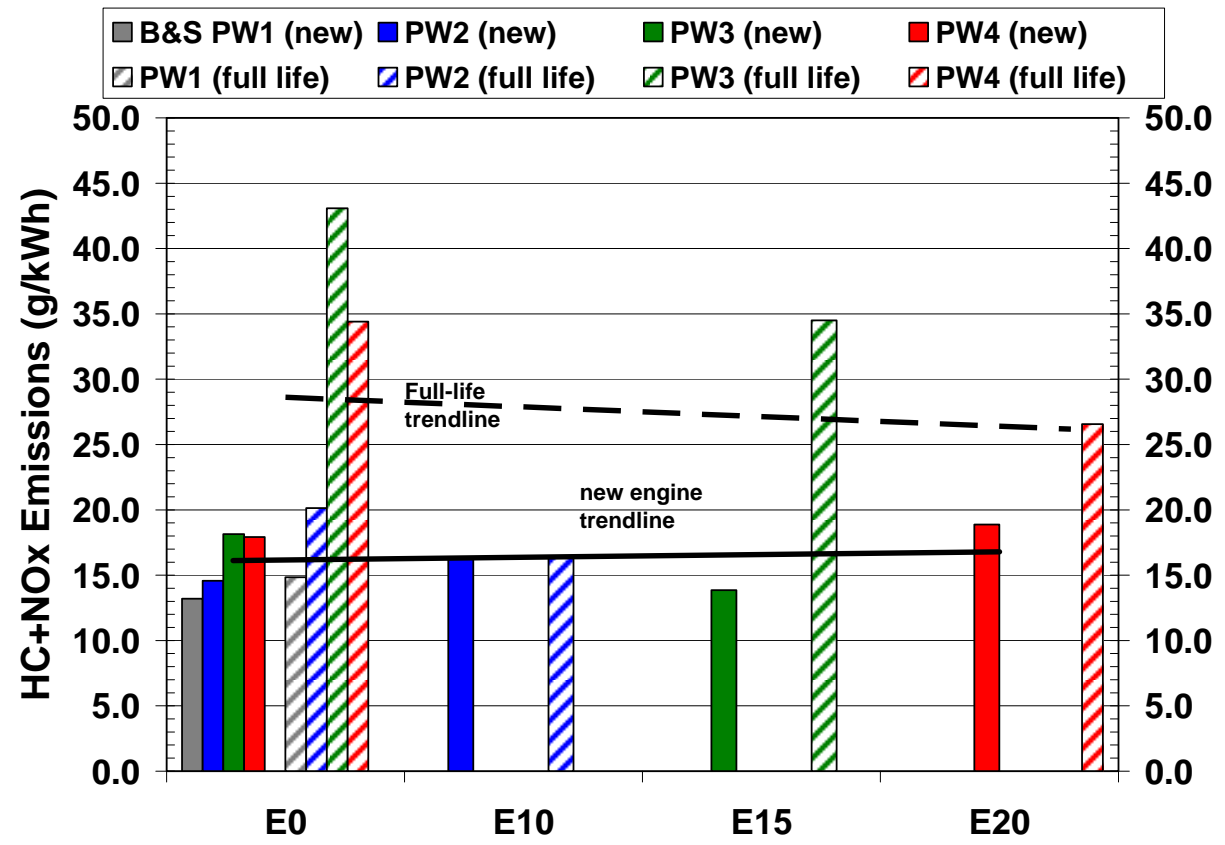

Fig. D.3. Hydrocarbon (HC) + nitrogen oxide $\left(\mathrm{NO}_{\mathrm{x}}\right)$ emissions for Class I Briggs and Stratton power washer engines on the Transportation Research Center protocol at new and full-useful-life (full-life) condition. Solid colors represent tests in the new condition while striped bars of the same color represent the same engine at the full-life condition. 


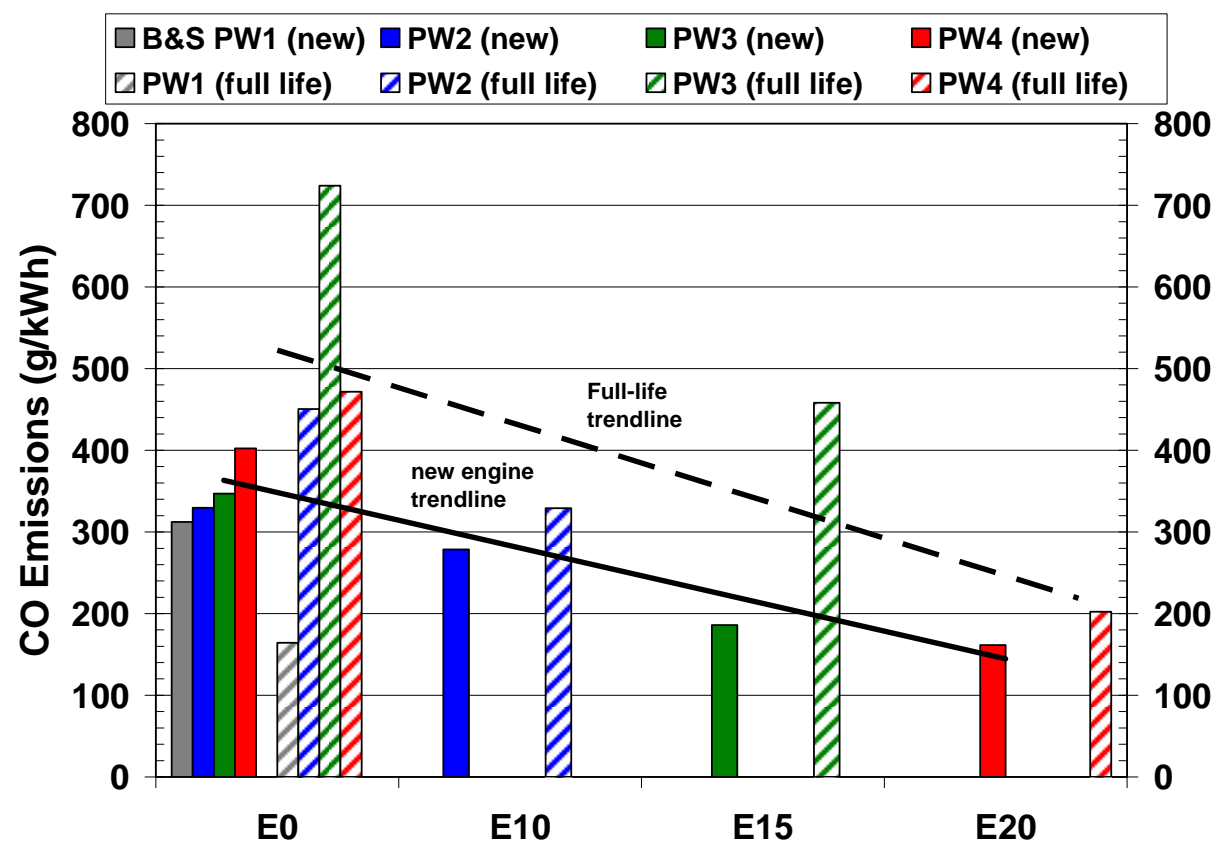

Fig. D.4. Carbon monoxide emissions for Class I Briggs and Stratton power washer engines on the Transportation Research Center protocol at new and fulluseful-life (full-life) condition. Solid colors represent tests in the new condition while striped bars of the same color represent the same engine at the full-life condition.

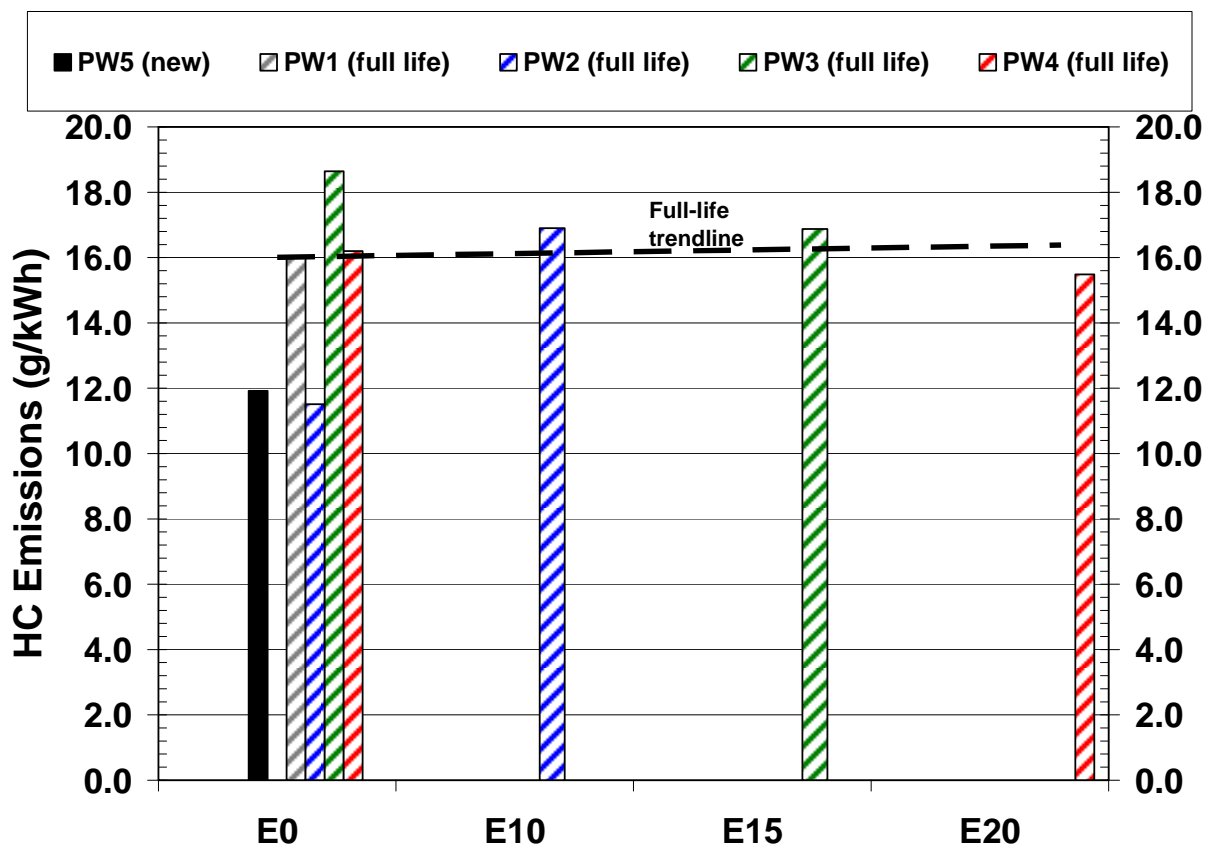

Fig. D.5. Hydrocarbon (HC) emissions for Class I Briggs and Stratton power washer engines on the Briggs and Stratton Company (BASCO) protocol. Only PW5 was baselined on E0 in new condition on the BASCO protocol. The solid black bar is for the new PW5 data, while the striped bars represent the full-useful-life (full-life) condition as in previous figures. 


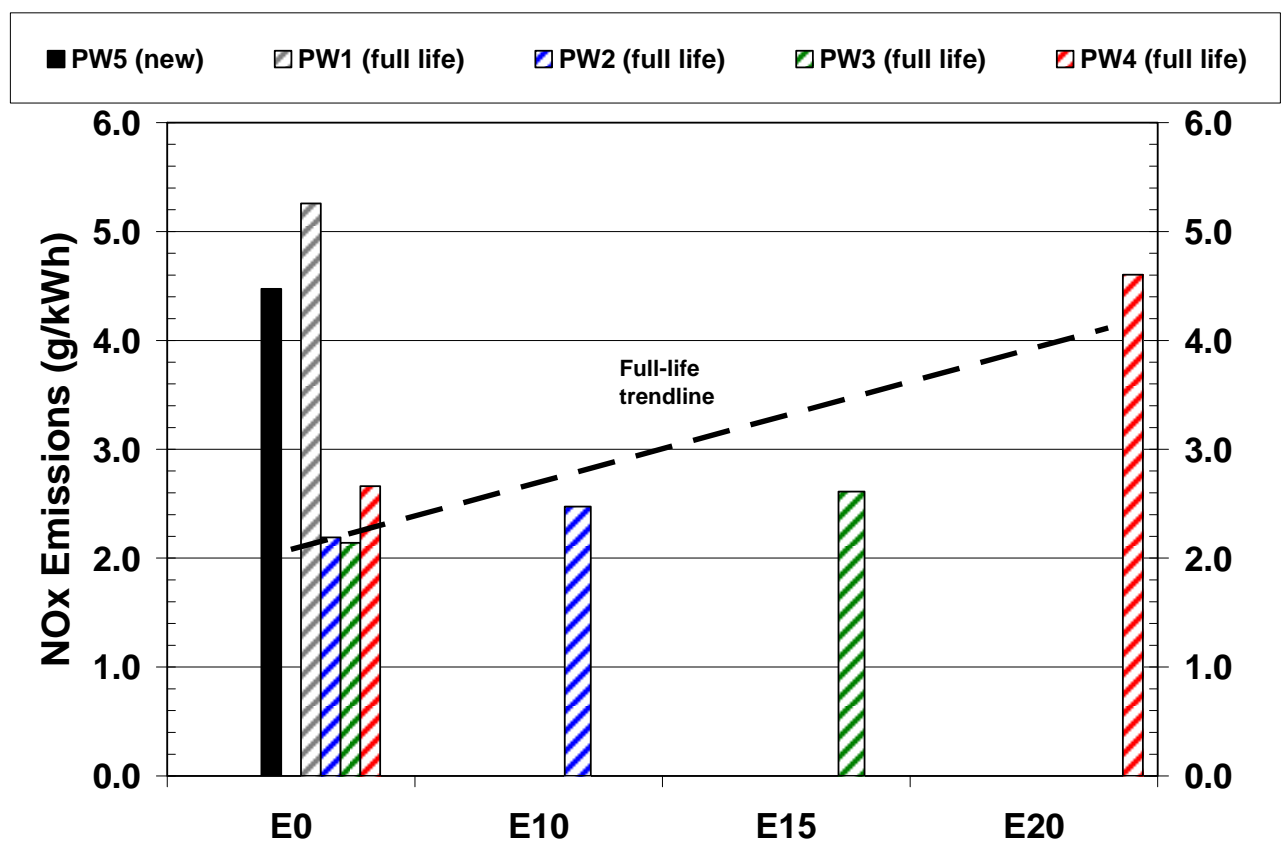

Fig. D.6. Nitrogen oxide $\left(\mathrm{NO}_{\mathrm{x}}\right)$ emissions for Class I Briggs and Stratton power washer engines on the Briggs and Stratton Company (BASCO) protocol at new and full-useful-life (full-life) condition. Only PW5 was baselined on E0 in new condition on the BASCO protocol. The solid black bar is for the new PW5 data, while the striped bars represent the full-life condition as in previous figures.

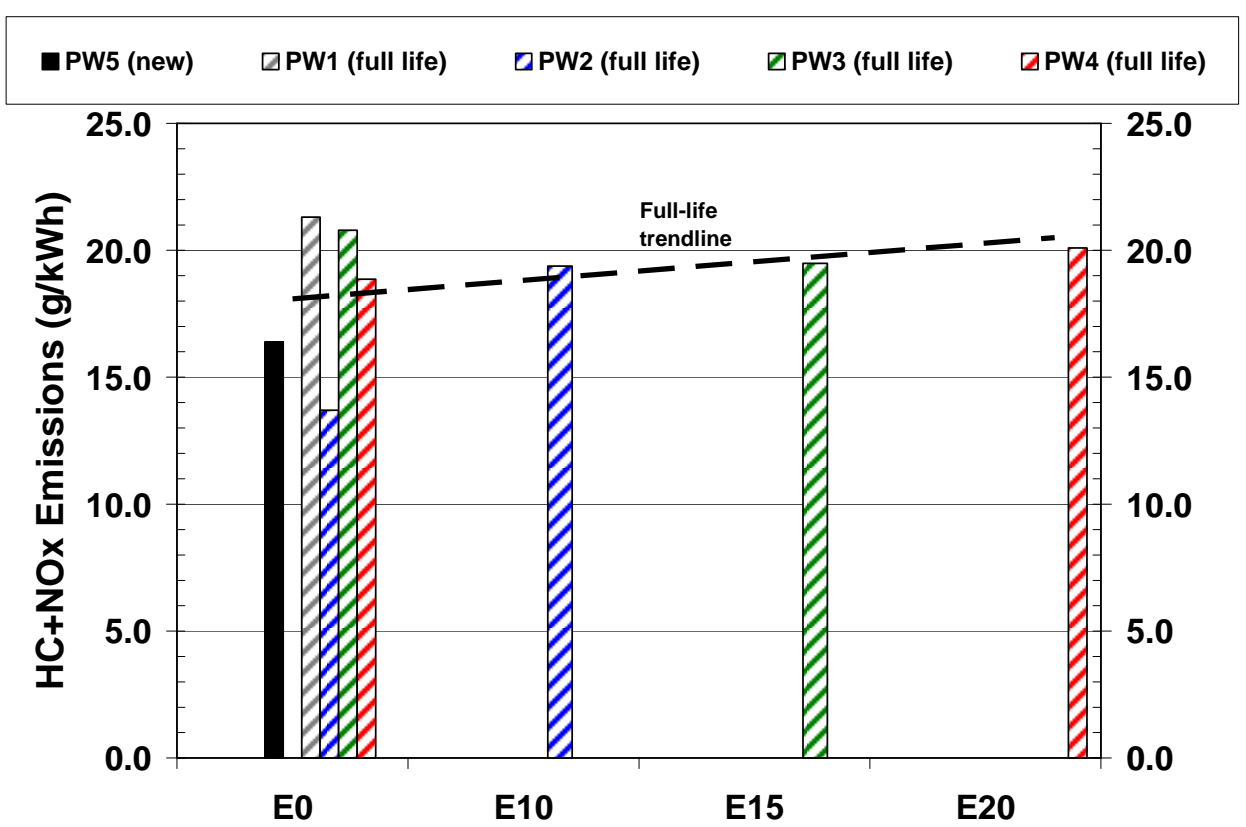

Fig. D.7. Hydrocarbon (HC) + nitrogen oxide $\left(\mathrm{NO}_{\mathrm{X}}\right)$ emissions for Class I Briggs and Stratton power washer engines on the Briggs and Stratton Company (BASCO) protocol at new and full-useful-life (full-life) condition. Only PW5 was baselined on E0 in new condition on the BASCO protocol. The solid black bar is for the new PW5 data, while the striped bars represent the full-life condition as in previous figures. 


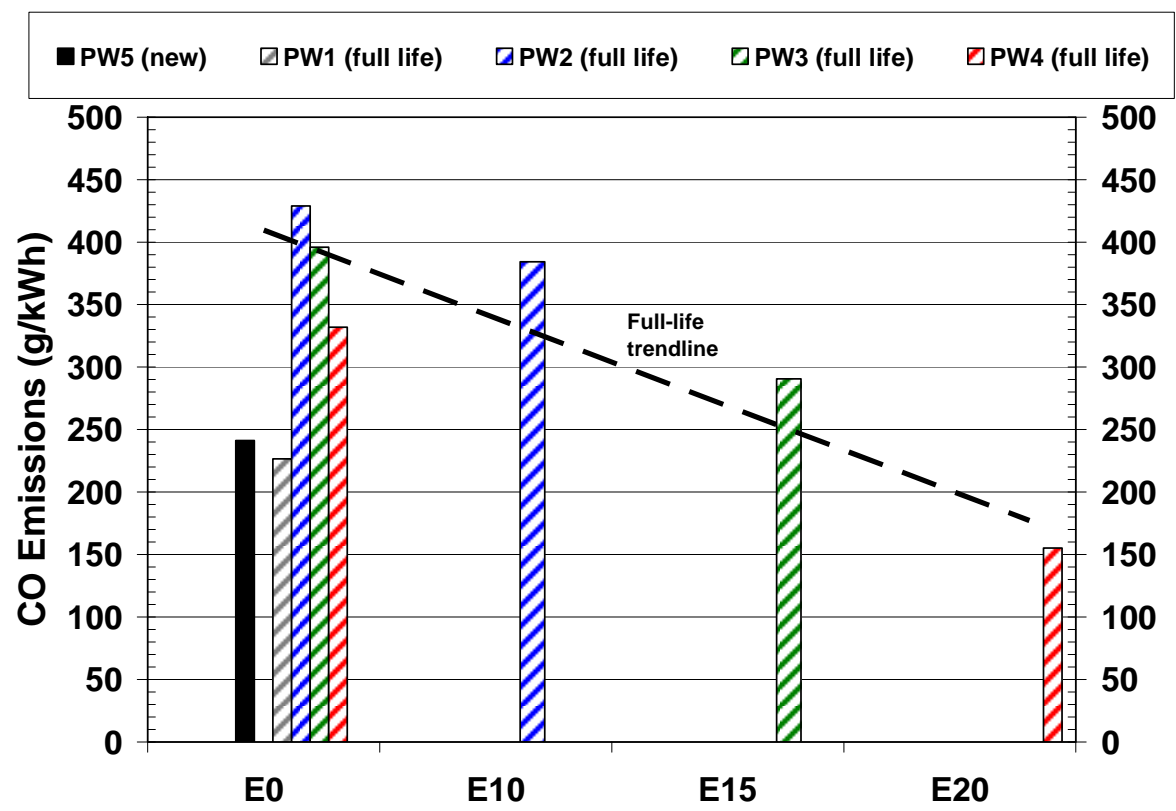

Fig. D.8. Carbon monoxide emissions for Class I Briggs and Stratton power washer engines on the Briggs and Stratton Company (BASCO) protocol at new and full-useful-life (full-life) condition. Only PW5 was baselined on E0 in new condition on the BASCO protocol. The solid black bar is for the new PW5 data, while the striped bars represent the full-life condition as in previous figures.

The same emissions constituents, in the same order, are shown for the Honda generators in Figs. D.9 through D.12. The Honda generators were tested using a 6-mode protocol, although the generator was used as the engine brake, using an electrical load bank to vary the load from mode 1 to mode 6.

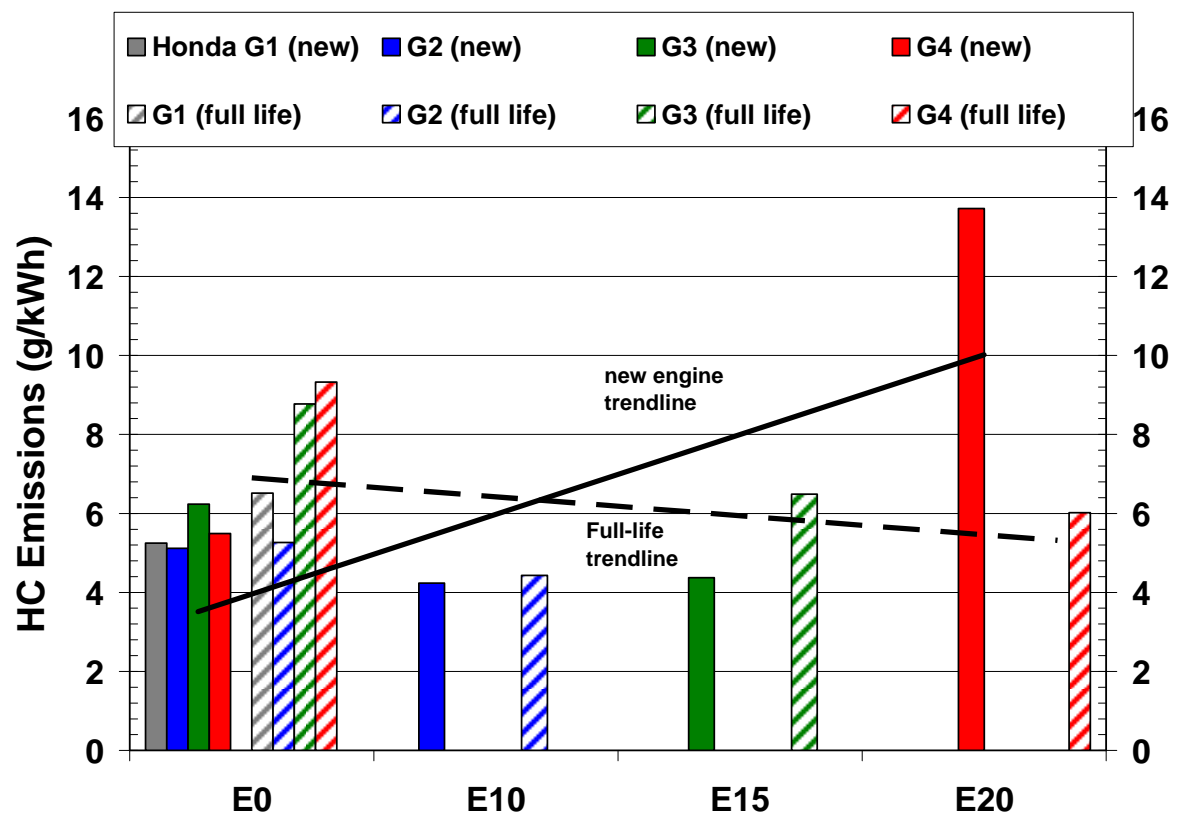

Fig. D.9. Hydrocarbon (HC) emissions for Class I Honda generator engines at new and full-useful-life (full-life) condition. Solid colors represent tests in the new condition while striped bars of the same color represent the same engine at the full-life condition. 


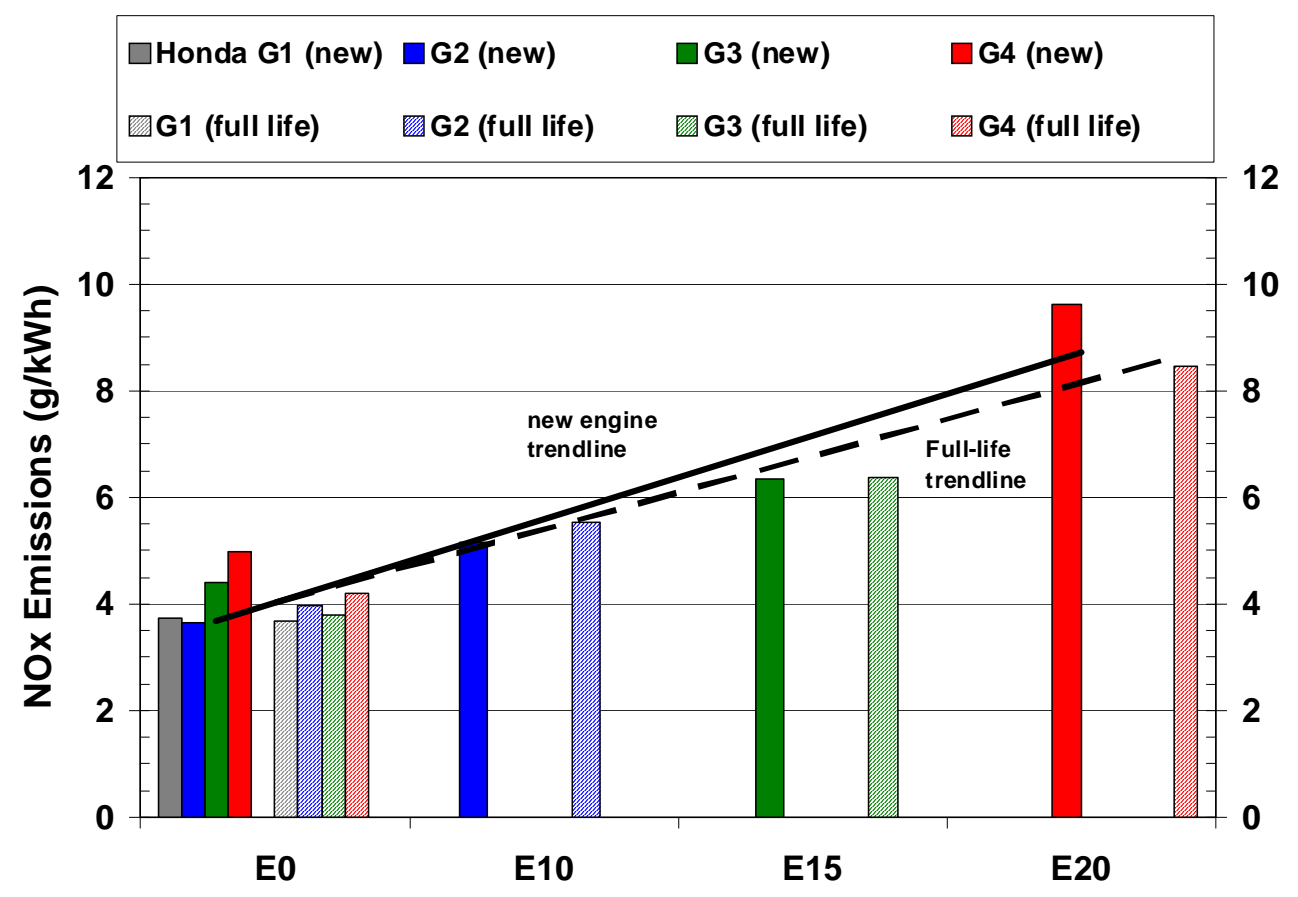

Fig. D.10. Nitrogen oxide $\left(\mathrm{NO}_{\mathrm{x}}\right)$ emissions for Class I Honda generator engines at new and full-useful-life (full-life) condition. Solid colors represent tests in the new condition while striped bars of the same color represent the same engine at the full-life condition.

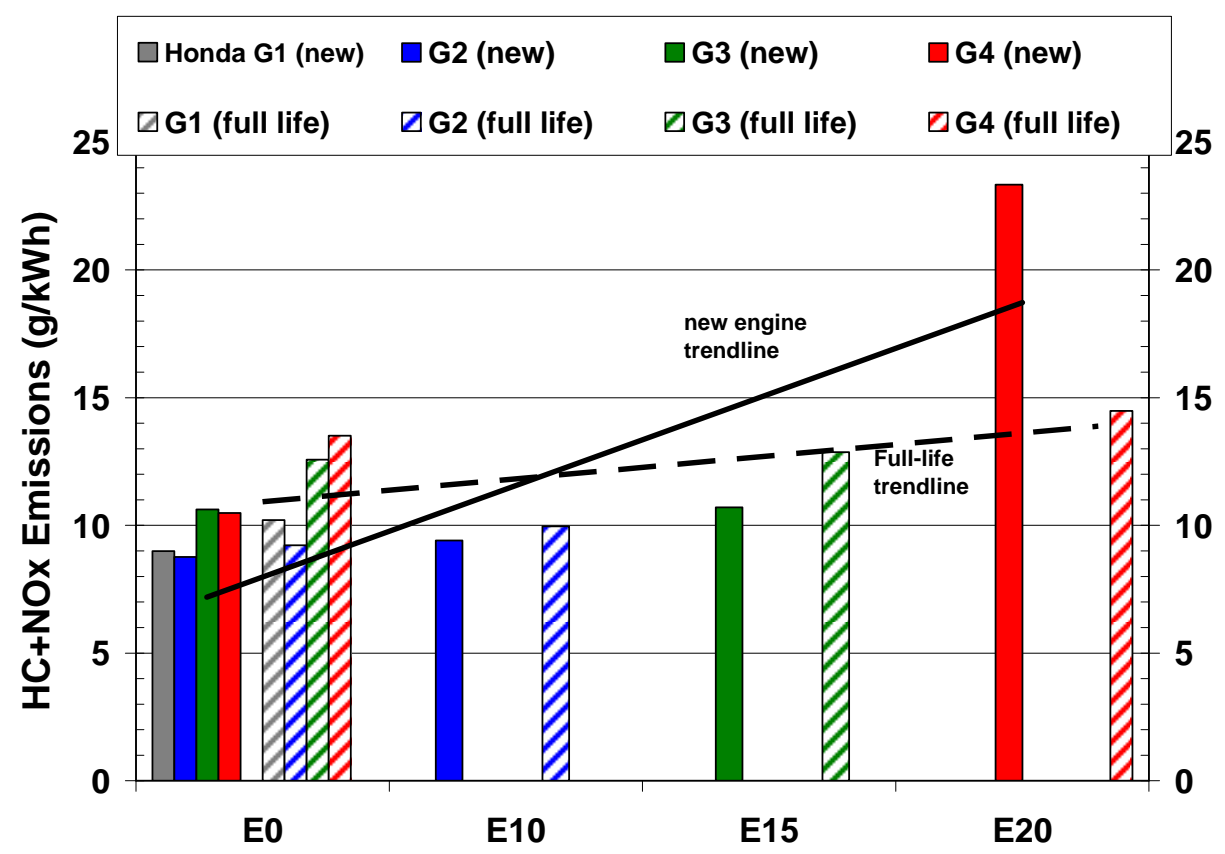

Fig. D.11. Hydrocarbon (HC) + nitrogen oxide $\left(\mathrm{NO}_{\mathrm{X}}\right)$ emissions for Class I Honda generator engines at new and full-useful-life (full-life) condition. Solid colors represent tests in the new condition while striped bars of the same color represent the same engine at the full-life condition. 


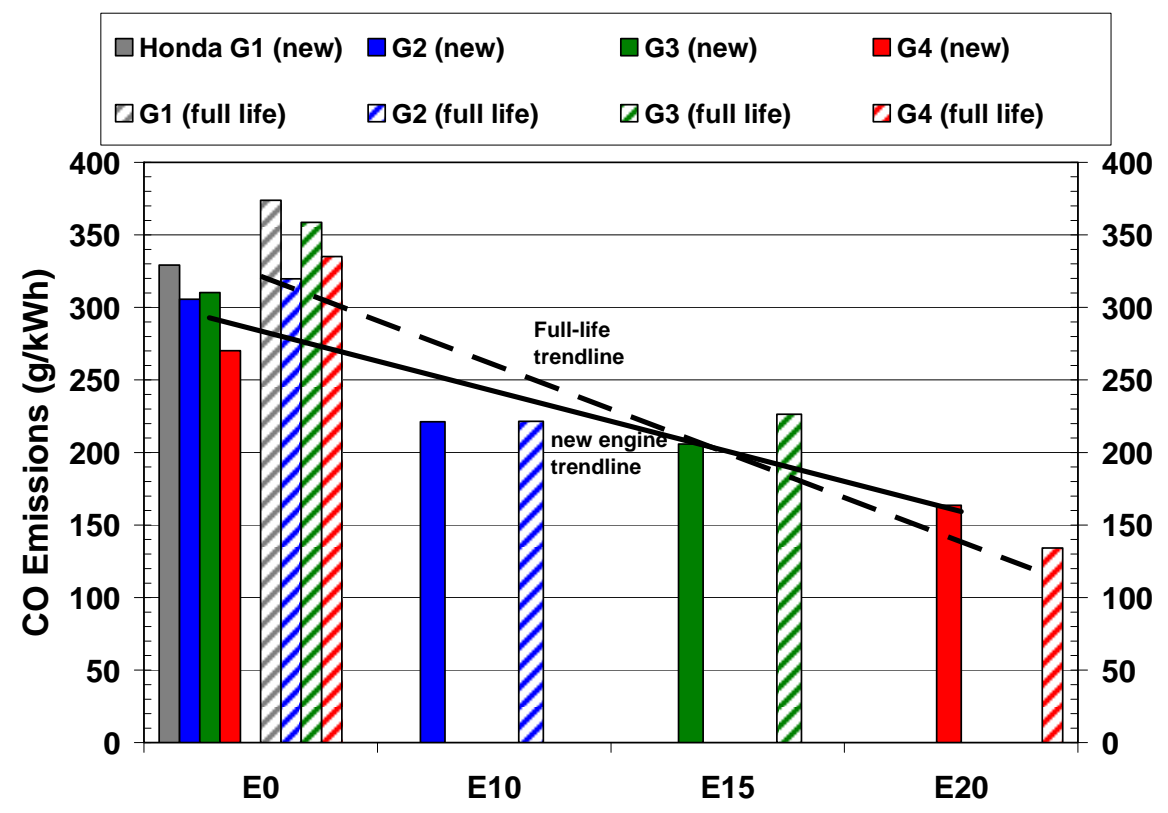

Fig. D.12. Carbon monoxide emissions for Class I Honda generator engines at new and full-useful-life (full-life) condition. Solid colors represent tests in the new condition while striped bars of the same color represent the same engine at the full-life condition.

Figures D.13 through D.16 show the $\mathrm{HC}, \mathrm{NO}_{\mathrm{X}}, \mathrm{HC}+\mathrm{NO}_{\mathrm{X}}$, and $\mathrm{CO}$ emissions for the residential Class IV Weed Eater blowers. The blowers were tested on the 2-mode test cycle using the blower wheel as the engine brake. The same emissions constituents, in the same order, are shown for the commercial Class IV Stihl line trimmers in Figs. D.17 through D.20. The Stihl engines were tested on the 2-mode test cycle per CFR guidelines on the dynamometer.

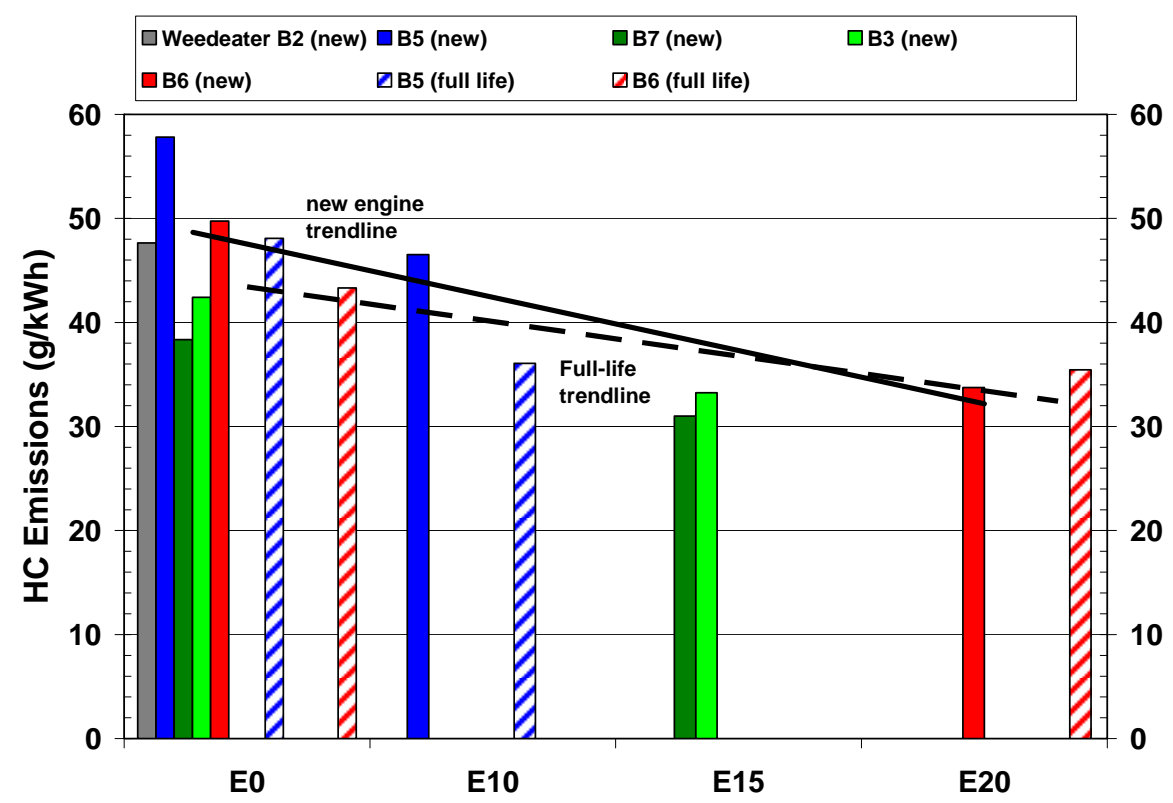

Fig. D.13. Hydrocarbon (HC) emissions for Class IV Weed Eater blower engines at new and full-useful-life (full-life) condition. Solid colors represent tests in the new condition while striped bars of the same color represent the same engine at the full-life condition. 


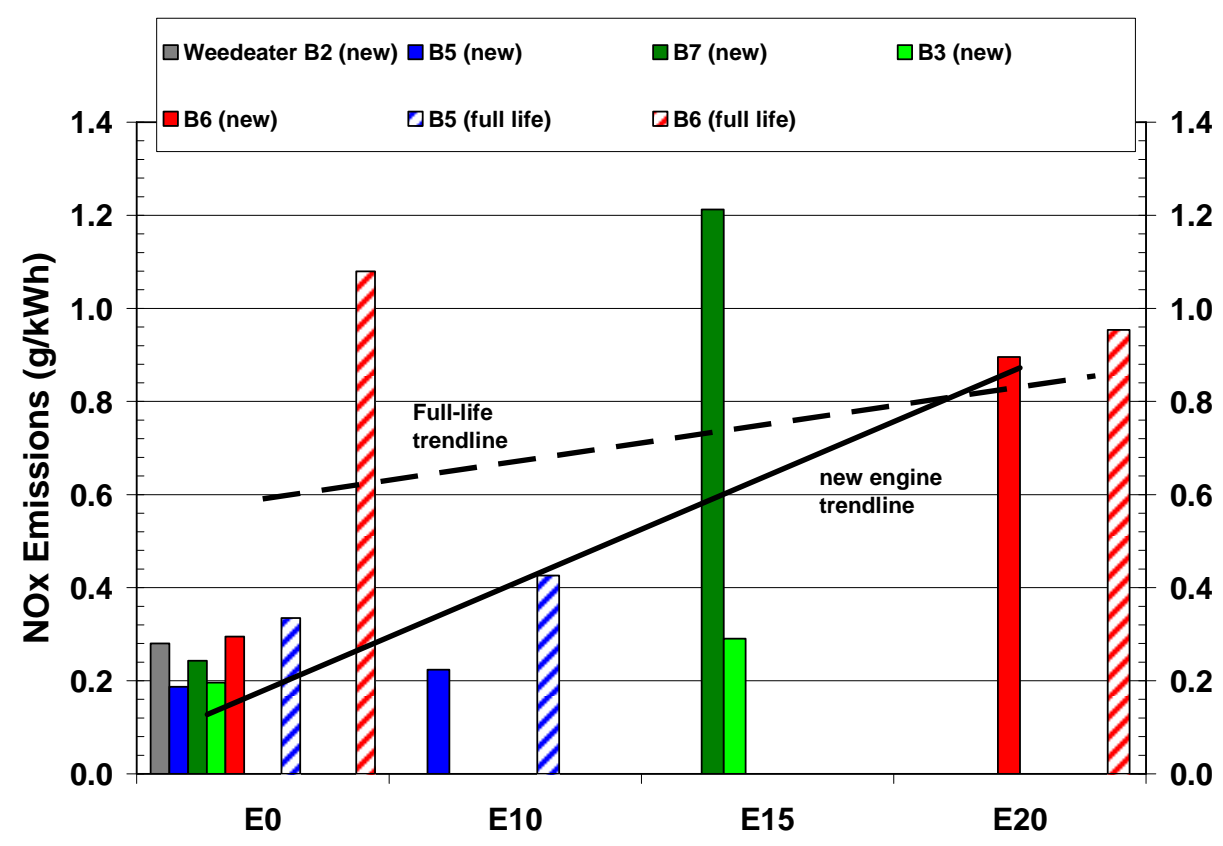

Fig. D.14. Nitrogen oxide $\left(\mathrm{NO}_{\mathrm{X}}\right)$ emissions for Class IV Weed Eater blower engines at new and full-useful-life (full-life) condition. Solid colors represent tests in the new condition while striped bars of the same color represent the same engine at the full-life condition.

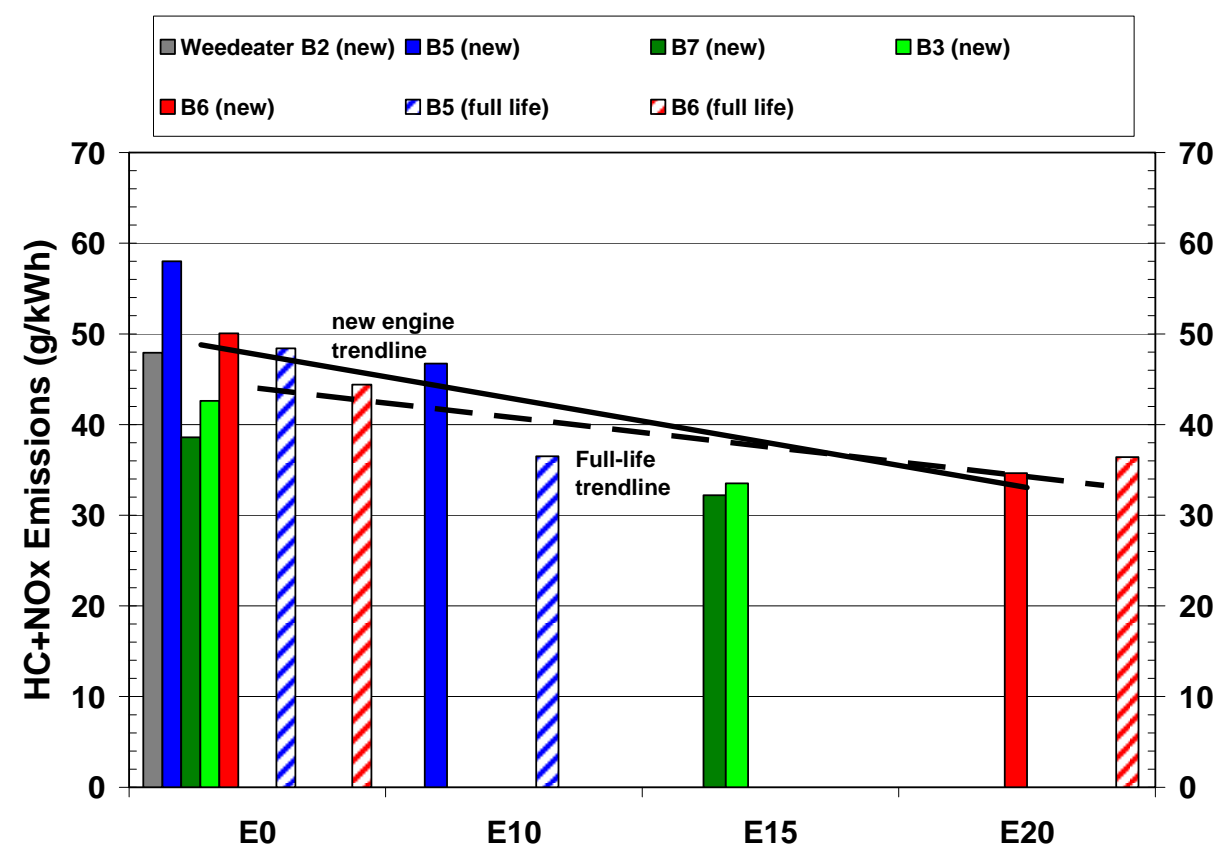

Fig. D.15. Hydrocarbon (HC) + nitrogen oxide $\left(\mathrm{NO}_{\mathrm{X}}\right)$ emissions for Class IV Weed Eater blower engines at new and full-useful-life (full-life) condition. Solid colors represent tests in the new condition while striped bars of the same color represent the same engine at the full-life condition. 


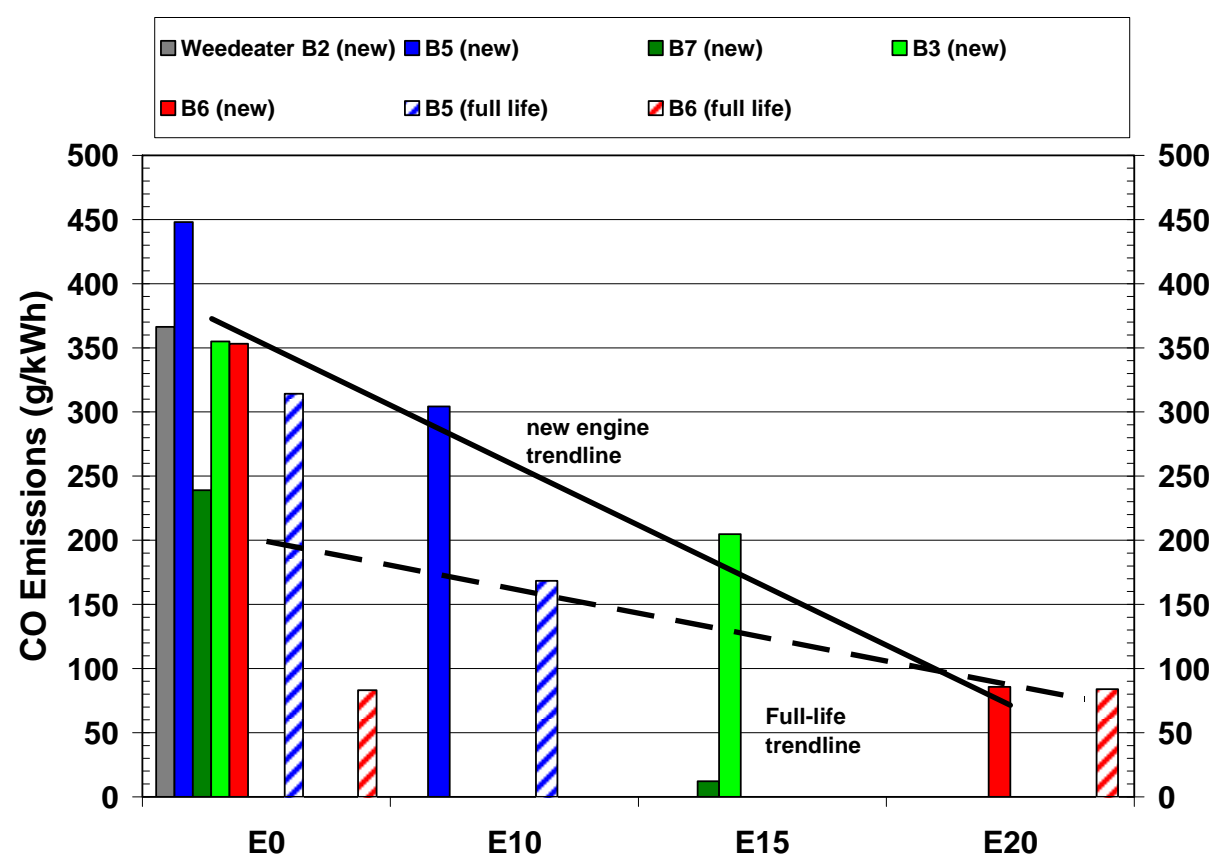

Fig. D.16. Carbon monoxide emissions for Class IV Weed Eater blower engines at new and full-useful-life (full-life) condition. Solid colors represent tests in the new condition while striped bars of the same color represent the same engine at the full-life condition.

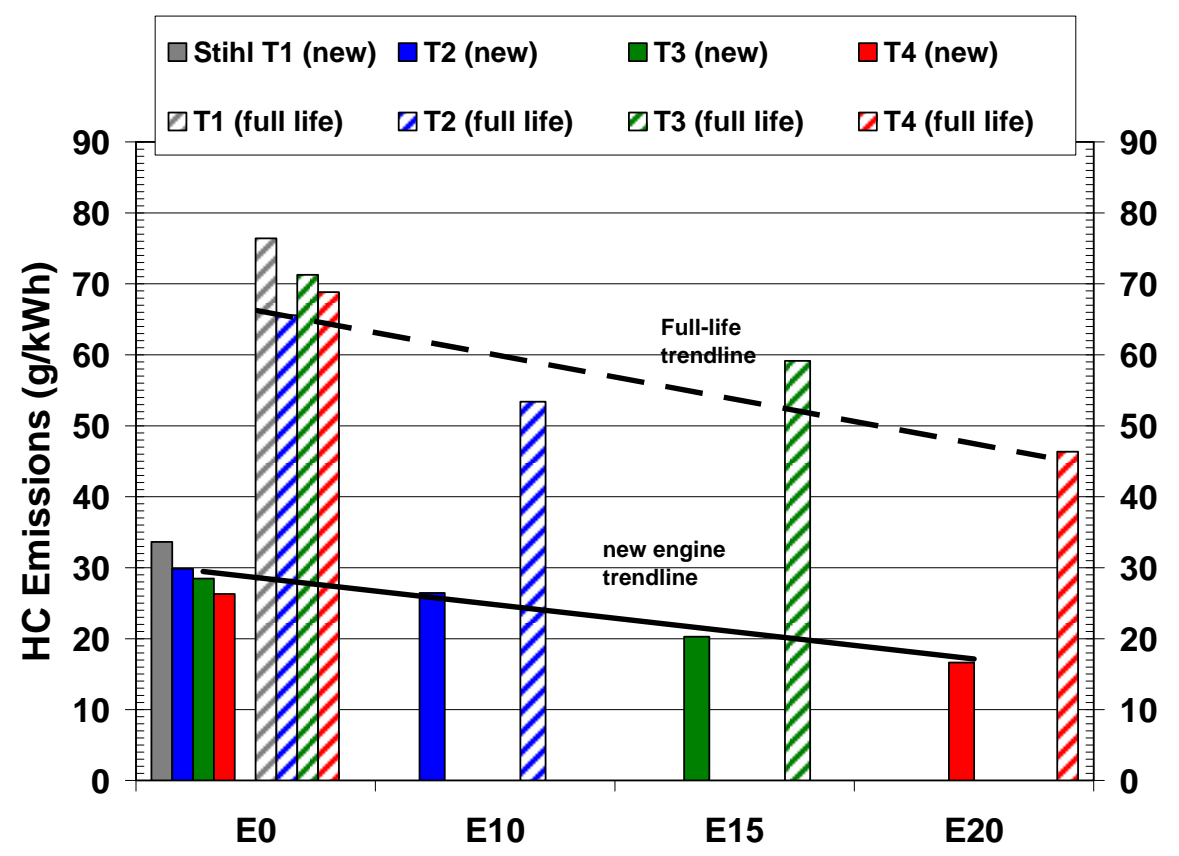

Fig. D.17. Hydrocarbon (HC) emissions for Class IV Stihl line trimmer engines at new and full-useful-life (full-life) condition. Solid colors represent tests in the new condition while striped bars of the same color represent the same engine at the full-life condition. 


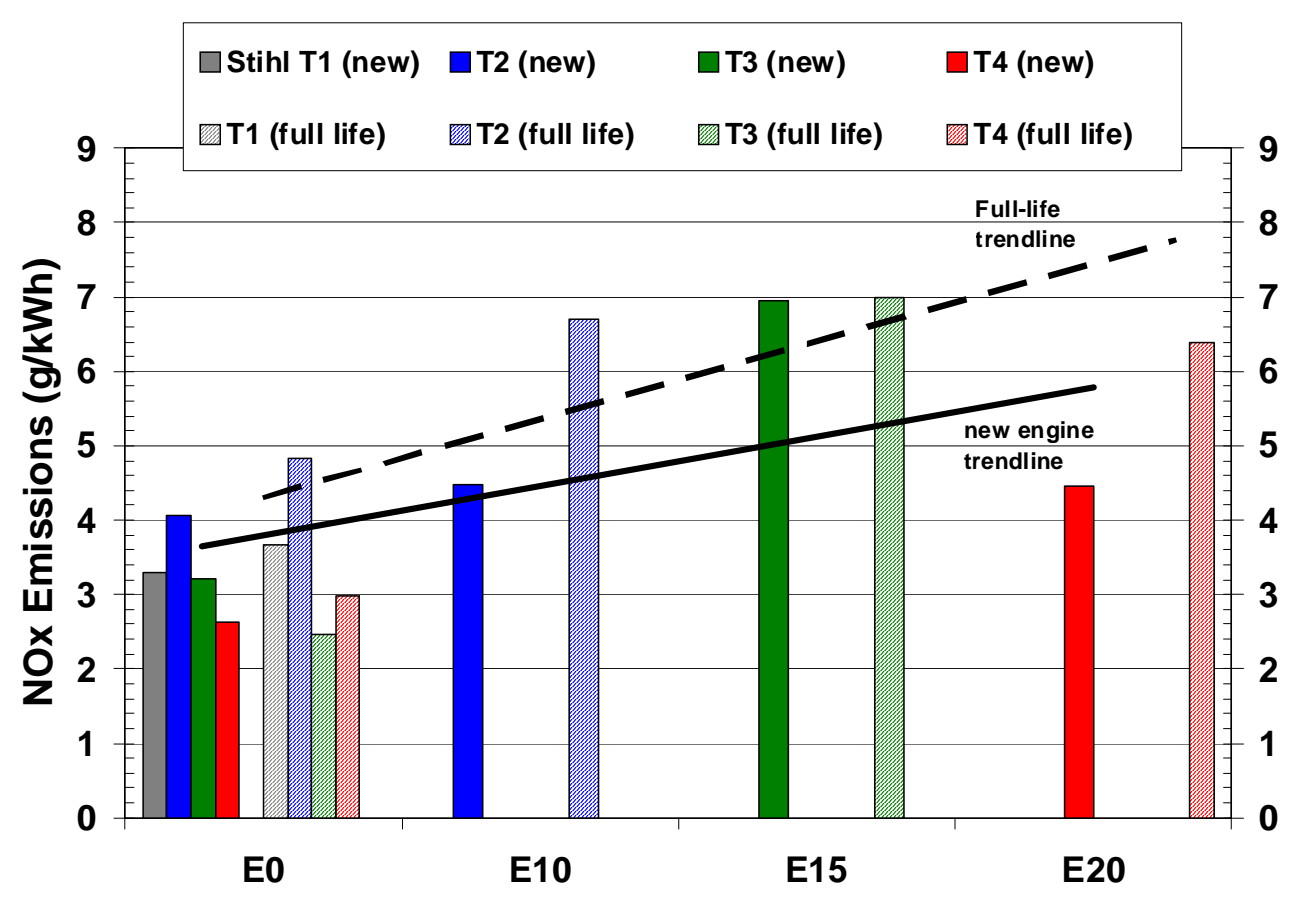

Fig. D.18. Nitrogen oxide $\left(\mathrm{NO}_{\mathrm{x}}\right)$ emissions for Class IV Stihl line trimmer engines at new and full-useful-life (full-life) condition. Solid colors represent tests in the new condition while striped bars of the same color represent the same engine at the full-life condition.

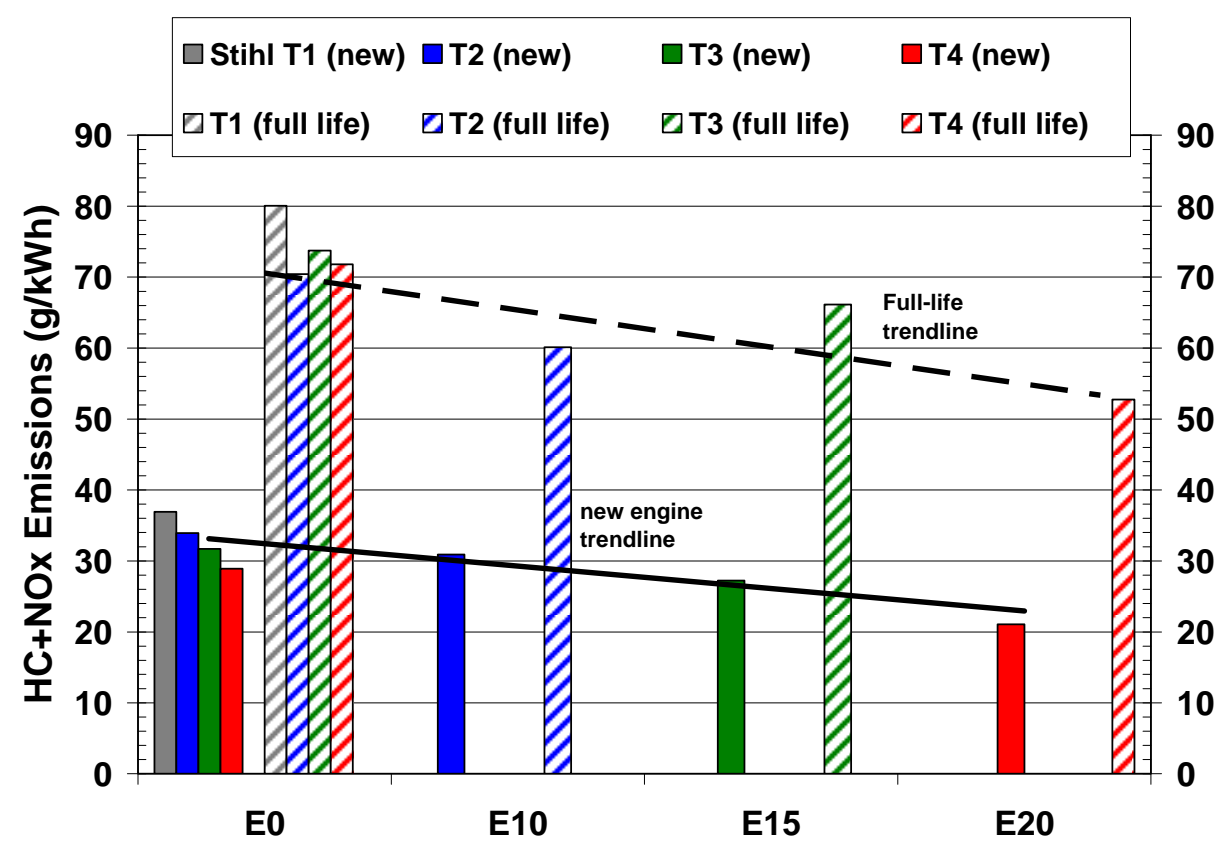

Fig. D.19. Hydrocarbon (HC) + nitrogen oxide $\left(\mathrm{NO}_{\mathrm{X}}\right)$ emissions for Class IV Stihl line trimmer engines at new and full-useful-life (full-life)condition. Solid colors represent tests in the new condition while striped bars of the same color represent the same engine at the full-life condition. 


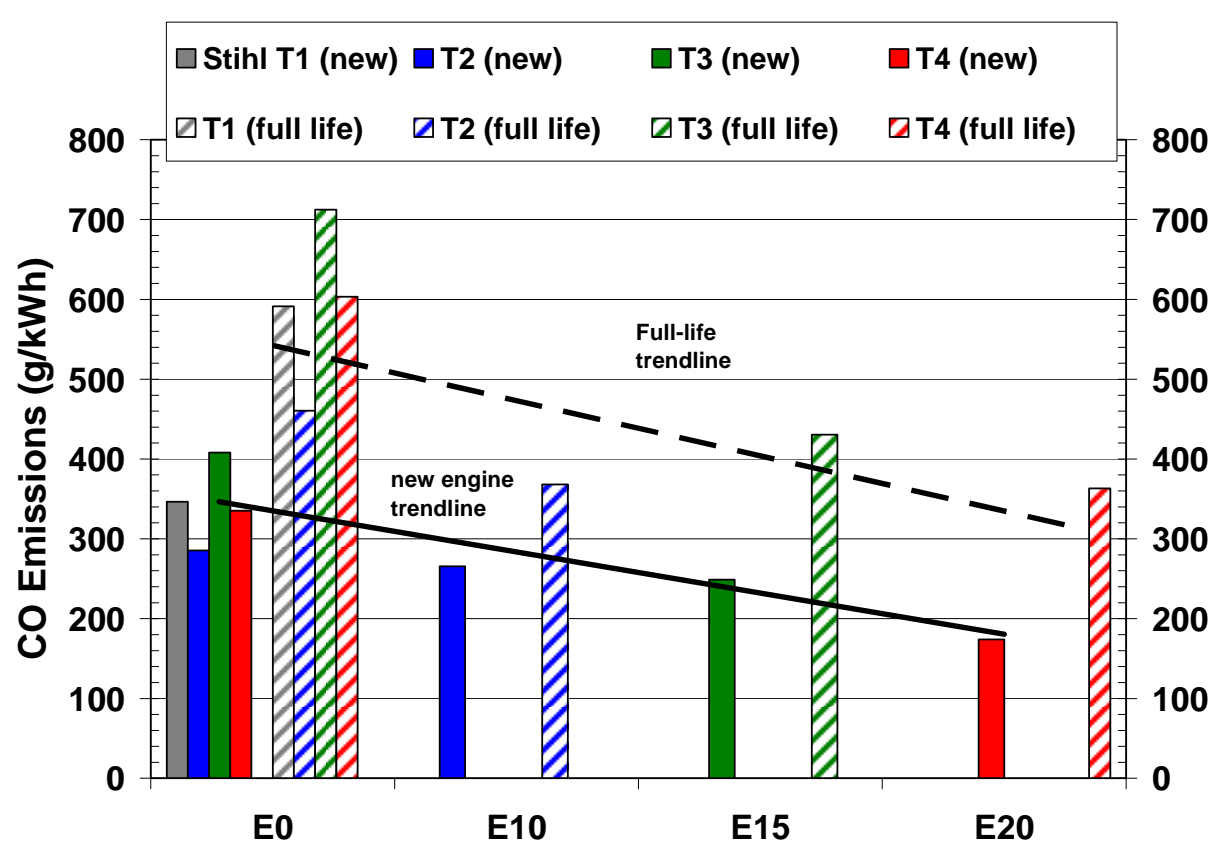

Fig. D.20. Carbon monoxide emissions for Class IV Stihl line trimmer engines at new and full-useful-life (full-life) condition. Solid colors represent tests in the new condition while striped bars of the same color represent the same engine at the full-life condition.

The tables that follow show the composite emissions results for all new engine and full-life tests at TRC, including the average of a series of tests, the maximum and minimum results for those tests, and the coefficients of variation (COVs). The COV for a full-life test on a given engine is generally lower than that for the same engine in the new condition on the same fuel. As stated previously, the engines in this program were run for $2 \mathrm{hr}$ for initial break-in before emissions testing. Although none of the owner's manuals specified any required break-in period, an EPA publication* suggests that 5 to $10 \mathrm{hr}$ of break-in are generally needed to stabilize emissions measurements. It is not clear whether longer break-in times would have harmonized the new condition and full-life COVs or impacted other noted trends.

Tables D.1 through D.3 show the Briggs and Stratton power washer results. The Honda generator results are in Table D.4. The Weed Eater blower emissions are provided in Table D.5. Emissions results for the Stihl line trimmers are shown in Table D.6.

\footnotetext{
""EPA Technical Study on the Safety of Emission Controls for Nonroad Spark-Ignition Engines < 50 Horsepower," EPA420-R-06-006, March 2006.
} 
Table D.1. Briggs and Stratton power washer baseline E0 emissions on the TRC protocol, at new (after initial break-in) condition and at full-useful-life (full-life) condition

\begin{tabular}{|c|c|c|c|c|c|c|c|c|}
\hline \multicolumn{9}{|c|}{$\begin{array}{l}\text { Briggs and Stratton (Residential, Class I) power washer emissions } \\
\text { (g/kW-hr) }\end{array}$} \\
\hline \multicolumn{9}{|c|}{ E0 baseline data, TRC protocol } \\
\hline & \multicolumn{4}{|c|}{ New condition } & \multicolumn{4}{|c|}{ Full-life condition } \\
\hline & HC & $\mathbf{N O}_{\mathrm{X}}$ & $\mathrm{HC}+\mathrm{NO}_{\mathrm{X}}$ & CO & HC & $\mathrm{NO}_{\mathrm{X}}$ & $\mathrm{HC}+\mathrm{NO}_{\mathrm{X}}$ & $\mathrm{CO}$ \\
\hline \multicolumn{9}{|c|}{ Power washer 1} \\
\hline Avg & 11.1 & 2.1 & 13.2 & 312 & 11.1 & 3.7 & 14.8 & 164 \\
\hline Max & 13.1 & 2.3 & 15.3 & 350 & 11.8 & 4.3 & 15.2 & 205 \\
\hline Min & 9.5 & 1.9 & 11.8 & 241 & 10.1 & 3.1 & 14.3 & 142 \\
\hline $\mathrm{COV}$ & $14 \%$ & $9 \%$ & $11 \%$ & $16 \%$ & $8 \%$ & $15 \%$ & $3 \%$ & $22 \%$ \\
\hline \multicolumn{9}{|c|}{ Power washer 2} \\
\hline Avg & 12.6 & 2.0 & 14.6 & 330 & 18.2 & 1.9 & 20.1 & 450 \\
\hline Max & 13.0 & 2.2 & 14.9 & 351 & 19.0 & 2.0 & 20.9 & 463 \\
\hline Min & 12.1 & 1.9 & 14.1 & 311 & 17.5 & 1.9 & 19.5 & 438 \\
\hline $\mathrm{COV}$ & $3 \%$ & $7 \%$ & $3 \%$ & $5 \%$ & $4 \%$ & $2 \%$ & $3 \%$ & $3 \%$ \\
\hline \multicolumn{9}{|c|}{ Power washer 3} \\
\hline Avg & 16.6 & 1.6 & 18.1 & 347 & 41.4 & 1.6 & 43.1 & 724 \\
\hline Max & 17.2 & 1.8 & 18.7 & 409 & 42.4 & 1.7 & 44.0 & 760 \\
\hline Min & 15.8 & 1.4 & 17.4 & 294 & 39.7 & 1.6 & 41.3 & 695 \\
\hline $\mathrm{COV}$ & $4 \%$ & $9 \%$ & $4 \%$ & $14 \%$ & $4 \%$ & $2 \%$ & $3 \%$ & $5 \%$ \\
\hline \multicolumn{9}{|c|}{ Power washer 4} \\
\hline Avg & 16.5 & 1.4 & 17.9 & 402 & 32.8 & 1.6 & 34.4 & 472 \\
\hline Max & 17.8 & 1.4 & 19.2 & 426 & 34.3 & 1.7 & 35.9 & 492 \\
\hline Min & 15.2 & 1.4 & 16.6 & 379 & 30.3 & 1.6 & 32.0 & 455 \\
\hline $\mathrm{COV}$ & $11 \%$ & $0 \%$ & $10 \%$ & $8 \%$ & $7 \%$ & $3 \%$ & $6 \%$ & $4 \%$ \\
\hline
\end{tabular}


Table D.2. Briggs and Stratton power washer emissions on the TRC protocol in new and full-useful-life (full-life) condition with respective ethanol blends

\begin{tabular}{|c|c|c|c|c|c|c|c|c|}
\hline \multicolumn{9}{|c|}{$\begin{array}{l}\text { Briggs and Stratton (Residential, Class I) power washer emissions } \\
\text { (g/kW-hr) }\end{array}$} \\
\hline \multicolumn{9}{|c|}{ Ethanol blend data, TRC protocol } \\
\hline & \multicolumn{4}{|c|}{ New condition } & \multicolumn{4}{|c|}{ Full-life condition } \\
\hline & HC & $\mathbf{N O}_{\mathrm{X}}$ & $\mathbf{H C}+\mathrm{NO}_{\mathrm{X}}$ & CO & HC & $\mathbf{N O}_{\mathbf{X}}$ & $\mathbf{H C}+\mathbf{N O}_{\mathbf{X}}$ & CO \\
\hline \multicolumn{9}{|c|}{ Power washer 1 (E0 fuel) } \\
\hline Avg & 11.1 & 2.1 & 13.2 & 312 & 11.1 & 3.7 & 14.8 & 164 \\
\hline Max & 13.1 & 2.3 & 15.3 & 350 & 11.8 & 4.3 & 15.2 & 205 \\
\hline Min & 9.5 & 1.9 & 11.8 & 241 & 10.1 & 3.1 & 14.3 & 142 \\
\hline COV & $14 \%$ & $9 \%$ & $11 \%$ & $16 \%$ & $8 \%$ & $15 \%$ & $3 \%$ & $22 \%$ \\
\hline \multicolumn{9}{|c|}{ Power washer 2 (E10 fuel) } \\
\hline Avg & 13.8 & 2.5 & 16.3 & 279 & 14.4 & 2.0 & 16.4 & 329 \\
\hline Max & 14.4 & 2.6 & 17.0 & 295 & 15.8 & 2.1 & 17.8 & 368 \\
\hline Min & 13.1 & 2.2 & 15.3 & 253 & 13.4 & 2.0 & 15.5 & 304 \\
\hline $\mathrm{COV}$ & $4 \%$ & $7 \%$ & $4 \%$ & $6 \%$ & $9 \%$ & $2 \%$ & $8 \%$ & $11 \%$ \\
\hline \multicolumn{9}{|c|}{ Power washer 3 (E15 fuel) } \\
\hline Avg & 11.9 & 1.9 & 13.9 & 186 & 32.8 & 1.7 & 34.5 & 458 \\
\hline Max & 13.0 & 2.0 & 14.9 & 198 & 34.6 & 1.8 & 36.3 & 505 \\
\hline Min & 10.5 & 1.9 & 12.4 & 163 & 31.7 & 1.6 & 33.4 & 404 \\
\hline COV & $9 \%$ & $2 \%$ & $8 \%$ & $9 \%$ & $5 \%$ & $4 \%$ & $4 \%$ & $11 \%$ \\
\hline \multicolumn{9}{|c|}{ Power washer 4 (E20 fuel) } \\
\hline Avg & 17.0 & 1.9 & 18.9 & 162 & 24.6 & 2.0 & 26.6 & 202 \\
\hline Max & 23.6 & 2.0 & 25.4 & 222 & 25.6 & 2.0 & 27.6 & 209 \\
\hline Min & 13.6 & 1.8 & 15.5 & 112 & 23.3 & 1.9 & 25.3 & 194 \\
\hline $\mathrm{COV}$ & $27 \%$ & $4 \%$ & $24 \%$ & $28 \%$ & $5 \%$ & $2 \%$ & $4 \%$ & $4 \%$ \\
\hline
\end{tabular}


Table D.3. Briggs and Stratton power washer emissions on the BASCO protocol, $\mathrm{EO}$ and ethanol blends.

(PW1-PW4 at full-useful-life (full-life) condition, PW5 in new condition.)

\begin{tabular}{|c|c|c|c|c|c|c|c|c|}
\hline \multicolumn{9}{|c|}{$\begin{array}{l}\text { Briggs and Stratton (Residential, Class I) power washer emissions } \\
\text { (g/kW-hr) }\end{array}$} \\
\hline \multicolumn{9}{|c|}{ BASCO protocol } \\
\hline & \multicolumn{4}{|c|}{ E0 fuel } & \multicolumn{4}{|c|}{ Ethanol blend } \\
\hline & HC & $\mathbf{N O}_{\mathbf{X}}$ & $\mathbf{H C}+\mathbf{N O}_{\mathrm{X}}$ & CO & HC & $\mathbf{N O}_{\mathrm{X}}$ & $\mathbf{H C}+\mathrm{NO}_{\mathrm{X}}$ & CO \\
\hline \multicolumn{9}{|c|}{ Power washer 1 (E0 fuel) } \\
\hline Avg & 16.1 & 5.3 & 21.3 & 227 & & & & \\
\hline Max & 17.8 & 5.4 & 22.9 & 233 & & & & \\
\hline Min & 13.7 & 5.1 & 19.2 & 216 & & & & \\
\hline $\mathrm{COV}$ & $12 \%$ & $3 \%$ & $8 \%$ & $4 \%$ & & & & \\
\hline \multicolumn{9}{|c|}{ (E0 fuel) power washer 2 (E10 fuel) } \\
\hline Avg & 11.5 & 2.2 & 13.7 & 429 & 16.9 & 2.5 & 19.4 & 384 \\
\hline Max & 12.6 & 2.3 & 14.8 & 433 & 20.7 & 2.7 & 23.2 & 414 \\
\hline Min & 10.0 & 2.1 & 12.0 & 423 & 10.4 & 2.2 & 13.1 & 344 \\
\hline COV & $10 \%$ & $5 \%$ & $9 \%$ & $1 \%$ & $30 \%$ & $9 \%$ & $25 \%$ & $8 \%$ \\
\hline \multicolumn{9}{|c|}{ (E0 fuel)power washer 3 (E15 fuel) } \\
\hline Avg & 18.6 & 2.1 & 20.8 & 396 & 16.9 & 2.6 & 19.5 & 291 \\
\hline Max & 20.6 & 2.3 & 22.7 & 439 & 19.3 & 2.9 & 21.7 & 337 \\
\hline Min & 17.1 & 2.1 & 19.4 & 321 & 14.1 & 2.4 & 16.7 & 261 \\
\hline COV & $8 \%$ & $4 \%$ & $7 \%$ & $14 \%$ & $14 \%$ & $9 \%$ & $12 \%$ & $12 \%$ \\
\hline \multicolumn{9}{|c|}{ (E0 fuel) power washer 4 (E20 fuel) } \\
\hline Avg & 16.2 & 2.7 & 18.9 & 332 & 15.5 & 4.6 & 20.1 & 155 \\
\hline Max & 17.5 & 2.9 & 20.0 & 341 & 17.1 & 4.8 & 21.3 & 173 \\
\hline Min & 15.1 & 2.5 & 17.9 & 315 & 13.9 & 4.3 & 18.7 & 143 \\
\hline COV & $7 \%$ & $6 \%$ & $5 \%$ & $4 \%$ & $9 \%$ & $5 \%$ & $6 \%$ & $9 \%$ \\
\hline \multicolumn{9}{|c|}{ Power washer 5 (E0 fuel, new condition) } \\
\hline Avg & 11.9 & 4.5 & 16.4 & 241 & & & & \\
\hline Max & 12.8 & 5.0 & 17.8 & 266 & & & & \\
\hline Min & 11.1 & 3.9 & 15.6 & 228 & & & & \\
\hline COV & $6 \%$ & $11 \%$ & $6 \%$ & $8 \%$ & & & & \\
\hline
\end{tabular}


Table D.4. Honda generator emissions at new and full-useful-life (full-life) condition, E0 baseline and respective ethanol blends

\begin{tabular}{|c|c|c|c|c|c|c|c|c|}
\hline \multicolumn{9}{|c|}{$\begin{array}{l}\text { Honda (Commercial, Class I) generator emissions } \\
\text { (g/kW-hr) }\end{array}$} \\
\hline & \multicolumn{4}{|c|}{ New condition } & \multicolumn{4}{|c|}{ Full-life condition } \\
\hline & HC & $\mathbf{N O}_{\mathrm{X}}$ & $\mathrm{HC}+\mathrm{NO}_{\mathrm{X}}$ & CO & HC & $\mathrm{NO}_{\mathrm{X}}$ & $\mathrm{HC}+\mathrm{NO}_{\mathrm{X}}$ & CO \\
\hline \multicolumn{9}{|c|}{ Generator 1 (E0 fuel) } \\
\hline Avg & 5.2 & 3.7 & 9.0 & 329 & 6.5 & 3.7 & 10.2 & 374 \\
\hline Max & 5.8 & 4.0 & 9.8 & 346 & 6.6 & 3.8 & 10.4 & 378 \\
\hline Min & 4.4 & 3.4 & 7.8 & 320 & 6.4 & 3.6 & 10.0 & 371 \\
\hline $\mathrm{COV}$ & $14 \%$ & $9 \%$ & $12 \%$ & $4 \%$ & $2 \%$ & $3 \%$ & $2 \%$ & $1 \%$ \\
\hline \multicolumn{9}{|c|}{ Generator 2 (E0 fuel) } \\
\hline Avg & 5.1 & 3.6 & 8.8 & 306 & 5.3 & 4.0 & 9.2 & 320 \\
\hline Max & 5.2 & 3.7 & 8.9 & 317 & 5.5 & 4.0 & 9.4 & 321 \\
\hline Min & 5.0 & 3.5 & 8.7 & 299 & 5.2 & 3.9 & 9.1 & 317 \\
\hline $\mathrm{COV}$ & $2 \%$ & $3 \%$ & $1 \%$ & $3 \%$ & $3 \%$ & $1 \%$ & $1 \%$ & $1 \%$ \\
\hline \multicolumn{9}{|c|}{ Generator 3 (E0 fuel) } \\
\hline Avg & 6.2 & 4.4 & $\begin{array}{l}10.6 \\
\end{array}$ & 310 & 8.8 & 3.8 & 12.6 & 359 \\
\hline Max & 6.8 & 4.7 & 11.0 & 320 & 8.9 & 3.9 & 12.6 & 360 \\
\hline Min & 5.6 & 4.2 & 10.3 & 298 & 8.6 & 3.7 & 12.5 & 357 \\
\hline $\mathrm{COV}$ & $10 \%$ & $6 \%$ & $3 \%$ & $4 \%$ & $2 \%$ & $3 \%$ & $0 \%$ & $1 \%$ \\
\hline \multicolumn{9}{|c|}{ Generator 4 (E0 fuel) } \\
\hline Avg & 5.5 & 5.0 & 10.5 & 270 & 9.3 & 4.2 & 13.5 & 335 \\
\hline Max & 5.7 & 5.1 & 10.7 & 274 & 9.4 & 4.2 & 13.6 & 336 \\
\hline Min & 5.2 & 4.9 & 10.2 & 268 & 9.2 & 4.2 & 13.4 & 334 \\
\hline COV & $5 \%$ & $2 \%$ & $2 \%$ & $1 \%$ & $1 \%$ & $0 \%$ & $1 \%$ & $0 \%$ \\
\hline \multicolumn{9}{|c|}{ Ethanol blends data } \\
\hline \multicolumn{9}{|c|}{ Generator 2 (E10 fuel) } \\
\hline Avg & 4.2 & 5.2 & 9.4 & 221 & 4.4 & 5.5 & 10.0 & 221 \\
\hline Max & 4.6 & 5.2 & 9.8 & 223 & 4.4 & 5.9 & 10.3 & 226 \\
\hline Min & 4.0 & 5.1 & 9.2 & 220 & 4.4 & 5.3 & 9.7 & 215 \\
\hline COV & $8 \%$ & $1 \%$ & $4 \%$ & $1 \%$ & $0 \%$ & $5 \%$ & $3 \%$ & $3 \%$ \\
\hline \multicolumn{9}{|c|}{ Generator 3 (E15 fuel) } \\
\hline Avg & 4.4 & 6.3 & 10.7 & 206 & 6.5 & 6.4 & 12.9 & 226 \\
\hline Max & 4.5 & 6.4 & 10.8 & 216 & 6.8 & 6.5 & 13.0 & 248 \\
\hline Min & 4.2 & 6.3 & 10.6 & 199 & 6.2 & 6.2 & 12.7 & 213 \\
\hline $\mathrm{COV}$ & $3 \%$ & $2 \%$ & $1 \%$ & $4 \%$ & $4 \%$ & $2 \%$ & $1 \%$ & $8 \%$ \\
\hline \multicolumn{9}{|c|}{ Generator 4 (E20 fuel) } \\
\hline Avg & 13.7 & 9.6 & 23.3 & 164 & 6.0 & 8.5 & 14.5 & 134 \\
\hline Max & 14.2 & 9.8 & 23.7 & 168 & 6.1 & 8.6 & 14.7 & 136 \\
\hline Min & 13.2 & 9.5 & 23.0 & 160 & 6.0 & 8.3 & 14.3 & 132 \\
\hline $\mathrm{COV}$ & $4 \%$ & $1 \%$ & $2 \%$ & $2 \%$ & $1 \%$ & $2 \%$ & $1 \%$ & $1 \%$ \\
\hline
\end{tabular}


Table D.5. Weed Eater Featherlite blower emissions at new and full-useful-life (full-life) condition, E0 baseline and respective ethanol blends

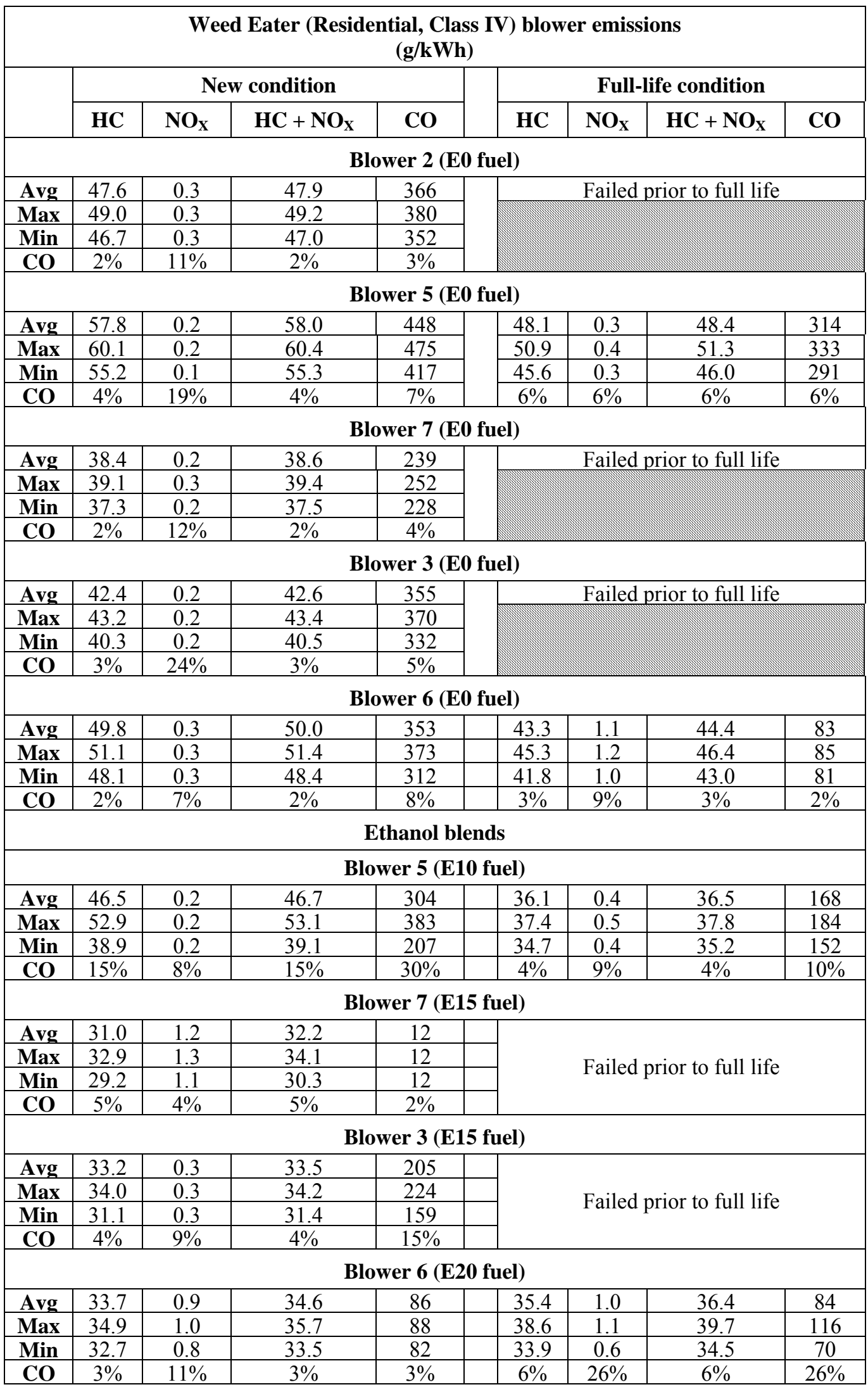


Table D.6. Stihl line trimmer emissions, new and full-useful-life (full-life) condition, E0 baseline and respective ethanol blends

\begin{tabular}{|c|c|c|c|c|c|c|c|c|}
\hline \multicolumn{9}{|c|}{$\begin{array}{l}\text { Stihl (Commercial, Class IV) line trimmer emissions } \\
\text { (g/kW-hr) }\end{array}$} \\
\hline & \multicolumn{4}{|c|}{ New condition } & \multicolumn{4}{|c|}{ Full-life condition } \\
\hline & HC & $\mathbf{N O}_{\mathrm{X}}$ & $\mathrm{HC}+\mathrm{NO}_{\mathrm{X}}$ & $\mathrm{CO}$ & HC & $\mathbf{N O}_{\mathrm{X}}$ & $\mathrm{HC}+\mathrm{NO}_{\mathrm{X}}$ & CO \\
\hline \multicolumn{9}{|c|}{ Trimmer 1 (E0 fuel) } \\
\hline Avg & 33.6 & 3.3 & 36.9 & 347 & 76. & 3.7 & 80.1 & 591 \\
\hline Max & 34.9 & 3.7 & 38.0 & 367 & 77. & 3.8 & 80.9 & 603 \\
\hline Min & 30.8 & 2.9 & 34.5 & 320 & 75. & 3.3 & 79.7 & 579 \\
\hline COV & $6 \%$ & $11 \%$ & $4 \%$ & $6 \%$ & $1 \%$ & $6 \%$ & $1 \%$ & $2 \%$ \\
\hline \multicolumn{9}{|c|}{ Trimmer 2 (E0 fuel) } \\
\hline Avg & 29.9 & 4.1 & 33.9 & 285 & 65. & 4.8 & 70.4 & 461 \\
\hline Max & 30.9 & 4.6 & 34.5 & 312 & 67. & 5.4 & 73.2 & 503 \\
\hline Min & 28.8 & 3.7 & 33.4 & 251 & 62. & 3.9 & 67.6 & 436 \\
\hline $\mathrm{COV}$ & $3 \%$ & $12 \%$ & $2 \%$ & 10 & $4 \%$ & $15 \%$ & $4 \%$ & $6 \%$ \\
\hline \multicolumn{9}{|c|}{ Trimmer 3 (E0 fuel) } \\
\hline Avg & 28.5 & 3.2 & 31.7 & 408 & 71. & 2.5 & 73.7 & 712 \\
\hline Max & 29.4 & 3.4 & 32.5 & 425 & 74. & 2.9 & 77.1 & 772 \\
\hline Min & 27.9 & 3.0 & 31.1 & 396 & 66. & 1.8 & 69.1 & 670 \\
\hline $\mathrm{COV}$ & $2 \%$ & $5 \%$ & $2 \%$ & $3 \%$ & $5 \%$ & $21 \%$ & $5 \%$ & $7 \%$ \\
\hline \multicolumn{9}{|c|}{ Trimmer 4 (E0 fuel) } \\
\hline Avg & 26.3 & 2.6 & 28.9 & 335 & 68. & 3.0 & 71.8 & 603 \\
\hline Max & 27.9 & 2.8 & 30.4 & 350 & 69. & 3.2 & 72.4 & 630 \\
\hline Min & 23.8 & 2.4 & 26.6 & 315 & 68. & 2.6 & 71.1 & 586 \\
\hline $\mathrm{COV}$ & $7 \%$ & $7 \%$ & $6 \%$ & $5 \%$ & $1 \%$ & $10 \%$ & $1 \%$ & $3 \%$ \\
\hline \multicolumn{9}{|c|}{ Ethanol blends data } \\
\hline \multicolumn{9}{|c|}{ Trimmer 2 (E10 fuel) } \\
\hline Avg & 26.4 & 4.5 & 30.9 & 265 & 53. & 6.7 & 60.1 & 368 \\
\hline Max & 29.3 & 5.1 & 32.3 & 343 & 54. & 7.2 & 61.6 & 381 \\
\hline Min & 24.7 & 3.0 & 29.7 & 234 & 52. & 6.1 & 58.1 & 341 \\
\hline $\mathrm{COV}$ & $8 \%$ & $23 \%$ & $3 \%$ & 20 & $2 \%$ & $7 \%$ & $3 \%$ & $5 \%$ \\
\hline \multicolumn{9}{|c|}{ Trimmer 3 (E15 fuel) } \\
\hline Avg & 20.3 & 6.9 & 27.2 & 249 & 59. & 7.0 & 66.1 & 431 \\
\hline Max & 22.0 & 7.3 & 28.8 & 254 & 60. & 7.2 & 67.0 & 441 \\
\hline Min & 18.6 & 6.8 & 25.5 & 237 & 57. & 6.8 & 64.6 & 424 \\
\hline $\mathrm{COV}$ & $7 \%$ & $3 \%$ & $5 \%$ & $3 \%$ & $2 \%$ & $2 \%$ & $2 \%$ & $2 \%$ \\
\hline \multicolumn{9}{|c|}{ Trimmer 4 (E20 fuel) } \\
\hline Avg & 16.6 & 4.5 & 21.1 & 174 & 46. & 6.4 & 52.8 & 363 \\
\hline Max & 17.1 & 4.6 & 21.6 & 192 & 46. & 6.7 & 53.2 & 375 \\
\hline Min & 15.7 & 4.2 & 20.1 & 162 & 45. & 6.2 & 51.6 & 356 \\
\hline $\mathrm{COV}$ & $4 \%$ & $4 \%$ & $3 \%$ & $7 \%$ & $2 \%$ & $3 \%$ & $1 \%$ & $2 \%$ \\
\hline
\end{tabular}




\section{D.2 TEMPERATURE}

The following figures show the full set of exhaust temperature data for the full-life SNRE testing at TRC (for completeness here, some are repeated from Sect. 3 of the report). The hottest engine condition is shown, which was the fast-idle or mode- 6 condition for the Class I Briggs and Stratton and Honda engines and the full-power or mode-1 condition for the handheld Class IV Stihl and Weed Eater engines. Figure D.21 shows the Briggs and Stratton results. Temperatures for the Honda generators are shown in Fig. D.22. Weed Eater blower temperatures are presented in Fig. D.23. Figure D.24 shows the temperature results for the Stihl line trimmers.

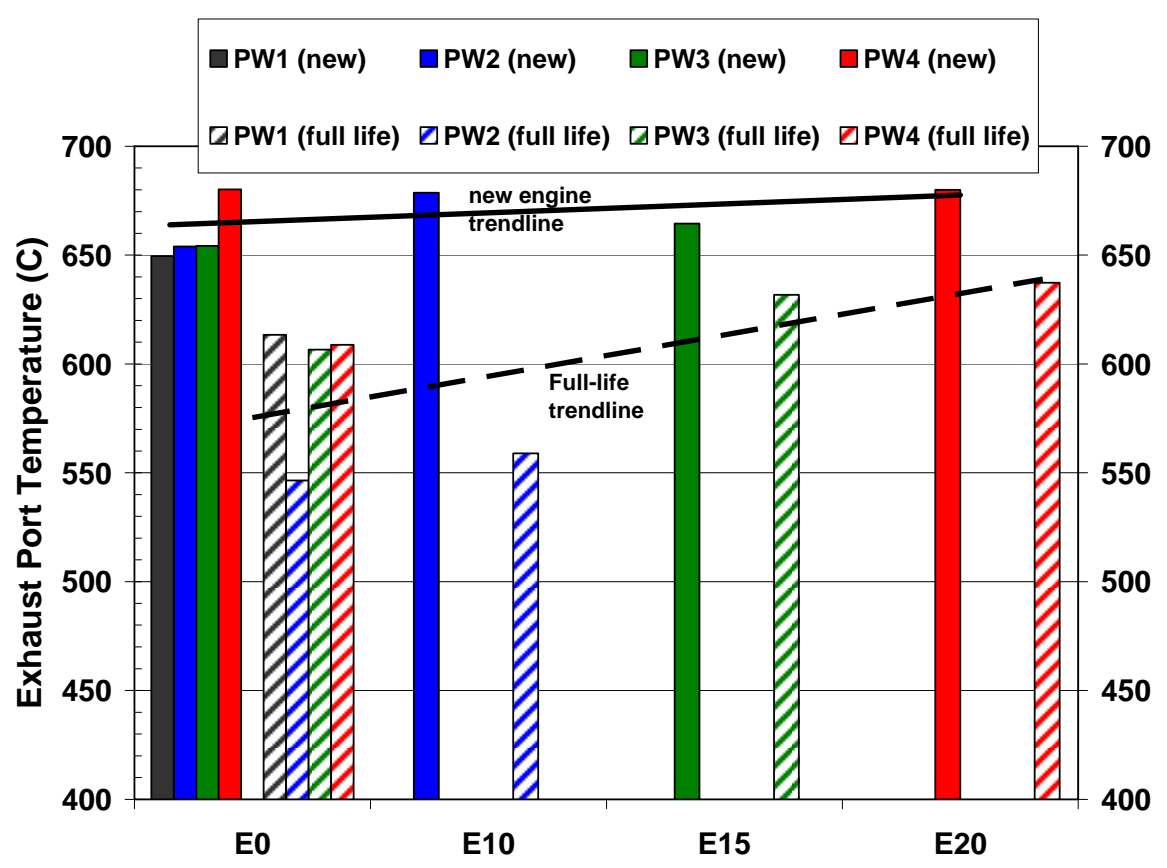

Fig. D.21. Exhaust port temperature for Class I Briggs and Stratton power washers at mode 6 (fast idle) at new and full-useful-life (full-life) condition. Solid colors represent tests at the new condition while striped bars of the same color represent the full-life condition. 


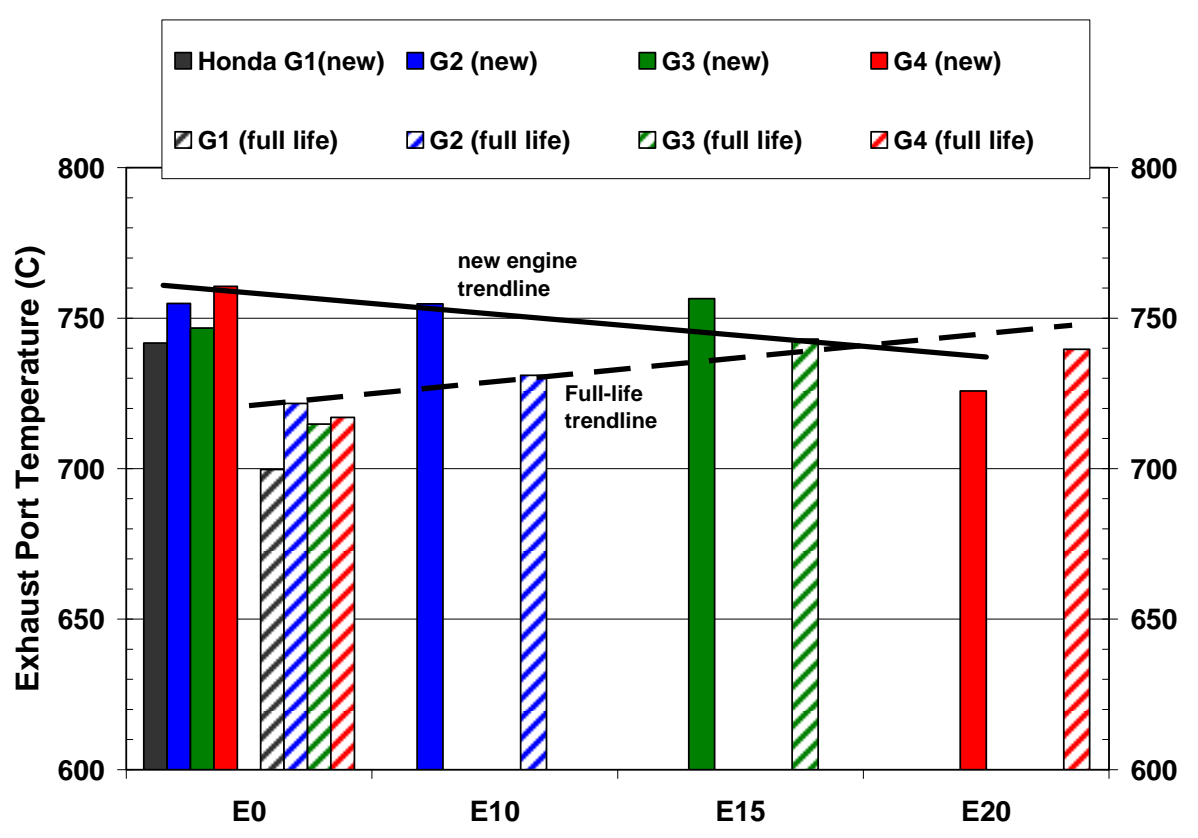

Fig. D.22. Exhaust port temperature for Class I Honda generators at mode 6 (fast idle) at new and full-useful-life (full-life) condition. Solid colors represent tests at the new condition while striped bars of the same color represent the same engine at the full-life condition. Erratic operation of G4 at light loads with E20 in the new condition resulted in lower exhaust temperature.

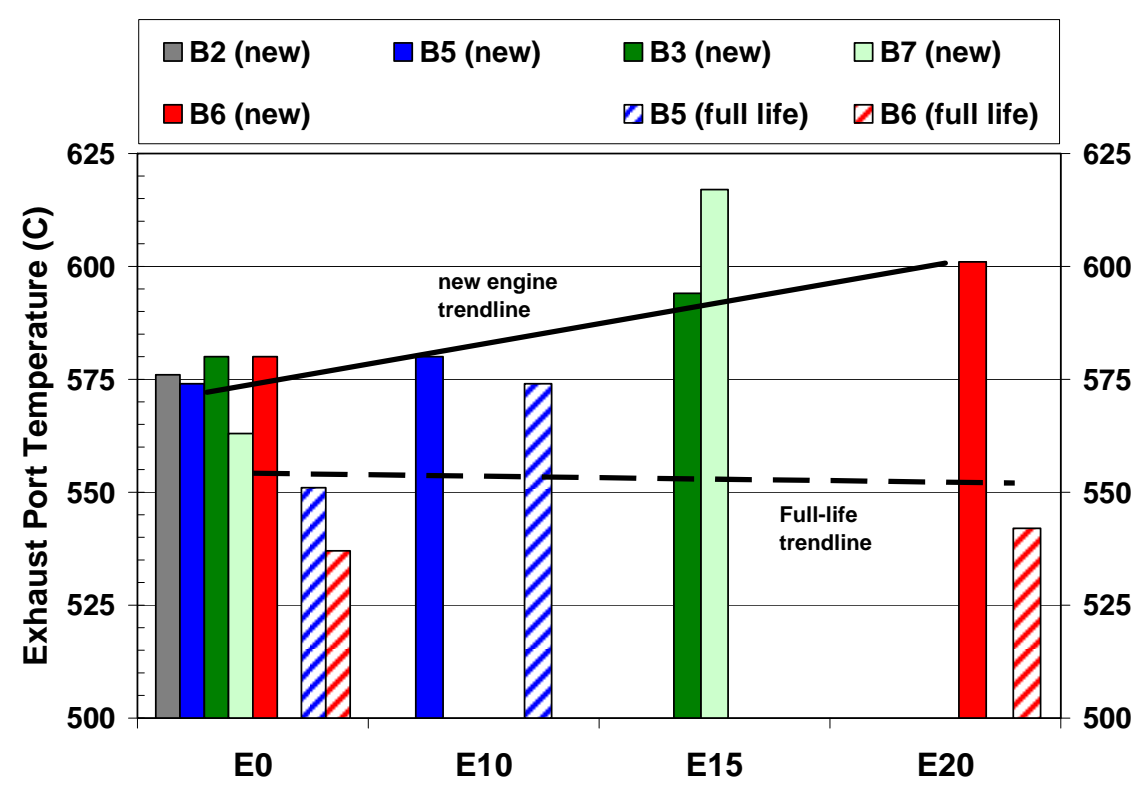

Fig. D.23. Exhaust port temperature for Class IV Weed Eater Featherlite blower engines at mode 1 (full power) at new and full-useful-life (full-life) condition. Solid colors represent tests at the new condition while striped bars of the same color represent the same engine at the full-life condition. Only B5 and B6 survived to be tested at the full-life condition. Blower-fuel combinations were as follows: B2-E0, B5-E10, B3 and B7-E15, B6-E20. 


\begin{tabular}{|llll|}
\hline$\square$ Stihl T1 (new) & $\square T 2$ (new) & $\square T 3$ (new) & $\square T 4$ (new) \\
$\square T 1$ (full life) & $\square T 2$ (full life) & $\square T 3$ (full life) & $\square T 4$ (full life) \\
\hline
\end{tabular}

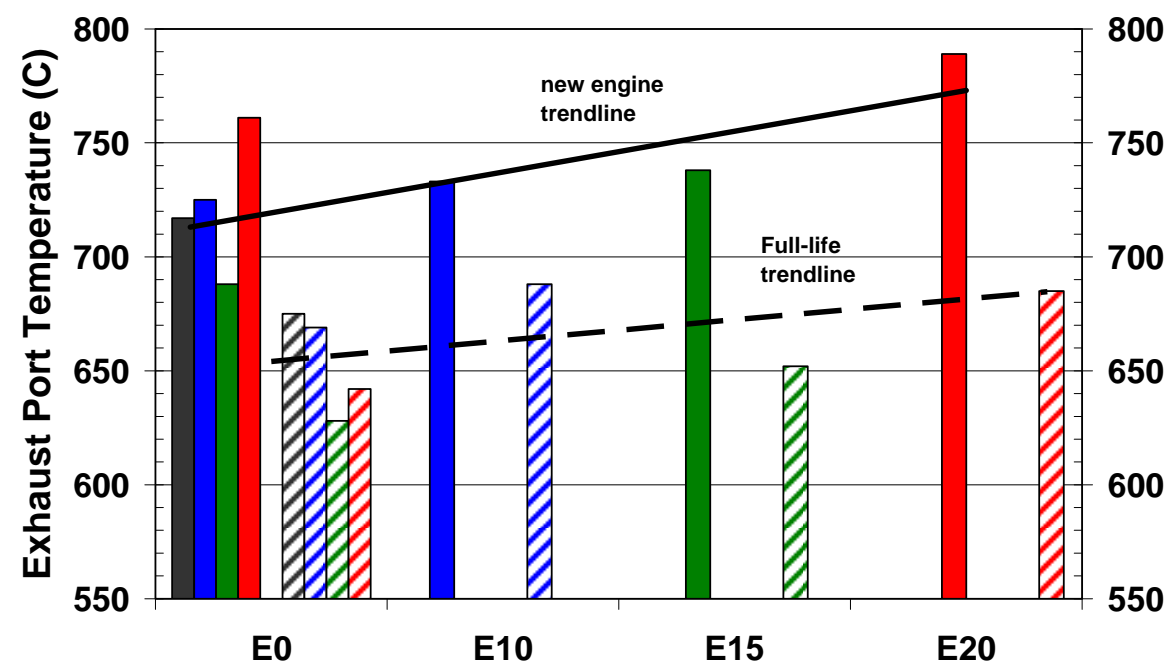

Fig. D.24. Exhaust port temperature for Class IV Stihl line trimmers at mode 1 (full power) at new and full-useful-life (full-life) condition. Solid colors represent tests at the new condition while striped bars of the same color represent the same engine at the full-life condition. 